\title{
La Necrópolis del "Corral de Mola" (Uncastillo, Zaragoza) y su contexto en el Ebro Medio durante la Edad del Hierro \\ The Necropolis of the "Corral de Mola" (Uncastillo, Zaragoza) and its context in the Middle Ebro during the Iron Age
}

José Ignacio Royo Guillén*

Recibido: 12-01-2017

Aceptado: 25-09-2017

\begin{abstract}
Resumen
En este trabajo se presenta el estudio definitivo de la necrópolis tumular de incineración del Corral de Mola en la comarca de las Cinco Villas (Zaragoza). A partir de sus estructuras funerarias y de sus ajuares, se establece su contexto crono-cultural y geográfico, el de la zona occidental del valle medio del Ebro, emparentando dicho yacimiento, así como otros cercanos a él, con el grupo de necrópolis protohistóricas del valle medio del Ebro. Dicho grupo se caracteriza por el uso exclusivo de la cremación, la arquitectura tumular y la riqueza de sus ajuares, especialmente los metálicos y cerámicos. Sus paralelos con las necrópolis navarras, del Ebro medio y aquitanas permiten plantear unas relaciones muy estrechas entre las dos áreas al norte y sur de los pirineos, al menos constatables entre los siglos VII y V a. C., periodo que supone un proceso de jerarquización social y ascenso de determinadas élites que pueden rastrearse a partir de la presencia de algunos enterramientos con ajuares singulares.
\end{abstract}

Palabras clave: Necrópolis, túmulos, incineración, protohistoria, valle medio del Ebro, Aquitania.

\begin{abstract}
In this paper the definitive study of the tumular cemetery of incineration Corral de Mola in the region of the Cinco Villas (Zaragoza) is presented. From their funerary structures and their grave goods, his chrono-cultural and geographical context, that of the western valley of the Ebro, becoming related that site as well as other close to him, with the group protohistoric necropolis is middle Ebro valley. This group is characterized by the exclusive use of cremation, tumular architecture and its rich grave goods, especially metal and ceramic. Its parallels with the navarran cemeteries, middle Ebro and raise aquitaines allow very close relations between the two areas north and south of the Pyrenees, at least ascertainable between 7th -5th centuries. C., a period that involves a process of social hierarchy and promotion of certain elites that can be traced from the presence of some burials with unique grave goods.
\end{abstract}

Key words: Cemetery, tumuli, incineration, protohistory, middle Ebro valley, Aquitaine.

\section{INTRODUCCIÓN}

En las siguientes páginas se aborda la publicación de la necrópolis tumular de incineración del Corral de Mola de Uncastillo, cuya excavación de urgencia se realizó entre los años 1977 y 1979. A pesar del tiempo transcurrido hasta la actualidad, diversas circunstancias habían impedido abordar un estudio de su arquitectura funeraria, sus ajuares y su contexto cronocultural, por lo que prácticamente permanecía inédita. Este conjunto está claramente relacionado con las necrópo-

* Arqueólogo. Dirección General de Cultura y Patrimonio. Gobierno de Aragón.jiroyo@ aragon.es 
lis tumulares de la $\mathrm{I}^{\mathrm{a}}$ Edad del Hierro de la comarca zaragozana de Las Cinco Villas y con otras del valle medio del Ebro y zonas geográficamente próximas, especialmente las situadas en la cuenca navarra de este río, las reconocidas en el río Huecha y las del valle del Jalón o alrededores de Huesca.

En el marco de los estudios de la Edad del Hierro en la mitad occidental del valle medio del Ebro, no muy desarrollados por el momento (Royo: 2005, 163), destacan los realizados en el último tercio del siglo pasado sobre las necrópolis y su arquitectura funeraria, cultura material o caracterización crono-cultural (Burillo: 1977; Pérez Casas: 1990; Juste 1993; Royo: 1990; 1992-93; 1994; 1996; 2000). Otras aportaciones más recientes, se han centrado en la región navarra (Armendáriz: 2008; Bienés: 1994; Castiella: 2005; 2007; Castiella y Bienés: 2002; Faro: 2015; Faro et alii: 2002-03; Faro y Unzu: 2006; Ruiz Zapatero: 2008). A todos estos trabajos deben sumarse los realizados en otras necrópolis tumulares del entorno geográfico cercano al conjunto que ahora se presenta, como sería el caso de Arroyo Vizcarra (Royo: 1997a; Royo y Fatás: 2017) o Barranco de la Paúl (Royo: 1997b) todas ellas en el entorno del embalse de Yesa, en el prepirineo zaragozano, en la comarca de las Altas Cinco Villas.

Estas necrópolis se localizan en la cuenca geográfica del Ebro medio y aparecen delimitadas en lo cultu- ral, según la terminología del último tercio del siglo XX, como grupo de los Campos de Urnas del valle medio del Ebro (Ruiz Zapatero: 1985, 535-662; Royo: 1990, 123-124). Sus límites cronológicos han quedado definidos (Ruiz Zapatero, op. cit.: 1985, 47-53; Almagro Gorbea: 1977, cuadro I; Maya: 1990, 306308; Royo, op . cit.: 1990, 124-125; 1994, 118; 199496, 94 y 96-98; 2000, 41-43), entre los Campos de Urnas del Hierro o Bronce Final III B y los Campos de Urnas Finales o Tardíos, también citados como periodo de transición del Ibérico Antiguo al Pleno (Burillo: 1991, 564-565), o como Primera Edad del Hierro o Hierro I, según las nuevas tendencias en la historiografía especializada (Fatás y Graells: 2010, 74-80). En cronología absoluta, podemos encuadrar este periodo entre el 800/750 y el 500/450 Cal BC, según las dataciones radiocarbónicas calibradas disponibles (Munilla et Alii: 1994-1996; Castro et alii: 1996; Mederos: 1997; Picazo y Rodanés: 2009).

En anteriores trabajos publicados sobre el mundo funerario de este periodo (Royo, op . cit.: 1990; 199293; 2000; Royo y Gómez: 2004), quedaron establecidos una serie de grupos bien diferenciados. De todos ellos, es el del valle medio del Ebro (Royo, op. cit.: 1990, 123-125), el que define en sus características generales a todas las necrópolis de la zona. A partir de una serie de elementos comunes -tipología y arquitectura funeraria, ritual, ajuares, cronología-, se propusie-

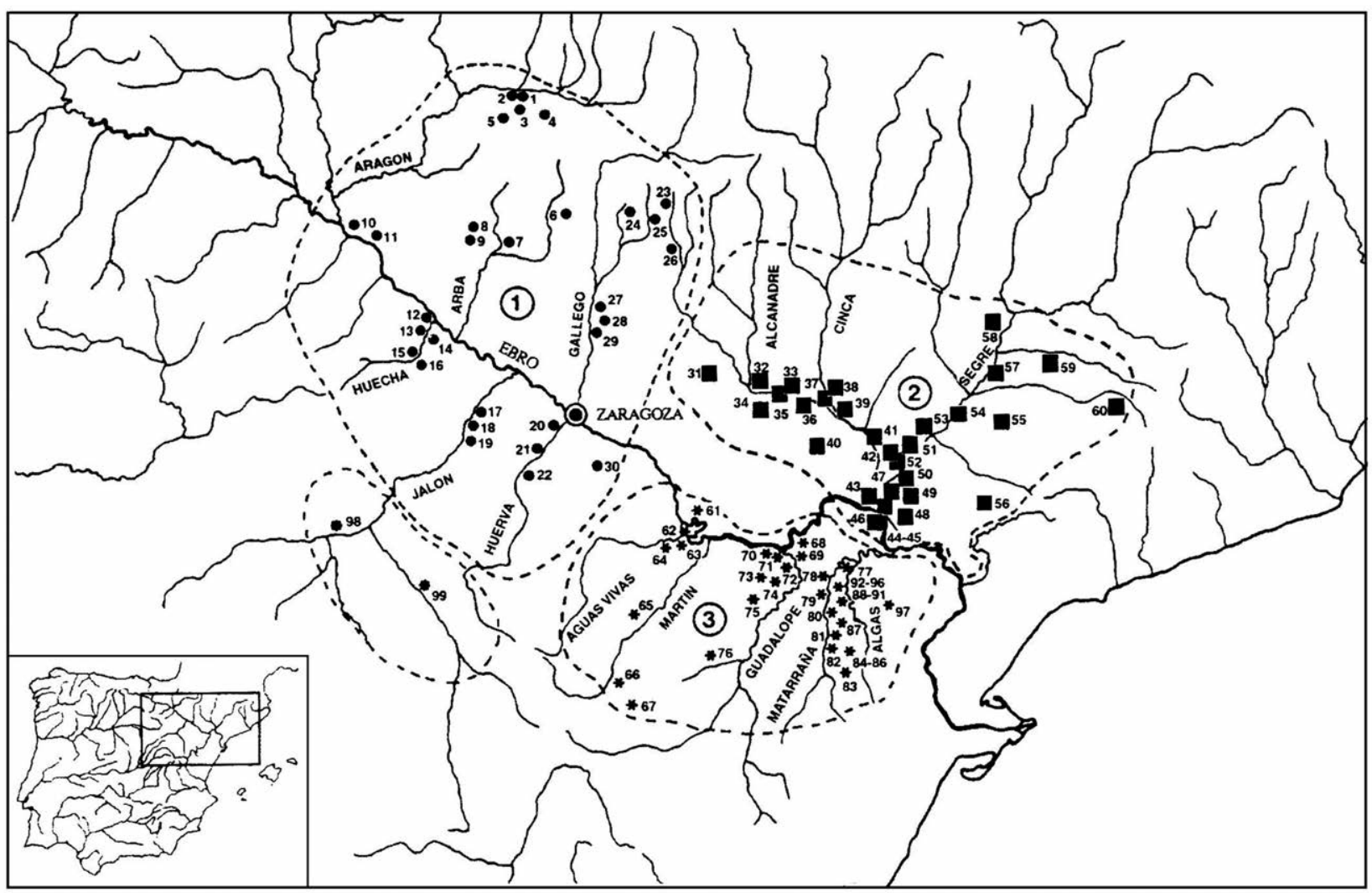

Fig. 1. Distribución geográfica de los grupos de necrópolis del Bronce Final y Hierro I en el valle medio del Ebro (Según Royo: 2000). 
ron dos subgrupos repartidos a ambos lados del río Ebro, en el sector occidental de su cuenca media: El Grupo 1A, compuesto por las necrópolis localizadas junto al río Ebro en su tramo navarro y en los cursos bajos y medios de los ríos Huecha, Jalón y Huerva y el Grupo 1B, en el que se encuentran las necrópolis tumulares de las Cinco Villas -donde se englobaría Corral de Mola-, junto a las de la Hoya de Huesca y del río Gállego (Royo, op. cit.: 2000, 42, fig. 1) (fig. 1).

El estudio de la necrópolis del Corral de Mola, nos ha permitido aportar elementos importantes sobre el origen y desarrollo de las necrópolis del sector occidental del valle medio del Ebro durante la $\mathrm{I}^{\mathrm{a}}$ Edad del Hierro, además de revisar otra vecina a ésta, la de Busal (Burillo, op . cit.: 1977) que a la luz de los nuevos datos, cobra un nuevo interés en el cuadro cronocultural de la zona. Esto ha permitido un mejor encaje en la secuencia evolutiva de los cementerios protohistóricos de este área, no sólo de las necrópolis aragonesas de las Cinco Villas y del río Huecha (Royo, op. cit.: 1992-93, fig. 1; 2000, 41-43, fig. 1), sino especialmente de las recientemente estudiadas en la vecina Navarra (Armendáriz, op. cit.: 2008, 185-188; Ruiz Zapatero, op, cit: 2008; Faro, op . cit.: 2015), aportando importantes novedades en el fenómeno tumular, la incineración y las sociedades protohistóricas del valle medio del Ebro.

\section{La NeCrópolis Tumular de INCINERACión DEL "Corral de Mola" (UnCastillo, Zaragoza)}

Aunque es la primera necrópolis excavada en las Cinco Villas de Zaragoza, diversas circunstancias han impedido completar su estudio. Desde su descubrimiento en 1977 (Pueyo: 1979), solamente se han publicado algunas noticias preliminares (Beltrán Lloris: 1978, 255; 1986, 26). Con posterioridad, parte de los materiales aparecen citados en la exposición del Museo de Zaragoza (Beltrán Lloris: 2003, 66). Por nuestra parte, sólo habíamos publicado algunas referencias de sus ajuares metálicos (Royo, op . cit.: 1980, 246-247), sus características constructivas, rituales o culturales (Royo, op . cit.: 1990, 127), o su inclusión en el grupo $1 \mathrm{~B}$ de necrópolis tumulares del valle medio del Ebro (Royo, op . cit.: 2000, 43, fig. 1). Otros trabajos citarían la pervivencia del espacio sacro de la necrópolis en la cultura pastoril de la zona (Royo: 1979), alguna referencia a piezas en colecciones particulares (Pellejero; 1984, 33), o aportarían imágenes de materiales en una exposición comarcal (Cabello: 2007, 45-46 y 177).

La intervención en este yacimiento se motivó por el grave deterioro provocado por el cambio en las labores agrícolas, lo que provocó el arrasamiento de la mayor parte de las estructuras funerarias de esta necrópolis, impidiendo conocer el número exacto de enterramien- tos del conjunto funerario. Para intentar documentar los restos arqueológicos conservados, el Museo de Zaragoza realizó tres campañas de urgencia en 1977, 1978 y 1979, coordinadas por su director, M. Beltrán Lloris y dirigidas en los trabajos de campo por J. Paz y J. I. Royo en 1977 y posteriormente sólo por J. I. Royo en 1978 y 1979, haciéndonos cargo a partir de ese momento del posterior estudio del yacimiento. En 1986 se realizó la datación radiocarbónica de este conjunto funerario. Los materiales de la necrópolis del Corral de Mola quedaron depositados en el Museo de Zaragoza, donde siguen en la actualidad sin que se haya procedido a su consolidación y restauración.

\subsection{Localización, entorno y descripción general del yacimiento}

La necrópolis del Corral de Mola se localiza en el término municipal de Uncastillo, en la comarca de las Cinco Villas de la provincia de Zaragoza. Se ubica en la ladera derecha del Barranco de Bastanes, afluente del río Riguel, en una pequeña elevación o cabezo que destaca sobre un paisaje relativamente llano, salpicado de ondulaciones y cerros testigo, actualmente ocupado en los fondos de vales y zonas más llanas para el cultivo extensivo de cereal, mientras que los barrancos y montes, aparecen ocupados por una densa cobertura vegetal de bosque de carrasca más o menos degradado. El soporte geológico del yacimiento se corresponde con el somontano pirenaico occidental, dominando toda la zona los materiales de areniscas y arcillas miocenas (Cabello, op. cit.: 2007, 15-23). La situación topográfica del conjunto según el Datum ETRS89 (Huso 30 extendido) es la que sigue: $\mathrm{x}=646.074, \mathrm{y}=$ 4.687.306, siendo la altura s. n. m. de 508 m. Junto a la ladera este de este pequeño cerro, se levanta el caserío pastoril del Corral de Mola (fig. 2).

Se accede por el camino que discurre en paralelo al río Riguel desde la localidad de Layana hasta este corral y el Barranco de Bastanes. Al llegar al lugar, el yacimiento queda enmarcado por un pequeño collado entre dos cabezos, en uno de los cuales se han recuperado restos cerámicos manufacturados de la Edad del Hierro posiblemente pertenecientes al hábitat relacionado con la necrópolis. Desde este collado se contempla el paraje, con la ladera oeste del cabezo ocupado por el yacimiento, en el que solamente una franja situada en el lado este del cabezo cuenta con su fisonomía original, mientras que el resto ha sido acondicionado para las labores agrícolas, disimulando en parte un pequeño barranco que delimitaba por el sur la referida elevación (fig. 3).

La ubicación de este altozano con respecto al Barranco de Bastanes, le confiere al mismo una gran visibilidad y dominio con respecto a esta extensa val, auténtico desagüe de las sierras circundantes que des- 

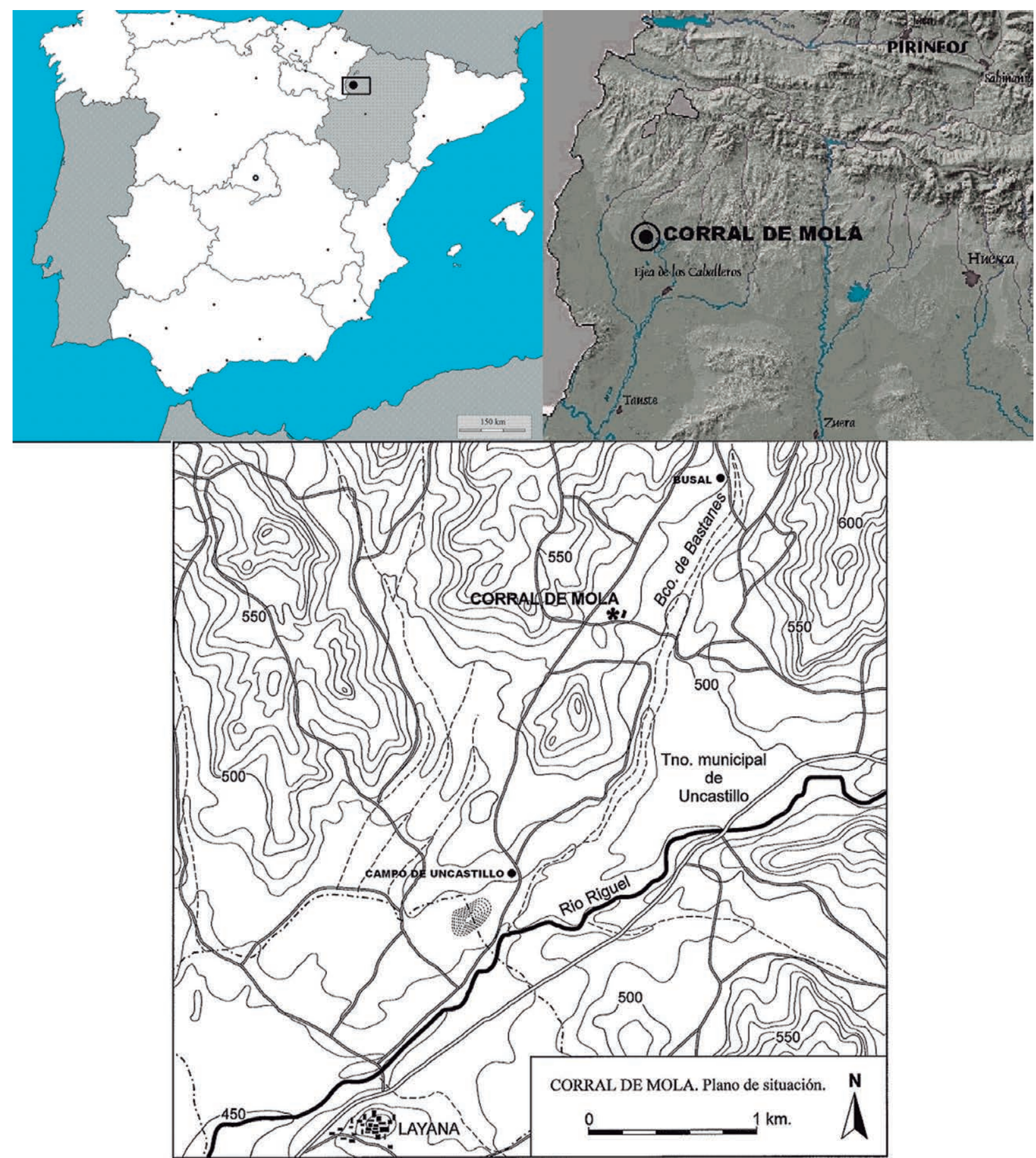

Fig. 2. Situación geográfica de la necrópolis del Corral de Mola y localización topográfica de la misma, así como de los conjuntos funerarios más cercanos (Elaboración propia, salvo la situación topográfica: A. Blanco 2000).

emboca en el río Riguel, afluente del río Arba que desagua en la margen izquierda del Ebro. Desde este punto dominante, se localiza aproximadamente a un $\mathrm{km}$. hacia el noreste la necrópolis de Busal (Burillo, op. cit.: 1977). No obstante, todo el entorno del Corral de Mola cuenta con restos arqueológicos protohistóricos, como el cabezo de Puy Arraso (Burillo, op . cit.: 1977, 52), destacando la presencia de importantes yacimientos prehistóricos y campaniformes, como los denominados Busal I, II y III o los restos de un taller de silex en el propio cabezo del Corral de Mola (Lanzarote et alii: 1991, 270-281).

\subsection{Las estructuras funerarias y sus ajuares}

Durante las tres campañas de excavación en el Corral de Mola (1977 a 1979), se pudieron documentar un total de cinco estructuras funerarias, aunque la escasez de medios disponibles en ese momento, junto 


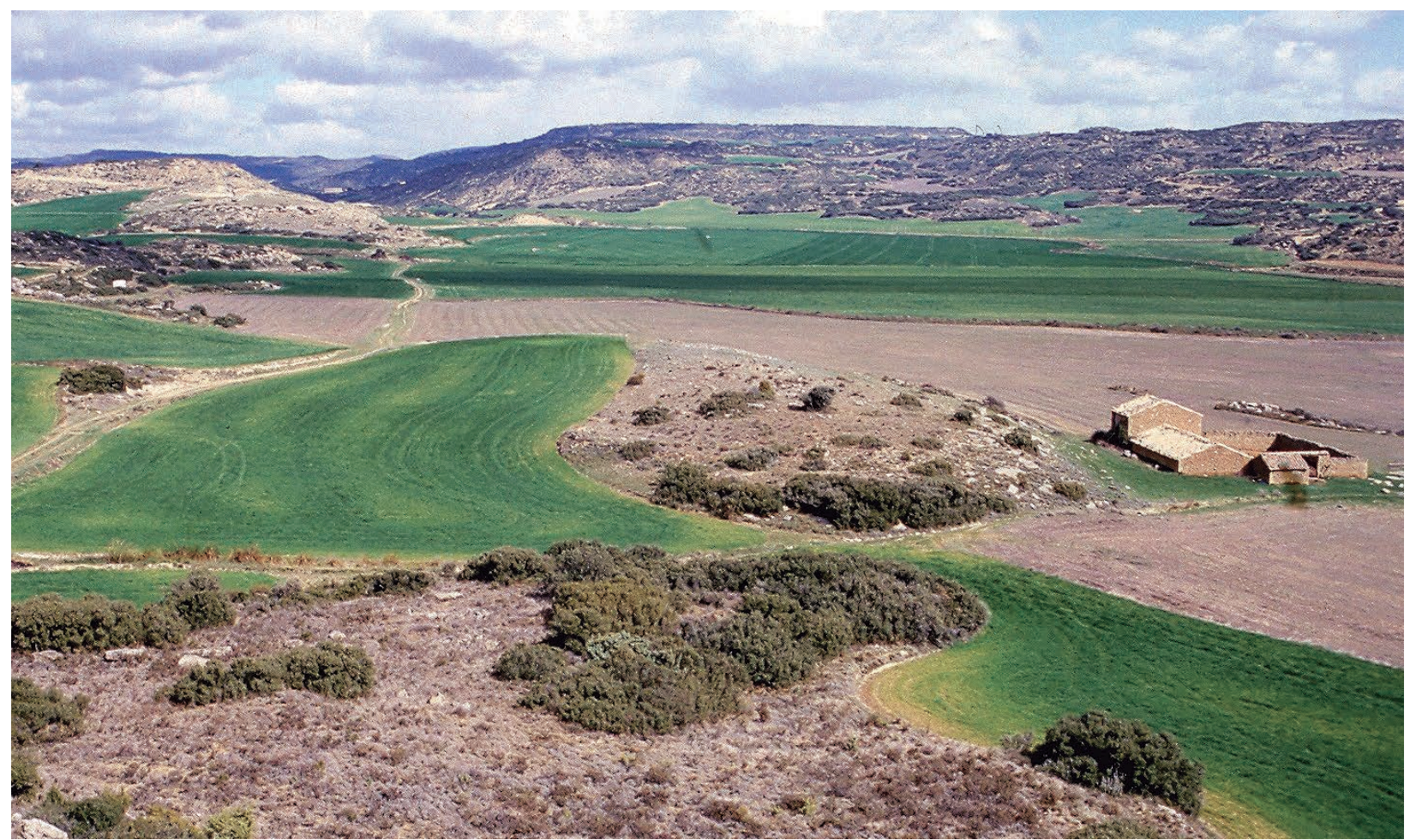

Fig. 3. Vista general el yacimiento desde el sur en el año 1998. En el centro, la necrópolis, a la derecha el caserío del Corral de Mola y al fondo el Barranco de Bastanes (Foto Royo).

a las adversas condiciones climatológicas durante la primera campaña de urgencia, impidieron una documentación exhaustiva del yacimiento. No obstante, se aplicó la metodología habitual en ese momento y para este tipo de yacimientos. Además del levantamiento topográfico del conjunto para localizar las diferentes estructuras funerarias (fig. 4), en todos los enterramientos se procedió a la delimitación y limpieza previa del conjunto, a su completa documentación planimétrica y a la realización de las secciones o altimetrías que permitieran constatar la estratigrafía existente, para lo cual se cuadriculó el área afectada siguiendo un eje de coordenadas cartesianas, decapando los niveles existentes y recuperando todas las evidencias mediante el cribado sistemático de todo el sedimento excavado. Esta detallada documentación nos ha permitido, casi cuarenta años después, abordar con garantías su publicación.

De las cinco estructuras descubiertas, las denominadas como T1 y T5 fueron localizadas en el interior de la finca agrícola, en ese momento en explotación, por lo que dichos enterramientos han desaparecido arrasados por las roturaciones anuales. El resto de construcciones funerarias, T2, T3 y T4, localizados en lo alto del pequeño cabezo, todavía se conservan en la actualidad (fig. 5), aunque en el caso de T2 y T3, muy arrasados por su exposición al aire libre. A este respecto, debemos citar el hallazgo entre los restos funerarios de esta necrópolis, de dos monedas de bronce, una de Felipe IV de 1655, reacuñada y con ceca de Segovia y otra de Fernando VI de 1789. Hoy sabemos que durante los siglos XVII y XVIII se saquearon muchos túmulos y enterramientos en la Península Ibérica, en busca de metales preciosos o en algunos casos como curiosidad científica fruto de las iniciativas ilustradas de los monarcas Borbones (DíazAndreu y Mora: 1995, 26-27).

\section{2. 1. Túmulo 1}

La actuación arqueológica se llevó a cabo en una sola campaña, entre los días 10 y 12 de septiembre y entre el 12 y 22 de octubre de 1977. Se localizaba en un pequeño promontorio de la ladera oeste del cabezo, en la parte central de la parcela roturada. La delimitación de la estructura funeraria fue relativamente sencilla, ya que en superficie destacaba entre la tierra de labor una mancha cenicienta muy intensa y de marcada planta circular, con un diámetro de unos 6,20 metros. Dado que toda la parcela se había roturado, removiéndose una capa del terreno de entre 20 y $30 \mathrm{~cm}$., se procedió a retirar dicha capa removida y a su cribado sistemático. Para ello se dividió toda la mancha cenicienta en cuatro sectores, concentrándose los trabajos en la mitad norte, sectores 1 y 2 , destacando la concentración de hallazgos en el sector 1 . Debido a la imposibilidad de completar toda la excavación del enterramiento, se procedió a excavar el área de mayor concentración de hallazgos, concretando la intervención en tres metros cuadrados de dicho 


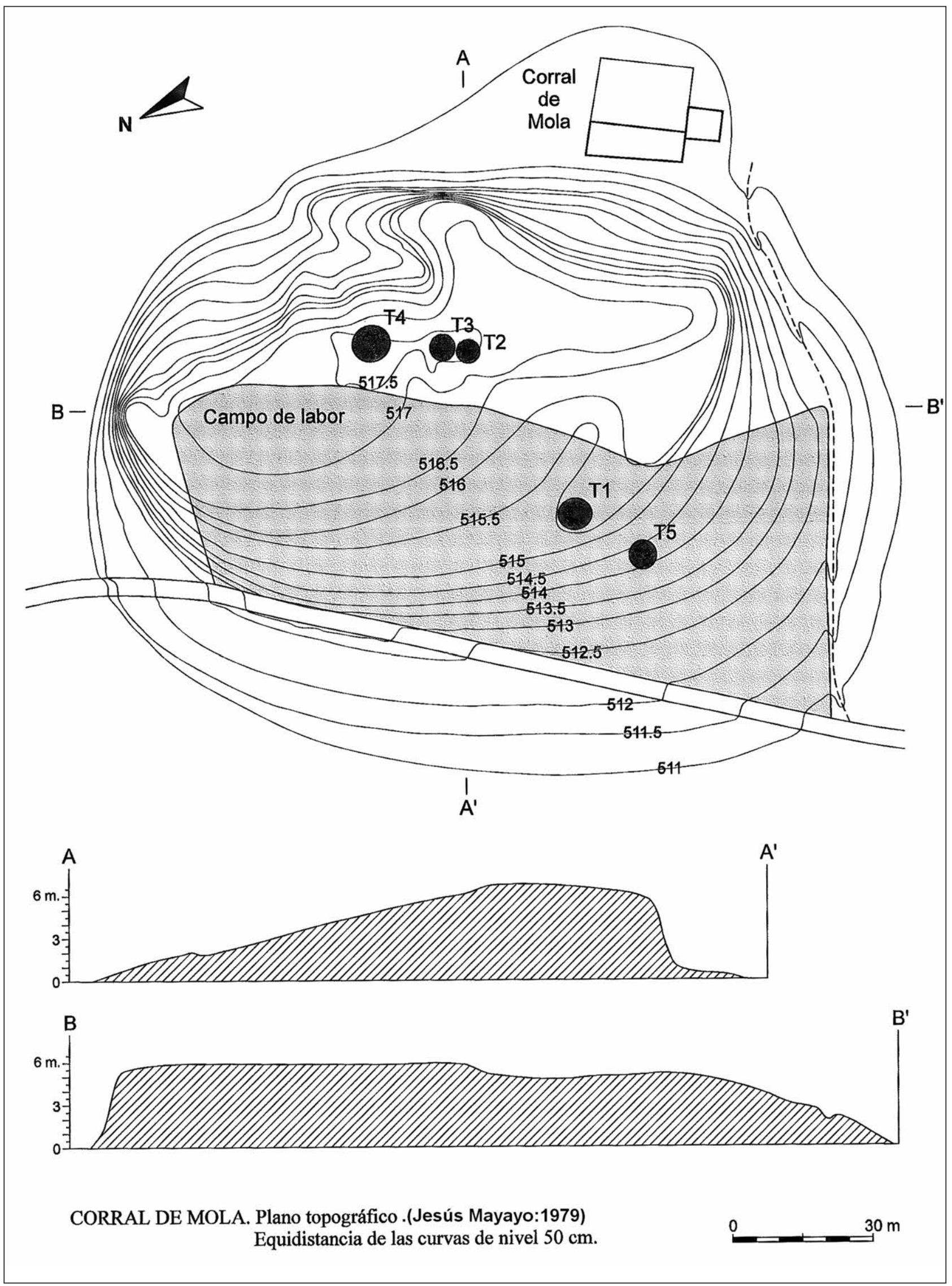

Fig. 4. Topografía del yacimiento del Corral de Mola, con ubicación de las cinco estructuras funerarias tumulares excavadas (Levantamiento topográfico: Jesús Mayayo y J. I. Royo 1978. Dibujo: A. Blanco 2000). 


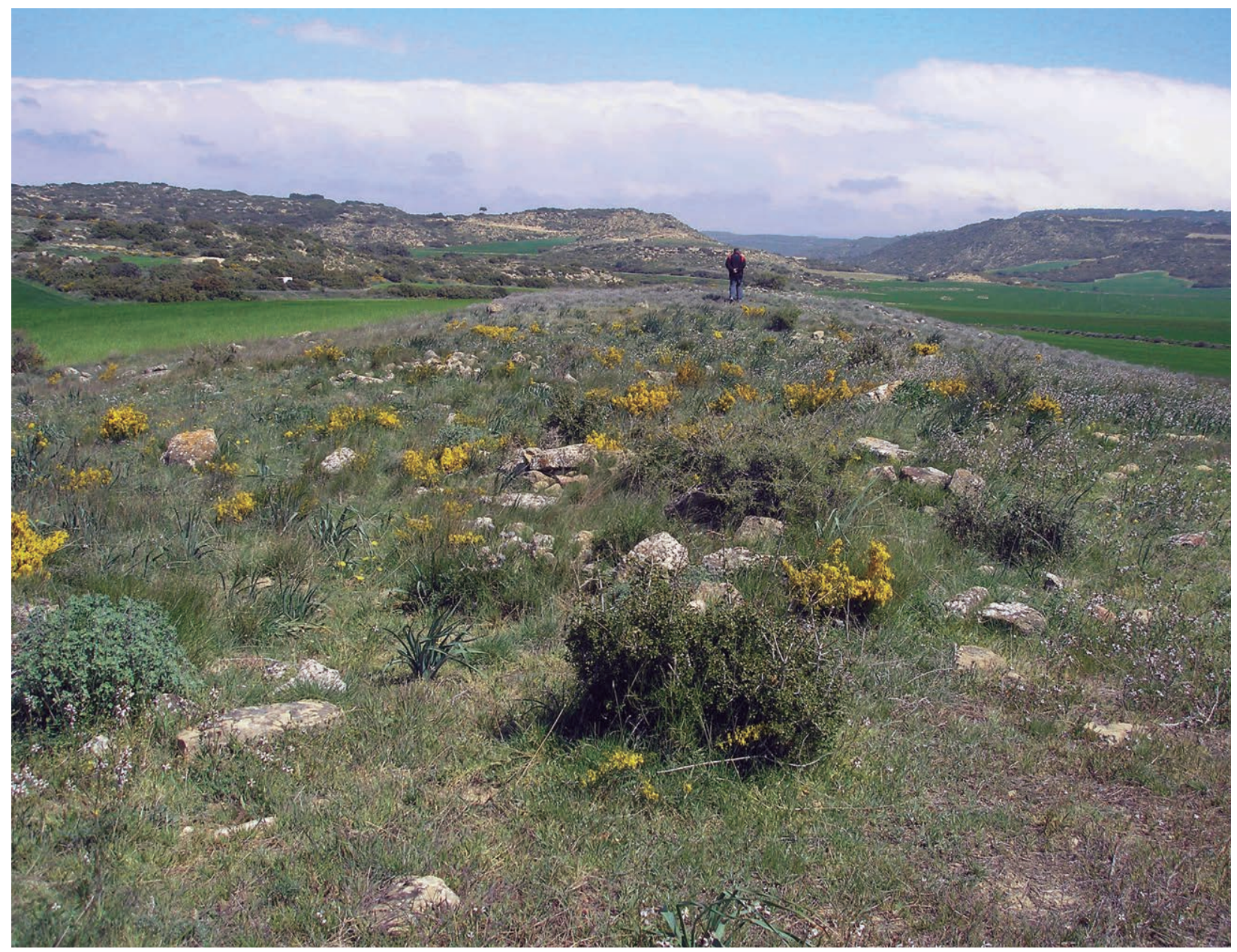

Fig. 5. Estado de la necrópolis en la zona no roturada de la necrópolis. Pueden observarse los restos de los túmulos y piedras sueltas de otros ya destruidos (Foto: Royo 1998).

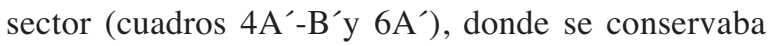
mejor la estratigrafía del conjunto (fig. 6). Aunque la excavación de la zona seleccionada permitió definir el tipo de enterramiento, parte de su estructura interna y la práctica totalidad del ajuar funerario, la excavación quedó paralizada debido a una intensa tormenta que cayó en la comarca de las Cinco Villas la noche del 18 de octubre de 1977, desbordando barrancos y ríos, aislando poblaciones y arrasando diversas infraestructuras. El arrasamiento de la zona excavada y a la imposibilidad de trabajar en esas condiciones, determinó el final de la intervención.

A pesar de todo lo dicho, la zona documentada nos permitió clasificar la estructura funeraria como los restos muy arrasados por el arado de un túmulo de incineración, de más de 6 metros de diámetro, con cubierta de piedras y lajas de arenisca y práctica de la cremación bajo dicha estructura, directamente en una pequeña hondonada sobre el propio terreno natural, en la que se encontraba gran parte del ajuar funerario y los restos óseos, éstos sometidos a una intensa incineración que aún así nos permitió identificar alguna pieza dental, de cráneo y de costilla, junto a otros restos humanos cremados que han sido objeto de un estudio específico que se incluye en este trabajo (fig. 7).

La estratigrafía, aunque alterada por la acción del arado, se conservaba bastante bien en los cuadros situados más al norte, en el sector 1 (fig. 8). Bajo un nivel $r$ generalizado de unos $20 \mathrm{~cm}$. de potencia media en el que todavía aparecen restos de la cubierta o encachado tumular, tierra cenicienta y restos del ajuar funerario, aparece el nivel $a$, compuesto por una capa de piedras de mediano y pequeño tamaño mezcladas con tierra que corresponde a la cubierta tumular. El nivel $b$ corresponde al paquete de la incineración propiamente dicha, realizada in situ y caracterizada por un estrato de cenizas carbonosas muy compactas de unos $10 \mathrm{~cm}$. de potencia media, con abundantes restos óseos calcinados y los diversos elementos del ajuar funerario. Por último, el nivel $c$ se identifica con el estrato natural de la zona, compuesto por una tierra muy arenosa o "buro" producto de la descomposición del nivel geológico de base compuesto por areniscas. Tanto la cubierta tumular como los res- 


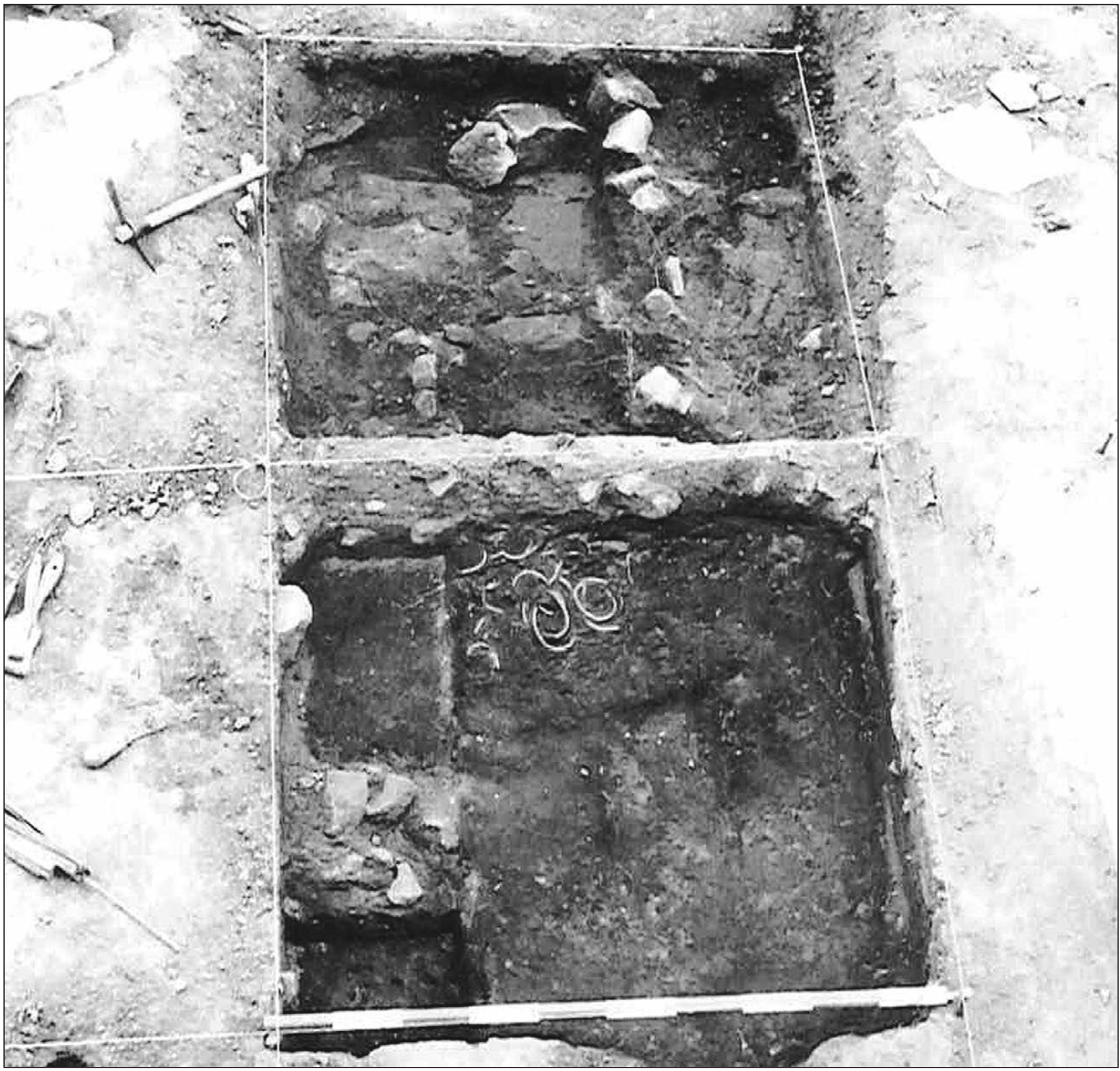

Fig. 6. Vista desde el sur de los cuadros 4 y $6 A^{\prime}$ del sector 1 del túmulo 1 . Puede verse parte del empedrado de la estructura funeraria, el nivel de la cremación y parte del ajuar metálico todavía "in situ" (Foto: Royo 1977).

tos de la cremación apoyan en este nivel al que todavía llegaron en su momento las cuchillas del arado, dejando la huella de los surcos tanto en planta como en el perfil sur del área excavada en 1977.

Del ajuar funerario, algunas piezas importantes (fíbula, broche de cinturón) se recuperaron en el nivel revuelto por las labores agrícolas. Sin embargo corresponden con seguridad al depósito de este túmulo, el cual aportó un importante conjunto de materiales exclusivamente realizados en bronce y que se concentraban en un punto concreto, protegidos por el encachado tumular, hasta presentar una acumulación de varias decenas de brazaletes que a pesar del proceso de incineración y de las afecciones antrópicas, habían mantenido su configuración y deposición originales (fig. 9). Hay que señalar la ausencia total de hierro en este ajuar, lo que a priori, supondría una cronología anterior a la determinada en la cercana necrópolis de Busal, donde aparece de forma significativa y con piezas claramente identificables (Burillo, op . cit.: 1977). La relación sucinta del ajuar funerario broncíneo de este túmulo es la que sigue:

- Fíbula completa de doble resorte en excelente estado de conservación (MOL.S-2). Presenta siete espirales en cada resorte, que junto al resto de la pieza presenta una sección cilíndrica filiforme, sin ningún tipo de decoración. La mortaja es corta y de claro perfil en U (fig. 10). El peso de la pieza es de 12,71 gramos.

- Torques con vástago liso de sección cilíndrica y terminaciones engrosadas en forma de bolas ligeramente alargadas (MOL.6A'-a-7 y MOL.4A'-b-20). 


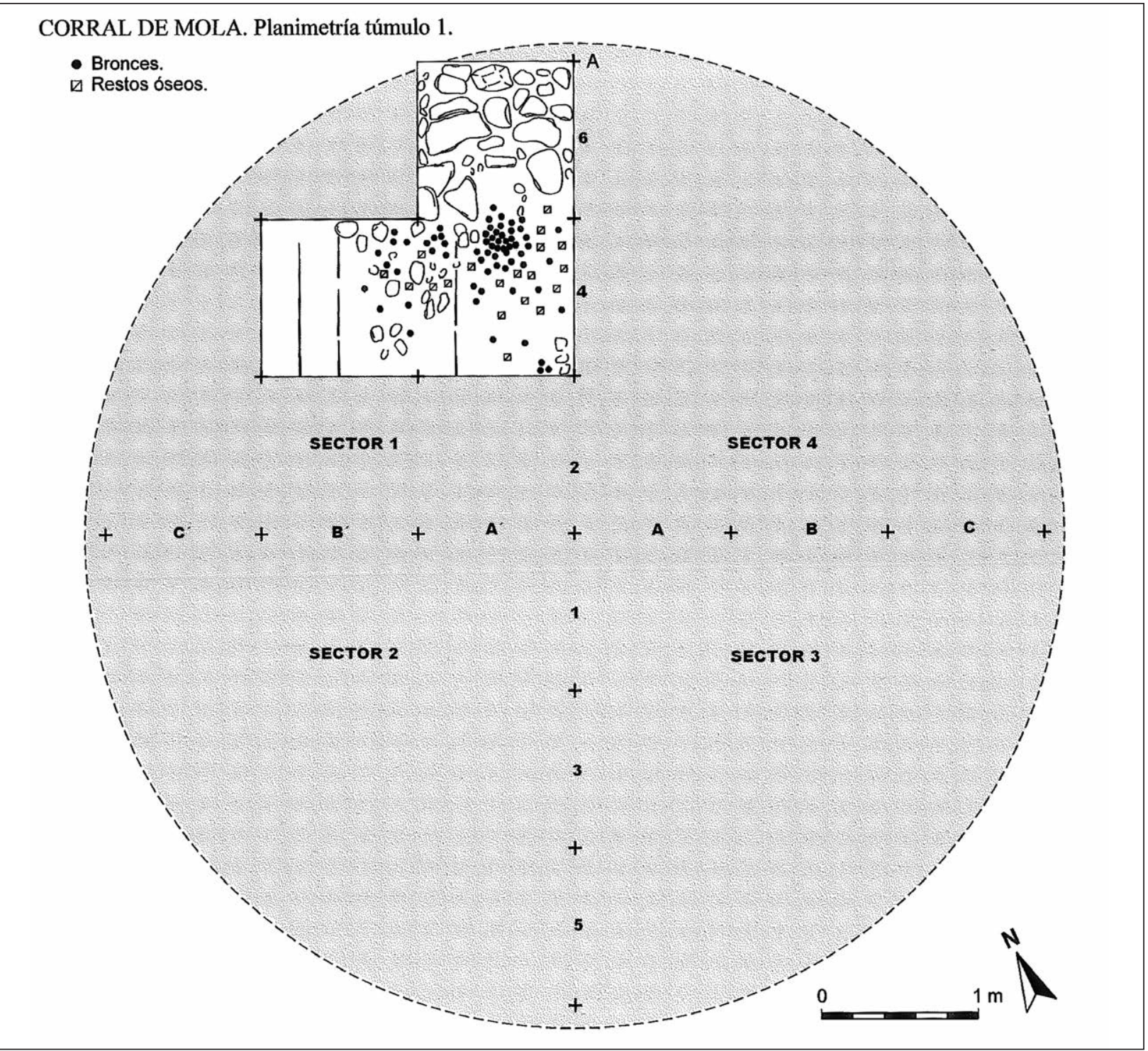

Fig. 7. Planimetría general del túmulo 1, con los cuadros excavados y la dispersión general de los restos (Dibujo: A. Blanco 2000).

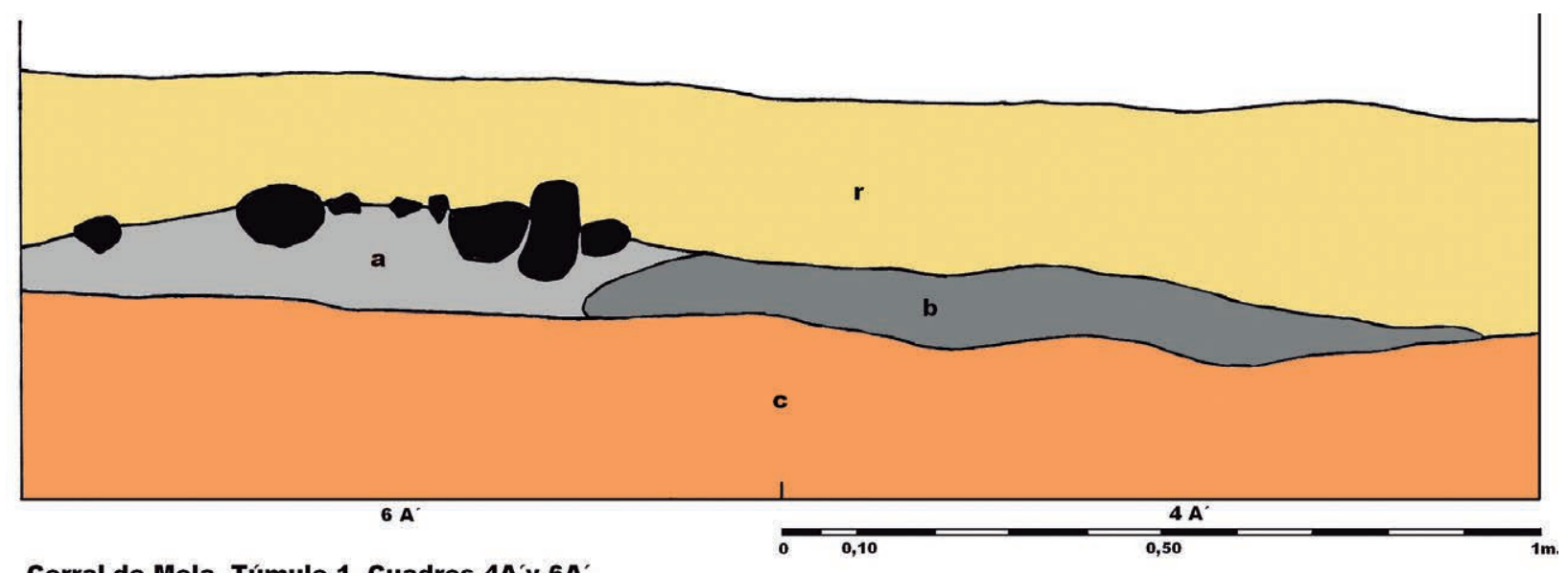

Corral de Mola. Túmulo 1. Cuadros 4A'y 6A': Estratigrafía del perfil este.

Fig. 8. Estratigrafía general del túmulo 1. Corte este de los cuadros 4 y 6A' (Dibujo: Royo 1977, modificado en 2016). 
Corral de Mola. Túmulo 1. Cuadros 4A' - 4B'y 6A' Planta de estructuras e incineración.

Piedras del túmulo.

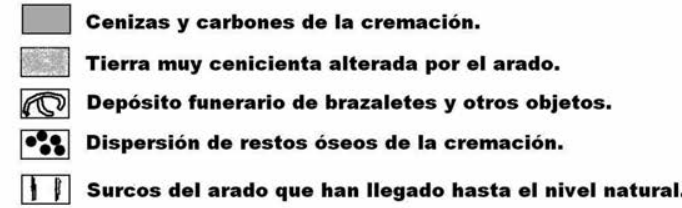

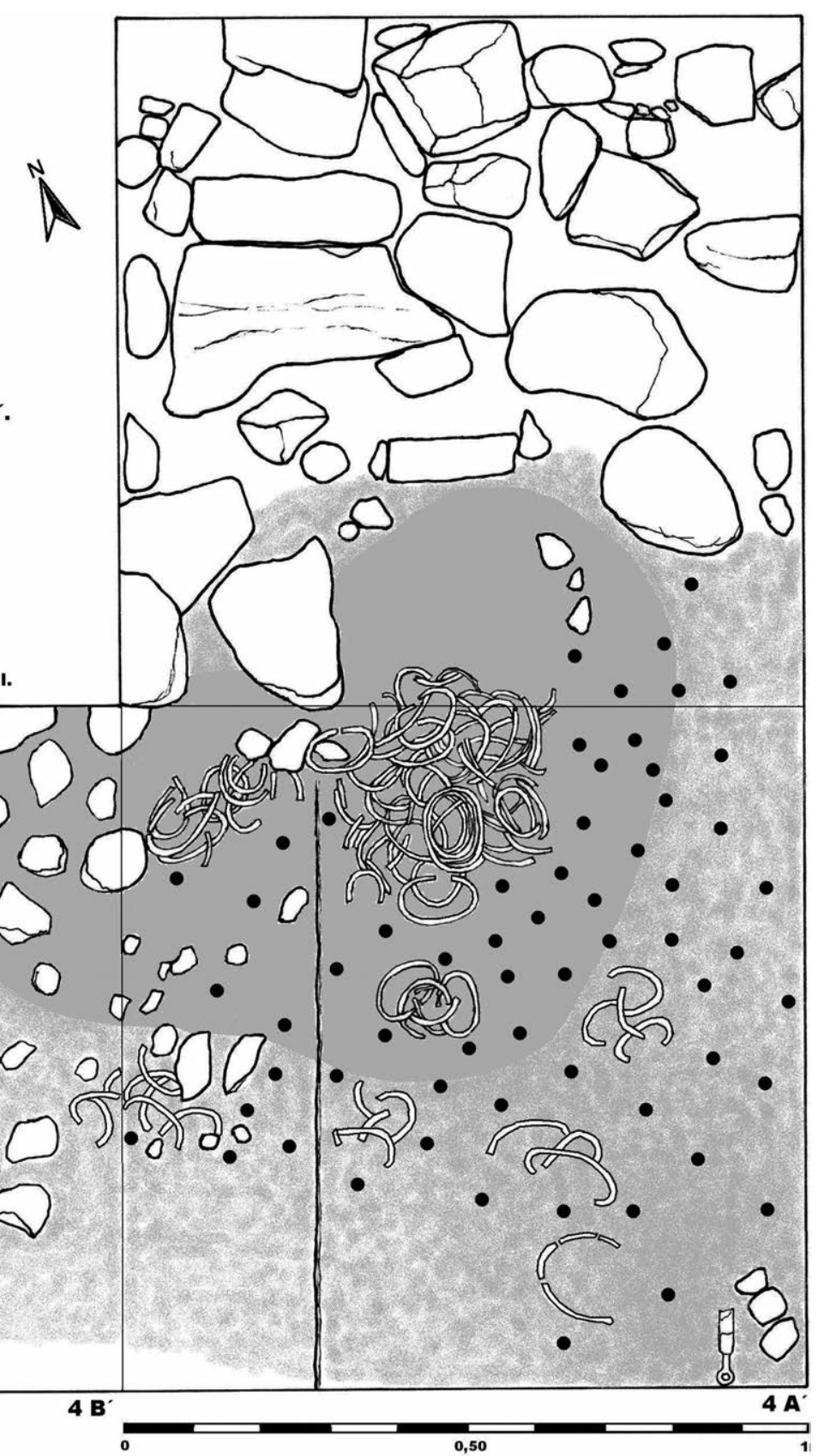

Fig. 9. Planimetría de detalle de los restos del túmulo 1 y de su ajuar funerario. Cuadros 4 y $6 \mathrm{~A}^{\prime}$ y $4 \mathrm{~B}^{\prime}$

(Dibujo: Royo 1977, digitalizado y modificado en 2016).

Aparece fragmentado de forma intencionada en ocho piezas pero conserva la mayor parte de su desarrollo, en el que no se ha constatado ningún tipo de decoración (fig. 10). El peso de lo conservado del torques es de 28,14 gramos.

- Tres botones semiesféricos con travesaño de diferente tamaño (fig. 10). El peso de estas piezas oscila entre los 0,70 gramos del más pequeño (MOL.4A'-a-11), pasando por los 0,97 del intermedio (MOL.S-25) y llegando a 1,80 gramos del mayor (MOL.S-12)

- Cuchillo o navaja de afeitar al que le falta la punta, con empuñadura en espiga o vástago terminado en anilla, ambos de sección aplastada (MOL.4A'-b30). Presenta la hoja recta, completamente cubierta de líneas incisas paralelas al filo en un número de diez y con una sección en la que se diferencia con claridad el filo de la hoja. Al igual que el torques, la pieza también parece amortizada y rota. También aparece otro fragmento de anilla muy similar a la pieza anterior (MOL.6A'-s-2), con seguridad correspondiente a otro ejemplar de cuchillo o navaja (fig. 10). Aunque incompleta, lo conservado de esta pieza singular tiene un peso de 29,25 gramos.

- Anillo o anillita de pequeño tamaño de sección cilíndrica (MOL.S-13) con un peso de 1,05 gramos (fig. 10). 


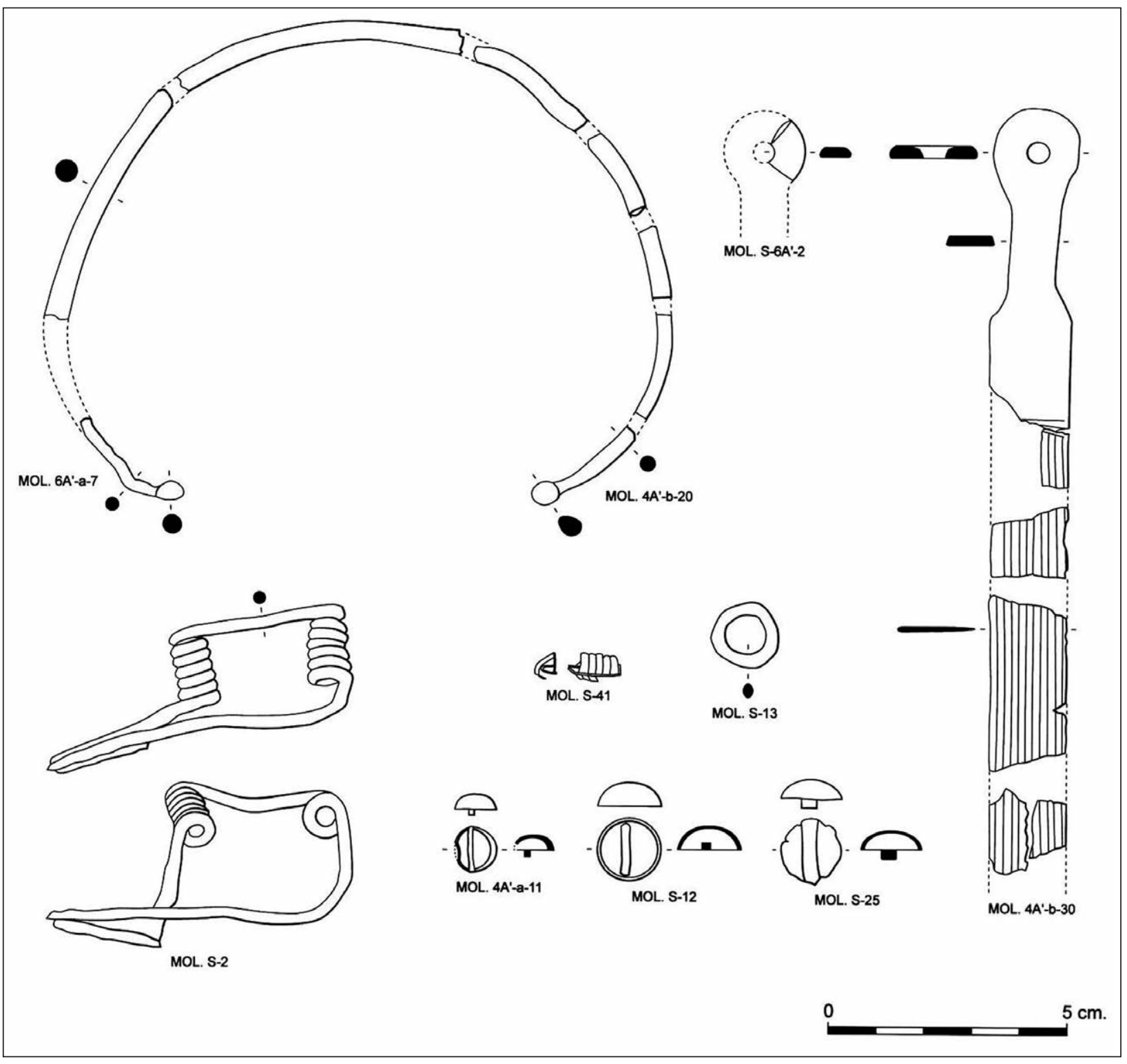

Fig. 10. Corral de Mola, túmulo 1, ajuar metálico en bronce: Fíbula de doble resorte, torques, cuchillo o navaja de afeitar, grapitas, anilla y botones semiesféricos (Dibujo: A. Blanco 2000).

- Fragmento de chapita con un ligero abombamiento de difícil identificación y un peso de 0,30 gramos.

- Broche de cinturón de un solo garfio, realizada con una placa triangular con engrosamiento o nervio central que recorre longitudinalmente toda la pieza por su cara superior. Presenta en su base o talón cuatro perforaciones, con lengüetas o pestañas soldadas en sus dos extremos, para coser o sujetar el broche al cinturón de tela o cuero, mediante dos pasadores que se han conservado. La pieza, completa aunque fragmentada, presenta una sencilla decoración incisa en el centro de la placa, a base de tres triángulos concéntricos unidos por su base a la nervadura central (MOL.S-10) (fig. 11). El peso del broche es de 81,60 gramos. A dicho broche debe asociarse una pieza de muy pequeño tamaño compuesta por una chapita a la que se sueldan hasta cinco grapas (MOL.S-41). Debió pertenecer posiblemente al cinturón, pudiendo corresponder a los remaches laterales de la pieza de cuero del mismo (fig. 10).

- Fragmento de borde y pared de un plato o escudilla de perfil troncocónico, perteneciente posiblemente al ajuar funerario (MOL.S-6). Está realizado a mano, con una pasta grisácea y acabados exteriores de las paredes muy bien espatulados (fig. 12).

- Grupo de ocho brazaletes abiertos de sección acintada o rectangular soldados en parte por el calor de la cremación y que conservan en algunos puntos restos de la decoración a base de finas incisiones en el lado exterior de cada brazalete (MOL.4A'-b-66) (fig. 12). El peso total de este conjunto de brazaletes, es de 115,50 gramos. 

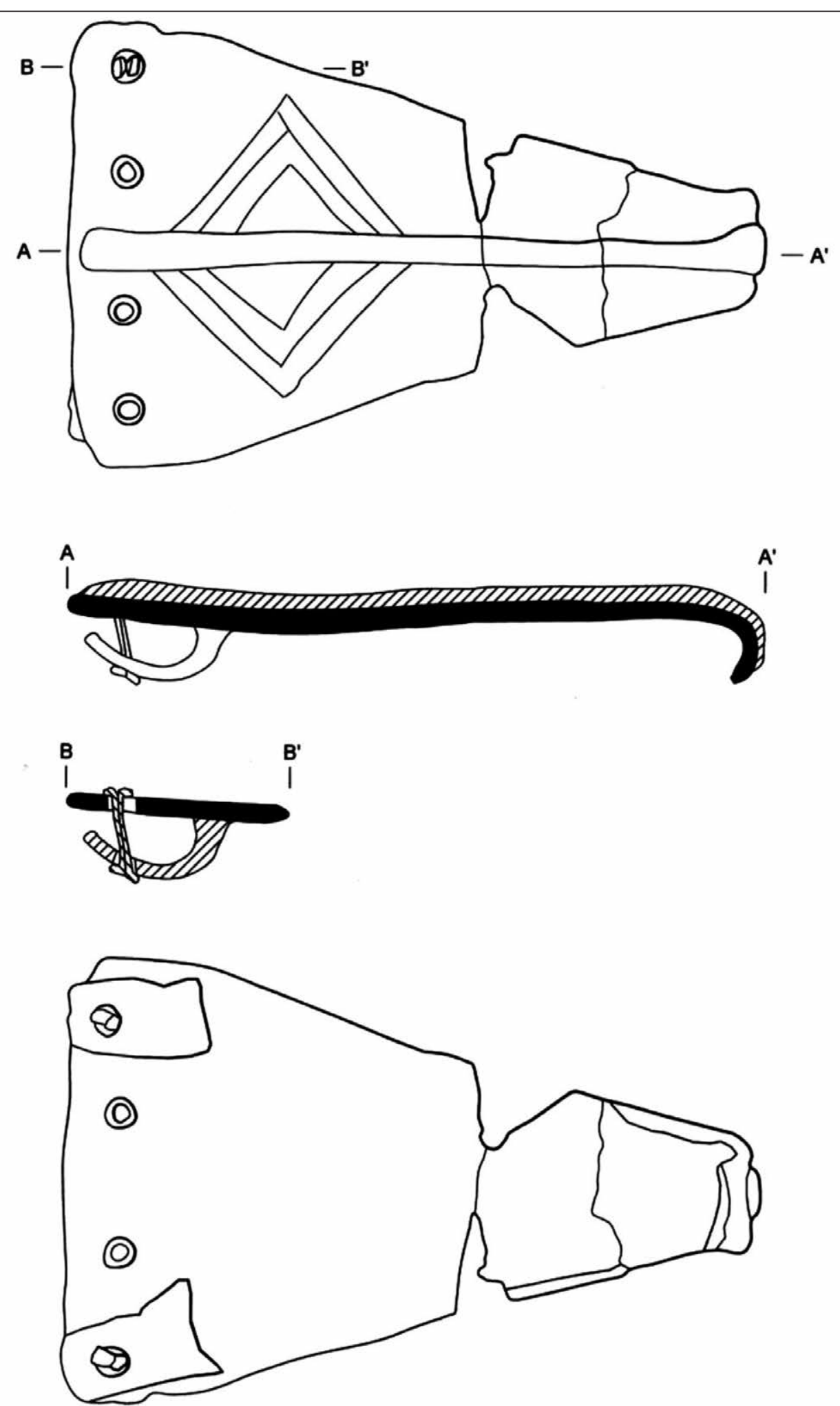

MOL. S-10

0

$5 \mathrm{~cm}$

Fig. 11. Corral de Mola, túmulo 1, ajuar metálico en bronce: Broche de cinturón de placa triangular decorada, pestañas laterales y un garfio (Dibujo: A. Blanco 2000). 
- Brazalete abierto de sección acintada o rectangular casi completo que presenta una fina decoración incisa en el canto de la pieza, conservándose de forma parcial (MOL.4A'-b-103). La decoración parece combinar motivos triangulares con verticales. En cuanto al peso de esta pieza es de 12,30 gramos (fig. 12).

- Grupo de cinco brazaletes abiertos de sección acintada o rectangular y como en el caso anterior, soldados por la cremación, aunque en este caso se podría plantear la posibilidad de una pieza múltiple, dada la perfecta soldadura del conjunto y de todos y cada uno de los vástagos de bronce que lo componen (MOL.S-5). En este caso también conservan restos de la decoración con incisiones en el lado exterior de cada pieza, lo que parece indicar que prácticamente todos las piezas estaban decoradas en sus laterales (fig. 13). El peso de este grupo de brazaletes es de 71,77 gramos.

- Brazalete abierto de sección acintada o rectangular casi completo que presenta una fina decoración incisa en un lateral de la pieza, conservándose de forma parcial (MOL.4A'-b-75). La decoración parece combinar motivos triangulares con verticales. En cuanto al peso de esta pieza es de 14,30 gramos (fig. 13).

- Selección de brazaletes abiertos de sección acintada o rectangular decorados con incisiones oblicuas en todo el lado exterior, de los que han podido reconstruir tres ejemplares (MOL.4A'-b-67, 82 y 97), así como otros dos de forma incompleta (MOL.4A'-b-98 y 104). El peso de los ejemplares completos oscila entre los 13,50 gramos de los menores y los más de 18 gramos del mayor (fig. 14).

- Selección de brazaletes abiertos de sección acintada o rectangular, completos o fragmentados, decorados con series de bandas y triángulos en sus costados laterales (MOL.4A'-b-21, 23, 61, 62, 63, $64,65,68,69,71,72,74,93,94,95,96,99,100$, $101,102,105)$. Debido a la grave afección de parte del depósito funerario de este túmulo por la tormenta, no se pudieron recuperar íntegramente ni de forma individualizada el gran número de este tipo de brazaletes depositados en el enterramiento. Con todo, se han podido reconstruir total o parcialmente un número aproximado de 30 ejemplares (figs. 15, 16 y 17), aunque la cantidad de fragmentos recuperada (más de 3.000) nos permite deducir que la cifra real sería mucho mayor de los identificados, como veremos más adelante. El peso medio de cada brazalete de este tipo es de 14,35 gramos.

- Selección de brazaletes abiertos de menor tamaño y de sección cuadrangular más reducida que la de los anteriores, decorados como los de sección acintada, en el lado exterior, con motivos incisos a base de líneas y triángulos (MOL.S-3, 15, 16, 17, 18, 24, $35,36,43,44)$. Del mismo modo que en el caso anterior, se han podido identificar un número cercano a la veintena, aunque los muchos fragmentos inventariados permiten suponer una cifra bastante mayor (fig. 17). El peso medio de cada brazalete de este tipo es bastante más bajo, de unos 8,40 gramos.

Para saber la cantidad aproximada de brazaletes de este enterramiento, procedimos en el Museo de Zaragoza a pesar con una balanza de precisión todos los fragmentos de brazaletes recuperados que suman un total de 1.896,37 gramos. Dividida esta cifra por el peso medio de un brazalete $(14,35$ gramos) y aplicando el peso más alto de los documentados, consideramos que el número total de brazaletes debió superar la cifra de 130 , lo que representa un número extraordinario para un ajuar de estas características, como más adelante comprobaremos.

De este enterramiento destaca el ajuar metálico confeccionado en bronce que presenta además una panoplia exclusiva de elementos de adorno y vestido, en la que se identifican los elementos más significativos y comunes de la misma, es decir, el broche de cinturón, el torques, la fíbula de doble resorte, los botones, el anillo, el cuchillo o navaja de afeitar y sobre todo, los brazaletes cuadrados o acintados, profusamente decorados con incisiones. El peso total de dicho ajuar asciende a los 2.052,84 grs., todo ello recuperado en la mitad norte del túmulo, aunque por el reparto de evidencias recuperadas, calculamos que supone más del $90 \%$ del posible ajuar funerario en su estado original, dada la escasez de restos metálicos en la mitad sur del túmulo estudiado. Este ajuar no aparece en el interior de la urna funeraria o de un vaso de ofrendas, sino en una acumulación o deposición intencionada en la zona de la cremación, junto a la mayor parte de los restos óseos recuperados en la excavación del túmulo. Todo ello apunta a un ajuar singular de indudable riqueza, a juzgar por la extraordinaria acumulación o atesoramiento de un determinado tipo de piezas -brazaletes-, por lo que podríamos estar ante un enterramiento significativo en el conjunto de esta necrópolis, sobre todo si lo comparamos con otros ejemplos conocidos.

\section{2. 2. Túmulo 2}

La siguiente estructura excavada en el Corral de Mola se localiza en la zona no roturada del cabezo, en su cota más alta, donde aflora la cantera de arenisca, por lo que es una zona poco propicia para la conservación de contextos estratigráficos. Se procedió a su delimitación, limpieza y documentación en la segunda campaña en este yacimiento, durante el mes de agosto de 1978 (fig. 18). 

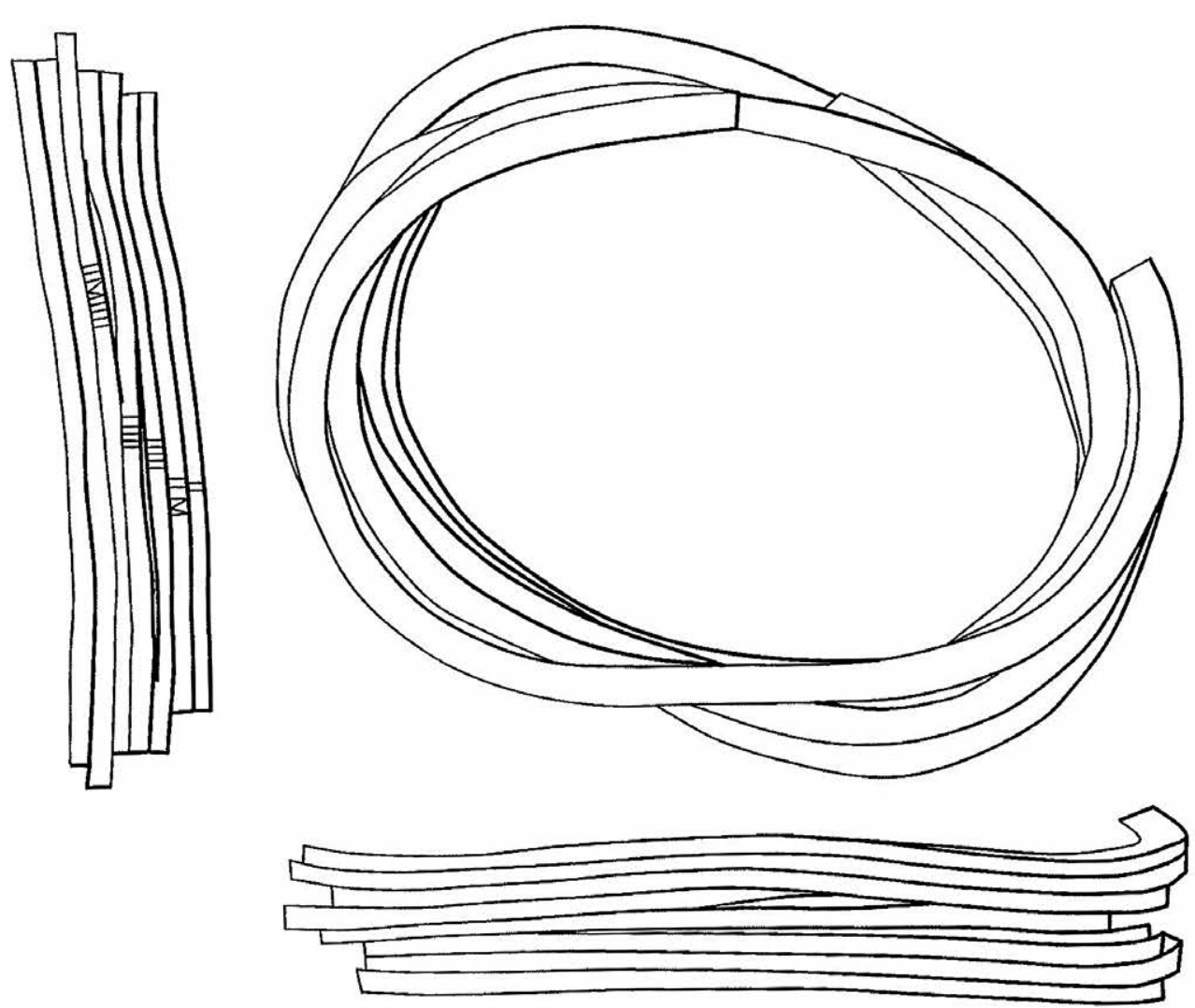

MOL. 4A'-b-66
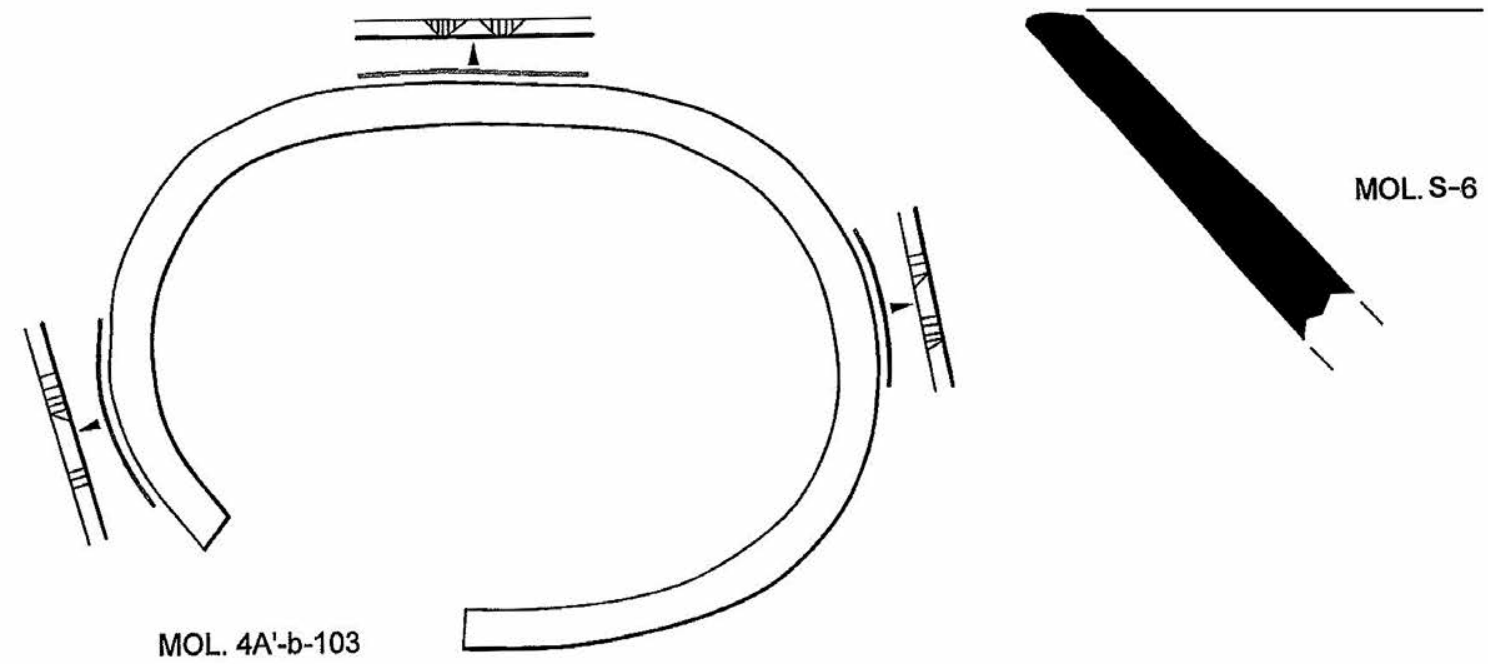

Fig. 12. Corral de Mola, túmulo 1, ajuar metálico en bronce: Brazaletes abiertos múltiples decorados, brazalete simple y fragmento cerámica (Dibujo: A. Blanco 2000). 


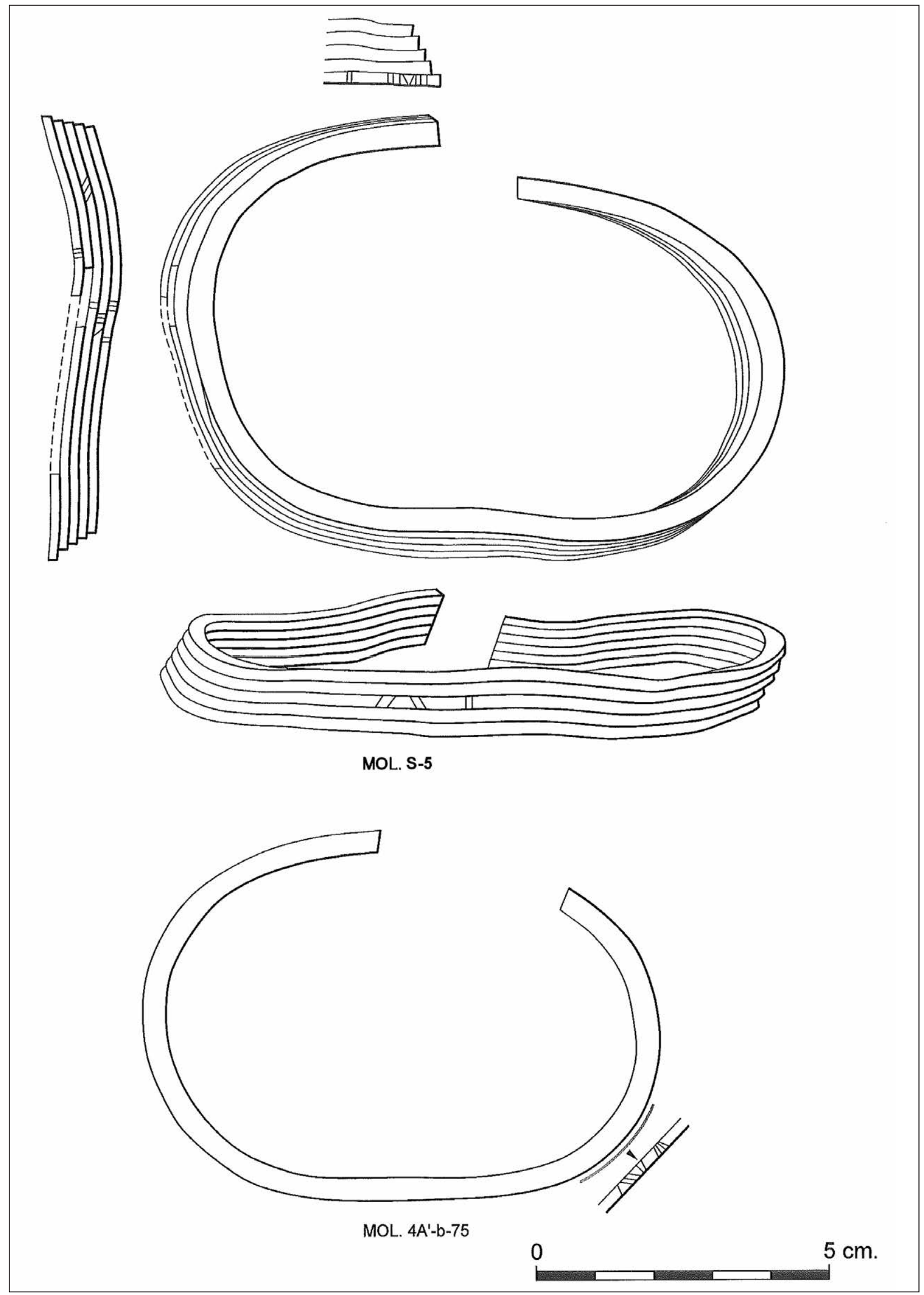

Fig. 13. Corral de Mola, túmulo 1, ajuar metálico en bronce: Brazaletes múltiples abiertos y brazalete simple (Dibujo: A. Blanco 2000). 


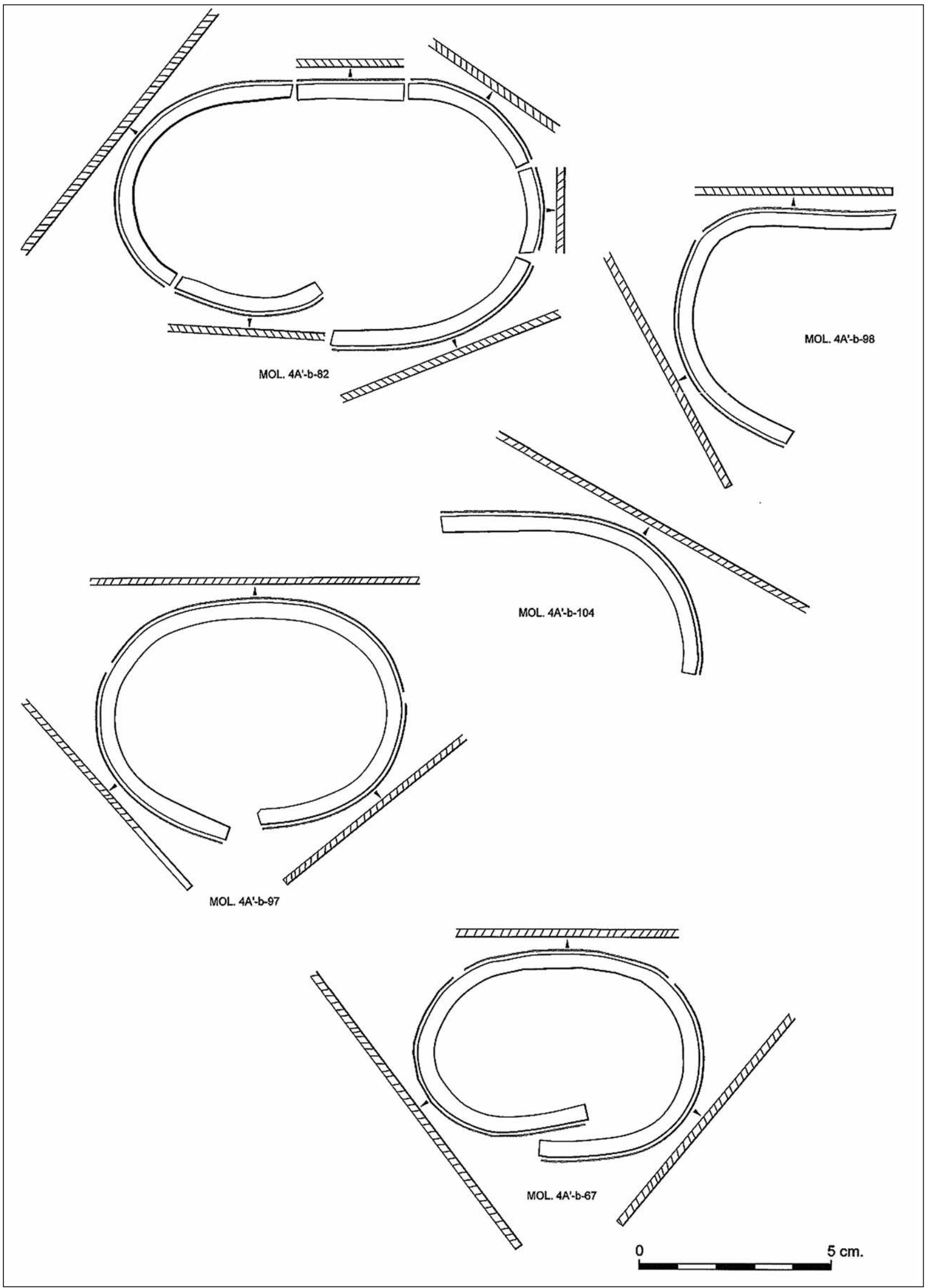

Fig. 14. Corral de Mola, túmulo 1, ajuar metálico en bronce: A.- Dos brazaletes abiertos con decoración lateral de incisiones oblicuas. B.- Brazalete completo y dos fragmentos de brazaletes abiertos con decoración lateral de incisiones oblicuas (Dibujo: A. Blanco 2000). 


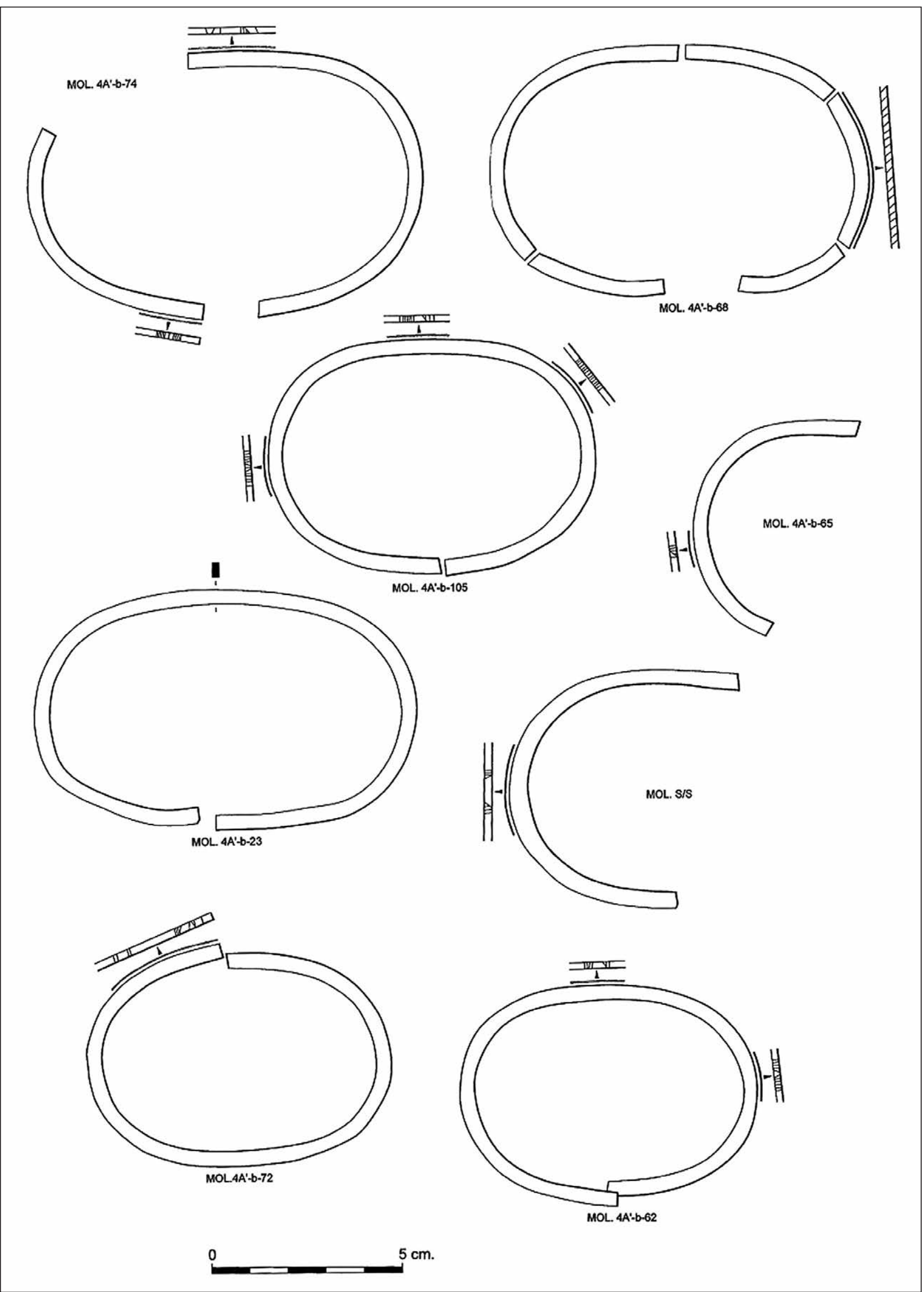

Fig. 15. Corral de Mola, túmulo 1, ajuar metálico en bronce: A.- Tres brazaletes completos abiertos y decorados con incisiones laterales. B.- Tres brazaletes completos abiertos y decorados con incisiones laterales, así como fragmentos de otros dos ejemplares. 


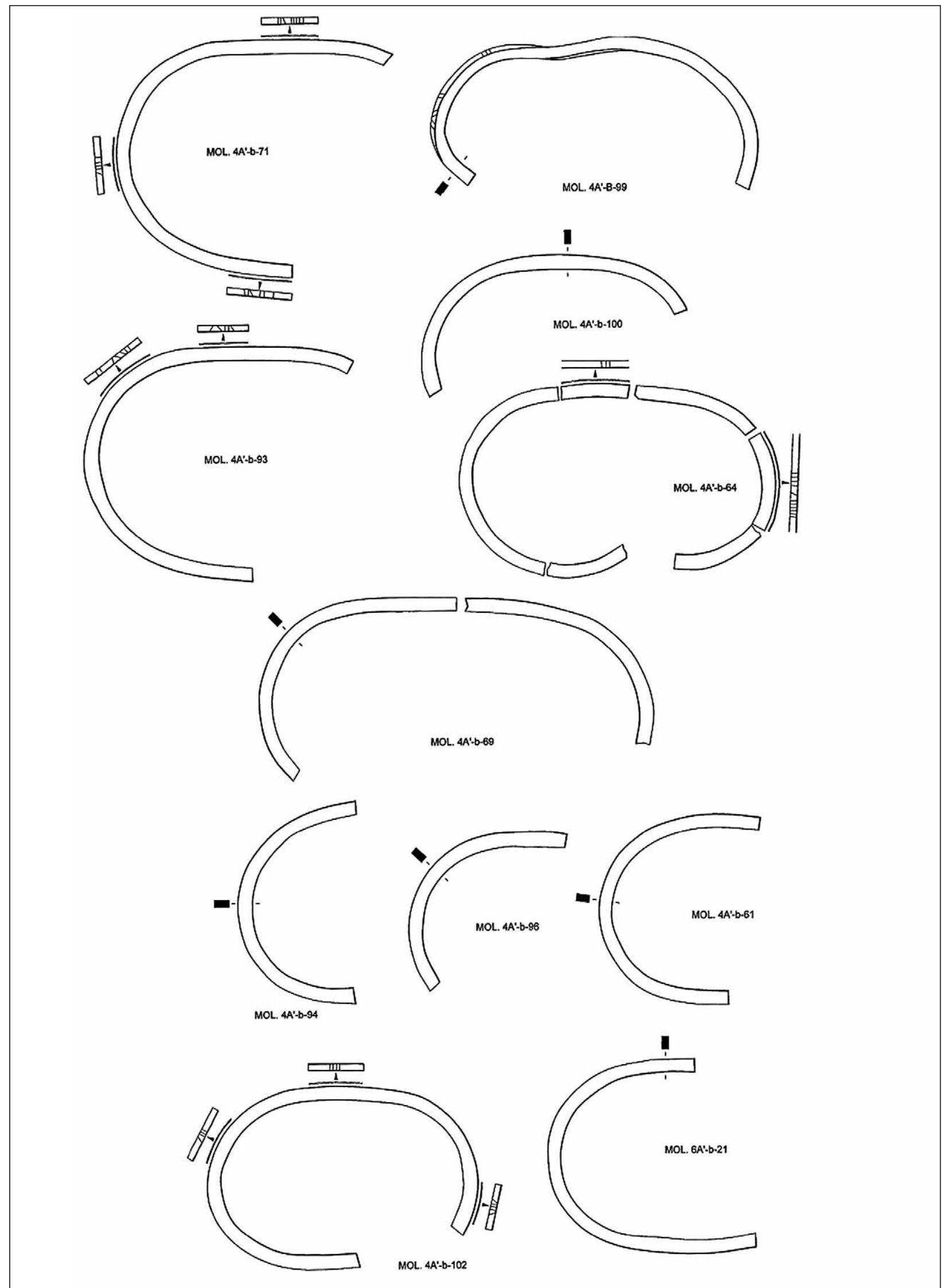

Fig. 16. Corral de Mola, túmulo 1, ajuar metálico en bronce: A.- Cinco ejemplares de brazaletes o fragmentos de brazaletes abiertos decorados con incisiones laterales. B.- Seis brazaletes incompletos abiertos de sección acintada o rectangular y decoración incisa lateral. 


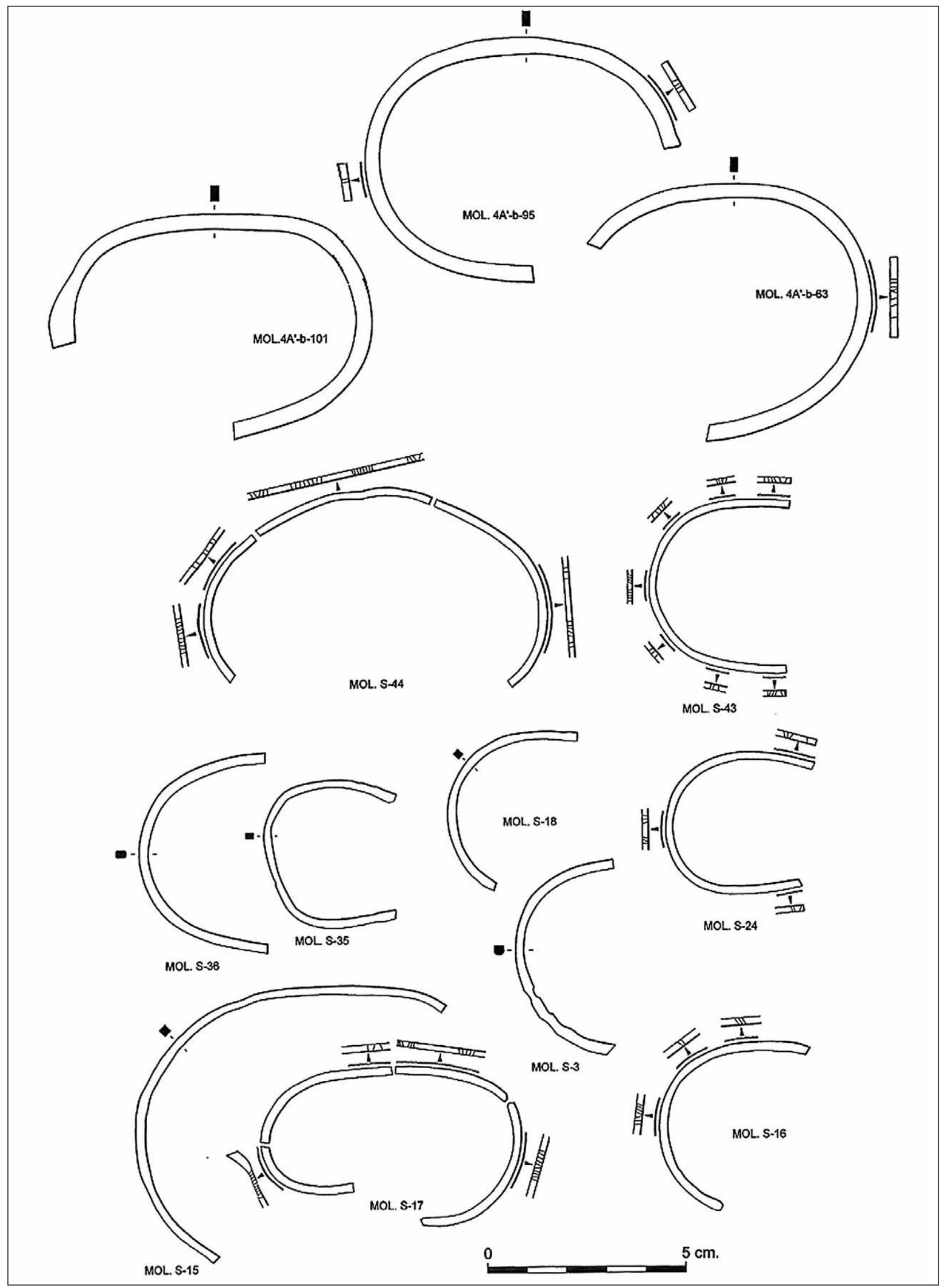

Fig. 17. Corral de Mola, túmulo 1, ajuar metálico en bronce: A.- Tres brazaletes incompletos abiertos de sección rectangular decorados y otros dos de sección cuadrangular también decorados en el lateral exterior. B.- Ocho brazaletes incompletos de sección cuadrangular y con decoración en el lateral exterior a base de combinaciones de incisiones triangulares. 


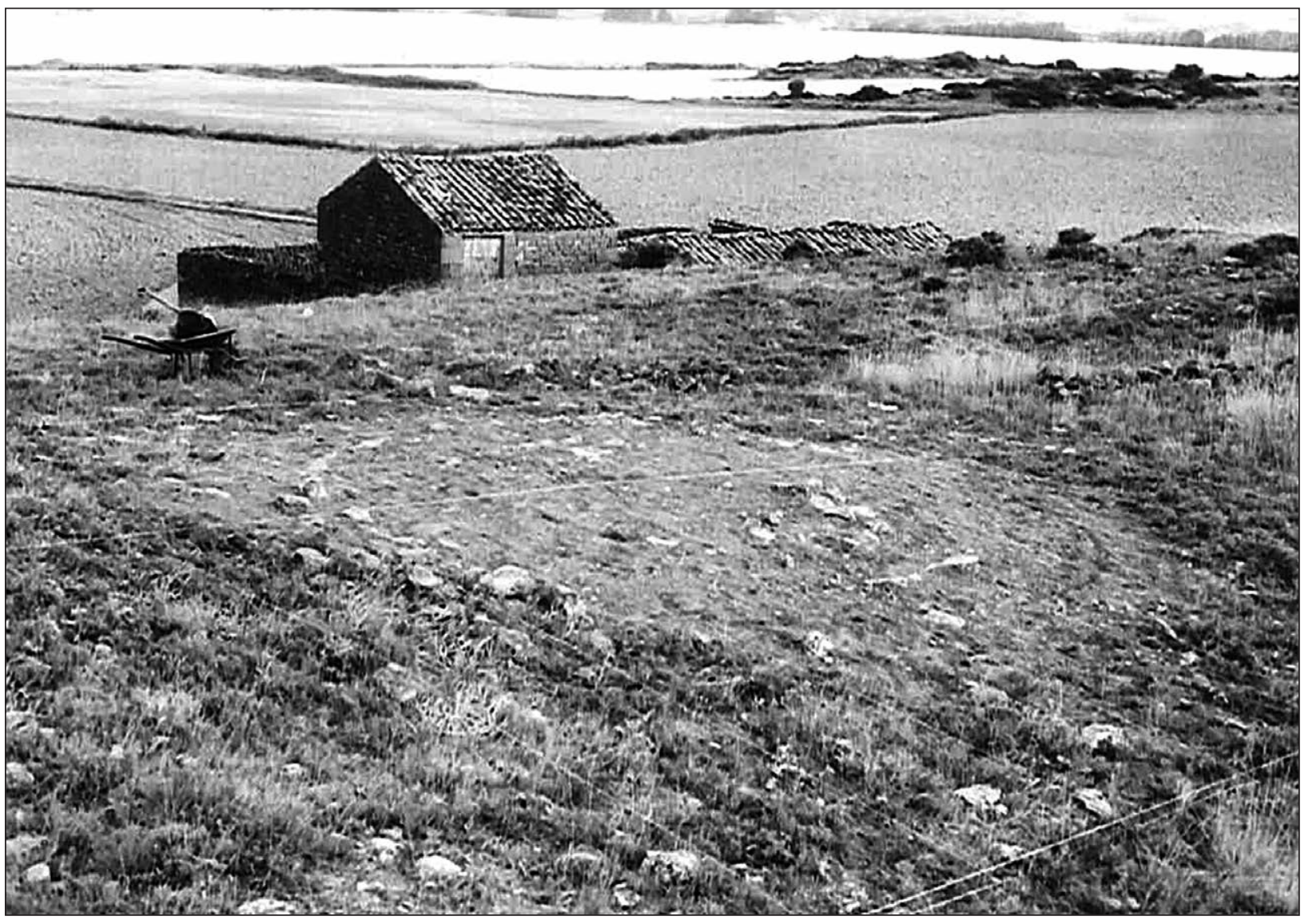

Fig. 18. Vista general desde el noroeste de la limpieza superficial del túmulo 2 (Foto: Royo 1978).

Se trata de una construcción de tipo tumular totalmente descarnada y arrasada por la erosión, de la cual sólo queda parte de la planta. Estamos ante un túmulo de forma ligeramente ovalada, con unas dimensiones de $5,10 \mathrm{~m}$. en su eje longitudinal por $4,50 \mathrm{~m}$. en su eje transversal (fig. 19). Aparece delimitado por un doble anillo concéntrico de lajas de arenisca clavadas verticalmente unos $20 \mathrm{~cm}$. con una separación media de unos $80 \mathrm{~cm}$. entre ambos anillos, con un relleno entre ambos a base de piedras de pequeño y mediano tamaño y tierra compactada (fig. 20). El interior del túmulo aparece totalmente desmontado, aflorando la cantera de arenisca descompuesta, por lo que prácticamente todo el lado noroeste del túmulo ha desaparecido. Ni en el proceso de limpieza, ni en el de excavación se recuperaron restos arqueológicos.

\section{2. 3. Túmulo 3}

Esta estructura se localiza al norte de la anterior, al lado de su anillo exterior, de forma casi contigua. Al igual que en el caso anterior, el afloramiento de la cantera rocosa del cabezo, no ha permitido la conservación del túmulo, salvo en una parte de su cimentación que fue delimitada y documentada durante la campaña de 1978 (fig. 21). Presenta una planta marcadamente circular, de unos $6 \mathrm{~m}$. de diámetro y unas característi- cas constructivas idénticas al caso anterior, aunque sólo conserva parte del anillo interior de lajas de arenisca en un $60 \%$ de su lado oeste, mientras que del anillo exterior sólo se conserva menos de un $40 \%$ de su lado suroeste (fig. 22). También en este caso existe un relleno de tierra y piedras entre los dos anillos, separados en este caso alrededor de $1 \mathrm{~m}$., aunque en esta estructura casi no se conservan elementos constructivos. Al igual que en el caso anterior, no se recuperó ningún tipo de material arqueológico.

\section{2. 4. Túmulo 4}

En este caso, también nos encontramos con una estructura localizada a unos 12 metros al noreste del túmulo 3 , en el punto más alto del cabezo y en la parcela no roturada del mismo (fig. 23). Aunque en esta zona también aflora la cantera rocosa, en esta ocasión los restos arqueológicos se encontraban en relativo buen estado, lo que permitió la limpieza, delimitación y documentación de los mismos, aunque dado su tamaño y complejidad, los trabajos se prolongaron entre las campañas de 1978 y 1979, a pesar de lo cual no pudo concluirse la excavación completa y el desmontaje del encachado de esta estructura, la cual todavía se conserva en el yacimiento, sin haber sufrido alteración (fig. 24). 


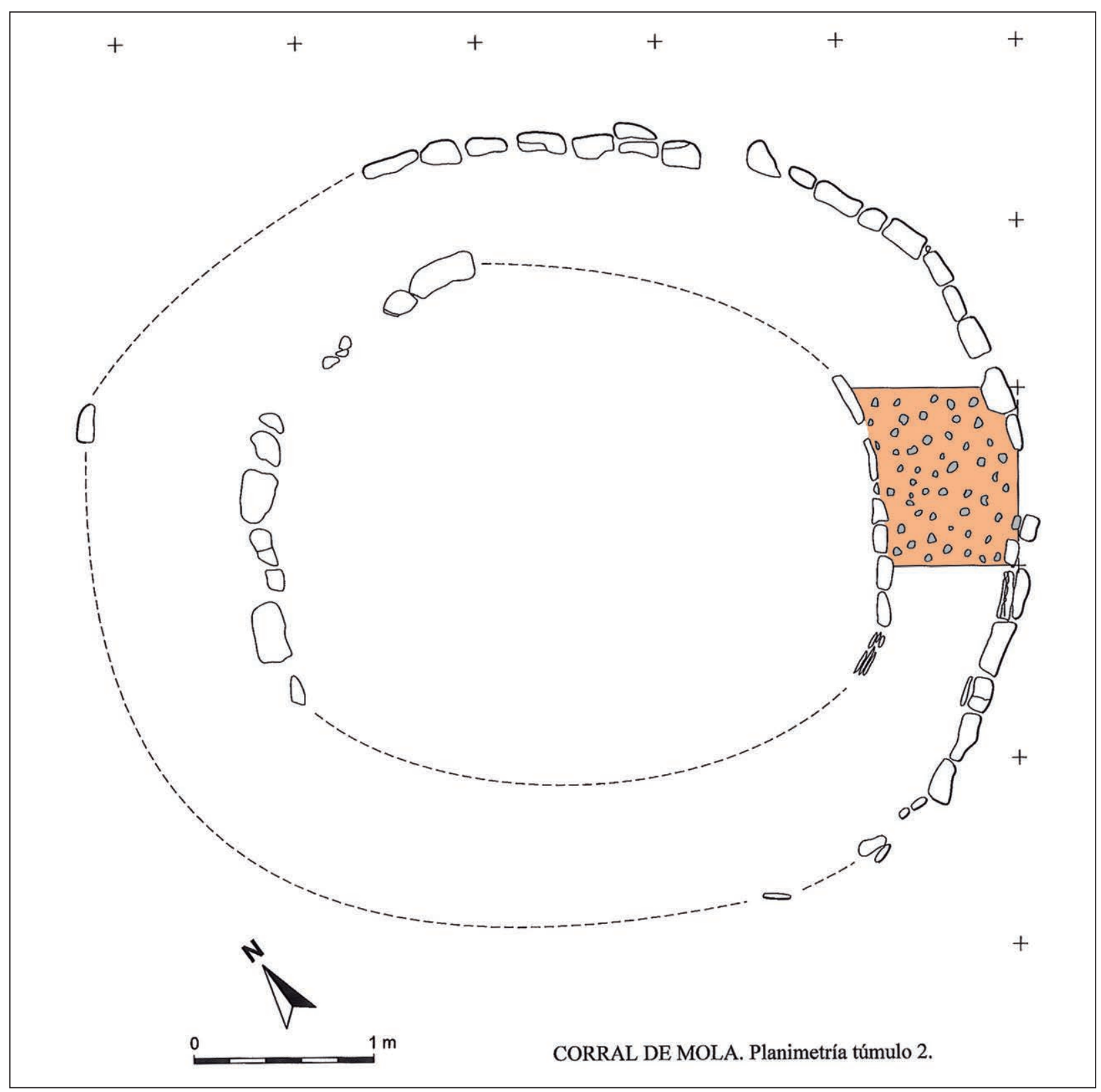

Fig. 19. Planimetría del túmulo 2, con representación del relleno entre los anillos interior y exterior de la estructura funeraria, en su lado este (Dibujo: A. Blanco 2000).

Estamos ante el monumento funerario de mayor tamaño conocido en esta necrópolis. Es un túmulo de encachado pétreo de planta prácticamente circular, de unos 8,20 m. de diámetro, asentado directamente sobre la cantera rocosa y delimitado por un anillo exterior de grandes losas de arenisca de forma rectangular colocadas horizontalmente (fig. 25). A partir de este anillo, casi a la misma altura del terreno circundante, se va elevando el túmulo con la acumulación de un relleno de piedras y tierra que en la parte central del mismo, llega a destacar algo más de $40 \mathrm{~cm}$., si bien el perfil tumular se aprecia mucho mejor en el perfil transversal que coincide con el abombamiento de la superficie del cabezo, llegando en este caso en el centro del túmulo, a más de $80 \mathrm{~cm}$. con respecto al suelo del cabezo. Además del anillo exterior de delimitación, bastante bien conservado en algo más del $70 \%$ del perímetro tumular, pudimos documentar la presencia de una losa de arenisca de gran tamaño (1,20 m de longitud por $0,40 \mathrm{~m}$. de anchura), localizada junto al anillo perimetral en el sector sureste del túmulo y que por sus características debe identificarse con una estela de señalización, en este caso caída junto al perímetro del conjunto. De hecho presenta la cara expuesta muy alisada y como se verá no es el único caso en esta necrópolis.

Para comprobar la estratigrafía del monumento y la posibilidad de encontrar un enterramiento intacto, se realizó una excavación sistemática de unos $4 \mathrm{~m}^{2}$ en el 


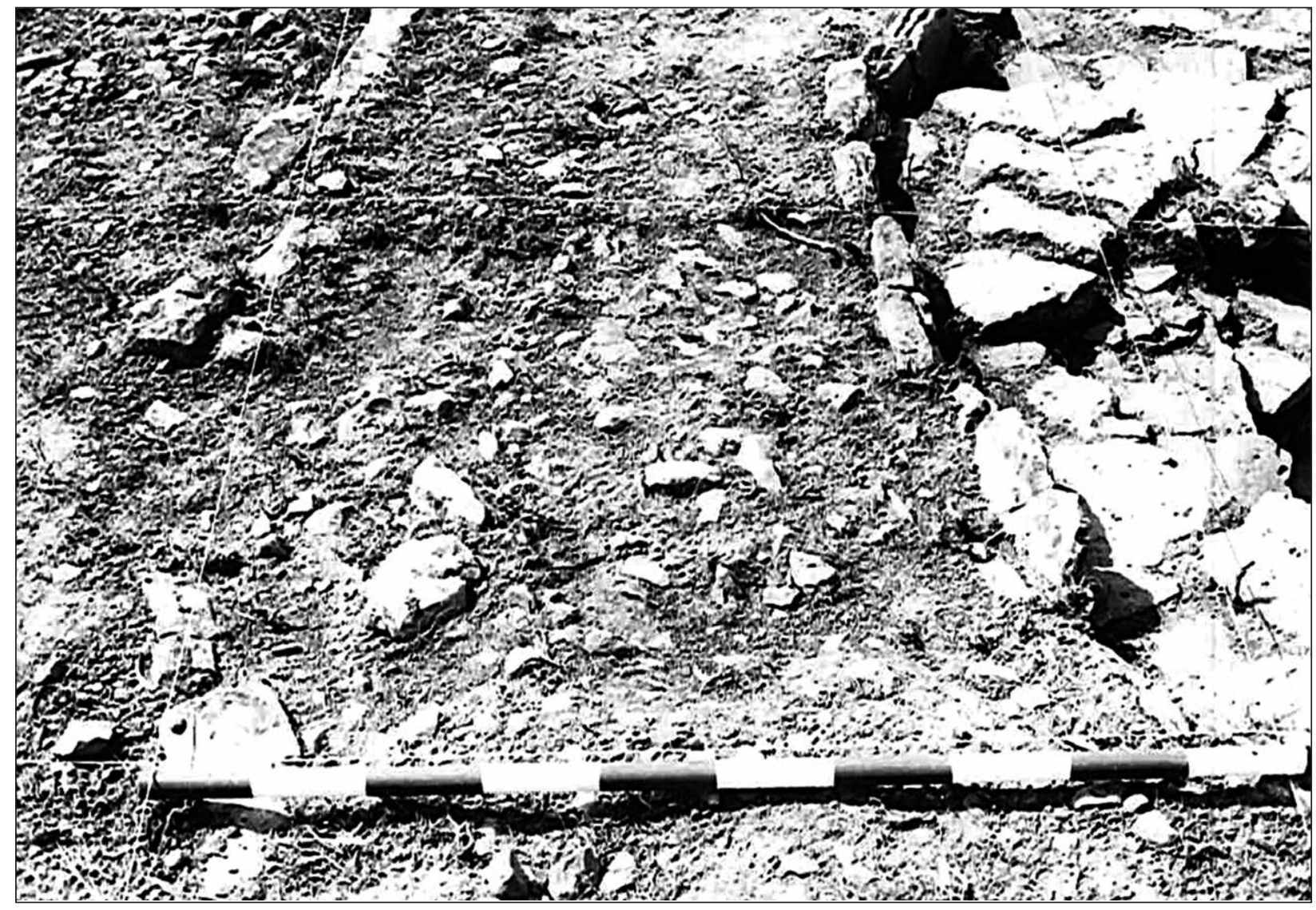

Fig. 20. Detalle del relleno de tierra y piedras de pequeño tamaño entre los anillos del túmulo 2 (Foto: Royo 1978).

centro del túmulo, hasta llegar a la cantera rocosa del cabezo. Aunque no se documentaron ni niveles de incineración ni ningún tipo de materiales arqueológicos, la excavación permitió comprobar el proceso constructivo de este túmulo, que en sus $40 \mathrm{~cm}$. de altura máxima contiene un relleno uniforme de piedras y tierra compactada, pero colocadas en tres niveles bien diferenciados: en contacto con la cantera aparece el relleno de piedras inferior, a base de un enlosado de grandes piedras sobre el que aparece el relleno intermedio con losas de arenisca de mediano tamaño y por encima de este el relleno superior a base de rocas de mediano y pequeño tamaño con tierra compactada (fig. 26). De este modo hemos comprobado que la construcción de este túmulo se llevó a cabo de fuera hacia dentro, colocando en primer lugar el perímetro o anillo y después cada uno de los rellenos, siendo el más superficial el que contiene el relleno de piedras de menor tamaño, como puede apreciarse en la fotografía del sector norte del túmulo durante el proceso de limpieza (fig. 27). Dado que no se pudo excavar en su momento todo el relleno interior de este túmulo, no pudimos comprobar la existencia o ausencia de un enterramiento, aunque se utilizó un detector de metales que no aportó ningún tipo de información adicional. Solamente podemos concluir que en la parte central de este túmulo, se cons- tata el relleno o encachado pétreo (fig. 28), sin poder constatar la presencia de enterramiento en otro sector de la estructura funeraria. Podría tratarse de un monumento fúnebre del tipo "cenotafio", dada su ubicación en el punto dominante del cabezo, por otro lado relativamente común en las necrópolis tumulares del Hierro del valle del Ebro y áreas limítrofes, documentándose su uso en Coll del Moro de Gandesa o Los Castellets II de Mequinenza, entre otros ejemplos (Rafel y Hernández: 1992, 53-54; Royo, op. cit.: 2000, 49).

\section{2. 5. Túmulo 5}

Este nuevo enterramiento se localizó y se excavó en la tercera y última campaña en este yacimiento, durante el mes de agosto de 1979. Se localizó en la parcela roturada del cabezo a unos $4 \mathrm{~m}$. al este del túmulo 1. Pudo localizarse al haberse roturado en profundidad el campo de cereal y verse en superficie una gran mancha de tierra cenicienta. Tras su delimitación se procedió a la excavación completa de la estructura y su estratigrafía, desmontando todos sus restos constructivos para poder documentar no sólo la arquitectura del monumento, sino también su estratigrafía y materiales (fig. 29). La acción del arado había afectado de forma muy importante al monu- 


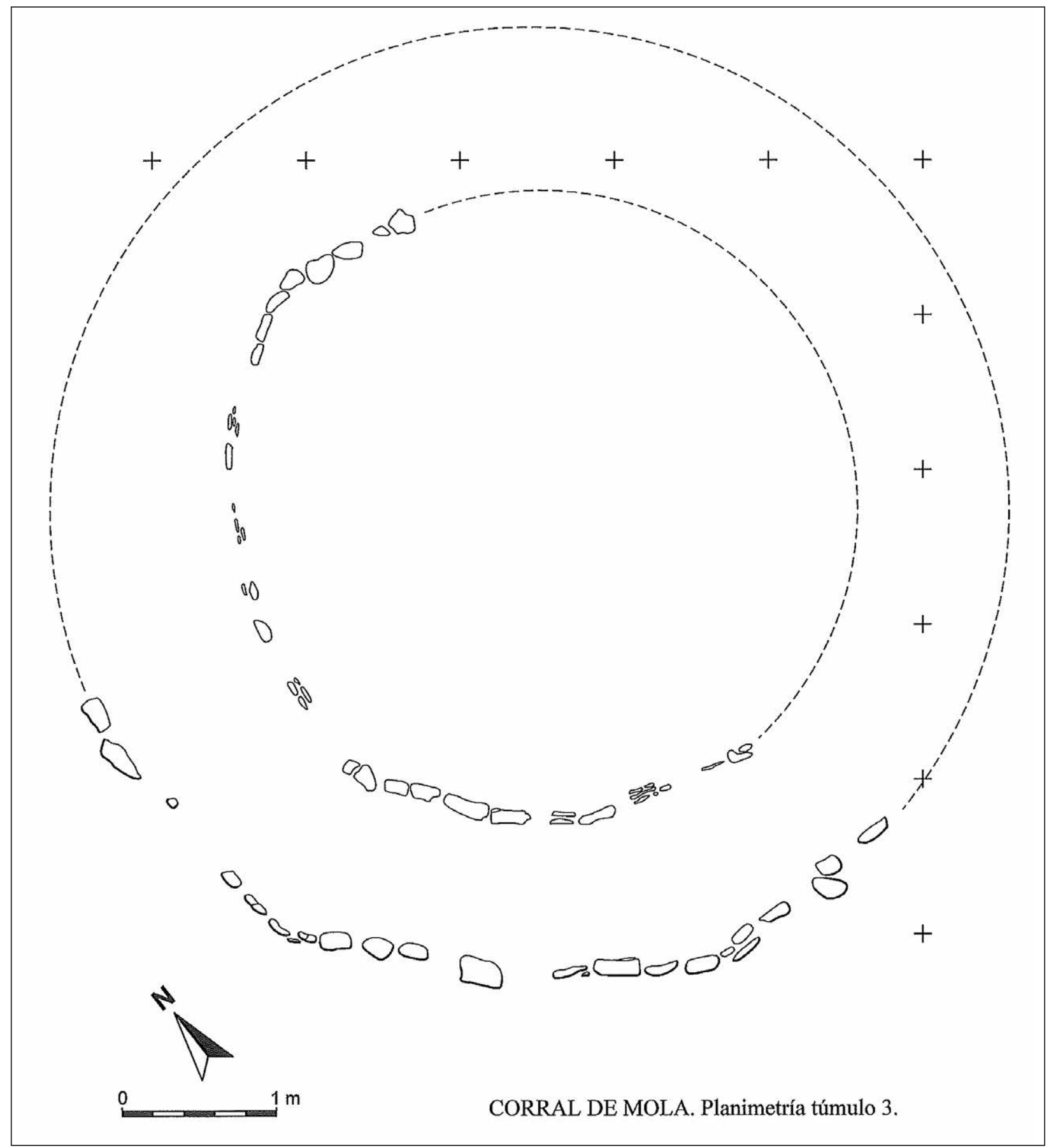

Fig. 21. Planimetría del túmulo 3, también con doble anillo (Dibujo: A. Blanco 2000).

mento funerario, pero su meticulosa excavación y documentación nos permitió contextualizar este conjunto y aportar más datos sobre el resto de los túmulos de esta necrópolis.

En este caso nos encontramos con un túmulo de encachado pétreo de similares características a los túmulos 1 y 4 de esta necrópolis. A pesar de que más del $40 \%$ de su superficie en el lado oeste del enterramiento había sido arrasado por las roturaciones agrícolas, se documentó la planta, de marcada forma circular y un diámetro máximo de unos 5 metros, con una altu- ra total conservada de entre 40 y $50 \mathrm{~cm}$. con respecto al suelo natural (fig. 30). Presenta una estratigrafía muy similar a la documentada en el túmulo 1: un nivel $r$ compuesto por la capa de tierra superficial revuelta por el arado, de entre 20 y $30 \mathrm{~cm}$. de potencia, entre la que aparece algún resto material del enterramiento, junto a piedras pertenecientes a la cubierta tumular desplazadas y un color ceniciento de la tierra. El nivel $a$ se corresponde con la cubierta tumular, con una potencia máxima de $20 \mathrm{~cm}$. y compuesta por tierras arcillosas compactas con tres capas de empedrado, la 


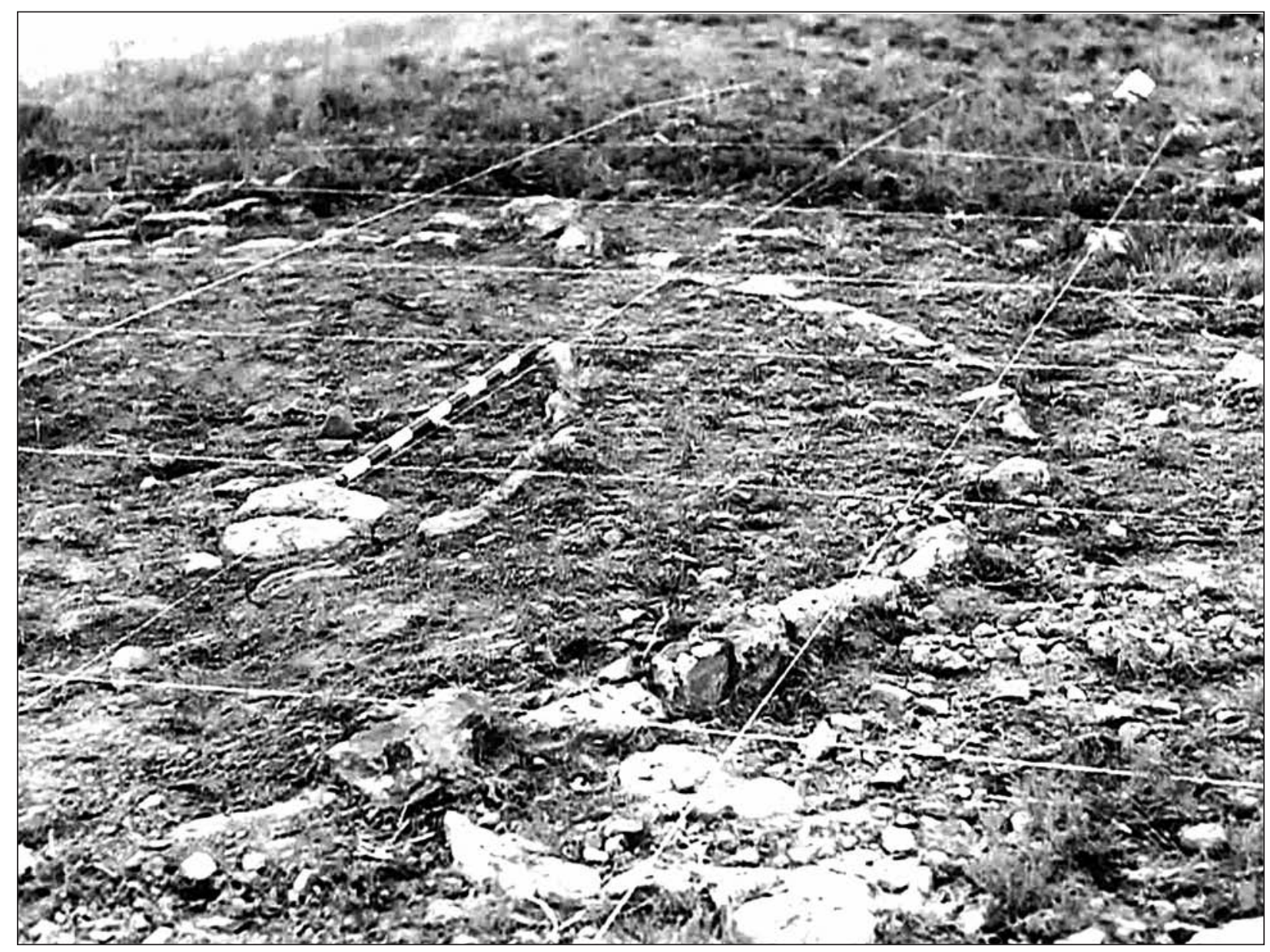

Fig. 22. Detalle de los dos anillos del túmulo 3 y de su relleno (Foto: Royo 1978).

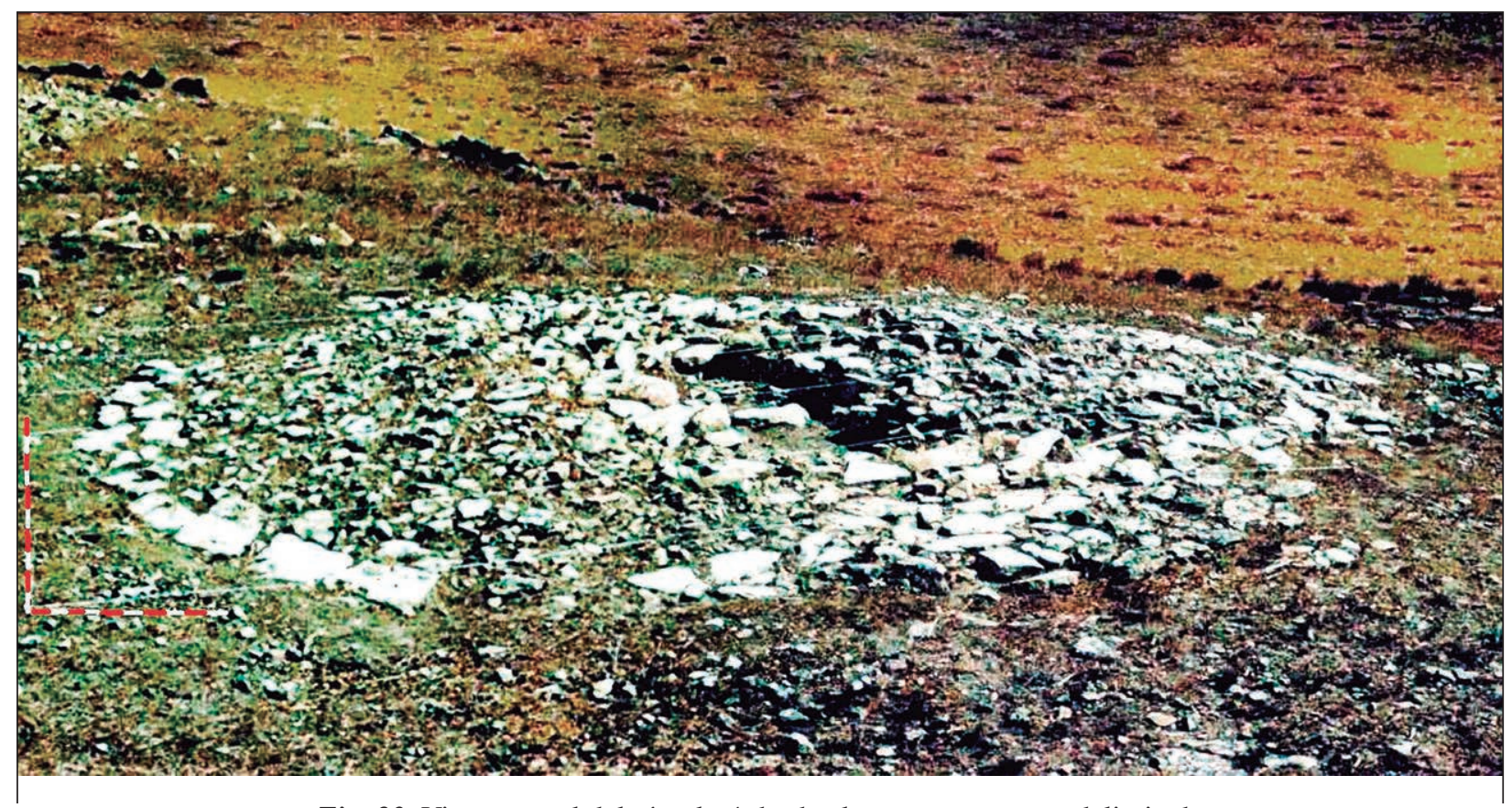

Fig. 23. Vista general del túmulo 4 desde el suroeste, una vez delimitado 


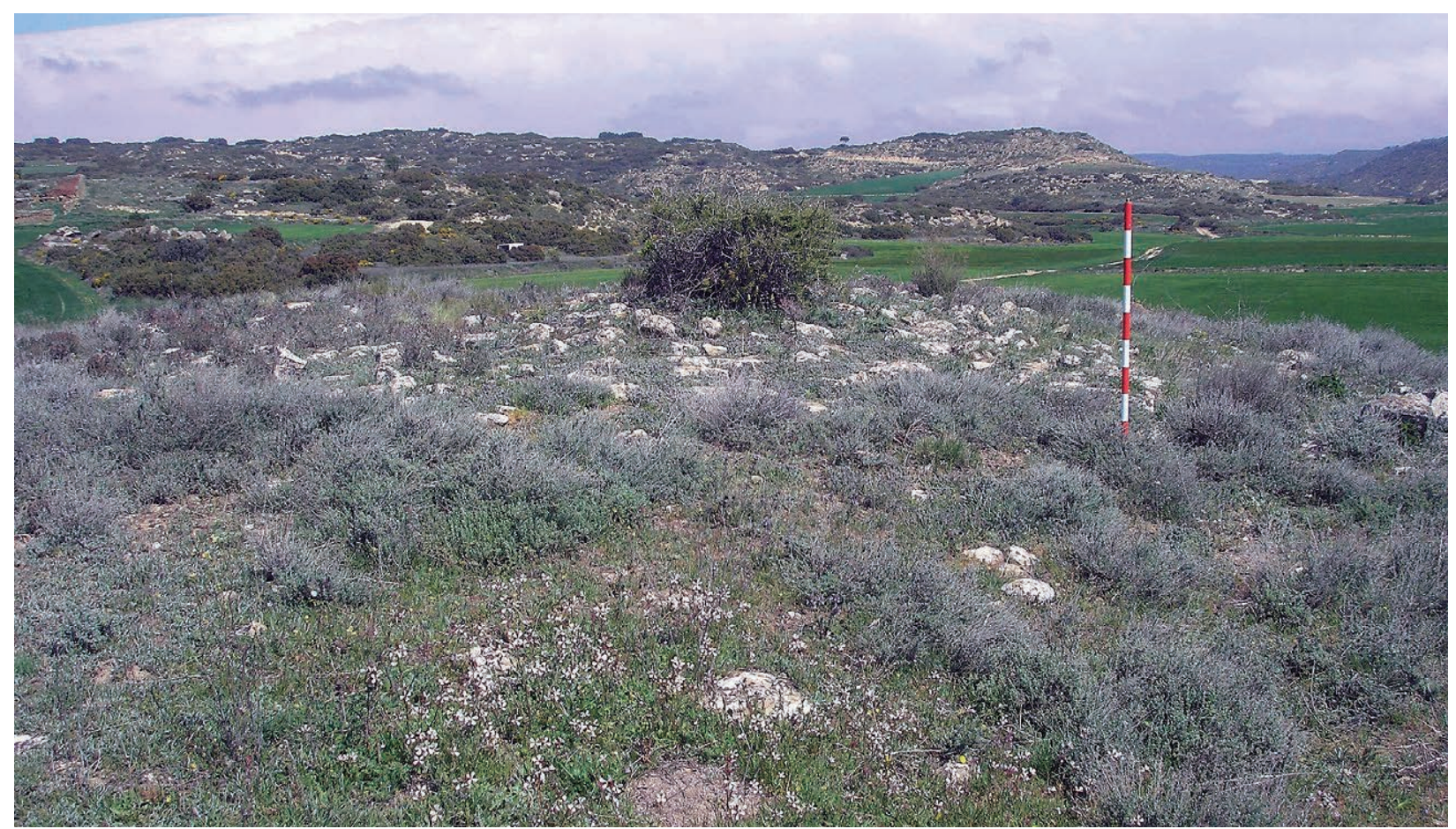

Fig. 24. El túmulo 4 en la primavera de 1998, en donde puede comprobarse su conservación (Foto: Royo 1998).

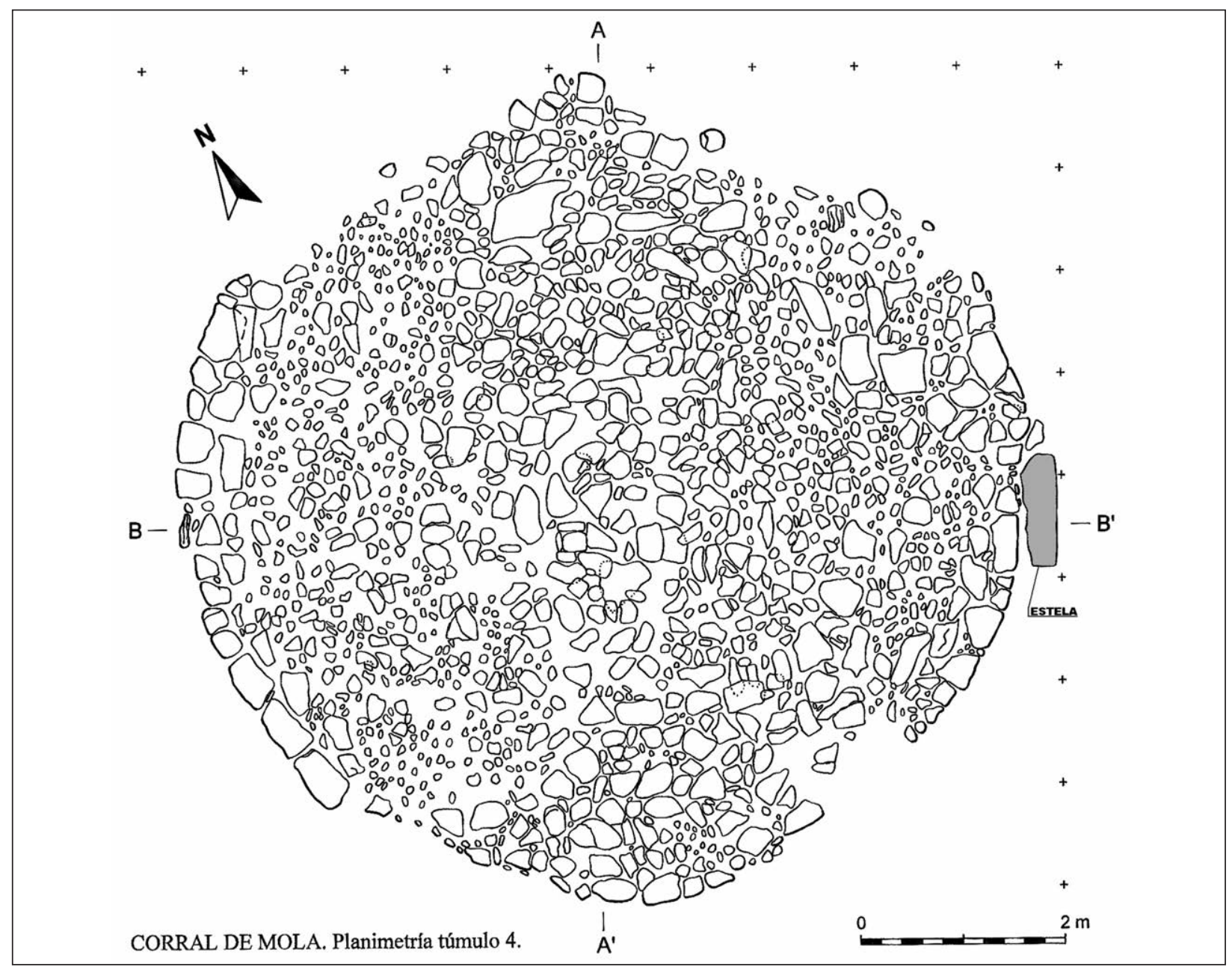

Fig. 25. Planimetría del túmulo 4, con todo su encachado y la localización de la estela "in itu" (Dibujo: A. Blanco 2000). 


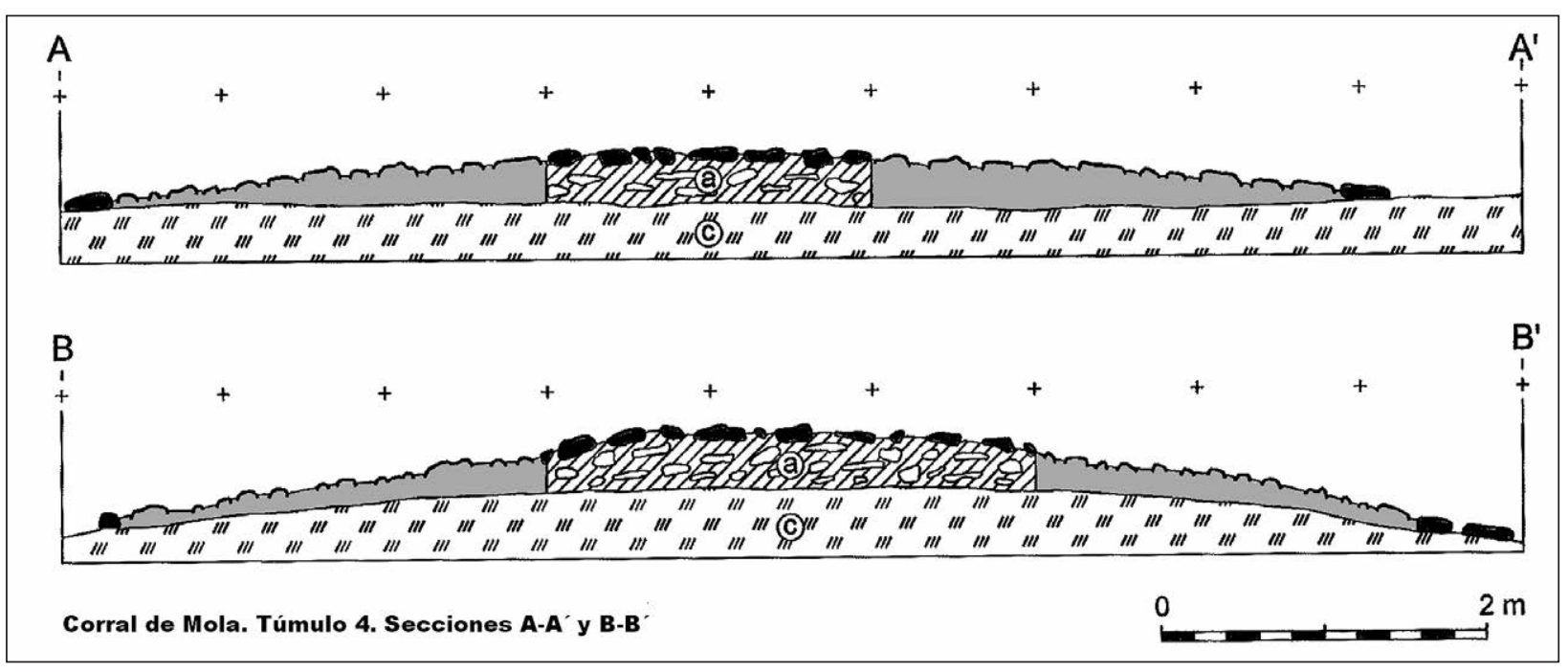

Fig. 26. Secciones A-A'y B-B’ del túmulo 4 (Dibujo: A. Blanco 2000, modificado por Royo 2016)

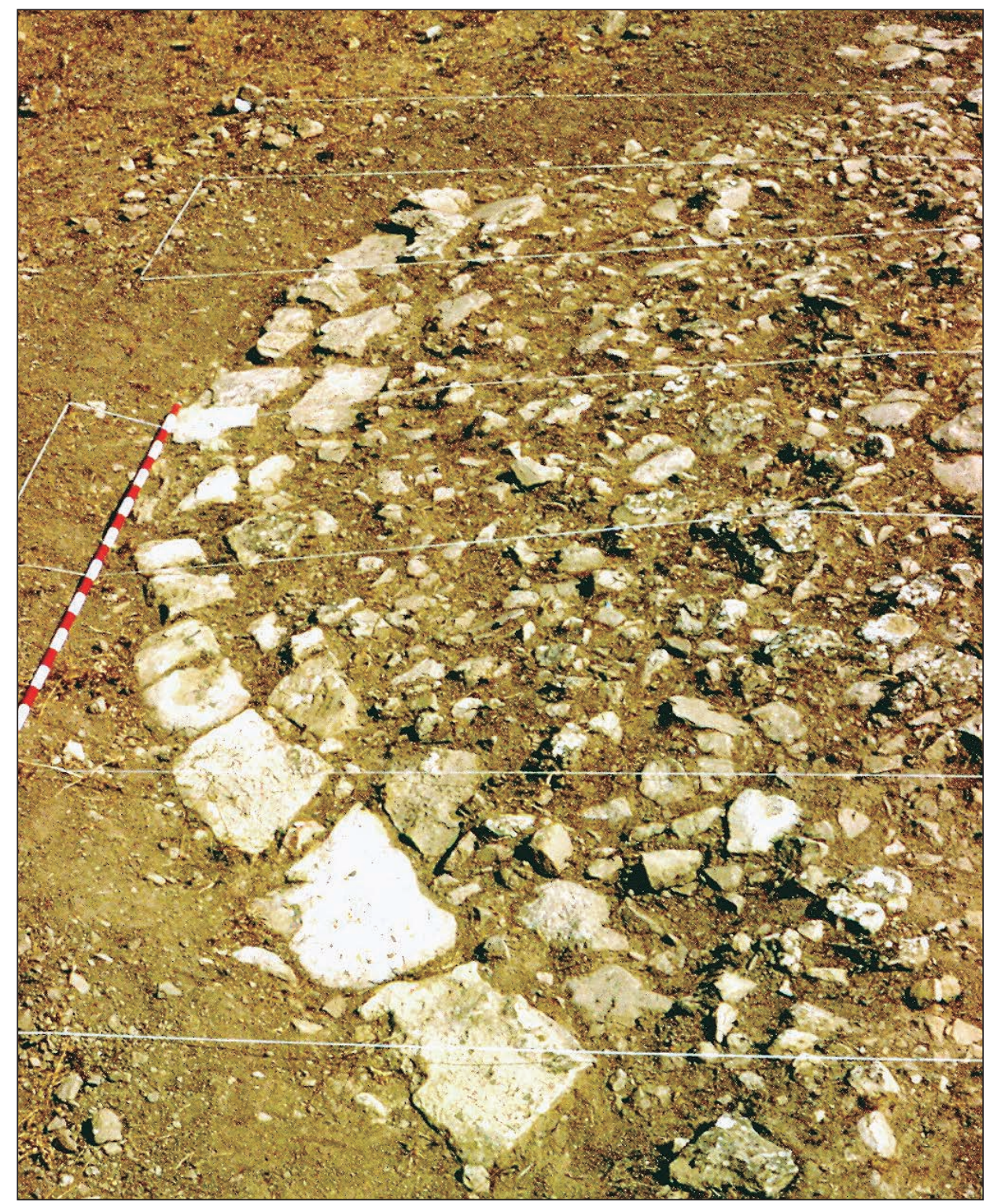

Fig. 27. Vista del lado norte del túmulo 4, en el que puede verse con claridad el anillo de la estructura, así como el relleno más superficial del encachado (Foto: Royo 1979). 


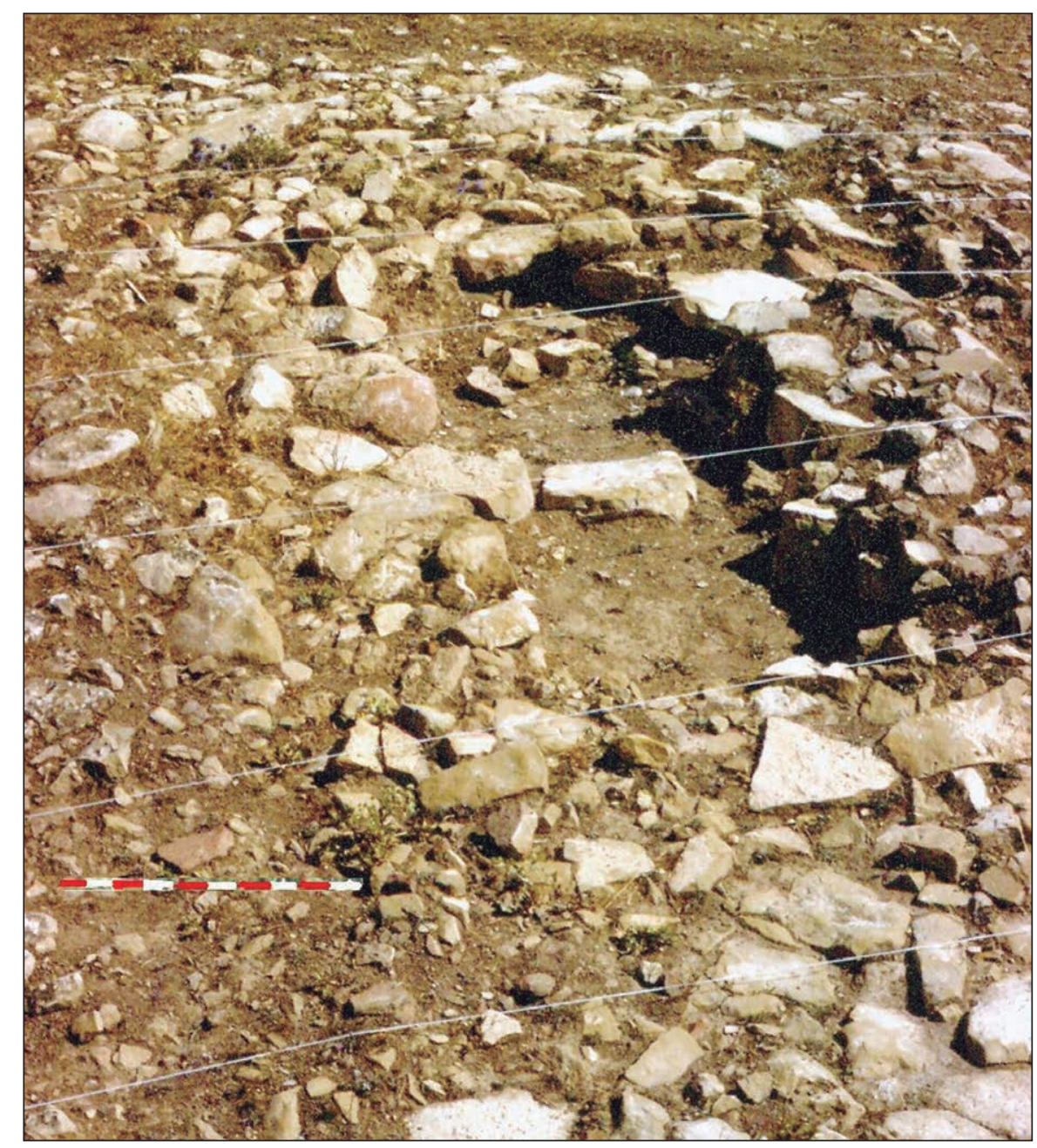

Fig. 28. Detalle de la parte central del túmulo 4, con el encachado retirado en cuatro metros cuadrados para ver el sistema de relleno del mismo (Foto: Royo 1979).

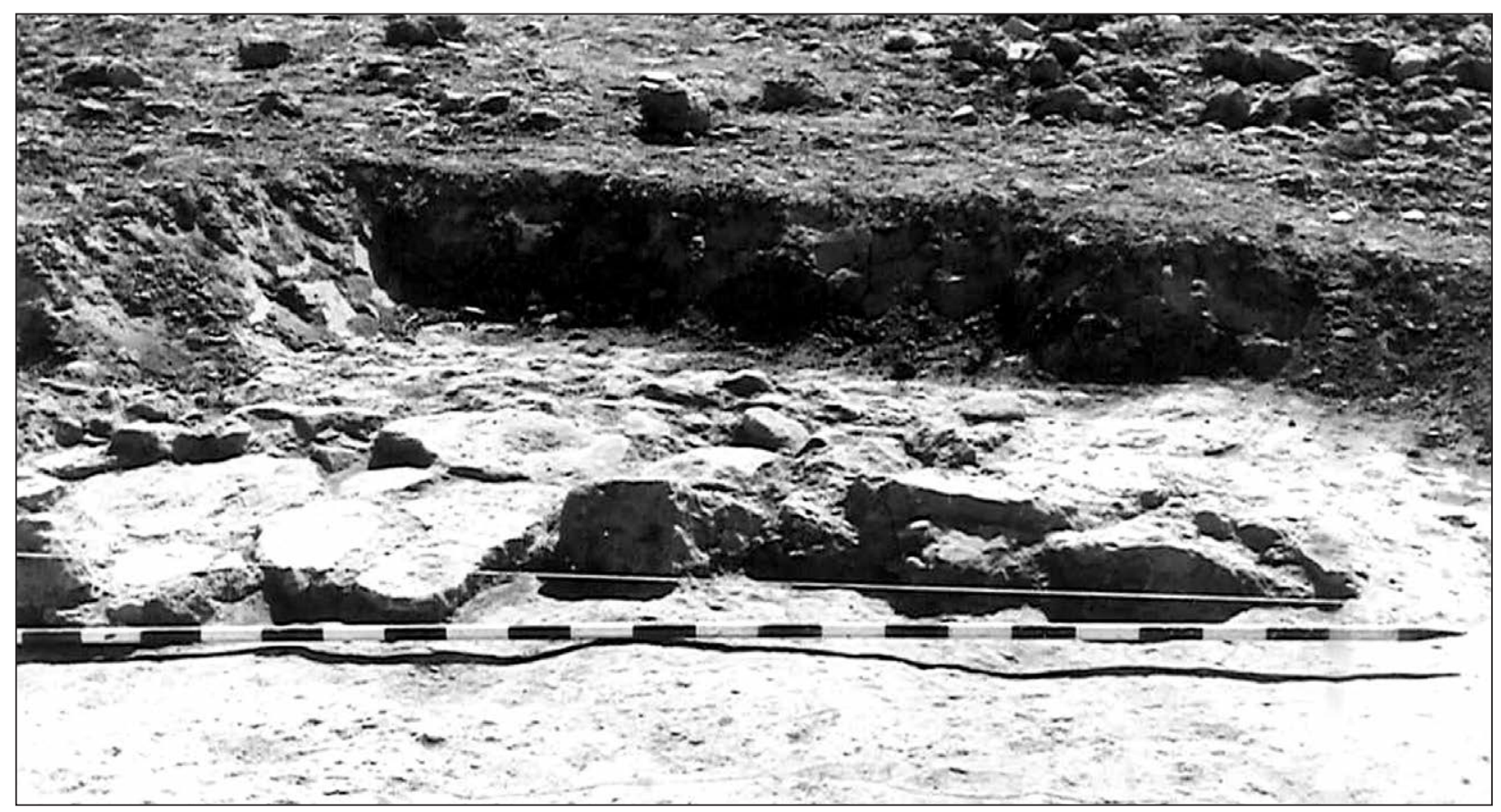

Fig. 29. Vista general desde el sur de los restos del empedrado del túmulo 5, una vez retirados los niveles revueltos por la acción del arado (Foto: Royo 1979). 


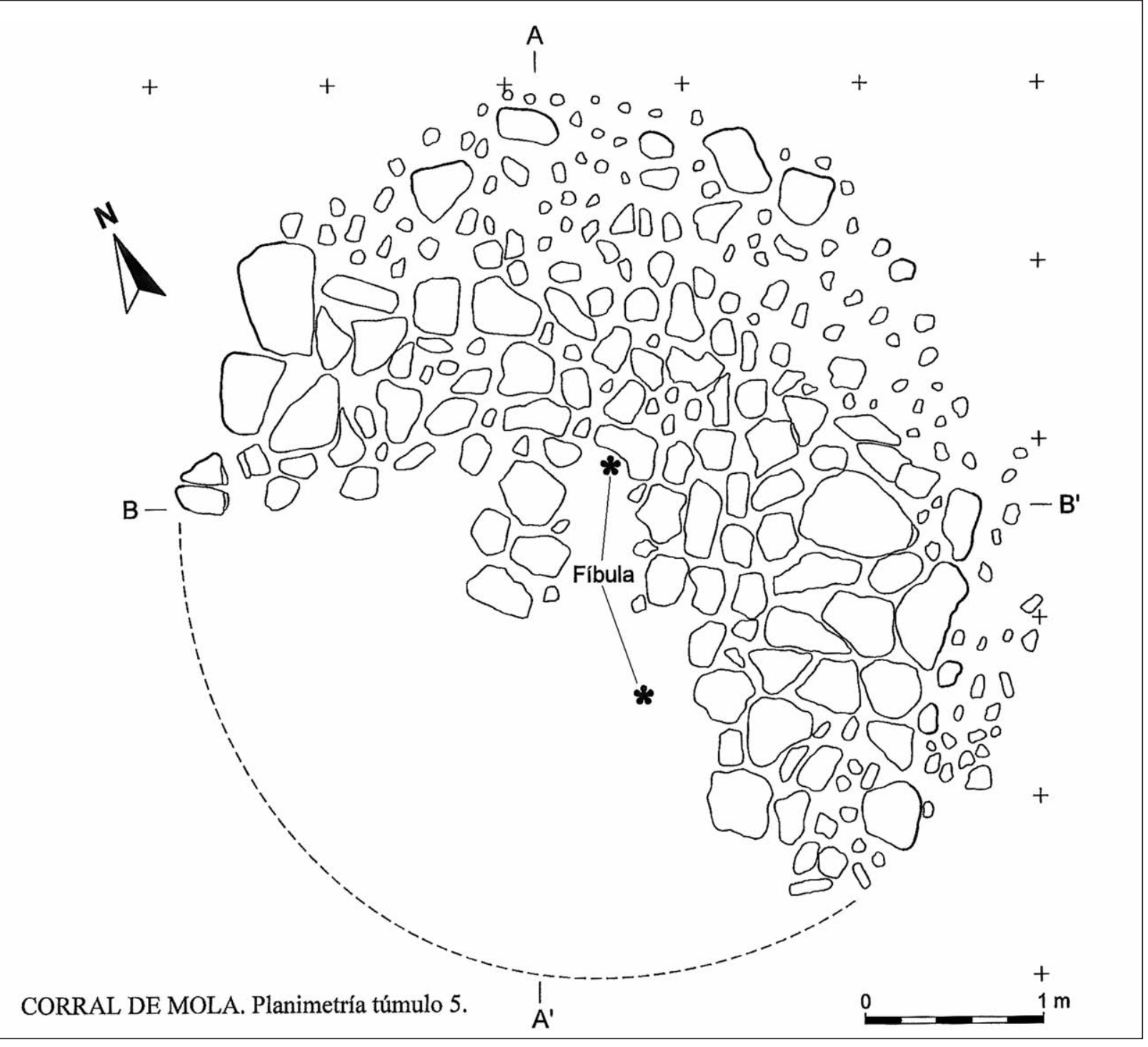

Fig. 30. Planimetría general de los restos del túmulo 5 (Dibujo: A. Blanco 2000).

superior de piedras de pequeño y mediano tamaño, la media con losas de arenisca de mediano tamaño y la inferior con losas de gran tamaño, calzadas en ocasiones con ripios o cantos rodados de arenisca (fig. 31). En este caso hemos podido comprobar que mezclados con este relleno tumular, pueden aparecer algunos materiales, en especial restos cerámicos pertenecientes al ajuar funerario. También pudieran estar relacionados con un determinado ritual vinculado al banquete funerario y a un proceso posterior de amortización, como una parte más del proceso del enterramiento. El nivel $b$ se corresponde con la deposición de ofrendas y la cremación, compuesta por una densa y compacta capa de cenizas y carbones de unos $10 \mathrm{~cm}$. de potencia, con restos óseos humanos calcinados y parte del ajuar metálico. Este nivel aparece enteramente cubierto por el encachado pétreo y ocupaba toda la parte central del túmulo con un diámetro superior a los cinco metros. Todo el monumento y su contenido se apoya en el nivel $c$ o estrato natural de tierra arenosa de color marrón amarillento rubefactada que muestra las señales de la incineración in situ por medio de una decoloración rojiza que ocupa gran parte del área cubierta por el túmulo, siendo mucho más intensa en la parte central del monumento funerario (fig. 32).

En cuanto a los materiales arqueológicos recuperados, hay que decir que al igual que en el túmulo 1, la afección por las labores agrícolas, ha causado la práctica desaparición del ajuar funerario, posiblemente más abundante y similar al ya conocido. No obstante, se recuperaron los siguientes elementos cerámicos y metálicos, destacando la presencia exclusiva de objetos de bronce con una identidad absoluta al ajuar descubierto en el túmulo 1:

- Varios fragmentos cerámicos de borde y arranque de pared de un vaso manufacturado de cuello cilíndrico y forma globular, de pasta gris y acaba- 


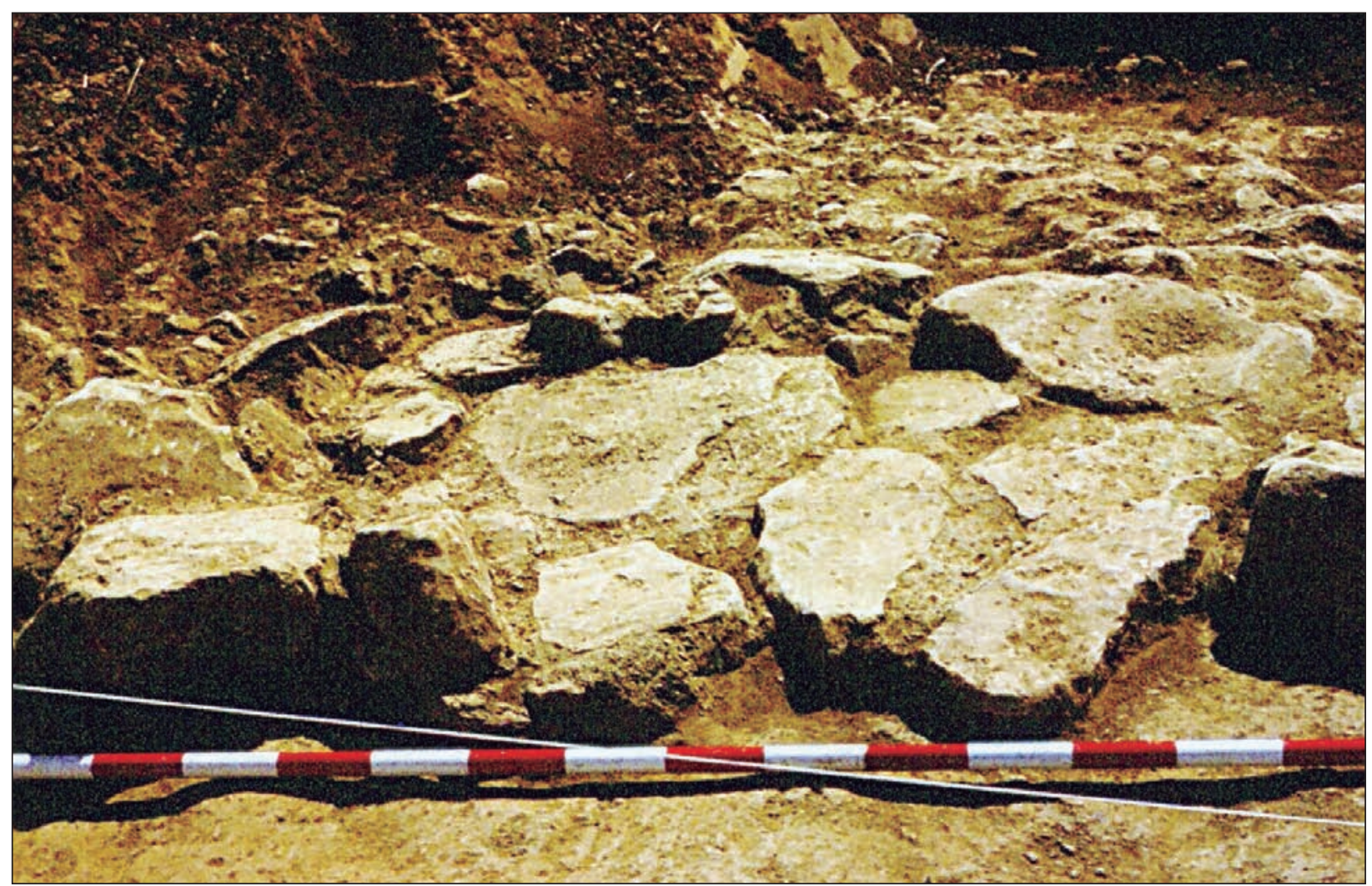

Fig. 31. Detalle del enlosado del nivel a del túmulo 5, una vez retirados los rellenos superiores (Foto: Royo 1979).

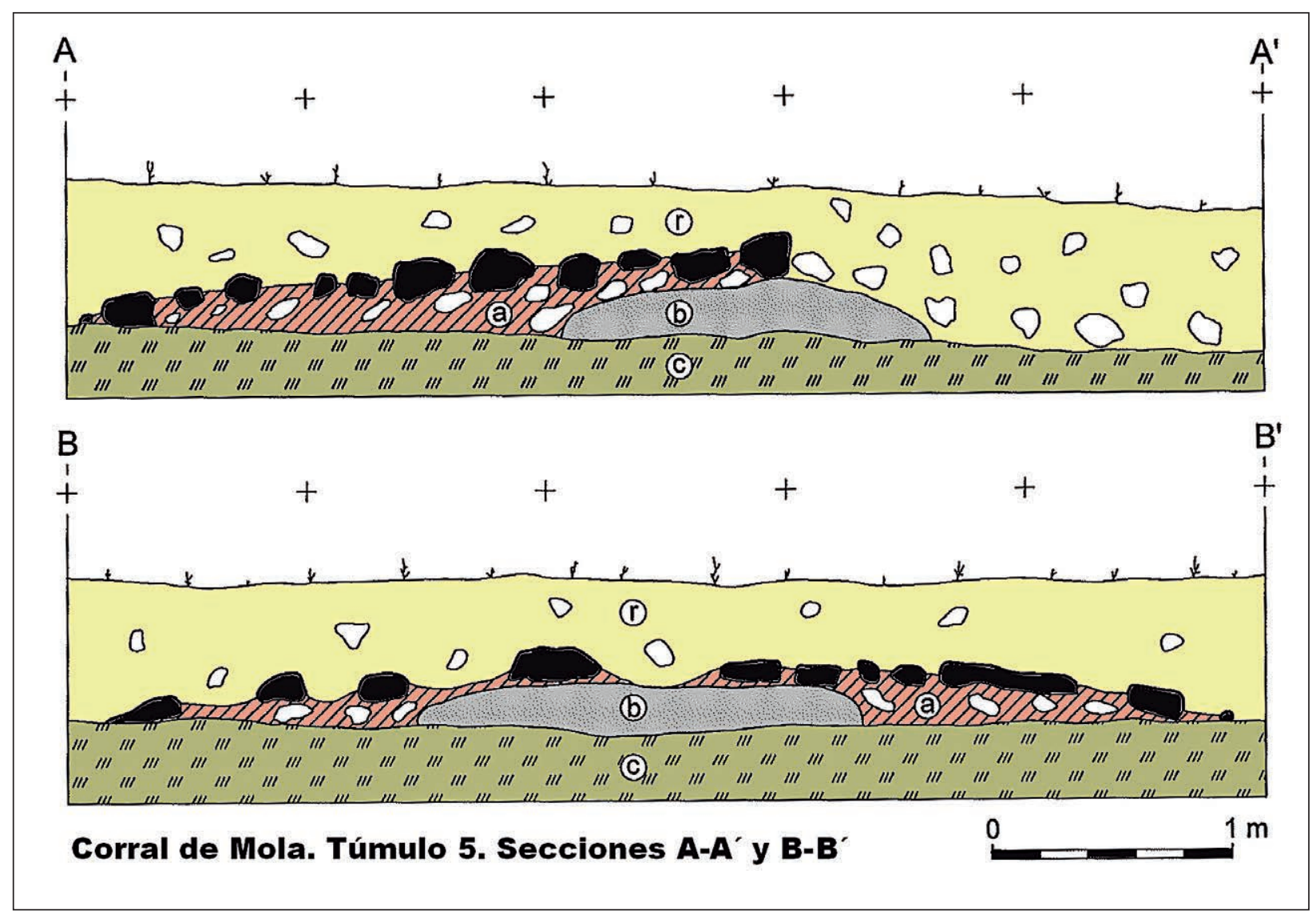

Fig. 32. Secciones A-A' y B-B’ del túmulo 5 (Dibujo: A. Blanco 2000, modificado por Royo 2016). 
dos de sus paredes interior y exterior espatulados (MOL.T5-a-17AÑ'). Su tamaño permite identificarlo con un vaso de ofrendas, pero también podría corresponder a una pequeña urna cineraria. Fue localizado en el relleno de la cubierta tumular. (fig. 33).

- Diversos fragmentos de borde y pared de un vaso manufacturado de paredes rectas, posiblemente perteneciente a un cuenco o escudilla, de pasta grisácea y acabado espatulado de sus superficies (MOL.T5-a-19AÑ). Al igual que en el caso anterior, también fue localizado en el relleno tumular (fig. 33).

- Fíbula de doble resorte en perfecto estado de conservación, con siete espirales en cada resorte y puente de sección cilíndrica, como en todo el resto de la pieza (MOL.T5-17AQ'). Es de un tamaño mucho menor que la recuperada en el túmulo 1 (fig. 34). Presenta una mortaja de perfil en U, con un buen desarrollo en relación al tamaño del ejemplar que presenta muy pocas deformaciones. El peso de esta pieza es prácticamente la mitad de la localizada en dicho enterramiento, es decir, 6,86 gramos.
- Fragmento de aguja de una fíbula posiblemente de doble resorte de sección cilíndrica, de tamaño sensiblemente superior a la anterior (MOL.T5-19AQ') (fig. 34). Tanto el tamaño de la aguja como su sección, casi doble que la anterior, indican que perteneció a otra fíbula de tamaño y peso muy similar a la documentada en el túmulo 1. Este fragmento así como el resto del ajuar metálico no ha sido pesado ya que su poca representatividad en cuanto a las posibles ofrendas funerarias de esta estructura, no permite calcular el volumen total del ajuar metálico de este enterramiento.

- Tres brazaletes incompletos abiertos de sección cuadrangular y con decoración incisa en el lado exterior de la misma composición y tipología que los documentados en el túmulo 1 (MOL.T5-Sup.) (fig. 34).

- Fragmento de anilla o pequeño brazalete de sección cilíndrica que no permite suponer su desarrollo o funcionalidad (MOL.T5-Sup.) (fig. 34).

- Dos bolitas de bronce soldadas, posiblemente como producto de la cremación (MOL.T5-Sup.) (fig. 34).
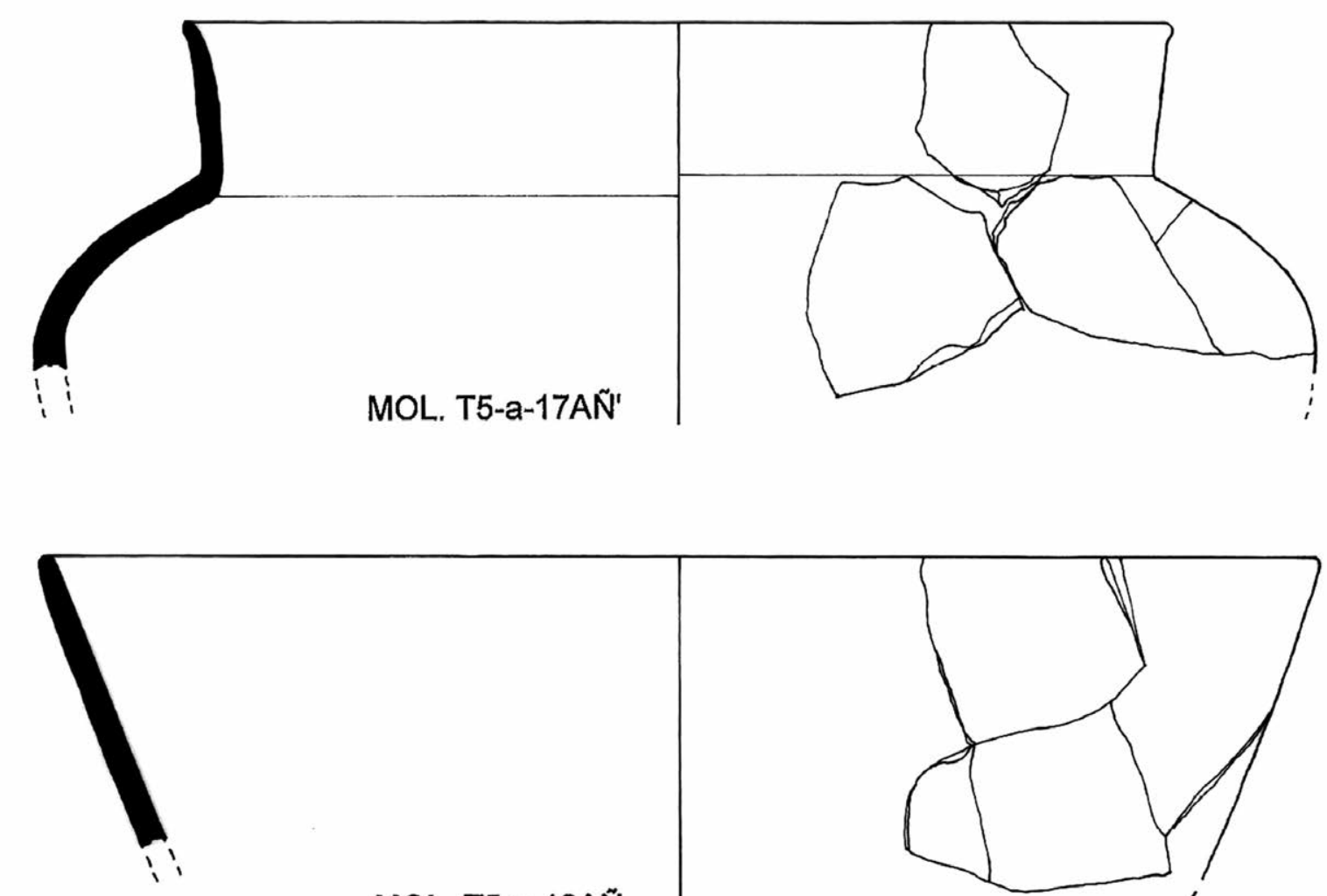

MOL. T5-a-19AÑ

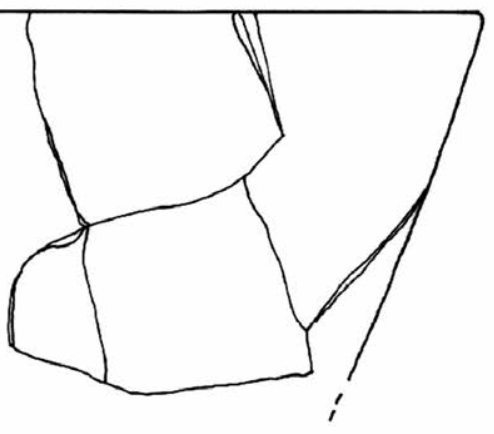

Fig. 33. Vaso de cuello cilíndrico y posible plato o escudilla, ambos manufacturados 


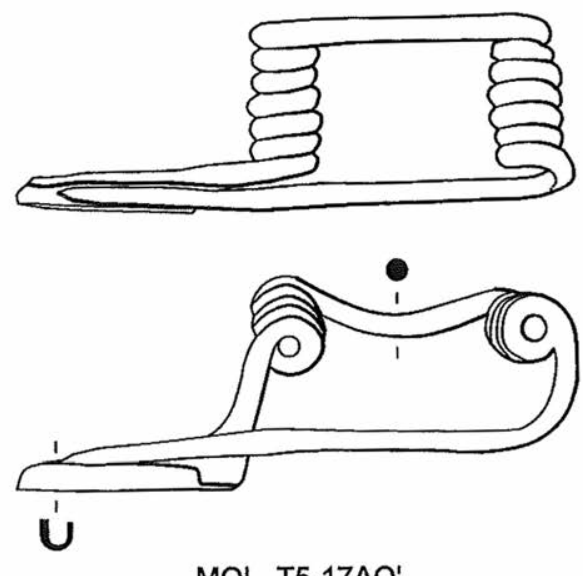

MOL. T5-17AQ'

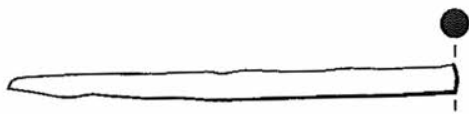

MOL. T5-19AQ'
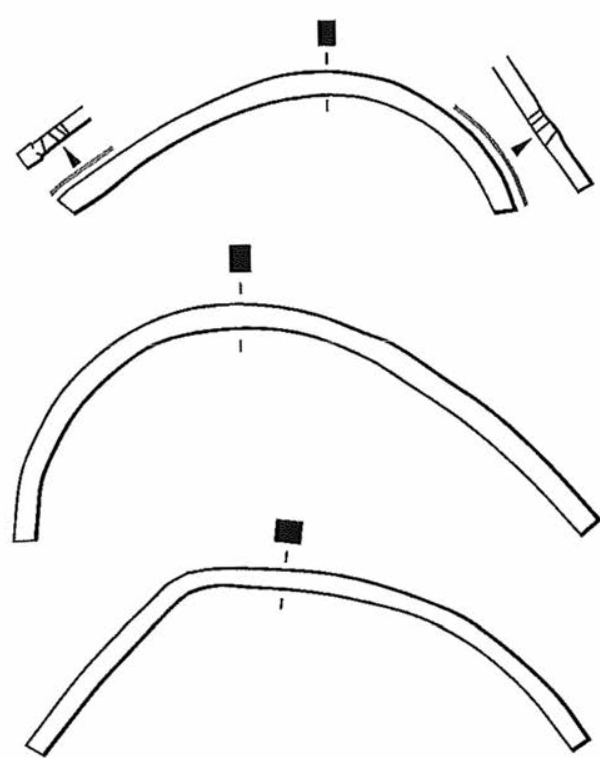

MOL. T5-Sup.

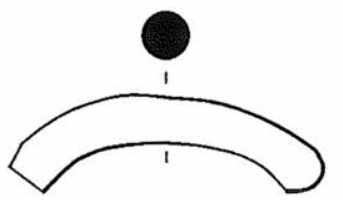

MOL. T5-Sup.

Fig. 34. Ajuar metálico recuperado en el túmulo 5: Fíbula de doble resorte, aguja de otra fíbula, fragmentos de brazaletes con decoración incisa lateral y fragmento de brazalete o anilla (Dibujo: A. Blanco 2000).

\section{3. Otros materiales fuera de contexto}

De las frecuentes visitas realizadas al yacimiento por D. Luis Pueyo Campos y D. Amado López Armisen a finales de los años 70 del pasado siglo XX, se recuperaron una serie de piezas cerámicas y metálicas que pasaron a sus colecciones particulares. Aunque alguna de ellas ha permanecido en poder del primero, otras fueron donadas por D. Amado López al Aula Museo del I. E. S. "Reyes Católicos" de la localidad de Ejea de los Caballeros, donde permanecen expuestas en la actualidad:

- Copita o escudilla casi completa de paredes rectas y perfil troncocónico, de cerámica manufacturada y acabados bien alisados, con pie elevado muy desarrollado (Aula Museo IES Reyes Católico de Ejea, vitrina $4, \mathrm{n}^{\circ}$ inventario: 209). Dado su pequeño tamaño pudo formar parte del ajuar funerario de otro enterramiento, utilizándose como vasito de ofrendas (fig. 38).

- Vaso incompleto de cerámica manufacturada, de paredes rectas, perfil troncocónico, fondo plano y acabados alisados; el cual también presenta un asa de pezón perforado cerca del borde. Este vaso pudo ser utilizado, tanto como ofrenda como pequeña urna cineraria (Aula Museo IES Reyes Católicos de Ejea, vitrina 4, $\mathrm{n}^{\circ}$ inventario: 210) (fig. 38).

- Fíbula de bronce de pie vuelto acabado en un gran disco que lleva decoración troquelada con hoyuelo central rodeado de 10 círculos concéntricos y una serie de hoyuelos rodeando por su exterior el referido disco. Aunque no tiene la aguja, conserva parte del resorte bilateral enrollado alrededor de un vástago de hierro con engrosamientos terminales esféricos. El puente, de sección trapezoidal, no conserva ningún tipo de decoración, pero en su parte inferior y junto al pie o mortaja aparece parte del dorado o sobredorado que podía recubrir casi toda la pieza, como parece deducirse de su buena conservación en la parte central del disco terminal. Este tipo de fíbulas, también denominadas como navarro-aquitanas por su dispersión geográfica mayoritaria, es muy común en las necrópolis del valle medio del Ebro durante la Edad del Hierro, apareciendo con profusión en las necrópolis antiguas celtibéricas de la meseta nororiental (Argente, 


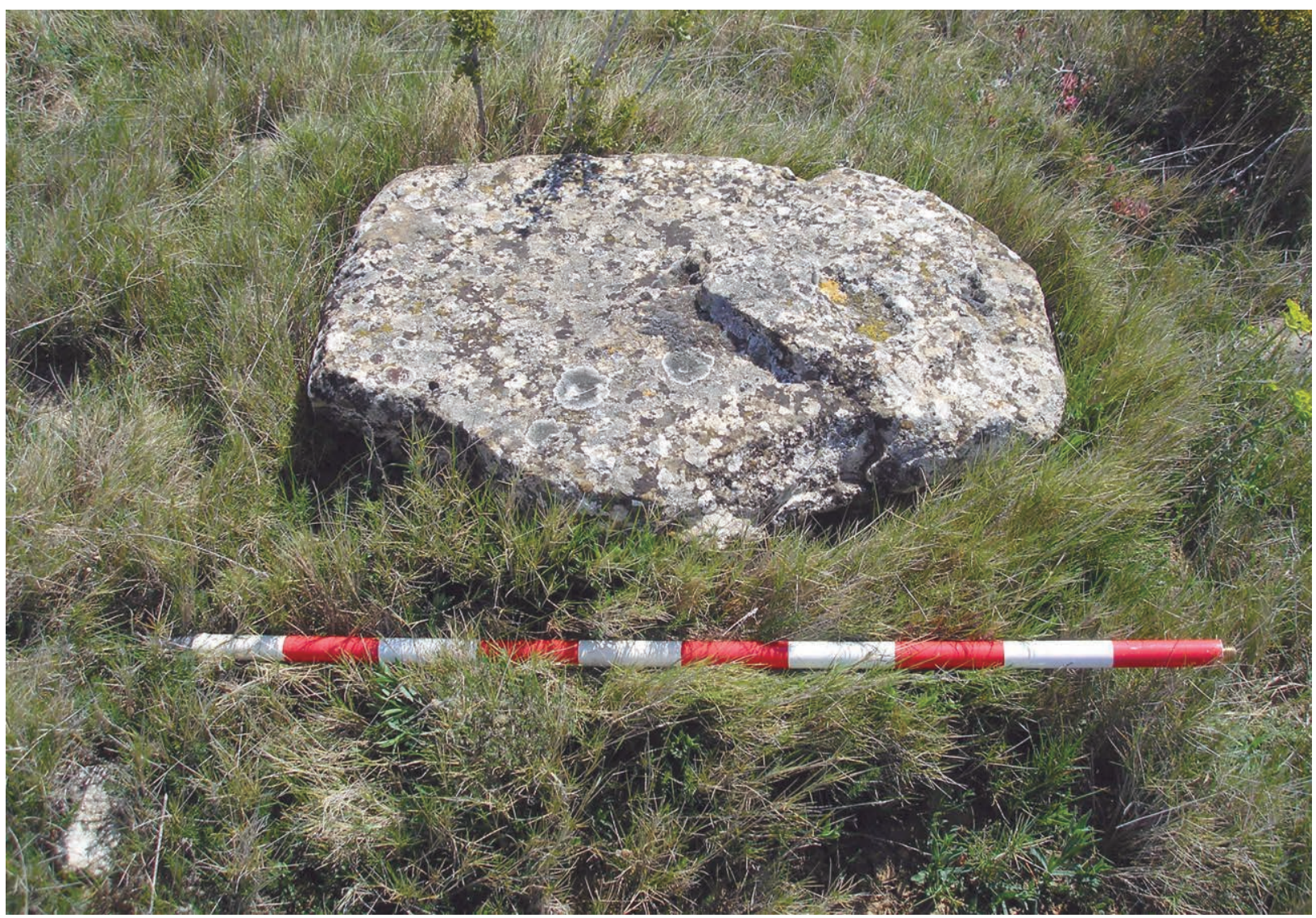

Fig. 35. Estela descontextualizada del Corral de Mola, localizada en el cerro sin roturar (Foto: Royo 1998).

op. cit.: 1994, 78, fig. 8) (Aula Museo IES Reyes Católicos de Ejea, vitrina 4, $\mathrm{N}^{\circ}$ de inventario: 211) (fig. 39). Hasta la fecha, se trataría del único objeto de esta necrópolis que combina en la misma pieza el bronce y el hierro en su manufactura, tal y como ocurre en algunos ejemplos que ya comentaremos más adelante.

- Dos fragmentos de fíbulas de bronce, uno correspondiente al pié y mortaja de una fíbula de tipo no identificable, dada su deformación y el otro corresponde al resorte o muelle de una fíbula de doble resorte de sección filiforme o cilíndrica. (Aula Museo IES Reyes Católicos de Ejea, vitrina 4, No de inventario: 213 y 214) (fig. 39).

- Colgante de bronce a base de una espiral de hilo metálico de sección cilíndrica y cuya sujeción depende de una grapa alargada. La pieza está incompleta (Aula Museo IES Reyes Católicos de Ejea, vitrina 4, $\mathrm{N}^{\circ}$ de inventario: 216) (fig. 39).

- Fragmento de un colgante de bronce de aros en espiral decreciente, en cuyo interior apareció un vástago vertical del mismo metal (Aula Museo IES Reyes Católicos de Ejea, vitrina 4, N de inventario: 217) (fig. 39).

- Torques de bronce casi completo con extremos en tampones o botones y decoración estriada o gallo- nada trasversal al vástago que se interrumpe a poca distancia del apéndice terminal (Colección Luis Pueyo Campos). Esta pieza permanece totalmente inédita, fue localizada por el Sr. Pueyo entre la tierra roturada de la necrópolis y aunque no hemos podido acceder a la misma para su documentación y estudio, aparece reproducida en una publicación comarcal de los años 80 del siglo XX, lo que nos ha permitido su documentación e identificación (Pellejero, op. cit.: 1984, 33) (fig. 40). Se trata de un modelo ampliamente extendido en las necrópolis de la Navarra oriental, como en El Castejón de Arguedas, o en el Castillo de Castejón, solo por citar algún ejemplo cercano (Castiella: 2008, figs. 7 y 8), aunque más adelante volveremos sobre esta pieza.

Además del material contextualizado en nuestras excavaciones, debe señalarse la existencia de otros elementos relacionados con las estructuras funerarias. Así, en la zona no roturada del yacimiento, en lo alto del cabezo y muy cerca de los túmulos 2 y 3 , hemos podido documentar con seguridad dos piezas pétreas que deben considerarse como estelas, ambas descontextualizadas y tumbadas en el suelo, debido posiblemente a su retirada de su primitivo lugar de origen por las labores agrícolas. Señalaremos aquí su existencia y características: 


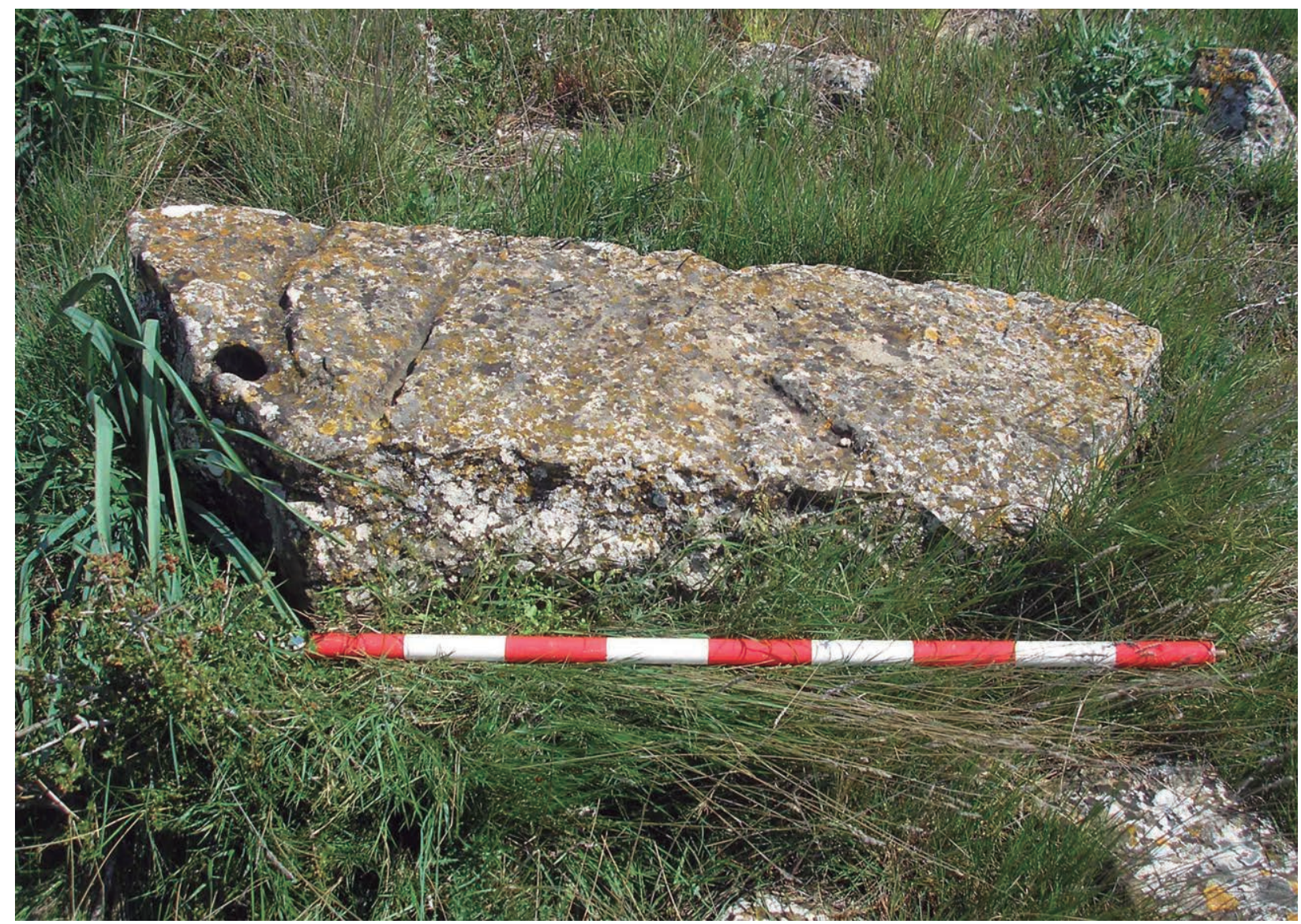

Fig. 36. Estela descontextualizada del Corral de Mola, localizada en el cerro sin roturar. Presenta una decoración grabada y una perforación (Foto: Royo 1998).

- Estela de piedra arenisca de forma vagamente rectangular, con una de las caras totalmente alisada y unas dimensiones de $0,80 \mathrm{~m}$. de altura, por 0,40 m. de anchura y $0,20 \mathrm{~m}$. de grosor (fig. 35).

- Estela de piedra arenisca de forma prismática alargada con los dos extremos apuntados a uno de los lados. Presenta una cara totalmente alisada y señales de haber sito recortada y trabajada someramente. En el extremo superior aparece una perforación de unos dos centímetros que atraviesa la pieza y justo debajo de ésta puede verse un motivo grabado en surco ancho y picado con dos líneas convergentes, muy similar a otro motivo ya descrito en una de las estelas del Barranco de La Paúl en Los Pintanos (Royo, op. cit.: 1997 b, 266, fig. 7). Las dimensiones del hito de señalización son $1,30 \mathrm{~m}$. de altura, por 0,40 m. de anchura y $0,30 \mathrm{~m}$. de grosor (fig. 36).

- A las piezas citadas debe añadirse la estela localizada en el anillo exterior del túmulo 4, junto al extremo Sureste de la estructura funeraria. Aunque en la actualidad aparece tumbada junto al anillo exterior, debió estar en pie señalando la sepultura, con algún tipo de orientación que no hemos sido capaces de identificar. Las dimensiones de la este- la son 1,10 m. de longitud, por $0,30 \mathrm{~m}$. de anchura, por $0,40 \mathrm{~m}$. de grosor (fig. 37).

\section{4. Tipología tumular y ritual funerario}

El yacimiento del Corral de Mola es una necrópolis tumular de incineración, muy similar a otros ejemplos de la propia comarca de Las Cinco Villas y del valle medio del Ebro, tanto en su sector central, como en su sector occidental, área en la que encontramos los paralelos más próximos de esta necrópolis, tanto en su arquitectura funeraria, como en su cultura material (Royo, op. cit.: 2000, 52, 56).

De las cinco estructuras funerarias documentadas entre 1977 y 1979, tres de ellas, las n 1 , 4 y 5, corresponden a auténticos túmulos de encachado pétreo, con cubierta tumular realizada a base de diferentes capas de piedras y tierra compactada, alternando los tamaños como se ha visto en los túmulos 4 y 5 . Por otro lado, las estructuras tumulares $\mathrm{n}^{\circ} 2$ y 3 , presentan un doble anillo perimetral con relleno de tierra y piedras que encierra un espacio central en el que debería situarse el enterramiento propiamente dicho, sin que tengamos seguridad de la existencia de algún tipo de cubierta pétrea tumuliforme sobre dicha 


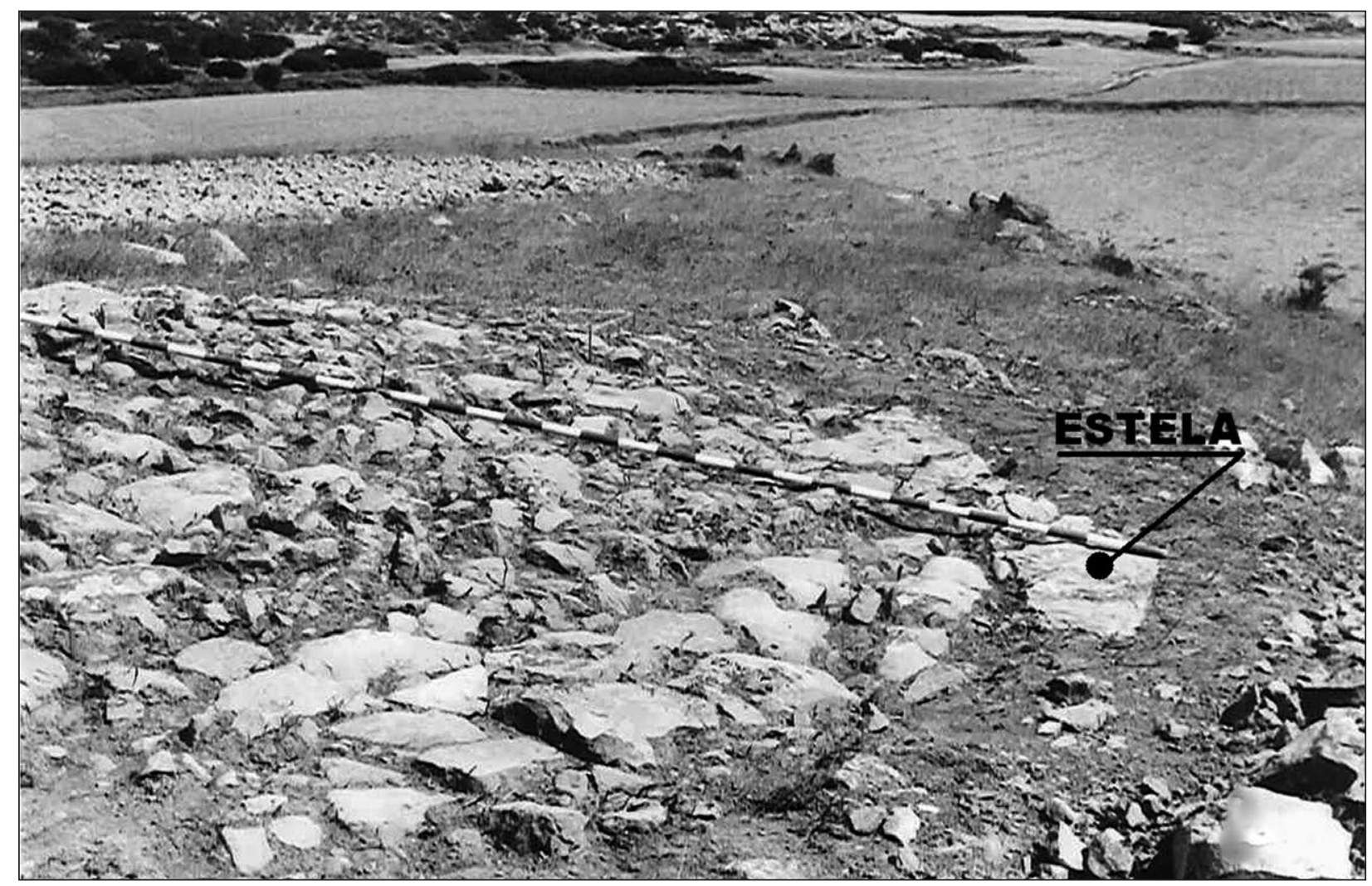

Fig. 37. Vista del lado este del túmulo 4 con la estela tumbada junto al anillo de la estructura funeraria (Foto: Royo 1979).

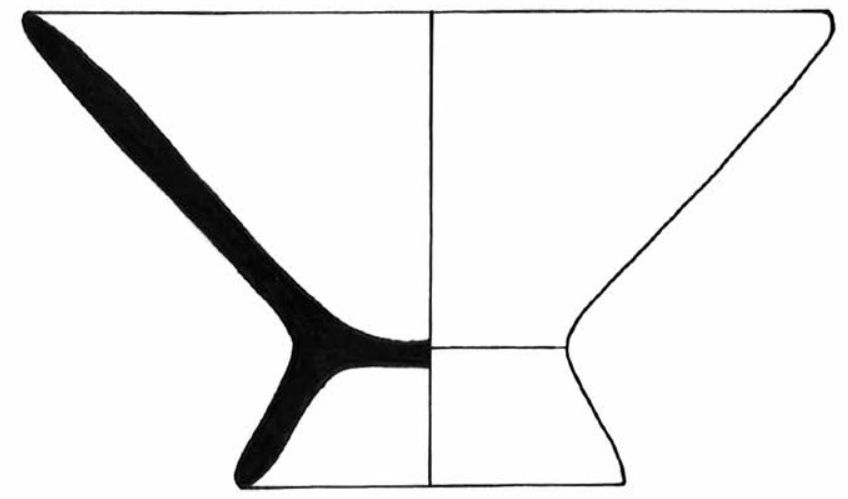

R. C. $n^{\circ} 209$

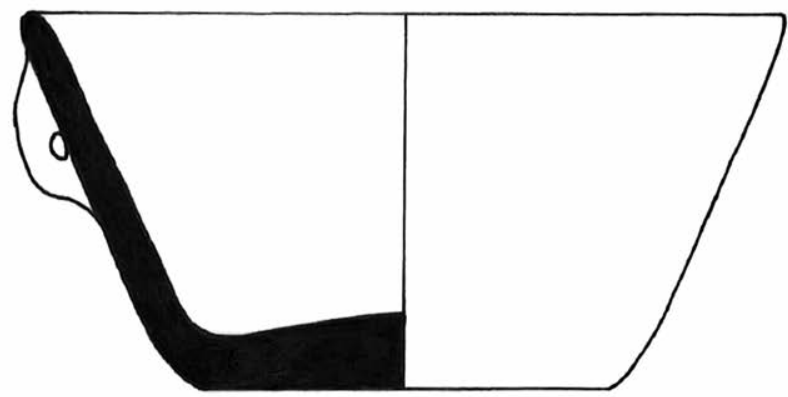

R. C. $\mathbf{n}^{\circ} 210$

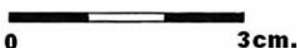

Fig. 38. Copa y vaso procedentes del Corral de Mola y depositados en el IES

"Reyes Católicos" de Ejea de los Caballeros (Dibujo: Royo 2016). 

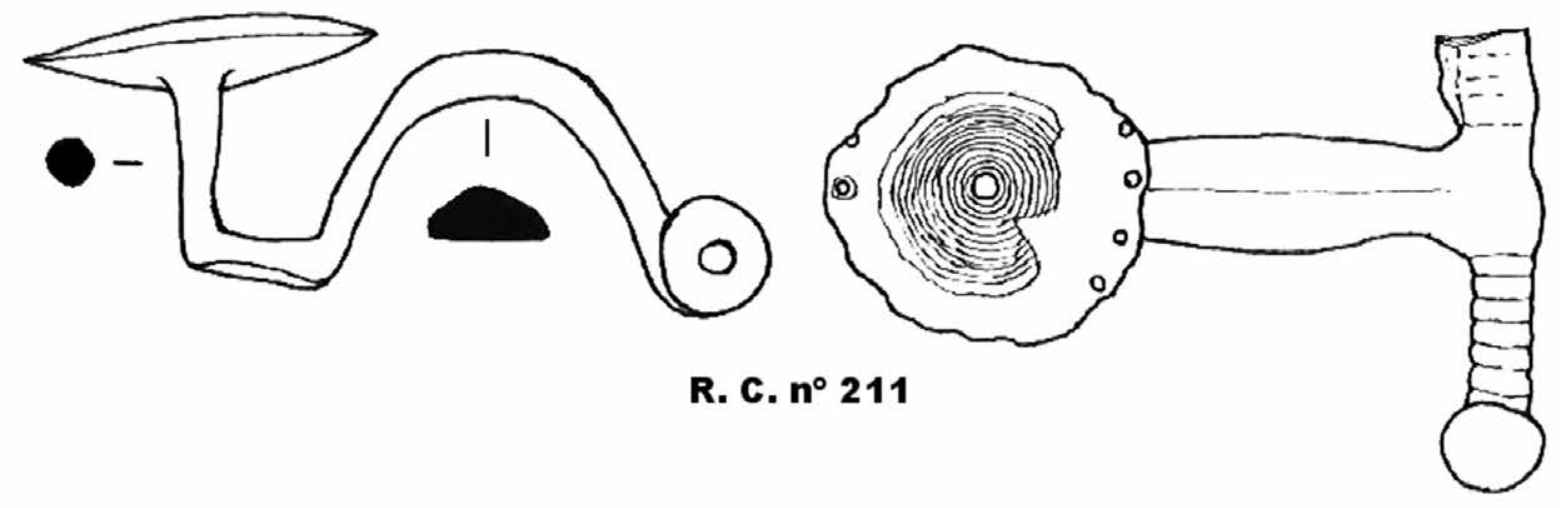

R. C. $n^{\circ} 211$

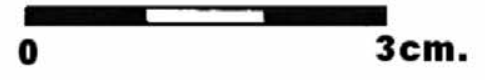

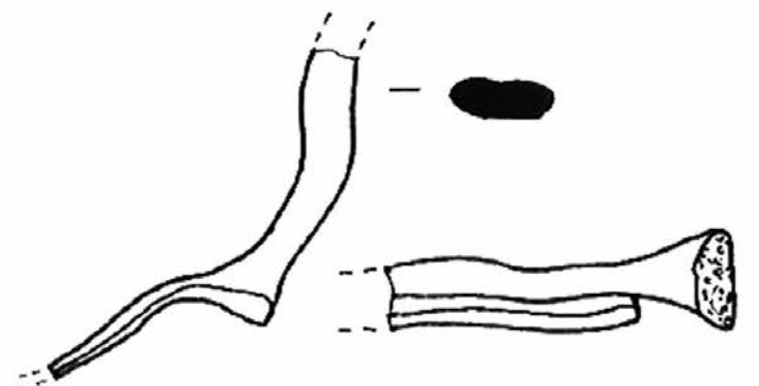

R. C. $n^{\circ} 213$

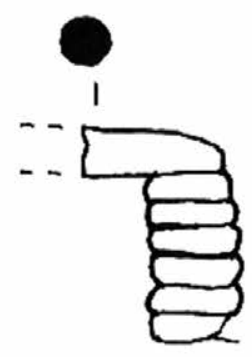

R. C. $n^{\circ} 214$
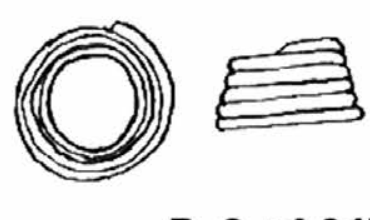

R. C. $n^{\circ} 217$
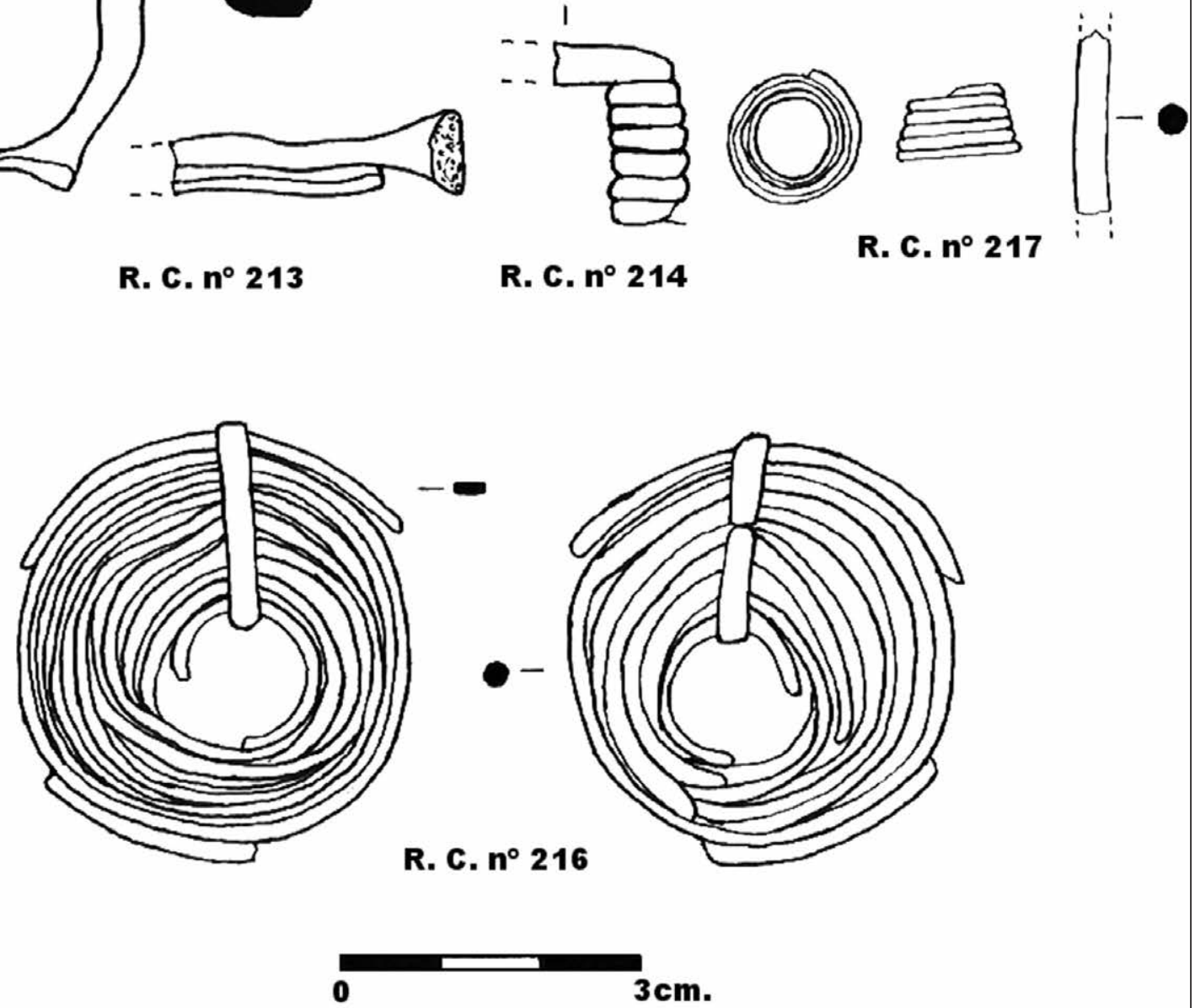

Fig. 39. Diversas piezas metálicas procedentes del Corral de Mola y depositadas en el IES "Reyes Católicos" de Ejea de los Caballeros (Dibujos: Royo 2016). 


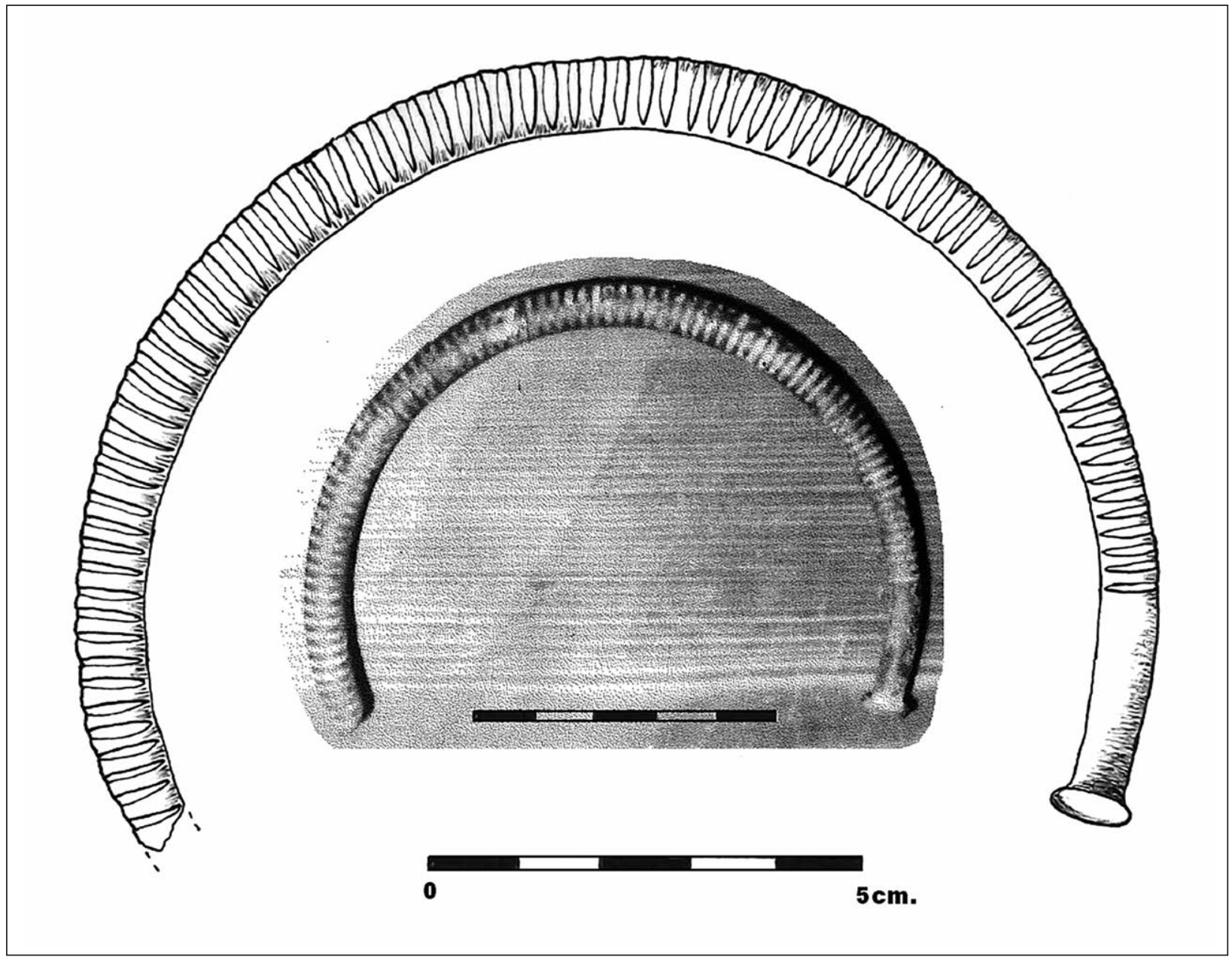

Fig. 40. Torques de bronce con tampones terminales y decoración estriada transversal al vástago, de la colección privada de D. Luis Pueyo Campos (Dibujo sobre foto: Royo 2016).

estructura de delimitación, o si esta ha desaparecido al ser solamente de tierra. En los cinco casos analizados, se trata de túmulos circulares o ligeramente ovalados, con diámetros que van desde los cinco o seis metros (túmulos 1, 2, 3 y 5) a los más de ocho metros del túmulo 4. En ninguno de los casos analizados, hemos podido constatar la presencia de estructuras internas, en forma de cistas o loculi, aunque dado el arrasamiento generalizado de los restos, no descartamos su uso en algún caso concreto.

En las estructuras funerarias mejor conservadas, el túmulo siempre aparece perfectamente delimitado, ya sea mediante anillos perimetrales realizados con lajas verticales de arenisca, como en el caso de los túmulos 2 y 3 , o mediante grandes losas o piedras de tendencia cuadrangular, como en el caso del túmulo 4. El material lítico utilizado es en todos los casos el propio de la zona, sin que se constate un tratamiento específico antes de su utilización, aprovechando siempre el sistema natural de disgregación de los afloramientos rocosos que por otra parte están presentes de forma constante en esta comarca.
La necrópolis debió contar con más enterramientos tumulares, a juzgar por las acumulaciones de piedras de pequeño y mediano tamaño en la zona no roturada del cabezo y por los manchones de cenizas detectados en diferentes lugares de la parcela roturada, por lo que no podemos concretar el número mínimo de estructuras existentes antes de las transformaciones agrarias, aunque por los datos recabados en el propio yacimiento y por la densidad de restos, desde luego pudo muy bien superar la decena de posibles enterramientos.

En los dos casos en los que ha sido posible constatarlo, el ritual funerario es el de la incineración, realizada en los dos túmulos documentados - T 1 y T 5- en el mismo lugar de la construcción de la estructura funeraria. En ambos casos, la cremación in situ ha dejado huellas sobre el terreno, en forma de una decoloración rojiza y una rubefactación del suelo arenoso, así como la preparación de una zona ligeramente rehundida o con una suave hondonada. Los restos de la cremación del cadáver, así como las ofrendas, sobre todo las metálicas, son depositadas sobre el terreno y cubiertas por el encachado tumular, sin que hayamos 
podido recuperar alguna urna funeraria con los restos de la incineración y su ajuar, aunque sí hemos comprobado que se utilizaron, como en el caso del túmulo 5 , aunque sus restos aparecen fragmentados y dispersos entre el relleno de la estructura tumular, hecho que podría significar la presencia de posibles rituales relacionados con la destrucción intencionada de las ofrendas, o como parte del ajuar relacionado con un posible banquete funerario (Faro, op. cit.: 2015, 97-98). Una prueba más de la cremación en el propio lugar de enterramiento, serían los ejemplares relativamente abundantes de carbones de origen vegetal aparecidos entre los ajuares y los restos óseos, lo que demostraría la existencia de una auténtica pira funeraria.

Del análisis de las distintas deposiciones funerarias y de los restos óseos recuperados, se desprenden varias cuestiones de interés para documentar el ritual funerario de esta necrópolis. Sabemos por el estado de conservación de los restos óseos que el proceso de incineración fue bastante intenso, con temperaturas relativamente elevadas y sin que se recogieran los restos en una urna como suele ser habitual. Por otra parte, el ajuar metálico presenta dos tipos de fractura: uno directamente relacionado con el ritual, con roturas intencionadas de algunas piezas singulares, como el broche de cinturón, el cuchillo/navaja o el torques; el otro, producto de los procesos postdeposicionales, en este caso debido al paso de maquinaria agrícola pesada sobre el ajuar funerario, en el caso de los brazaletes. Pero a pesar de dichas fracturas y de ligeras deformaciones, las piezas metálicas no aparecen ni excesivamente deformadas ni fundidas, lo que denota que su exposición al calor ni fue muy intensa ni duradera, lo que habría provocado la aparición de los típicos goterones metálicos. Esto nos permite suponer que el ajuar metálico pudo ser depositado en una fase terminal del proceso de incineración con temperatura poco elevada, posiblemente una vez que la pira funeraria ya estuviera casi extinguida.

En cuanto al combustible utilizado, sólo podemos especular en parte sobre su composición, aunque los escasos datos aportados por el análisis polínico encargado por el museo de Zaragoza hace ya más de 10 años, aportan algunos datos significativos (Iriarte: $2009,124)$. El paisaje vegetal protohistórico no debió ser muy distinto del actual, aunque ahora presenta una clara degradación por la actividad antrópica, especialmente en su cubierta arbórea. Aunque las muestras polínicas tienen la problemática derivada de su extracción en un nivel de cremación, el 33\% de los restos pertenecen a especies arbóreas, entre las que se han identificado Pinus Sylvestris, Quercus ilex y Juniperus. Las tres especies -Pino silvestre, encina y enebro- siguen dominando el paisaje vegetal arbóreo en la actualidad y con seguridad pudieron ser utilizados para el proceso de cremación, dado su alto poder calórico. En cuanto a las especies herbáceas, sólo se han constatado pólenes de algunas gramíneas del tipo Poaceae, junto a plantas o arbustos suculentos del tipo Chenopodiaceae, sin que se haya documentado restos de Cerealia (Iriarte, op. cit.: 2009, 124).

Entre los túmulos documentados, hemos constatado la presencia de estelas o hitos de señalización, en el caso del túmulo 4 todavía en su lugar pero caída y en los otros dos casos sin que podamos señalar su pertenencia a un túmulo en concreto. En una de las estelas conservadas, nos encontramos restos de un motivo geométrico grabado, así como una perforación que atraviesa la losa y cuyo significado se nos escapa (fig. 36). La presencia de estelas en las necrópolis tumulares de las Cinco Villas no es en absoluto un hecho aislado. Se ha planteado su existencia en la vecina necrópolis de Busal, también en Uncastillo (Burillo, op. cit. 1977, 64), pero donde su utilización es más evidente es en la necrópolis de Arroyo Vizcarra en el embalse de Yesa, donde se documenta su uso con una doble función, como señal o hito del propio túmulo (Royo y Fatás, op. cit.: 2017, 51-52, fig. 2), o como elemento delimitador del anillo exterior y con posible función astral, a tenor de su orientación geográfica (Royo, op . cit.: 1997 a, 5354, fig. 6) (fig. 41) . También se encuentran en la necrópolis del Bco. de La Paúl en Los Pintanos, en este caso con decoraciones grabadas de tipo geométrico y un motivo muy similar al de la estela decorada del Corral de Mola (Royo, op. cit.: 1997 b, 266).

La presencia de estructuras como el túmulo 4, localizada en el punto con mejor visibilidad del yacimiento, así como el cuidado en su construcción, nos permite plantear la presencia de un monumento funerario sin ningún tipo de enterramiento, o cenotafio. Estos monumentos aparecen documentados en muchas necrópolis del Hierro del valle del Ebro y áreas geográficas próximas, pudiendo citar su hallazgo en Azaila, Castellets II, Roques de Sant Formatge, Loma de los Brunos o Coll del Moro, sólo por citar algunos ejemplos (Royo, op. cit.: $2000 ; 49)$.

El carácter sagrado del espacio de la necrópolis ha podido pervivir a lo largo del tiempo, posiblemente por la presencia de los monumentos funerarios y sus hitos de señalización, pero también por la pervivencia de tradiciones seculares en la cultura tradicional y pastoril de la zona. Tal es así que es uno de los pocos lugares con enterramientos de incineración en la zona de estudio, donde hemos constatado la pervivencia del lugar como un espacio ritual que debe ser respetado. La presencia de pastores en la zona que nunca pisaban el espacio de la necrópolis porque era "tierra santa" y porque había muertos, a pesar de no identificarse restos óseos dada su cremación, nos probó la pervivencia de ciertas tradiciones enraizadas en el paisaje ritual de la zona y en su cultura pastoril milenaria (Royo, op. cit.: 1979), tal y como recientemente hemos documen- 


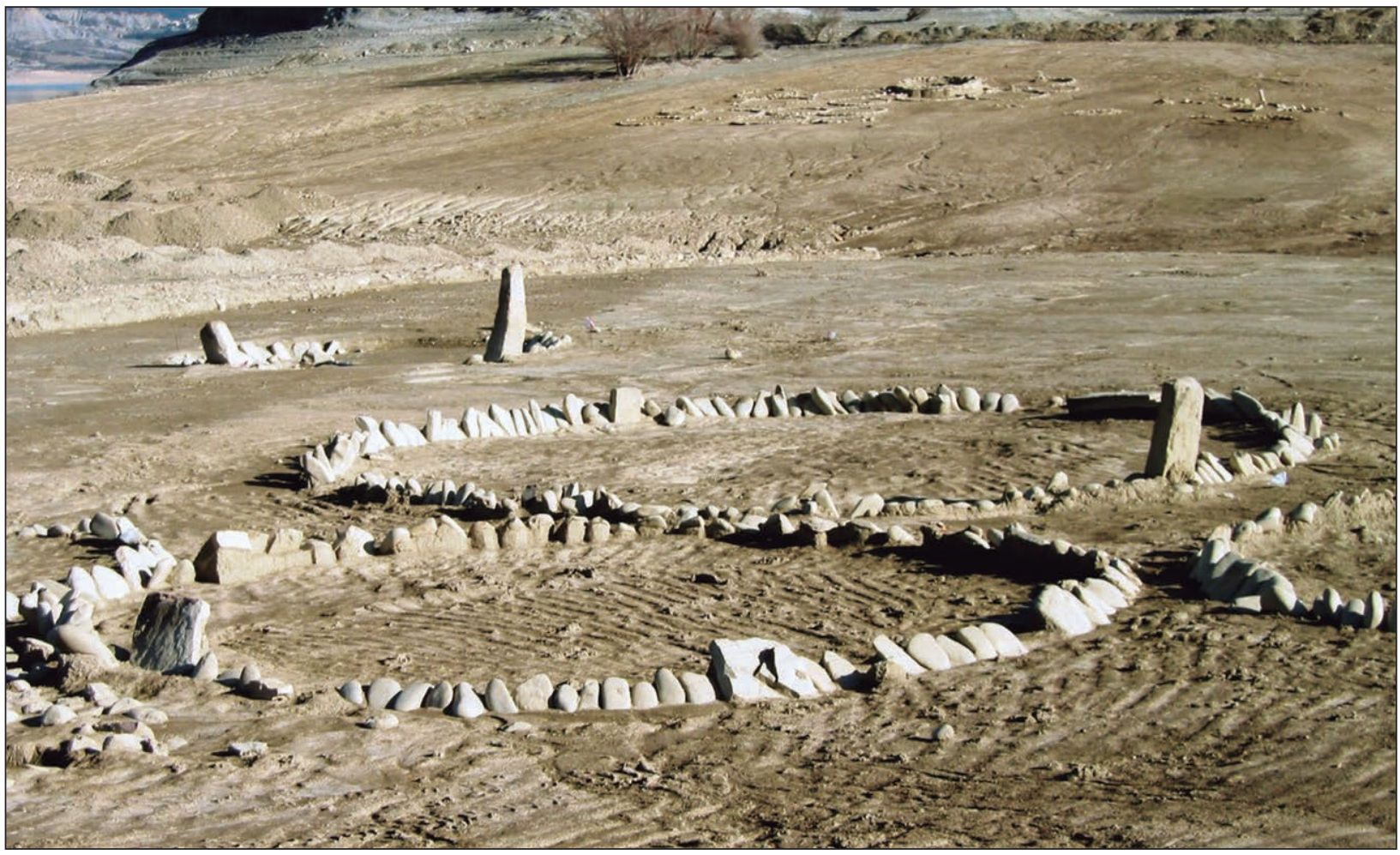

Fig. 41. Vista de algunos túmulos del sector noroeste de la necrópolis de Arroyo Vizcarra, donde se pueden ver las estelas como elemento señalizador ubicadas en los anillos de las estructuras funerarias (Foto: Royo 2005).

tado para otras tradiciones pastoriles en algunos momentos de la prehistoria reciente de los Pirineos (Rojo et alii: 2014).

\section{5. La datación radiocarbónica de la necrópolis del Corral de Mola}

Durante el proceso de excavación de los túmulos 1 y 5 , se procedió a tomar una serie de muestras para su datación radiocarbónica. Dado que los huesos aparecían totalmente calcinados, se optó por la toma de muestras de carbón vegetal procedente de las respectivas cremaciones. En los dos casos se recogieron en el nivel $b$, perteneciendo al material vegetal utilizado en la pira funeraria. Las muestras fueron remitidas al laboratorio de Groningen en 1985, aportando las siguientes fechas (sin calibrar):

- GrN-13341. Túmulo 1 (carbón vegetal). 2440+30 $\mathrm{BP}=490$ a. C. (Valor Libby).

- GrN-13342. Túmulo 5 (carbón vegetal). 2360£60 $\mathrm{BP}=410$ a. C. (Valor Libby).

Los resultados obtenidos en esos momentos situaban los túmulos 1 y 5 entre los inicios y el final del siglo V a. C. Dichas fechas presentaban una cierta discordancia con la cronología arqueológica que aportaba el propio yacimiento, sobre todo por el uso exclusivo del bronce y otras características del ritual y de la arquitectura funeraria, ya que dichas dataciones parecían demasiado modernas para el conjunto estudiado, sobre todo si lo comparábamos con el ajuar de la vecina necrópolis de Busal, en la que ya aparece el hierro y las armas.

La necesidad de acercar la cronología radiocarbónica a la cronología histórica y el uso generalizado de diferentes tablas de calibración, ha permitido en las dos últimas décadas ajustar las cronologías absolutas a las fechas del calendario, aunque también ha causado una cierta incertidumbre al no ofrecer una fecha concreta, sino una banda estadística de dataciones que puede dificultar la fechación de un contexto arqueológico determinado, sobre todo cuando se trata de yacimientos protohistóricos, o bien se cuenta con un número reducido de dataciones (Castro y Micó: 1995). Algunos trabajos posteriores sobre el valle medio del Ebro abordan el problema de las fechas absolutas y su calibración, intentando en todo caso ajustar dichas dataciones a los contextos arqueológicos, de los que en muchos casos carecemos de fechas de C14, salvo por los datos aportados en los alrededores de Zaragoza, con dataciones en el Castillo de Miranda, en Los Castellazos de Mediana, en el solar de las calles Gavín/Sepulcro de Zaragoza o en el Cabezo de La Cruz de La Muela y en el extremo occidental del sector central del valle medio del Ebro, en los poblados PIIa y PIIb del Alto de la Cruz de Cortes, que centran la I ${ }^{\text {a }}$ Edad del Hierro entre finales del siglo IX y finales del siglo VI cal. B. C. (Munilla et alii, op. cit.: 1994-96, 170; Picazo: 2005, 112-114; Picazo y Rodanés; 2009, 78-80). 
La ausencia de fechas absolutas en las necrópolis correspondientes al sector occidental del valle medio del Ebro, incluidos los cementerios navarros de La Atalaya, La Torraza, el Castillo y El Castejón (Armendáriz, op . cit.: 2008, 182) o los localizados en las Alta Cinco Villas -Busal, Arroyo Vizcarra, Bco. de la Paúl, etc.-, nos priva de una secuencia cronológica absoluta con la que comparar las fechas obtenidas en el Corral de Mola. De hecho, solamente las dataciones radiocarbónicas obtenidas en algunas necrópolis del río Jalón, publicadas en su momento sin calibrar, nos permiten acercarnos a una secuencia cronológica para este grupo de necrópolis tumulares de incineración. En el conjunto funerario del Barranco de la Peña de Urrea de Jalón se dataron tres sepulturas de incineración, dando como resultado 490, 430 y 355 a. C. que se asemejarían a las muestras de Corral de Mola, máxime si tenemos en cuenta que el material cerámico y metálico es similar (Pérez Casas: 1990, 114-115, fig. 5). Por lo que respecta a la necrópolis del Cabezo de Ballesteros en Épila, las dataciones absolutas suman un total de doce fechas, entre el 610 a. C. como la más antigua y 380 a. C., como la más moderna, centrándose el periodo de utilización de la necrópolis en el siglo VI a. C., a juzgar por el número de dataciones de este momento y por el material arqueológico asociado a éstas (Pérez Casas, op. cit.: 1990, 115-118, figs. 6-8).

Intentando ajustar el contexto cronológico de estas necrópolis, hemos reunido las todavía escasas fechas radiocarbónicas existentes para la Edad del Hierro en el valle medio del Ebro, ampliando estas fechas a los sectores central y oriental del mismo e incluyendo dataciones tanto de contextos funerarios, como de habitación, todas ellas sin calibrar en su día (fig. 42). Así aportamos algunas ya conocidas, como las del poblado del Castillo de Miranda -490 a. C.- (Fatás: 1972, 115, n 44; Beltrán Llorís, op . cit.: 1976, 97) o las del fondo de cabaña de la calle Gavin-Sepulcro de Zaragoza - 630 y 600 a. C.- (Aguilera et alii: 1984), junto a otras menos conocidas como la de Los Castellazos de Mediana de Aragón, procedente de una sepultura de incineración y con una fecha de 615 a. C. (Maestro: 2005, 144), o las procedentes del poblado y necrópolis de La Codera y que aportan para el primero una data de 620 a. C. y para la segunda otras dos situadas entre el 660 y 525 a. C. (Montón: 2002). Ya en el extremo oriental del valle medio del Ebro contamos con las dataciones de la necrópolis de Los Castellets que cubren una amplia cronología desde el Bronce Final hasta el Ibérico Antiguo, con seis fechas (sin calibrar): 1090, 870, 830, 805, 610 y 580 a. C. (Royo, op. cit.: 1994-96, 98), además de las dos dataciones conocidas para el abandono del poblado de la Loma de los Brunos en Caspe, situadas entre el 500 y el 490 a. C. (Eiroa y Bachiller: 1985, 169-170). Por último cabe citar el poblado de San Jorge en Plou (Teruel), yacimiento algo alejado del valle medio del Ebro, pero con una cultura material muy similar a los yacimientos del Hierro I del sector central de este río y que aportó tres fechas radiocarbónicas (sin calibrar): 485, 470 y 450 a. C. (Lorenzo Magallón: 1991, 158).

Teniendo en cuenta lo dicho, y para intentar ajustar las dataciones del Corral de Mola a la cronología que debe asignarse al contexto material de este yacimiento, hemos calibrado las dos dataciones realizadas en su momento, utilizando el programa on line OxCal v4.2.4, según la curva atmosférica IntCal13 (Reimer et alii: 2013), con el siguiente resultado (fig. 43):

- GrN-13341. Túmulo 1. Datación radiocarbónica: 2440 \pm 30 BP. Fechas calibradas a dos sigmas: 592/408 cal BC (al 64,5\%) y 751/682 cal BC (al 23,5\%).

- GrN-13342. Túmulo 5. Datación radiocarbónica: 2360 \pm 60 BP. Fechas calibradas a dos sigmas: 594/356 cal BC (al 74,8\%) y 753/682 cal BC (al 11,3\%).

Las dos fechas calibradas aportan unas cronologías que sin ser aberrantes, plantean problemas, como viene observándose en las dataciones radiocarbónicas de los contextos protohistóricos, como varios autores ya han señalado para el valle del Ebro (Belarte et alii: 2013, 308; Picazo, op . cit: 2005, 112-114; Picazo y Rodanés, op. cit.: 2009, 76) y que se viene denominando en la bibliografía como "meseta de Hallstatt" (Nuñez: 2015, 30). Si observamos las dataciones y su curva de calibración, vemos que atendiendo a las desviaciones estándar de probabilidad más alta, ambos túmulos del Corral de Mola podrían situarse entre los inicios del siglo VI y el final del siglo $\mathrm{V}$ a. C., para el túmulo 1 y entre inicios del siglo VI y mediados del siglo IV a. C. lo que da dos siglos para el túmulo 1 y de dos siglos y medio para el túmulo 5 , sin que puedan descartarse otras posibles fechas más antiguas e incluso más modernas, pero con un margen de probabilidad mucho más reducido. Resulta evidente que dichas desviaciones estándar resultan demasiado amplias para poder aportar una datación que se acerque a la cronología que parece aportar el ajuar funerario estudiado. Solamente el extremo superior de la banda, el situado en la primera mitad del siglo VI se podría acercar al contexto material documentado.

Intentar comparar estas dataciones con los resultados que han aportado otros yacimientos del Hierro I en el valle medio del Ebro, era complicado a priori, sin establecer un marco de comparación previo que permita establecer las posibles relaciones entre los mismos. Por esta razón, hemos procesado todas las dataciones conocidas para poblados y necrópolis del Ebro medio de la $I^{\text {a }}$ Edad del Hierro y establecido su contexto arqueológico o estratigráfico, su composición o su clasificación crono-cultural, procediendo a continuación a su calibración con el mismo sistema que el realizado para el Corral de Mola, lo que podría haber dado lugar a un análisis estadístico bayesiano del problema, pero la ausencia de contextos estratigráficos fiables, la esca- 


\begin{tabular}{|c|c|c|c|c|c|}
\hline YACINIIENTO & CONIEXTO & NTVEL & MLATERIA & EDAD B.P. & \pm \\
\hline CORRAL DE MOLA & TÚMULO 1 & CREMACTÓN & CARBÓN VEGETAL & 2440 & 30 \\
\hline CORRAL DE MOLA & TÚMULO 5 & CREMACTÓN & CARBÓN VEGETAL & 2360 & 60 \\
\hline CABEZO BALLESTEROS & TÚMULO $10 \mathrm{~B}^{\prime}$ & CREMACIÓN & CARBON VEGETAL & 2390 & 50 \\
\hline CABEZO BALLESTEROS & TÚMULO $644 \mathrm{~A}^{\prime}$ & CREMACIÓN & CARBÓN VEGETAL & 2410 & 50 \\
\hline CABEZO BALLESTEROS & TÚMULO 18 & CREMACTÓN & CARBÓN VEGETAL & 2490 & 30 \\
\hline CABEZO BALLESTEROS & TÚMULO 85/3 & CREMACIÓN & CARBÓN VEGETAL & 2560 & 30 \\
\hline CABEZO BALLESTEROS & TÚMULO 85:4 & CREMACIÓN & CARBÓN VEGETAL & 2480 & 40 \\
\hline CABEZO BALLESTEROS & TÚMULO $85 / 5$ & CREMACTÓN & CARBÓN VEGETAL & 2510 & 35 \\
\hline CABEZO BALLESTEROS & TÚMULO 23 & CREMACIÓN & CARBÓN VEGETAL & 2330 & 50 \\
\hline CABEZO BALLESTEROS & TÚMULO S.R & CREMACIÓN & CARBÓN VEGETAL & 2500 & 30 \\
\hline CABEZO BALLESTEROS & TÚMULO S.R & CREMACIÓN & CARBÓN VEGETAL & 2475 & 35 \\
\hline CABEZO BALLESTEROS & TÚMULO S.R & CREMACIÓN & CARBÓN VEGETAL & 2480 & 35 \\
\hline CABEZO BALLESTEROS & TÚMULO S.R & CREMACIÓN & CARBÓN VEGETAL & 2470 & 25 \\
\hline CABEZO BALLESTEROS & TUMULO S.R & CREMACTÓN & CARBÓN VEGETAL & 2530 & 30 \\
\hline BARRANCO DE LA PEÑA & TÚMULO S.R & CREMACIÓN & CARBÓN VEGETAL & 2305 & 50 \\
\hline BARRANCO DE LA PEÑA & TÚMULO S.R & CREMACIÓN & CARBÓN VEGETAL & 2380 & 50 \\
\hline BARRANCO DE LA PEÑA & TÚMULO S.R & CREMACIÓN & CARBÓN VEGETAL & 2440 & 50 \\
\hline LOS CASTELLAZOS & TÚMULO S.R & CREMACIÓN & CARBÓN VEGETAL & 2565 & 150 \\
\hline LOS CASTELLETS II & TUंMULO 2 A & INHUMACIÓN & HUESO & 2755 & 30 \\
\hline LOS CASTELIETS II & TÚMULO 2 B & INHUMACIÓN & HUESO & 2820 & 30 \\
\hline LOS CASTELIETS II & TÚMULO 3 & INHUMACIÓN & HUESO & 2780 & 35 \\
\hline LOS CASTELIETS II & TÚMULO 14 & INHUMACIÓN & HUESO & 3040 & 140 \\
\hline LOS CASTELIETS II & TÚMULO 30 & INCINERACIÓN & CARBÓN VEGETAL & 2530 & 90 \\
\hline LOS CASTELLETS II & TÚMULO 32 & INCINERACIÓN & CARBÓN VEGETAL & 2560 & 70 \\
\hline CASTILLO MIRANDA & POBLADO & CENIZAS & CARBON VEGETAL & 2440 & 80 \\
\hline CABEZO LA CRUZ & POBLADO & CONSTRUCCIÓN & CARBON VEGETAL & 2610 & 20 \\
\hline CABEZO LA CRUZ & POBLADO & CONSTRUCCIÓN & CARBON VEGETAL & 2680 & 20 \\
\hline CABEZO LA CRUZ & POBLADO & CONSTRUCCIÓN & CARBON VEGETAL & 2610 & 20 \\
\hline CABEZO LA CRUZ & POBLADO & CONSTRUCCIÓN & CARBON VEGETAL & 2620 & 20 \\
\hline CABEZO LA CRUZ & POBLADO & INCENDIO & CEBADA CARBONIZADA & 2590 & 20 \\
\hline CABEZO LA CRUZ & POBLADO & INCENDIO & ESTIERCOL & 2530 & 40 \\
\hline CABEZO LA CRUZ & POBLADO & INCENDIO & ESTIERCOL & 2500 & 60 \\
\hline CABEZO LA CRUZ & POBLADO & INCENDIO & CARBONES & 2520 & 25 \\
\hline CABEZO LA CRUZ & POBLADO & INCENDIO & CEBADA CARBONIZADA & 2540 & 20 \\
\hline CABEZO LA CRUZ & POBLADO & INCENDIO & MIJO CARBONIZADO & 2510 & 30 \\
\hline CABEZO LA CRUZ & POBLADO & INCENDIO & VID CARBONIZADA & 2470 & 30 \\
\hline CABEZO LA CRUZ & POBLADO & INCENDIO & CARBON VEGETAL & 2470 & 30 \\
\hline CABEZO LA CRUZ & POBLADO & INCENDIO & TRONCOS CARBONIZADOS & 2515 & 20 \\
\hline ZARAGOZA.Cl.GAVIN & POBLADO & ABANDONO & CARBON VEGETAL & 2550 & 50 \\
\hline ZARAGOZA.C/.GAVIN & POBLADO & ABANDONO & CARBON VEGETAL & 2580 & 50 \\
\hline LA CODERA & TU்MULO 6 & CREMACIÓN & HUESO & 2610 & 40 \\
\hline LA CODERA & TÚMULO 13 & CREMACIÓN & CARBÓN VEGETAL & 2475 & 35 \\
\hline LA CODERA & POBLADO M1 & ABANDONO & CARBÓN VEGETAL & 2570 & 60 \\
\hline SAN JORGE (PLOU-TE.) & POBLADO & ABANDONO & CARBÓN VEGETAL & 2400 & 190 \\
\hline SAN JORGE (PLOU-TE.) & POBLADO & ABANDONO & CARBÓN VEGETAL & 2420 & 60 \\
\hline SAN JORGE (PLOU-TE.) & POBLADO & ABANDONO & CARBÓN VEGETAL & 2400 & 65 \\
\hline LOMA DE LOS BRUNOS & POBLADO & ABANDONO R. & CARBÓN VEGETAL & 2440 & 50 \\
\hline LOMA DE LOS BRUNOS & POBLADO & ABANDONO A. & CARBÓN VEGETAL & 2450 & 50 \\
\hline
\end{tabular}




\begin{tabular}{|c|c|c|c|c|}
\hline VALOR LIBBY & FASE YACIIIENTO & FASE CRONOLOGICA & REF. LAB. & FECHAS CALIBRADAS 2 SIGMAS \\
\hline 490 a.C. & ENTERRAMIENTO & HIERRO I TARDIO & GrN. 13341 & $592 / 408-751 / 682 \mathrm{cal} \mathrm{BC}$ \\
\hline 410 a.C. & ENTERRAMIENTO & HIERRO I TARDIO & GrN. 13342 & $594 / 356-753 / 682 \mathrm{cal} \mathrm{BC}$ \\
\hline 410 a.C. & ENTERRAMIENTO & HIERRO I TARDIO & CSIC. 607 & $592 / 386 \mathrm{cal} \mathrm{BC}$ \\
\hline 460 a.C. & ENTERRANIIENTO & HIIRRO I TARDIO & CSIC. 608 & 595/397-754/681 cal BC \\
\hline 540 a.C. & ENTERRAMIENTO & HIIERRO I TARDIO & GN. 13343 & $781 / 511 \mathrm{cal} \mathrm{BC}$ \\
\hline 610 a.C. & ENTERRAMIIENTO & HIERRO I MEDIO & GrN. 13444 & $805 / 746-643 / 553 \mathrm{cal} \mathrm{BC}$ \\
\hline 530 a.C. & ENTERRAMIENTO & HIERRO I MEDIO & GrN. 13445 & $775 / 430 \mathrm{cal} \mathrm{BC}$ \\
\hline 560 a.C. & ENTERRAMIIENTO & HIERRO IMEDIO & GrN. 13446 & $794 / 536 \mathrm{cal} \mathrm{BC}$ \\
\hline 380 a.C. & ENTERRAMIENTO & HIERRO II & GrN. 13447 & $543 / 350-305 / 210 \mathrm{cal} \mathrm{BC}$ \\
\hline 550 a.C. & ENTERRAMIIENTO & HIERRO I MEDIO & GrN. 14352 & $788 / 537 \mathrm{cal} \mathrm{BC}$ \\
\hline 525 a.C. & ENTERRAMIIENTO & HIIERRO I TARDIO & GrN. 14353 & $771 / 474 \mathrm{cal} \mathrm{BC}$ \\
\hline 530 a.C. & ENTERRAMIENTO & HIIERO I TARDIO & GrN. 14354 & $775 / 476 \mathrm{cal} \mathrm{BC}$ \\
\hline 520 a.C. & ENTERRAMIENTO & HIERRO I TARDIO & GrN. 14355 & $767 / 482 \mathrm{cal} \mathrm{BC}$ \\
\hline 580 a.C. & ENTERRAMIIENTO & HIERRO IMEDIO & GrN. 14356 & $651 / 543-797 / 731 \mathrm{cal} \mathrm{BC}$ \\
\hline 355 a.C. & ENTERRAMIIENTO & HIERRO II & GrN. 14357 & $510 / 344-324 / 205 \mathrm{cal} \mathrm{BC}$ \\
\hline 430 a.C. & ENTERRAMIIENTO & HIIERO I TARDIO & GrN. 14358 & $592 / 377-751 / 683 \mathrm{cal} \mathrm{BC}$ \\
\hline 490 a.C. & ENTERRANIENTO & HIERRO I TARDIO & GNN. 14359 & $672 / 406-757 / 679 \mathrm{cal} \mathrm{BC}$ \\
\hline 615 a. C. & ENTERRAMIENTO & HIERRO I MEDIO & GrN. 16317 & $1058 / 361 \mathrm{cal} \mathrm{BC}$ \\
\hline 805 a.C. & ENTERRAMEENTO & HIERRO I ANTIGUO & GrN. 14084 & $978 / 827 \mathrm{cal} \mathrm{BC}$ \\
\hline 870 a.C. & ENTERRAMIIENTO & BRONCE FLNAL III & GrN. 14083 & $1055 / 899 \mathrm{cal} \mathrm{BC}$ \\
\hline 830 a.C. & ENTERRANIIENTO & BRONCE FINAL II & GN. 14085 & $1008 / 838 \mathrm{cal} \mathrm{BC}$ \\
\hline 1090 a.C. & ENTERRAMIENTO & BRONCE FINALII & GrN.13977 & $1611 / 922 \mathrm{cal} \mathrm{BC}$ \\
\hline 580 a.C. & ENTERRANIENTO & HIERRO I MEDIO & GrN. 17276 & $820: 408 \mathrm{cal} \mathrm{BC}$ \\
\hline 610 a.C. & ENTERRAMIENTO & HIERRO I MEDIO & GrN. 17274 & $835 / 430 \mathrm{cal} \mathrm{BC}$ \\
\hline 490 a. C. & DESTRUCCION POBLADO & HIIERRO I TARDIO & CSIC. 169 & $778 / 399 \mathrm{cal} \mathrm{BC}$ \\
\hline 660 a. C. & CONSTRUCCIÓN POBLADO II & HIERRO I ANTIGUO & GrN. 29138 & $812 / 778 \mathrm{cal} \mathrm{BC}$ \\
\hline 730 a. C. & CONSTRUCCION POBLADO II & HIERRO I ANTIGUO & GrN. 29139 & $850 / 802 \mathrm{cal} \mathrm{BC}$ \\
\hline 660 a. C. & CONSTRUCCION POBLADO II & HIERRO I ANTIGUO & GrN. 29140 & $812 / 778 \mathrm{cal} \mathrm{BC}$ \\
\hline 670 a. C. & CONSTRUCCION POBLADO II & HIERRO I ANTIGUO & GrN. 29141 & $818 / 785 \mathrm{cal} \mathrm{BC}$ \\
\hline 640 a. C. & DESTRUCCIÓN POBLADO II & HIERRO IMEDIO & GrN. 29142 & $805 / 769 \mathrm{cal} \mathrm{BC}$ \\
\hline 580 a. C. & DESTRUCCION POBLADO II & HIERRO I MEDIO & GrN. 29143 & $798 / 537 \mathrm{cal} \mathrm{BC}$ \\
\hline 550 a. C. & DESTRUCCION POBLADO II & HIERRO I MEDIO & GrN. 29144 & $791 / 483 \mathrm{cal} \mathrm{BC}$ \\
\hline 570 a. C. & DESTRUCCION POBLADO II & HIERRO I MEDIO & GrN. 29863 & $652 / 543 \mathrm{cal} \mathrm{BC}$ \\
\hline 590 a. C. & DESTRUCCIÓN POBLADO III & HIERRO I MEDIO & GrN. 29145 & $794 / 748 \mathrm{cal} \mathrm{BC}$ \\
\hline 560 a. C. & DESTRUCCION POBLADO III & HIERRO I MEDIO & GrN. 29146 & $788 / 538 \mathrm{cal} \mathrm{BC}$ \\
\hline 520 a. C. & DESTRUCCIÓN POBLADO III & HIERRO I TARDIO & GrN. 29147 & $672 / 484 \mathrm{cal} \mathrm{BC}$ \\
\hline 520 a. C. & DESTRUCCIÓN POBLADO III & HIERRO I TARDIO & GrN. 29148 & $672 / 484 \mathrm{cal} \mathrm{BC}$ \\
\hline 565 a. C. & DESTRUCCION POBLADO IV & HIERRO I MEDIO & GrN. 29149 & $650 ! 545 \mathrm{cal} \mathrm{BC}$ \\
\hline 600 a. C. & DESTRUCCION POBLADO & HIERRO I MEDIO & GrN. 12410 & $811 / 536 \mathrm{cal} \mathrm{BC}$ \\
\hline 630 a. C. & DESTRUCCION POBLADO & HIERRO I MEDIO & GrN. 12411 & $836 / 727-695 / 541 \mathrm{cal} \mathrm{BC}$ \\
\hline 660 a.C. & ENTERRALIENTO & HIERRO I ANTIGUO & GrN. 26966 & $849 / 750 \mathrm{cal} \mathrm{BC}$ \\
\hline 525 a.C. & ENTERRANIENTO & HIERRO I TARDIO & GrN. 26134 & $771 / 474 \mathrm{cal} \mathrm{BC}$ \\
\hline $620 \mathrm{a} . \mathrm{C}$. & ABANDONO POBLADO & HIERRO I MEDIO & GrN. 26053 & $840: 507 \mathrm{cal} \mathrm{BC}$ \\
\hline 450 a. C. & ABANDONO POBLADO & HIERRO I TARDIO & Ly. 3745 & $929 / 39 \mathrm{cal} \mathrm{BC}$ \\
\hline 470 a. C. & ABANDONO POBLADO & HIIRRO I TARDIO & GFF. 7539 & $672 / 399-757 / 679 \mathrm{cal} \mathrm{BC}$ \\
\hline 485 a. C. & ABANDONO POBLADO & HIIRRO I TARDIO & Ly. 4385 & $762 / 388 \mathrm{cal} \mathrm{BC}$ \\
\hline 490 a. C. & ABANDONO POBLADO & HIERRO I TARDIO & CSIC. 599 & $672 / 406-757 / 679 \mathrm{cal} \mathrm{BC}$ \\
\hline 500 a. C. & ABANDONO POBLADO & HIERRO I TARDIO & CSIC. 600 & $760 / 410 \mathrm{cal} \mathrm{BC}$ \\
\hline
\end{tabular}

Fig. 42. Tabla con los yacimientos de la Edad del Hierro del valle medio del Ebro que cuentan con dataciones radiocarbónicas, tanto sin calibrar como calibradas. (Elaboración propia: Royo 2016) 

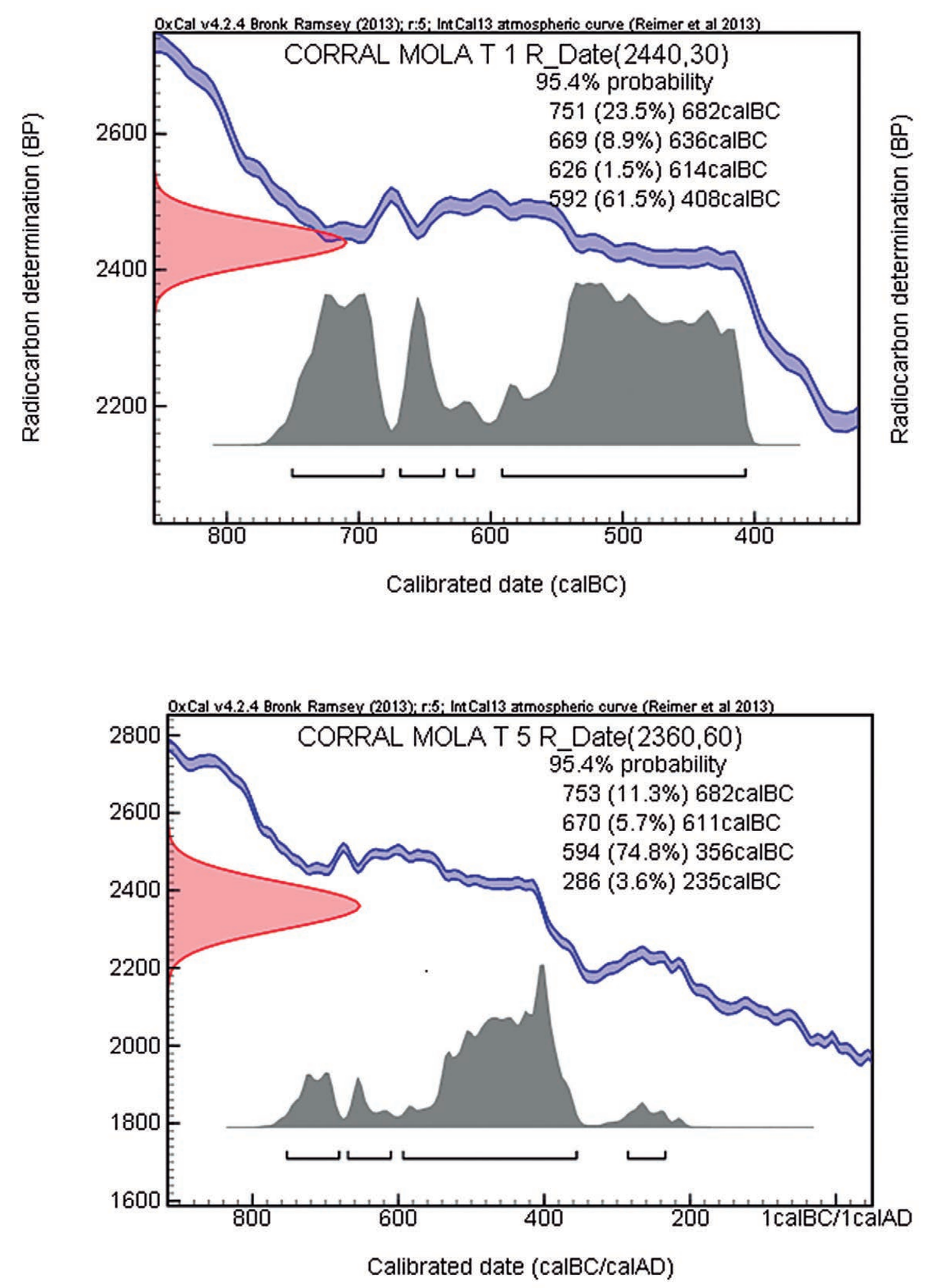

Fig. 43. Dataciones radiocarbónicas del Corral de Mola, con las curvas de calibración, realizadas con el programa Oxcal v4.2.4. 
sez de yacimientos con dataciones absolutas y sobre todo la presencia de muchas de las muestras radiocarbónicas sobre elementos de vida larga, hace hoy por hoy muy complicada la realización de dicho análisis, como así se ha planteado en áreas cercanas y para problemáticas similares (Jover et alii: 2016, 84-85). A pesar de estas dificultades, por vez primera se puede ofrecer al resto de investigadores un listado completo de dataciones calibradas de un área geográfica que hasta la fecha contaba con muy pocas fechas absolutas (fig. 42) y que nos ha servido para aportar algunas novedades sobre la aplicación de la estadística bayesiana a la periodización de la Edad del Hierro en el valle medio del Ebro (García-Martínez et alii: prensa).

Si admitimos como plenamente válida la periodización comúnmente aceptada de la Edad del Hierro en el Noreste peninsular y zona del Golfo de León, es decir la que divide la $\mathrm{I}^{\mathrm{a}}$ Edad del Hierro en tres fases: Hierro I Antiguo (800-750/650 a. C.), Hierro I Medio o Pleno (650/550 a. C.) y Hierro I Tardío (550/450 a. C.) (Graells, op . cit.: 2014; Constantin: 2014), vemos que la mayoría de las dataciones calibradas a dos sigmas aportan unas bandas cronológicas tan amplias que dificultan enormemente cualquier tipo de secuencia cronológica, especialmente en las fases del Hierro I Antiguo y Medio. También resulta evidente que este desfase entre la cronología absoluta aportada por el C14 y la datación de los contextos arqueológicos analizados y su entronque con la cronología histórica, sólo puede deberse a los problemas derivados de la "meseta de Hallstatt", de las propias muestras de vida larga y de la falta de buenos contextos arqueológicos, como ya hemos señalado (Nuñez, op. cit.; 2015, 30-31). No obstante, algunas dataciones calibradas, sobre todo las correspondientes a yacimientos de hábitat, con buenas estratigrafías y abundantes muestras de "vida corta" han dado buenos resultados, como parece deducirse de las dataciones de los tres poblados superpuestos del Cabezo de la Cruz (Picazo y Rodanés, op . cit.: 2009, 7679), que vienen a coincidir casi plenamente con las fases cronológicas del Hierro I anteriormente propuestas.

A la vista de lo expuesto y teniendo en cuenta el contexto arqueológico documentado en esta necrópolis, una datación alta de la banda cronológica absoluta propuesta, sería más acorde con la cultura material documentada y se encuadraría mejor con la secuencia crono-cultural de los principales poblados de la $\mathrm{I}^{\mathrm{a}}$ Edad del Hierro del valle medio del Ebro: el Alto de la Cruz de Cortes (Navarra) (Munilla et alii, op . cit.: 1994-96) y el Cabezo de la Cruz de la Muela (Zaragoza) (Picazo y Rodanés, op . cit.: 2009), por lo que debería proponerse para el Corral de Mola una cronología situada entre el último tercio del siglo VII y el primer tercio del siglo VI a. C.

\section{6. Los restos óseos incinerados del Corral de Mola}

Durante los trabajos de excavación en esta necrópolis, se procedió a recuperar la totalidad de los restos óseos procedentes de las cremaciones, especialmente en los dos únicos túmulos donde se pudo constatar, los túmulos 1 y 5 . Del túmulo 1 se recuperó un lote de restos óseos tanto de los niveles a y b, correspondientes al relleno del propio enterramiento, como a los recuperados en el proceso de criba de los niveles alterados por las labores agrícolas. Por desgracia, en el túmulo 5, debido a la alteración del nivel de cremación, sólo se pudieron recuperar algunos escasos fragmentos correspondientes a los restos óseos de esta incineración.

El estudio realizado por nosotros mismos con el Dr. José Ignacio Lorenzo, e incluido en este volumen, ha permitido documentar el ritual funerario de esta necrópolis y conocer algún dato de la población enterrada en este lugar. El análisis antropológico de los huesos quemados, sólo ha permitido extraer información de los conservados en el túmulo 1, constatándose solamente la incineración del cadáver en el túmulo 5 .

El referido estudio, viene a sumarse a los todavía escasos trabajos sobre las incineraciones de las necrópolis protohistóricas del valle medio del Ebro y zonas aledañas, entre los que cabe citar los realizados en las necrópolis del Castejón de Arguedas (Lorenzo Lizalde y Sinusía: 2002), El Cabo de Andorra (Lorenzo Lizalde: 2015) o Sant Joaquim de la Menarella (Vizcaino: 2010, 113-125), por citar algunos conjuntos de similar contexto y cronología al Corral de Mola. Por lo que respecta al túmulo 1, adelantaremos en este apartado las principales aportaciones del estudio antropológico:

- Los restos óseos incinerados del Corral de Mola representan una cantidad proporcionalmente pequeña si tenemos en cuenta las dimensiones y el ajuar del enterramiento del túmulo 1 , sobre todo si la comparamos con otras muestras procedentes de yacimientos similares, donde el peso de los huesos cremados es considerablemente mayor.

- El estudio de dichos restos permite concluir que la cremación fue intensa, alcanzándose temperaturas muy elevadas, por encima de los 600 grados centígrados, pudiendo llegar hasta los 800 .

- La clasificación osteológica de los restos conservados, no representa más que a algunas partes del cuerpo humano, faltando otras muy significativas. Este hecho puede deberse a una selección previa a su deposición definitiva o a la falta de una excavación completa del túmulo 1 .

- Los fragmentos de huesos incinerados parecen identificar en el túmulo 1, la presencia de dos individuos incinerados, ambos de sexo masculino, uno 
de ellos de edad adulta y otro de edad joven posterior a la adolescencia. Los escasos fragmentos recuperados en el túmulo 5 , sólo permiten constatar la presencia de al menos un individuo adulto.

- El proceso de cremación pudo incluir como parte del ritual el triturado o fragmentación intencionada de los restos mejor conservados, a juzgar por algunas marcas más o menos regulares de cortes que se han documentado en algunos huesos.

- La identificación de algunos restos incinerados de fauna, entre ellos algún fragmento de pájaro, permite plantear la posibilidad de que dichos elementos formasen parte de ofrendas funerarias o incluso pertenecieran a un posible banquete funerario, cuestiones que más adelante trataremos.

\section{Otras Necrópolis próximas al Corral de Mola}

Para una mejor comprensión y contextualización de esta necrópolis hemos considerado necesario revisar algunos hallazgos próximos a este yacimiento que permiten ampliar el esquema crono-tipológico de este tipo de necrópolis. Dicha revisión se realiza sobre otra necrópolis de características muy similares al Corral de Mola y situada en su entorno geográfico próximo; este es el caso de la necrópolis de Busal I.

\section{1. Una revisión de la necrópolis de incineración de Busal (Uncastillo, Zaragoza)}

Se trata de la primera necrópolis del Hierro I conocida en la zona. Aunque citada en repetidas ocasiones, el yacimiento de Busal sólo cuenta con el estudio preliminar de sus materiales recogidos fuera de contexto estratigráfico (Burillo: 1977), sin que exista otra documentación al respecto. Dado el interés de este hallazgo, hemos decidido realizar una nueva relectura del mismo, de su ajuar funerario y del tipo de estructuras documentadas, aportando los nuevos datos que sobre este tipo de materiales se han ido dando a conocer.

Los restos publicados fueron localizados en el curso de unas roturaciones agrícolas en la partida de Busal, en un área aproximada de $1 \mathrm{Ha}$. de extensión junto a la orilla derecha del Barranco de Bastanes, a unos $3 \mathrm{~km}$. de su desembocadura con el río Riguel, en el extremo sur del termino municipal de Uncastillo, aunque a unos $4 \mathrm{~km}$. de la localidad de Layana (fig. 44). El área donde aparecieron los restos fue desmontada con maquinaria agrícola pesada, lo que destruyó o alteró todo el yacimiento, en un área donde precisamente existía una concentración anómala de piedras de pequeño y mediano tamaño, al parecer correspondientes a las estructuras tumulares y con presencia más que probable de algún hito o estela, a juzgar por los datos aportados por Burillo (op, cit.: 1977, 52-53, fig. 1). El

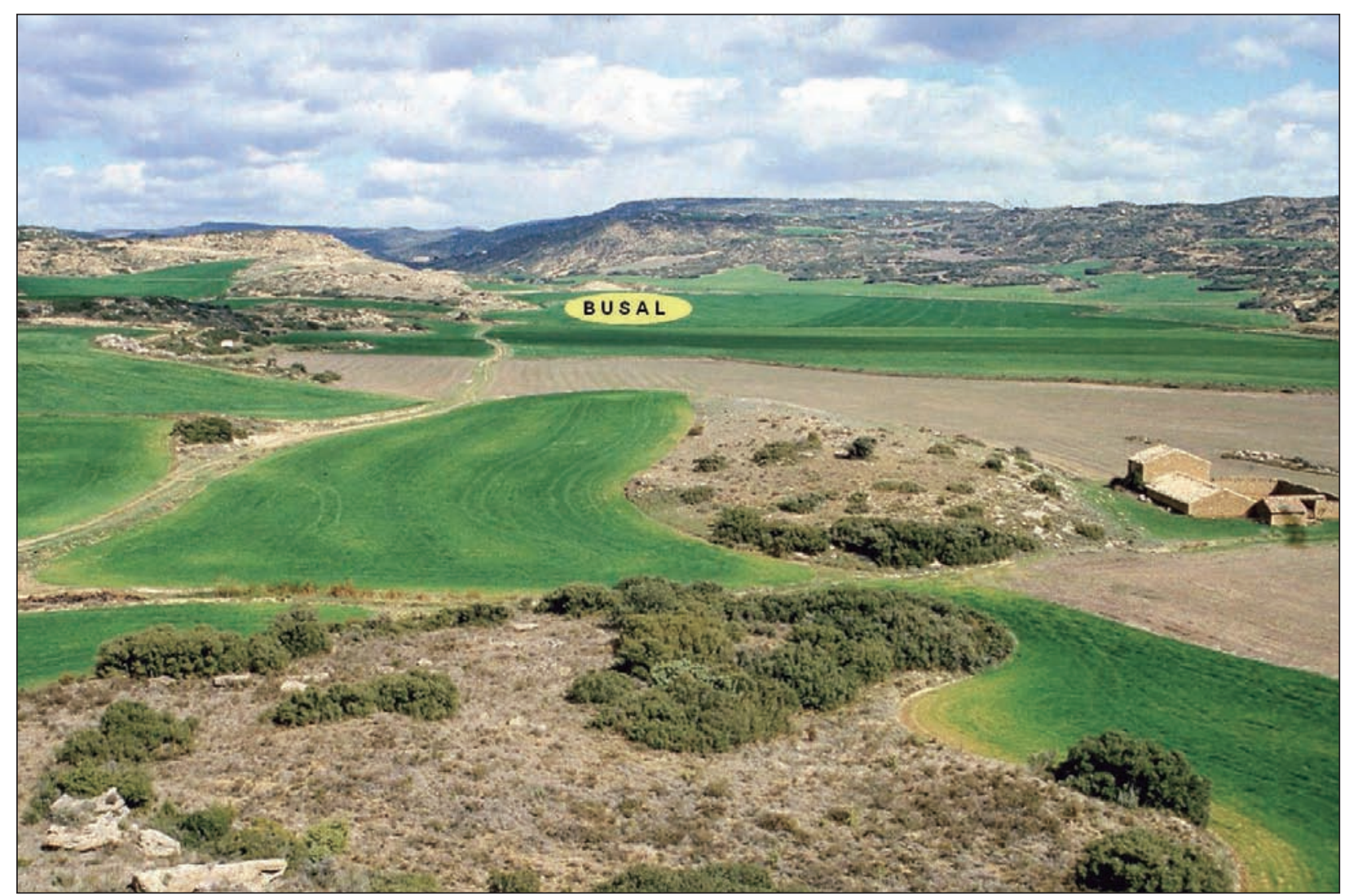

Fig. 44. Situación de la necrópolis de Busal con respecto al Corral de Mola, junto al barranco de los Bastanes en Uncastillo, Zaragoza (Foto: Royo 1998). 
área destruida aportó una gran cantidad de piedra arenisca y algunas manchas de tierra cenicienta, localizada cerca de la orilla del Barranco de Bastanes, a menos de $1 \mathrm{~km}$. al noreste de la necrópolis del Corral de Mola (fig. 44). Nosotros mismos tuvimos la oportunidad de recorrer el yacimiento y comprobamos la existencia de un número considerable de enterramientos tumulares, más o menos arrasados, casi todos ellos de tendencia circular y variados tamaños, así como la presencia masiva de encachados pétreos en la totalidad de los enterramientos, algunos con estelas de señalización y posiblemente con presencia de cistas.

Aunque no detallaremos ni la descripción ni el estudio de los materiales publicados en su momento (Burillo, op . cit.: 1977, 54-60), comentaremos algunos elementos de contextualización de este yacimiento. En primer lugar hay que señalar que la casi totalidad de la cerámica recuperada es manufacturada, salvo un solo fragmento de cerámica a torno (fig. 45, 5). Los escasos materiales identificados corresponden a restos de urnas o vasos de ofrendas hechos a mano, con superficies espatuladas o alisadas, perfiles suaves en $\mathrm{S}$ u ovoides, con collarinos aplicados entre el borde y la pared decorados con digitaciones (fig. 45, 1-4), presencia de algún mamelón o pezón aplicado, fondos planos y decoración acanalada o peinada en dos fragmentos cerámicos (fig. 45, 6-7). Este tipo de cerámicas es totalmente representativo de los hallazgos cerámicos de las necrópolis navarras de La Atalaya, Valtierra, El Castejón o El Castillo (Royo, op. cit: 2000, 53, fig. 8) y también de las aragonesas del sector occidental del valle medio del Ebro a partir del siglo VI a. C., pudiendo llegar hasta los inicios del IV a. C., como sería el caso de las conocidas en el río Huecha (Royo: 1986; Royo y Pérez Casas: 1987; Royo et alii: 1992) o en el Bajo Jalón (Pérez Casas: 1988, 83; 1990, figs. 3.5 y 7).

$\mathrm{Su}$ aparición en contextos habitacionales, marca el final de la Primera Edad del Hierro y el inicio de la Segunda, periodo que en el valle del Ebro También se ha denominado como Ibérico Antiguo, como puede comprobarse en el poblado PIa del Alto de la Cruz de Cortes o en el Molino de Trasmoz, ambos en el río Huecha (Royo: 2008-2009, 91-92, lams. 11-12), o bien en el nivel tardío de la Edad del Hierro del Cabezo de la Cruz de La Muela o en el Castillo de Cuarte, ambos fechados a partir de la segunda mitad del siglo VI y sobre todo en la primera mitad del siglo V a. C. (Picazo y Rodanés, op . cit.:2009, 80; Royo y Burillo, op. cit.: 1997, 126-127, figs. 5-6). En todos estos casos, es común la presencia de cerámicas con collarinos digitados, cerámica peinada y un significativo porcentaje de cerámica a torno, tal y como parece reflejar el conjunto cerámico de Busal I.

Los restos metálicos, sin ser abundantes, son muy representativos de los ajuares funerarios de la $\mathrm{I}^{\mathrm{a}} \mathrm{Edad}$ del Hierro del valle medio del Ebro, con presencia tanto de piezas de hierro como de bronce. Entre los objetos de hierro, aparecen una serie de fragmentos correspondientes a una espada de hoja recta, doble filo y nervio central de tipología lateniense, a la que acompañan restos de la vaina metálica enteriza y posiblemente del aro o anilla de sujeción (fig. 46) y que recientemente han sido fechados entre el 500 y el 300 a. C., en la transición entre la $\mathrm{I}^{\mathrm{a}}$ y $2^{\mathrm{a}}$ Edad del Hierro (Farnié y Quesada: 2009, 117-120, figs. 93-94). Hay que señalar que el mejor fragmento de espada conservado (fig. 46,1 ) aparece claramente doblado de forma intencional, documentando sin lugar a dudas un ritual funerario constatado en muchas necrópolis de la Edad del Hierro, tanto del valle del Ebro como de la Meseta, como se documenta en la necrópolis del Cabezo Ballesteros de Epila (Pérez Casas, op. cit. 1990, 117). También citaremos la amortización ritual de cuchillos, lanzas o espadas en las necrópolis celtibéricas (Lorrio, op. cit.: 340-342, fig. 127). Es muy posible que estos restos de espada puedan ponerse en relación con las escasas muestras de armamento que se constatan en las necrópolis de su entorno geográfico, en especial del área Navarra, donde sólo conocemos ejemplares de tipología similar en las necrópolis de La Atalaya y en la del Castillo de Castejón.

En el caso de La Atalaya, Maluquer y Vázquez de Parga sólo citan de la sepultura AA 10 una espada casi completa de hoja recta y doble filo con nervadura central y empuñadura maciza, con restos de la vaina también metálica, con una longitud total de $43 \mathrm{~cm}$. (Maluquer y Vázquez, op. cit.; 1956, 18, fig. 14). Aunque no se documentaron en Busal I, en La Atalaya también aparecen otras armas en hierro, como las lanzas, los regatones y los cuchillos afalcatados, documentados en las sepulturas AA8, AA16, AB17, AB20 y AB39 (Maluquer y Vázquez, op. cit., 1956, figs. 16, 20 y 24). Con posterioridad, se realizó una primera revisión de este material (Castiella y Sesma: 1988-89, 385-393, figs. 2 a 7). Mas tarde vuelve a revisarse la espada de La Atalaya, que ahora aparece incompleta, aunque una mejor documentación permite ahora su correcta adscripción tipológica, ya que Quesada y Farnié clasifican como espada con empuñadura de lengüeta con remaches y que suponen de tradición peninsular, fechando el ejemplar entre finales del siglo VI y el siglo V a. C. (Quesada y Farnié, op. cit.: 2009, 105107 y 130-131, figs. 81-84 y 112). No obstante, en un trabajo anterior en el que se revisan los materiales de La Atalaya (Castiella: 2005), sorprende la aparición de varios restos que deben identificarse con espadas, especialmente uno de ellos sin ningún tipo de referencia o sepultura que presenta una hoja de doble filo con nervadura central y ligero engrosamiento de la hoja junto a la empuñadura que parece ser de espiga y que cuenta con una longitud superior a los $50 \mathrm{~cm}$. sin contar con la empuñadura (Castiella, op . cit.: 2005, 194, 

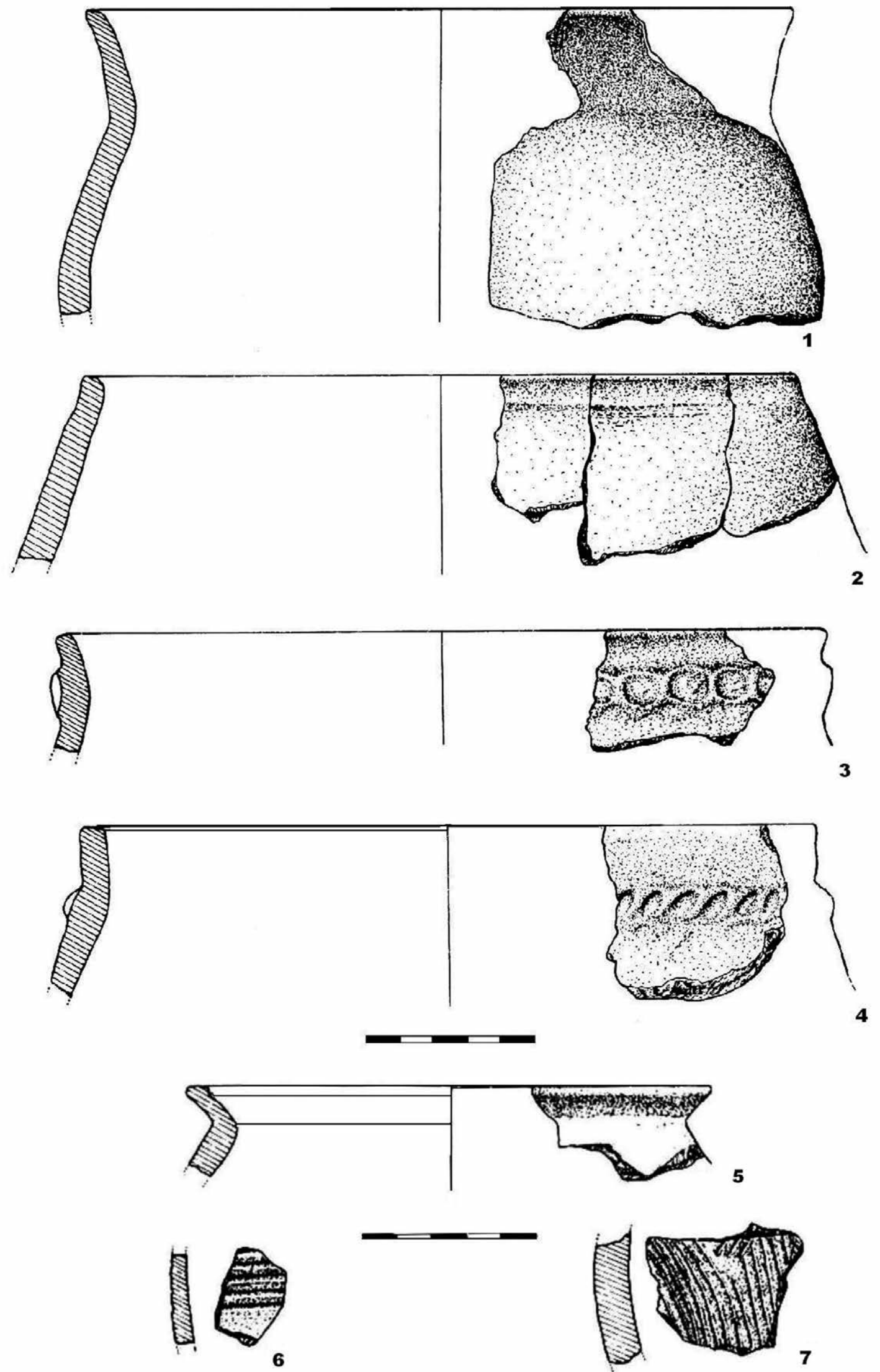

Fig. 45. Restos cerámicos de urnas a mano y a torno de la necrópolis de Busal (Dibujos: Burillo 1977, modificado por Royo 2016). 


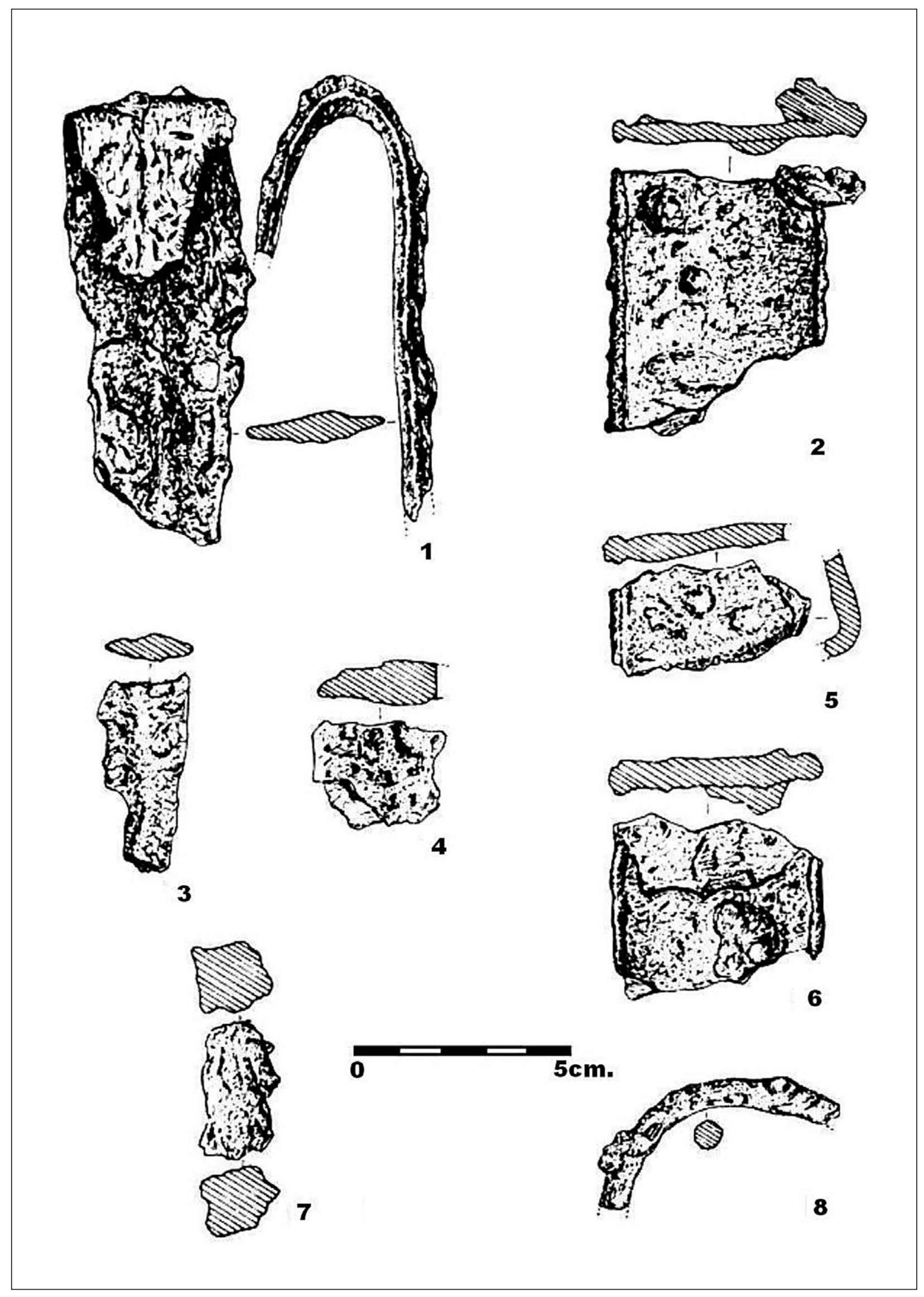

Fig. 46. Restos de espada de hierro y vaina enteriza recuperados en la necrópolis de Busal (Dibujos: Burillo: 1977, modificado por Royo 2016). 
fig. 109, sepultura 10) y que por lo representado no tiene nada que ver con la publicada por Maluquer. A esta espada le acompañan otros restos de hoja y punta que permiten suponer la presencia en La Atalaya de al menos cuatro espadas de hierro (Castiella, op cit.: 2005, fig. 109, conjunto 41).

Desgraciadamente, las espadas procedentes de La Atalaya no cuentan con un contexto estratigráfico o con conjuntos cerrados o asociados que permitan ajustar una cronología o su relación con el resto del ajuar de una determinada sepultura. No obstante, debe descartarse la idea de la ausencia de armas en La Atalaya $\mathrm{y}$ es seguro que futuras revisiones todavía podrían aumentar el número de ejemplares conocidos, lo cual permite encuadrar la cronología de estas piezas a partir del siglo $\mathrm{V}$ a. C., incluyendo en dicha cronología los restos documentados en Busal I. Las piezas de armamento recuperados en la necrópolis del Castillo de Castejón, de las que sólo se ha publicado un avance (Faro et alii: 2002-2003, 69-71), representan un panorama mucho más rico. La presencia de armas ofensivas y defensivas, con hallazgo de puntas de lanza y regatones, soliferra, cuchillos afalcatados, una falcata de clara filiación ibérica y varios tipos de espadas, supone la constatación de una realidad ya documentada en necrópolis correctamente excavadas, destacando la presencia de una espada maciza de La Tène y empuñadura de espiga, cuya fisonomía es prácticamente idéntica a la documentada en La Atalaya (Faro et alii, op. cit.: 2002-2003, 71).

Las referencias al origen centroeuropeo y a los modelos de La Tène como precedentes de este tipo de espadas de hierro de las necrópolis navarras o de la de Busal I, son constantes en la bibliografía, si bien defienden un origen peninsular para este tipo de modelos (Quesada y Farnié, op. cit.: 2009). No obstante, los nuevos hallazgos y sus paralelos con piezas similares bien conocidas de las necrópolis francesas del sudeste entre los siglos VII y VI a. C. (Dedet y Marchand: 2015, figs. 11 y 13), o de las necrópolis tumulares de Aquitania, de la región de Arcachon (Mohen y Coffyn: 1970, planches XXII-XXIII), permiten al menos plantear unas claras relaciones tipológicas y cronológicas entre los ejemplares franceses y navarros que deben valorarse en su justa medida (Castiella y Sesma, op. cit.: 1988-89, 385).

En lo que se refiere a los objetos de bronce, se recuperaron algunas piezas identificables, destacando dos fragmentos de fíbulas, varios fragmentos de brazaletes de sección cuadrada u ovalada, un brazalete completo cerrado y de sección rectangular o acintada, junto a un anillo, una campanilla, un remache y dos discos perforados (fig. 47), todo ello bastante común en las necrópolis de incineración de la Edad del Hierro del valle del Ebro, desde el siglo VII al siglo IV a. C (Royo: 2000, 55-56, fig. 9), siendo muy comunes en la necró- polis de Ballesteros en Épila (Pérez Casas: 1988), la de La Atalaya en Cortes (Castiella, op . cit.: 2005, 175186) o las de El Castejón de Arguedas, o El Castillo de Castejón (Faro et alii, op. cit: 2002-2003, 73-74). Tanto los fragmentos de brazaletes de sección cuadrangular, como los acintados (fig. 47, 3-5 y 8) son idénticos a los aparecidos en Corral de Mola, además de su presencia masiva en todas las necrópolis navarras de la Edad del Hierro, así como el anillo. En cuanto a las dos plaquitas discoidales perforadas (fig. 47, 9-10) parecen corresponder a unas piezas muy comunes, como así se comprueba en su aparición en Corral de Mola, aunque en este caso sólo se ha conservado un pequeño fragmento aparecido en el túmulo 1. Del ajuar broncíneo debemos destacar los dos fragmentos de fíbulas documentados, uno de ellos clasificado por Burillo como fíbula de bucle con puente romboidal y decoración troquelada de círculos concéntricos y puntos y el otro como fíbula de pie vuelto, éste último en mal estado de conservación que lo hace casi inclasificable (Burillo, op. cit.: 1977, 63, figs. 23 y 24) (fig. 47, 1-2). Respecto a la primera, de la documentación y descripción pormenorizada presentada en su día por Burillo, no debemos excluir otras posibles clasificaciones, especialmente la que identificaría la pieza como una fíbula de doble resorte con puente de placa romboidal decorada, con el resorte deformado, sobre todo teniendo en cuenta que es un tipo mucho más común en estas necrópolis, con una amplia cronología entre los siglos VI y IV a. C. (Navarro: 1970, 33, fig. 6 y 47 48, fig. 9; Royo: 1980, 281-282, gráfico III, mapa III; Argente: 1994, 105, cuadro 3). Del análisis detallado de la pieza (fig. 47, 1), proponemos su adscripción al grupo de la fíbulas de doble resorte de puente con placa romboidal, o tipo IIIC de Argente, un tipo que por su cronología avanzada (Lorrio, op . cit.: 2005, 208, fig. 83), encajaría a la perfección con el ajuar recuperado en Busal I.

En cuanto a la interpretación de los restos citados, nos encontramos con una extensa necrópolis de incineración con estructuras tumulares cuya disposición y arquitectura nos son desconocidas debido a la destrucción por labores agrícolas del yacimiento. No obstante, a partir de los datos conocidos, tras identificar la presencia de un volumen considerable de piedras y lajas de arenisca, podemos suponer la existencia de un número considerable de túmulos de encachado pétreo, con posibilidad de existencia de cistas y con presencia de estelas de señalización. No sabemos nada ni del tipo ni de las dimensiones de dichas estructuras tumulares, pero contaban con ajuares funerarios compuestos por cerámica y metales que acompañan a la cremación que no sabemos si se realizó en el propio túmulo o en ustrina. La presencia de un fragmento de urna a torno y la decoración peinada, así como los collarinos decorados con digitaciones, permiten situar el conjunto en un 


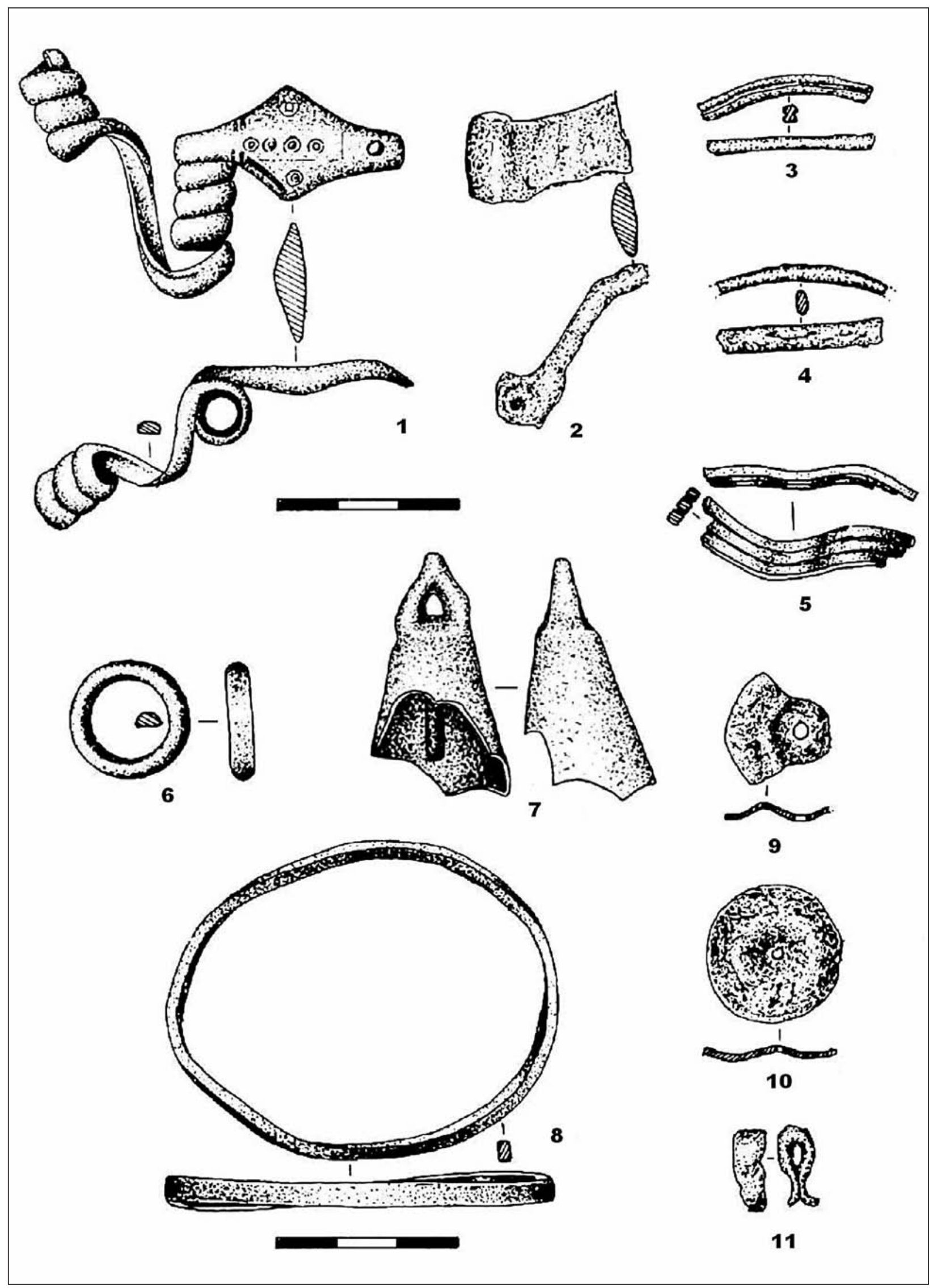

Fig. 47. Restos de ajuar metálico broncíneo recuperado de la necrópolis de Busal: 1, Fibula de doble resorte. 2, Fibula indeterminada. 3-5, fragmentos de brazalete de sección cuadrangular. 6, anillo. 7, campanilla.

8 , brazalete completo de sección acintada. 9-10, plaquitas discoidales perforadas. 10, posible remache. 
momento de transición de la $\mathrm{I}^{\mathrm{a}}$ a la $\mathrm{II}^{\mathrm{a}}$ Edad del Hierro, o dicho de otro modo, en un periodo situado entre los Campos de Urnas Tardíos o Hierro I Tardío y el Ibérico Antiguo, pudiendo ajustarse dicho momento, por sus paralelos con los materiales metálicos de necrópolis similares, como La Atalaya, El Castillo o El Castejón, a partir de la segunda mitad del siglo VI a. C. e incluso en la primera mitad del siglo V a. C. (Royo y Burillo: 1997, 127, fig. 6; Royo, op . cit.: 2000, 55-56), con lo que este cementerio debe situarse en una fase inmediatamente posterior al Corral de Mola.

\section{2. Otra posible necrópolis en el Campo de Uncastillo (Uncastillo, Zaragoza)}

Casi nada sabemos de esta necrópolis que en la actualidad sigue inédita. Su descubridor, D. Luis Pueyo Campos sólo dio la noticia de su existencia en una breve nota en la que sólo aporta su ubicación (Pueyo, op. cit: 1979, 222-223). En una visita al Museo de Zaragoza nos comentó algunas características de este lugar. Se localiza en una parcela roturada, junto al camino que conduce al Corral de Mola, en la orilla derecha del Barranco de Bastanes, muy cerca de su desembocadura con el río Riguel y del límite del término municipal de Layana, aunque todavía dentro del término de Uncastillo (fig. 2). Según los escasos datos aportados por su descubridor estaríamos ante otra necrópolis tumular de incineración, de la que sólo conocemos una posible pieza. Se trata de un pequeño broche de cinturón de placa perforada con tres garfios y decoración geométrica troquelada que el Sr. Pueyo llegó a enseñarnos personalmente. Tampoco sabemos nada del tipo de enterramientos existente, ni del estado de conservación del yacimiento, aunque lo hemos citado en este trabajo por tratarse con seguridad de otra necrópolis del mismo tipo que Corral de Mola o Busal I.

\section{Las Necrópolis Protohistóricas del Valle del Ebro (Un ESTAdo de la CUESTIÓN)}

El estudio de las necrópolis de incineración durante la Edad del Hierro en el valle del Ebro y las estructuras funerarias tumulares asociadas a éstas, ha sido abordado desde diferentes ópticas y con distintos planteamientos, al menos de forma continuada a partir de mediados del siglo XX. En la primera gran síntesis planteada por Almagro Basch (1952) se sistematizan los hallazgos conocidos hasta el momento, donde la cerámica acanalada, el fenómeno de la incineración y la arquitectura tumular se vinculan a las "invasiones célticas" y más concretamente a la cultura de los urnenfelder de Centroeuropa. Este planteamiento se vio complementado con el estudio realizado en el área catalana (Maluquer: 1945-46). El hallazgo de la necrópolis de Pajaroncillo en la serranía de Cuenca, permitirá a Almagro Gorbea plantear otras posibles interpre- taciones relacionadas con la arquitectura funeraria tumular del Bronce Final y $1^{\text {a }}$ Edad del Hierro en la Península Ibérica, aunque se mantiene la vinculación de los grupos tumulares del Noreste peninsular con las culturas centroeuropeas y su influencia directa en la difusión del ritual de la incineración y de la arquitectura tumular del N. E. peninsular (Almagro Gorbea: 1973, 101-122). Dicha teoría se mantendrá y sistematizará en posteriores trabajos, como el realizado sobre el Pic dels Corbs de Sagunto (Almagro Gorbea: 1977).

La aparición continuada en las necrópolis tumulares del Noreste peninsular, de significativos materiales vinculados al comercio mediterráneo, permitirá que algunos investigadores planteen nuevas teorías en las que la influencia orientalizante, básicamente relacionada con el comercio griego y fenicio, jugaría una importancia cada vez mayor, no sólo en la cultura material de los pueblos de la Edad del Hierro peninsular, sino también en sus prácticas funerarias e incluso en sus propias estructuras tumulares (Pellicer: 1982; 1987). Ya en los inicios del nuevo siglo, el propio Pellicer ha matizado en repetidas ocasiones sus opiniones, en las que manteniendo la importancia del elemento mediterráneo, plantea tres focos distintos de origen del ritual incinerador peninsular (Pellicer: 2008): Uno centroeuropeo que se extendería a través del Sureste francés, llegando hasta el valle del Ebro a partir del siglo IX a. C., otro mediterráneo oriental que afectaría a dos núcleos diferenciados el sureste y el Guadalquivir, proveniente del influjo fenicio, y un tercero que desde las islas británicas afectaría al suroeste peninsular, aprovechando el comercio atlántico de elementos metálicos (Pellicer, op . cit.: 2008, 25)

A partir de la década de los 80 y durante los 90 del siglo XX, una serie de trabajos de síntesis, permitirán conjugar los influjos exteriores centroeuropeos y del sudeste francés, con los aportes culturales y materiales de procedencia mediterránea, en especial la fenicia y la griega, generando una "regionalización" de la cultura de los Campos de Urnas de la Península Ibérica en grupos netamente diferenciados, pero con elementos comunes (Ruiz Zapatero: 1985, 36-41; Maya: 1986). Entre los nuevos investigadores, cada vez cobra más fuerza el peso de la tradición indígena en el origen de la arquitectura funeraria tumular. En diversos trabajos se valoran las tradiciones autóctonas, al menos desde el Neolítico Final, pero con toda seguridad desde la Edad del Bronce, más o menos matizadas por las aportaciones ultrapirenáicas, pero también por la influencia mediterránea (Pellicer, op . cit.: 1987; Rovira y Cura: 1989; López y Pons: 1995; Royo, op . cit.: 1994-1996, 106).

Será a finales del siglo XX, cuando las necrópolis tumulares de la Edad del Hierro de las Cinco Villas, comiencen a ser conocidas en la bibliografía científica, tanto a través de estudios específicos (Royo, op. cit.: 
1997a; 1997b), como a partir de otros trabajos de síntesis en los que se abordarán algunos elementos concretos, como las estelas funerarias (Royo, op . cit.: 1994, 125) o el fenómeno tumular en los Pirineos, en donde se destaca la presencia de círculos de piedra o crómlech asociados a enterramientos de incineración (López y Pons, op . cit.: 1995, 116-117 y 121). En algún trabajo anterior, ya se habían descrito las características de algunas de estas necrópolis y su reparto geográfico que nos llevó a incluirlas en el Grupo I del valle medio del Ebro (Royo, op. cit.: 1992-93. 93, fig. 1). Posteriormente, dichas necrópolis quedarán incluidas en un subgrupo denominado I B en el que se incluyen las necrópolis tumulares de las Cinco Villas, junto a las de la Hoya de Huesca y las del río Gallego (Royo, op. cit.: 2000, 43, fig. 1).

En su trabajo monográfico sobre la necrópolis de El Calvari (El Molar, Tarragona), Castro (1994) hace una serie de consideraciones importantes sobre el origen del mundo tumular de la zona oriental del valle medio del Ebro, o dicho de otro modo, del Grupo del Segre, cuyas altas cronologías parecen relacionarse con la revisión al alza de los primeros Campos de Urnas centroeuropeos, aunque sin dejar de lado el componente autóctono, plenamente presente en la zona citada desde los inicios de la Edad del Bronce (Castro, op. cit.: 1994, 132-136).

Otros investigadores se centran en el análisis del mundo tumular situado en el Bajo Aragón. Algunos siguen apostando por las tradiciones indígenas y en especial por el megalitismo, como el posible origen del fenómeno tumular de los grupos del Segre-Cinca y del Bajo Aragón (Rafel: 2003, 72-73). En cambio, otros prefieren retomar las viejas ideas de Pellicer e insistir en un fenómeno generalizado, pero que cuenta con elementos tanto indígenas, como extrapeninsulares, siendo especialmente importantes los aportes mediterráneos (Fatás y Graells, op. cit.: 2010, 45-58). En este contexto los contactos entre el extremo del noreste peninsular, el Languedoc y el norte de Italia, especialmente la Liguria, parecen ser determinantes, como parece constatarse en las evidencias arqueológicas existentes desde el Bronce Final y muy especialmente con determinadas manifestaciones artísticas o artesanales presentes en la cerámica o en la metalurgia de este momento y los inicios de la Edad del Hierro en todo el Golfo de León, como muy bien han señalado Neumaier (2006, 157-163, figs.4, 6 y 7) y otros autores con posterioridad (Graells, op. cit.: 2011 y 2014).

Por otra parte, el estudio de algunos conjuntos sepulcrales catalanes, como la necrópolis de Can Piteu/Can Roqueta (Sabadell), han permitido a López Cachero realizar una profunda revisión del tema del ritual funerario y de la dualidad campos de túmulos/campos de urnas (López Cachero: 2005). Este investigador plantea nuevas dinámicas en el proceso, como el hecho de la generalización de la incineración en el Bronce Final, lo que plantea una clara ruptura con el mundo de la Edad del Bronce, así como el hecho de que la incineración, los túmulos y la cerámica acanalada no son coetáneos ni en el tiempo ni en el espacio, lo que provoca una crítica nítida al concepto de "Cultura de los Campos de Urnas", proponiendo una clara comarcalización de las distintas comunidades protohistóricas en función del control y del aprovechamiento del territorio (López Cachero: 2007, 102-105). A partir de dichos supuestos, también se cuestionan otros elementos de discusión, como la supuesta coexistencia de necrópolis de campos de túmulos y de campos de urnas. Para López Cachero, tanto el ritual de la incineración como el fenómeno tumular están generalizados a partir del B. F. III, lo que ocurre es que no en todas las necrópolis se conserva la cubierta tumular, hecho especialmente reconocido en el área catalana, y además hay un gran cantidad de variaciones territoriales en función de distintas tradiciones autóctonas o de disponibilidad de materia prima (López Cachero: 2008, 144-148).

Por otra parte, la excavación de nuevas necrópolis y la revisión de viejos conjuntos funerarios en el área navarra del Ebro medio, han permitido contemplar un panorama bastante más complejo y dinámico de lo que hasta la fecha se había planteado. La excavación de las necrópolis de El Castejón de Arguedas (Castiella y Bienés: 2002), del Castillo de Castejón (Faro et alii: 2002-2003), y la revisión de la necrópolis de La Atalaya de Cortes de Navarra (Castiella, op. cit.: 2005), todas ellas similares a las necrópolis presentes en la comarca de las Cinco Villas (Royo, op . cit.: 2000, 41, fig. 1; Faro y Unzu: 2006, 151, fig. 5), permite hoy en día abordar el estudio de este grupo, clave para estudiar el paso de las sociedades rurales de la I ${ }^{\mathrm{a}}$ Edad del Hierro a las estructuras sociales formadas por aristocracias guerreras ibéricas y celtibéricas (Royo, op. cit.: 2005, 162).

En este sentido, la síntesis realizada por Armendáriz sobre el poblamiento del primer milenio a. C. en Navarra (Armendáriz, op. cit.: 2008) aborda una actualización del conocimiento de las necrópolis de dicha región, incluidas en nuestro Grupo I. Al igual que ocurre en algunas comunidades protohistóricas del valle medio del Ebro (Royo, op. cit.: 2005, 161, fig. 63), el poblamiento de la $\mathrm{I}^{\mathrm{a}}$ Edad del Hierro en la Navarra baja y media se concentra en las orillas del Ebro y las áreas bajas de sus afluentes principales, adoptando una economía basada en la producción cerealista y en la creación de una tupida red de poblados que controlan el territorio a los que se asocian las necrópolis de incineración, en un entorno cercano que permite su ubicación dentro del campo visual del poblado (Armendáriz, op . cit.: 2008, 181-183). Para Armendáriz, la adopción de la arquitectura tumular y 
del ritual incinerador se generaliza en la región desde los inicios de la Edad del Hierro, aunque la ausencia de dataciones absolutas sólo permite situar las principales necrópolis tumulares navarras en la fase plena de este periodo, entre los siglos VI-V a. C. Armendáriz documenta una clara diferencia entre las necrópolis tumulares de la Navarra baja y media, con cementerios con numerosos enterramientos con estructuras pétreas con cantos y adobes y los restos funerarios de la montaña y tierras altas, donde la economía de base ganadera y la cultura pastoril, permite la pervivencia de los círculos de piedras hincadas o crómlechs, de evidente tradición megalítica, en una clara dualidad entre las tierras bajas agrícolas y las tierras altas ganaderas (Armendáriz, op . cit.: 2008, 184-186), algo que también hemos constatado entre las tierras bajas y altas de las Cinco Villas zaragozanas. Por último, la presencia de tumbas "principescas" con presencia de ajuares de gran riqueza, así como armamento, elementos de banquete funerario y piezas procedentes del comercio mediterráneo, permiten a este autor plantear la presencia de élites guerreras o de caballería, cuya iconografía permite rastrear los primeros síntomas claros de diferenciación social en la fase plena de este momento (Armendáriz, op . cit.: 2008, 186-188).

Insistiendo en el tema de la desigualdad social y su reflejo en las necrópolis y sus ajuares funerarios, Ruiz Zapatero plantea una serie de cuestiones para valorar correctamente dichas diferencias (Ruiz Zapatero: 2004). En primer lugar, teniendo en cuenta la pobreza metalogenética del valle del Ebro durante el Bronce Final y el valor del atesoramiento de piezas elaboradas, se plantea cuatro criterios básicos para poder definir dicha desigualdad: La arquitectura funeraria y el esfuerzo necesario para la construcción de una sepultura tumular, el ritual utilizado, el ajuar funerario y los propios restos humanos incinerados (Ruiz Zapatero, op, cit.: 2004, 294-299, fig. 2). A partir del análisis de dichas premisas, insiste en la pobreza de los ajuares metálicos en la fase antigua del Hierro I (750/650 a. C.) en el sector oriental del valle medio del Ebro, en las necrópolis de Los Castellets II o en la fase III de Roques de Sant Formatge (Ruiz Zapatero, op. cit.: 2004, 311-312), aunque algunos casos como Coll del Moro o El Calvari, parecen contar hacia el final de dicho periodo con algunas sepulturas singulares (Ruiz Zapatero, op . cit.: 2004, 315-319). A partir del siglo VII y sobre todo en el VI se constataría una clara diferenciación social y de género en los ajuares funerarios, con presencia de armamento asociado a tumbas masculinas y adornos a las femeninas, destacando el papel de las élites ecuestres a través de la presencia o representación del caballo, en La Pedrera -frenos y bridas-, Les Ferreres -soporte- o El Castillo -tapaderas cerámicas con prótomo de caballo-, como fiel reflejo del ascenso social y económico de determinadas élites guerreras que manifiesta una fuerte homogeneidad cultural entre el Herault y el norte del País Valenciano (Ruiz Zapatero, op. cit.: 2004, 320-326). Este mismo investigador plantea que las fuertes relaciones entre el nordeste de la Península Ibérica y el sur de Francia y norte de Italia, a partir de finales del Bronce Medio (Ruiz Zapatero: 2013, 642), fueron un factor decisivo en la expansión y generalización del ritual de la incineración, al que asocia la presencia de cerámica acanalada, para a partir del Bronce Final III convertirse dicho ritual en el modo de enterramiento exclusivo en grandes necrópolis convertidas en elementos claves en la construcción del paisaje de la Edad del Hierro (Ruiz Zapatero, op. cit.: 2013, 651-652).

En los últimos tiempos algunos investigadores han planteado nuevas metodologías de estudio para los diferentes grupos de necrópolis tumulares existentes en el noreste de la Península Ibérica y el sur de Francia, intentando establecer concordancias y divergencias entre los diferentes grupos culturales identificados entre los ríos Garona y Ebro (Adroit: 2014, 204, fig. 1). Tradicionalmente las comparaciones se han realizado en gran medida a partir de la cultura material y especialmente del ajuar funerario, pero éste es inseparable de todo el proceso que lleva a la construcción de un enterramiento, o como se ha definido, de "las cadenas operativas de las prácticas funerarias” (Adroit, op . cit.: 2014, 206). A partir de la definición de una cincuentena de criterios relacionados con el tipo de construcción funeraria, su tamaño, el ritual y el ajuar, y su aplicación a una importante selección de yacimientos bien documentados repartidos en la zona definida, se han establecido una serie de agrupaciones repartidas entre el Bronce Final III B y el Hierro I Reciente, resultando entre otros, la convergencia de criterios similares entre varios yacimientos del Bajo Aragón, Pirineos Centrales y Corral de Mola (Adroit, op. cit:: 2014, 212-213, fig. 6).

Los nuevos estudios vienen insistiendo en los cambios producidos en las poblaciones de la Edad del Hierro por el impacto de las colonizaciones y el comercio mediterráneo, no sólo con fenicios y griegos, sino de forma muy especial con el norte de Italia. De este modo, se han publicado trabajos en los que se analizan ajuares espacialmente lujosos o con presencia de armamento y otros elementos relacionados con élites guerreras, tanto al otro lado de los pirineos (Dedet y Marchand: 2015), como en el noreste peninsular (Graells: 2011; 2013), lo que se ha relacionado con un proceso cultural y económico de cambio y asimilación por parte de las élites dominantes indígenas de los estímulos y rituales mediterráneos.

Además de los grupos de necrópolis tumulares de incineración del valle del Ebro, en la última década se han realizado excavaciones en zonas geográficas aledañas a ésta, como el reborde de la Meseta, o el Alto Maestrazgo, dando como resultado el descubrimiento 
de conjuntos funerarios claramente emparentados con los grupos del Ebro. Tal sería el caso de la necrópolis de Herrería (Guadalajara), en cuyas fases I y II aparecen inhumaciones e incineraciones bajo túmulo en fechas absolutas similares a las establecidas para el grupo del Segre-Cinca (Cerdeño: 2008, 98-100, tabla 2). En este sentido, el descubrimiento y excavación de la necrópolis tumular de Sant Joaquim de la Menarella (Forcall, Castellón), aporta estructuras tumulares del siglo VII a. C. muy similares a las del Bajo Aragón y Bajo Segre y ajuares funerarios asimilables a las culturas del Hierro I del valle del Ebro, siendo especialmente importante su vinculación al grupo de necrópolis del Matarraña y Guadalope (Vizcaíno: 2010, 159161, fig. 1). Esta penetración de elementos materiales y rituales vinculados a la incineración y a la denominada cultura de los Campos de Urnas del Noreste, se ha comprobado en distintos yacimientos de la costa mediterránea, llegando incluso hasta el Sudeste de la Península Ibérica, en este caso, con reutilizaciones de tumbas megalíticas, fenómeno también constatado en el Noreste peninsular (Lorrio: 2009-2010).

En resumen, el fenómeno de los enterramientos de incineración bajo túmulo no corresponde a una sola corriente cultural, ni es uniforme para un territorio como el valle del Ebro, sino que refleja un mundo más complejo y dinámico, aunque también compartimentado geográficamente. En dicho territorio, las diferentes comunidades indígenas del Hierro I, asimilaron dichas tradiciones tumulares autóctonas prehistóricas, en la confluencia del Segre con el Ebro (Mequinenza) desde el Neolítico Final y en el resto del valle medio del Ebro desde los inicios de la Edad del Bronce, coexistiendo en muchos casos con la influencia de los estímulos externos desde Centroeuropa y Sudeste francés a partir del Bronce Final y desde el propio Mediterráneo o Aquitania a partir de la I Edad del Hierro. Los últimos estudios de las necrópolis del Bajo Ebro (Fatás y Graells, op. cit.: 2010, 45-58), Cataluña (Pons: 2012), o sur de Francia (Adroit, op . cit.: 2014), apuntan en esa dirección y no hacen más que corroborar que la arquitectura funeraria tumular es un hecho generalizado que afecta a todo el Noreste peninsular, al menos desde el Bronce Final, extendiéndose hacia la Meseta y la costa mediterránea desde fechas muy tempranas (Rovira et alii: 2012).

\section{Corral de Mola y Su contexto geográfico y CULTURAL}

\section{1. Arquitectura tumular e incineración: Las necrópolis del sector occidental del Ebro Medio}

Hay dos elementos definidores que aglutinan a todas las necrópolis de la Edad del Hierro del área occidental del valle medio del Ebro, refiriéndonos solamente a las necrópolis de la mitad occidental de la provincia de Zaragoza y del extremo oriental de Navarra: Por un lado la presencia sistemática de estructuras tumulares en los enterramientos y por otro la existencia exclusiva del ritual de la incineración.

A tenor de lo expuesto hasta ahora, Corral de Mola se identifica plenamente con las necrópolis tumulares de incineración fechadas entre los siglos VIII-VII y V a. C. en el sector occidental del valle medio del Ebro, es decir, con los yacimientos incluidos en nuestro Grupo I (Royo, op. cit.: 2000, 41-43, fig. 1) (fig. 48). Refiriéndonos a su arquitectura funeraria, los grandes túmulos de encachado pétreo son muy comunes en todas las necrópolis de la comarca de las Cinco Villas, destacando en Arroyo Vizcarra, en el embalse de Yesa, Los Pedregales de Urriés, o Finca de la Casiana, en Ejea de los Caballeros, esta última todavía inédita, donde los túmulos de empedrado pueden alcanzar dimensiones entre los 6 y los 9 metros de diámetro. Las incineraciones in situ se han documentado en la necrópolis de Arroyo Vizcarra (Royo, op . cit.: 1997 a, 51), yacimiento en el que existe una auténtica organización del espacio funerario de la necrópolis, con varias agrupaciones de sepulturas de una riqueza tipológica notable, presencia sustancial de grandes estelas y combinando el encachado pétreo con la presencia de cistas o cámaras de adobes cocidos (Royo y Fatás, op. cit.: 2017). De tipología y cronología similares y con presencia de estelas decoradas podemos citar la necrópolis del Barranco de la Paúl en el municipio de los Pintanos, junto al río Aragón y el embalse de Yesa (Royo, op . cit,: 1997 b, 266, figs. 6-7). La arquitectura funeraria de estas dos necrópolis permite constatar dos tipos de enterramientos con ritual de incineración: auténticos túmulos con encachados de piedras, y estructuras realizadas con círculos de piedras (Royo, op. cit.: 1997 a, 52-54, figs. 6 a 8), asimilables a los crómlech de los pirineos occidentales (López y Pons: 1995, 116-117) y a las culturas pastoriles trashumantes de esta zona montañosa (Peñalber: 2005, 310-311). La cronología de ambos conjuntos debe situarse junto a la de Busal I, a partir de mediados del siglo VI y durante todo el siglo $\mathrm{V}$ a. C., aunque no disponemos de ninguna datación radiocarbónica.

En cuanto a las necrópolis de la Navarra oriental: La Atalaya de Cortes, La Torraza de Valtierra, El Castejón de Arguedas y el Castillo de Castejón, también cuentan con una arquitectura tumular, aunque ésta presenta notables diferencias en cuanto a los materiales utilizados en su confección. La ausencia de rocas en la cubeta central del Ebro, obligaría a la utilización de las material primas más disponibles, como el barro y los cantos rodados, dando lugar a unas construcciones funerarias realizadas exclusivamente en adobe, como en el caso del Castejón de Arguedas (Castiella y Bienés, op. cit.: 2002, 128-130, fig. 174) o de forma 
mixta, con cantos rodados para el túmulo y adobes para la cámara o cista, como en el caso del Castillo de Castejón (Faro et alii, op. cit.. 2002-03, 55-60; Pérez Casas: 1987). La posibilidad de que las necrópolis de La Torraza de Valtierra o La Atalaya de Cortes sean auténticos campos de urnas, como se ha citado en repetidas ocasiones (Castiella y Tajadura: 2001, 204-206), debe ya descartarse definitivamente ante la presencia evidente de estructuras tumulares de adobes, mal interpretada en su día en el caso de La Atalaya como "pequeño horno para facilitar la aireación de la pira" (Maluquer y Vázquez, op. cit.: 1956, 9-10, fig. 1). Algo similar sucede con La Torraza, donde las escasas evidencias apuntan en esa dirección (Maluquer: 1957, 247-249). Otras necrópolis mal conocidas como La Ra en Arroniz y algunas inéditas, confirman el uso sistemático de la arquitectura tumular y del ritual incinerador (Armendáriz, op . cit.: 2008, 182-183).

Es evidente que la economía de medios y la presencia o no de materia prima litológica, debió suponer un hándicap para la construcción de grandes monumentos funerarios pétreos, como se constata en áreas junto al Ebro o en sus afluentes, como es el caso del río Huecha o del Jalón. En el primer caso, se ha identificado la presencia de túmulos de adobe en las necrópolis de Burrén y Burrena (Royo y Pérez: 1987: 208; Royo, op. cit.:1986,50) y El Quez, aquí combinando su presencia con túmulos de cantos rodados (Royo, op . cit.:1986, 49). En el Bajo Jalón se han estudiado en la necrópolis del Cabezo Ballesteros, donde aparecen sistemáticamente estructuras tumulares de adobe, tanto circulares como cuadradas (Pérez Casas, op. cit.: 1987), aunque también combinándose con estructuras pétreas de pequeños cantos de yeso (Pérez Casas: 1988). Ni en las necrópolis navarras ni en las aragonesas se ha evidenciado la presencia de elementos lígneos, probablemente por su desaparición o por falta de una metodología depurada en el proceso de excavación y documentación.

Otras necrópolis pertenecientes a este Grupo I, serían las localizadas en el río Gallego y en el curso bajo de La Huerva (Royo, op . cit.: 2000, fig. 1) las cuales se localizan en el límite oriental de dicho grupo. Aunque en su mayoría no se han excavado, citaremos la documentada en pleno casco urbano de Huesca, en la Avenida Martínez de Velasco, una necrópolis tumular con encachados pétreos y ritual de incineración que guarda relación con las necrópolis de las Cinco Villas zaragozanas (Juste: 1993; Royo, op . cit.: 2000, 43). En el río Huerva destaca la casi desconocida necrópolis del Lugar Viejo de María de Huerva (Burillo: 1981, 64-74). A tenor de los datos disponibles, los límites geográficos de nuestro Grupo I deben señalarse entre los ríos Gallego y Huerva hacia el Este y el río Aragón y Arga hacia el oeste, mientras que los límites norte y sur debemos señalarlos en los somontanos pirenaico e ibérico (fig. 48).

\section{2. Otras necrópolis tumulares similares del valle del Ebro y zonas limítrofes}

Las necrópolis de este Grupo I del Ebro Medio mantienen estrechas relaciones materiales, rituales o de arquitectura funeraria con otros conjuntos del valle del Ebro y zonas aledañas (fig. 49). En este sentido, señalaremos algunas necrópolis y los elementos que pueden asimilarse o relacionarse con el Corral de Mola o el resto de necrópolis de las Cinco Villas y de la Navarra oriental.

Las necrópolis del Alto Ebro (fig. 49) adolecen de estudios detallados que permitan comparaciones exhaustivas, pero no obstante, conocemos un número significativo de yacimientos, como Miraveche, Arce Mirapérez, La Cascajera, Etxauri, La Redonda o La Hoya, entre otras (Llanos, op . cit.: 1990, fig. 1). Estos conjuntos carecen de estructuras tumulares seguras, aunque si cuentan con cistas y ritual incinerador, así como posibles estelas de señalización, vinculándose todas ellas al mundo de la Meseta norte y al fenómeno celtibérico (Llanos, op. cit.: 1990, 144-145). Tanto los ajuares metálicos, con un numeroso conjunto de armas, fíbulas de La Tène o broches de cinturón de placa, como su cronología, entre los siglos V y III a. C. (Llanos, op . cit.: 145-146, figs. 2-4), permiten asimilar estos ajuares a las necrópolis celtibéricas de la meseta norte, pero también a las fases más modernas de la necrópolis del Castillo de Castejón, también con presencia de armas y elementos de banquete vinculados posiblemente a alguna sepultura singular o principesca (Faro, op . cit.: 2015, 103).

De las necrópolis celtibéricas de los ríos Jiloca, Alto Jalón y Alto Tajo y Duero, muy numerosas, solo citaremos como representativas La Umbría de Daroca, Herrería III, Carratiermes, o Griegos, esta ya muy alejada de los conjuntos anteriores. Interesa destacar la necrópolis de La Umbría de Daroca, en el Bajo Jiloca, afluente del Jalón, por tratarse de un yacimiento en el que se han documentado hasta cuatro niveles de enterramientos, de los que el más antiguo, el nivel $\mathrm{D}$, se correspondería con las necrópolis más avanzadas de nuestro Grupo I. En esta fase se documentan enterramientos tumulares de incineración con cerámicas plenamente identificadas con la tipología del Hierro I del valle medio del Ebro (Aranda, op . cit.: 1990, 104-105, fig. 2) y ajuares metálicos en los que aparecen fíbulas de doble resorte con puente acintado y broches de cinturón de un garfio y escotaduras laterales fechados a partir del fines del siglo VI y durante el siglo $\mathrm{V}$ a. C. (Aranda, op . cit.: 1990, 109, fig. 5). La fase III de la necrópolis de Herrería también presenta claros paralelismos con los cementerios protohistóricos del valle medio del Ebro, tanto por el uso del rito de la incineración bajo túmulo con algún elemento de señalización del tipo estela, como de un ajuar muy similar (Cerdeño y Sagardoy, op. cit.: 2007, 120-122, tablas 7 y 8), en 


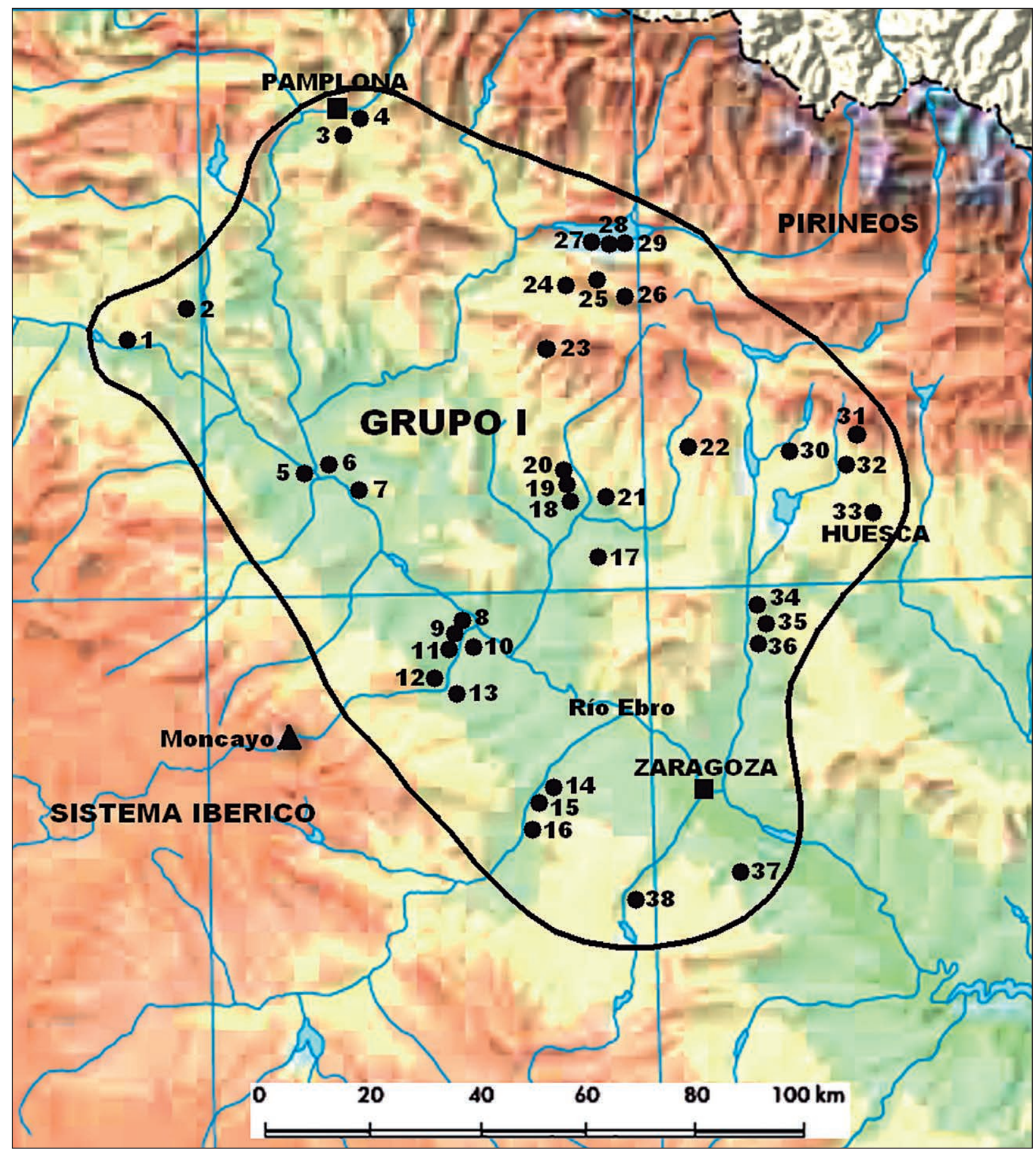

Fig. 48. Delimitación y localización geográfica del Grupo I de las necrópolis tumulares de incineración de la Edad del Hierro, conocidas en el sector occidental del valle medio del Ebro: 1, El Rincón (Mendavia, Navarra). 2, La Ra (Arróniz, Navarra). 3, La Playa Grande (Pamplona, Navarra). 4, Lezana (Pamplona, Navarra)). 5, El Castillo (Castejón, Navarra).

6, La Torraza (Valtierra, Navarra). 7, El Castejón (Arguedas, Navarra). 8, La Atalaya (Cortes, Navarra). 9, Mallén (Mallén, Zaragoza). 10, Burrén y Burrena (Fréscano, Zaragoza). 11, Carraveruela (Magalllón, Zaragoza). 12, Cabezo de las Viñas (Albeta, Zaragoza). 13, El Quez (Alberite de San Juan, Zaragoza). 14, San Sebastián (Urrea de Jalón). 15, Barranco de la Peña (Urrea de Jalón, Zaragoza). 16, Cabezo de Ballesteros (Épila, Zaragoza). 17, Valseca (Ejea de los Caballeros, Zaragoza). 18, Campo de Uncastillo (Uncastillo, Zaragoza). 19, Corral de Mola (Uncastillo, Zaragoza). 20, Busal (Uncastillo, Zaragoza). 21, Finca de la Casiana (Ejea de los Caballeros, Zaragoza). 22, La Tiñica (Luna, Zaragoza). 23, El Salado (Sos del Rey Católico, Zaragoza). 24, La Pardina (Urriés, Zaragoza). 25, Los Pedregales (Urriés, Zaragoza). 26, Barranco de la Paúl (Los Pintanos, Zaragoza). 27, Valles II (Undués de Lerda, Zaragoza). 28, La Salada I (Urriés-Ruesta, Zaragoza). 29, Arroyo Vizcarra (Urriés-Ruesta, Zaragoza). 30, Betance (Bolea, Huesca). 31, Castilsabás (Loporzano, Huesca). 32, Castillón (Puybolea, Huesca). 33, Avenida Martínez de Velasco (Huesca, Huesca). 34, Perellés (Leciñena, Zaragoza). 35, Pontarrón (Leciñena, Zaragoza). 36, Replano II (Leciñena, Zaragoza). 37, Los Castellazos (Mediana de Aragón, Zaragoza). 38, Lugar Viejo (María de Huerva, Zaragoza). 


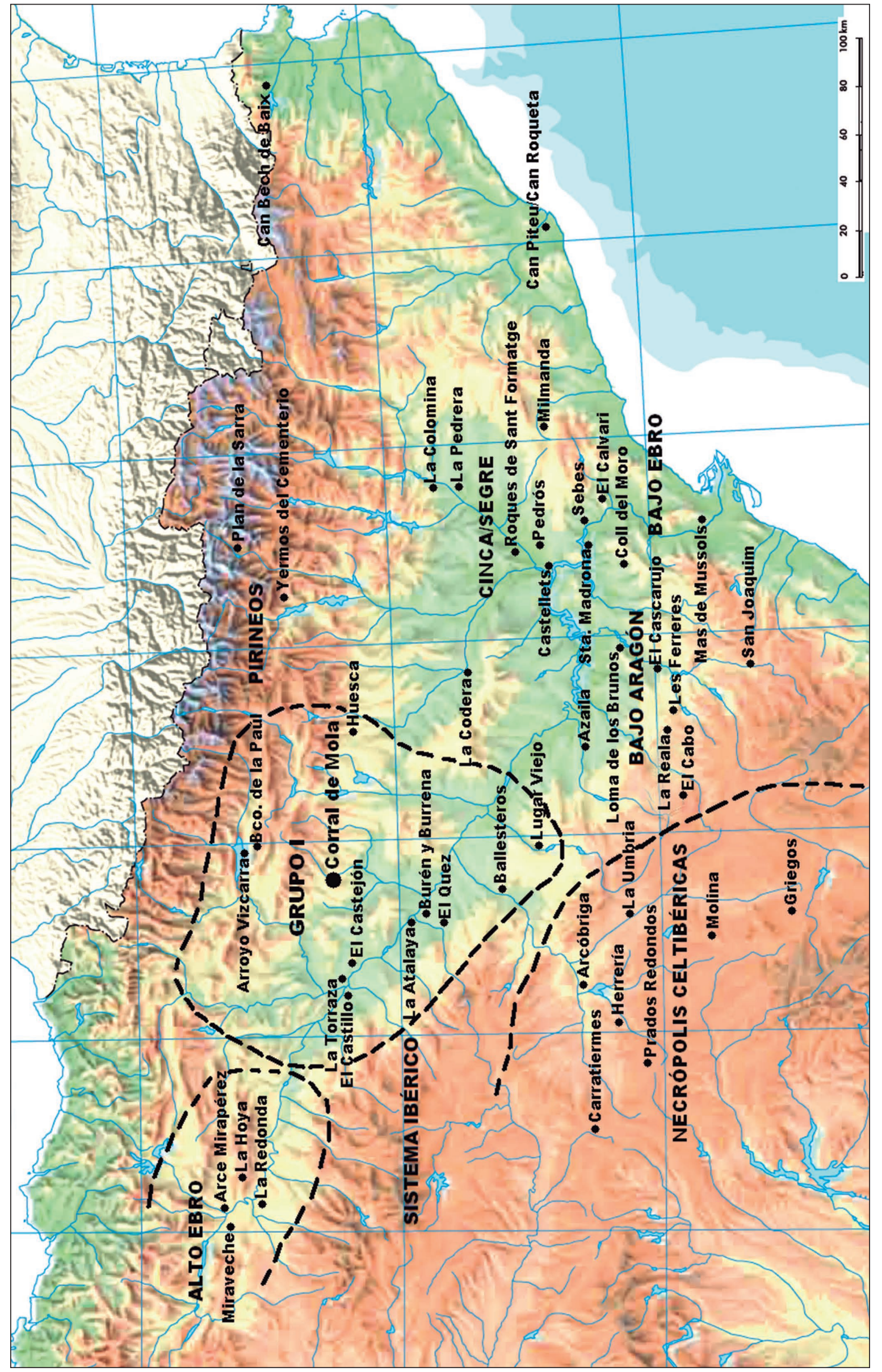


este caso representado por las fíbulas de doble resorte de puente acintado, los broches de cinturón de un garfio y escotaduras laterales y los brazaletes abiertos aislados o agrupados (Cerdeño y Sagardoy, op . cit.: 2007, fig. 295).

Algo similar ocurre en la fase más antigua de la necrópolis de Carratiermes, denominada como "protoceltibérica", donde son generalizados los enterramientos de incineración en hoyo bajo cubierta tumular y en varios casos con presencia de estela señalizadora (Argente et alii., op . cit.: 2000, 48-50). La cerámica manufacturada de Carratiermes presenta muchos paralelos con los tipos del Hierro I del valle medio del Ebro (Argente et alii., op . cit.: 2000, fig. 59), así como algunos ejemplares metálicos del ajuar funerario, entre los que destacan las fíbulas de doble resorte con puente decorado, los broches de cinturón de un garfio y escotaduras laterales y los brazaletes abiertos de sección acintada (Argente, et alii., op. cit.: 2000, figs. 43, 47 y 51). Por lo que respecta a la necrópolis del Cuarto de Griegos, tanto los trabajos previos (Almagro Basch: 1942), como los recientemente publicados (Chordá et alii.: 2013-14), apuntan hacia un cementerio protohistórico de cronología antigua, caracterizado por sus enterramientos de incineración en hoyos protegidos o rodeados por piedras y sin estelas que no permiten aseverar la presencia de auténticos túmulos (Chordá et alii, op . cit.: 2013-14, 234-235). Los ajuares recuperados en las excavaciones más recientes remiten a urnas y vasos manufacturados muy similares a los del valle medio del Ebro y brazaletes abiertos idénticos a los del Corral de Mola (Chordá et alii., op . cit.: 2013-14, figs. 8, 911 y 13), aunque entre los ajuares de los hallazgos más antiguos también se confirma la presencia de cantidades considerables de brazaletes abiertos y algún broche de cinturón de un garfio y escotaduras laterales (Almagro Basch, op. cit.: 1942, figs 3 y 5).

Algunas necrópolis del Hierro de la margen derecha del Ebro medio se encuentran a caballo entre las clasificadas en nuestro grupo I y las del Bajo Aragón, participando de elementos y características comunes a ambos grupos. Como más representativas citaremos las de Azaila, El Cabo y la sepultura de guerrero de Les Ferreres. La necrópolis de Azaila -Teruelcuenta con dos fases de utilización, de las que la primera se caracteriza por sus enterramientos tumulares de incineración, de planta circular o cuadrada con una variada tipología (Beltrán Lloris: 1976 b, figs.16 y 18), cuyos ajuares metálicos, no demasiado abundantes, y su cerámica parecen paralelizarse con las necrópolis del Grupo I del Ebro Medio (Beltrán Lloris: 2013, 168-172). La pequeña necrópolis de El Cabo de Andorra -Teruel- (Benavente et alii: 2015), ha permitido documentar seis túmulos de encachado pétreo y planta circular, con enterramientos de incineración femeninos y cuyos ajuares cerámicos remi- ten a modelos del Bajo Aragón y áreas vecinas -Azaila-. Su ajuar metálico, compuesto por fíbulas de doble resorte, torques y arracadas, cadenas, anillas y un botón semiesférico, permite fechar todo el conjunto entre finales del siglo VII y el primer cuarto del siglo VI a. C. (Benavente et alii, op . cit.: 2015, 150), una datación semejante a la que proponemos para el Corral de Mola. La sepultura aislada de incineración de Les Ferreres, conocida por el hallazgo de un magnífico soporte broncíneo o thymaterion como denominó en un primer momento su primer estudioso (Cabré: 1942), manifiesta un enterramiento excepcional cuyo ajuar metálico, compuesto por el citado soporte, dos espadas, una coraza, un simpulum, un pátera de tipología etrusca y posiblemente dos cnémides, todo ello fechado a mediados del siglo VI a. C., representa el ascenso social y económico de las élites guerreras en el tránsito del Hierro I a la cultura Ibérica en el Bajo Aragón y el atesoramiento de diversos elementos de prestigio de origen mediterráneo (Graells y Armada: 2011, 32-34, fig. 5), cuyos paralelos más evidentes podemos situar en la tumba de guerrero de Llinars del Vallès -Barcelona(Sanmartí: 1993).

El grupo compuesto por las necrópolis de los ríos Alcanadre, Cinca y Segre es quizás uno de los más numerosos y conocidos, con una significativa presencia de necrópolis tumulares cuyo origen puede remontarse hasta el Bronce Final I, por encima del 1.250 a. C. cal BC, como se evidencia en el túmulo 14 de Los Castellets II (fig. 42), pero cuya perduración puede seguirse en algunos casos hasta bien entrado el Ibérico Antiguo y Medio, hacia el 500/450 a. C. De este grupo señalaremos las necrópolis de La Codera, La Pedrera, La Colomina, Roques de Sant Formatge, Pedrós y Los Castellets I y II (Royo, op. cit.: 2000, 43, fig. 1) (fig. 49). Es por el momento el único grupo de todo el valle del Ebro donde puede estudiarse todo el proceso crono-cultural del origen, desarrollo y posterior evolución de las necrópolis tumulares con rito generalizado de incineración, salvo el caso excepcional de Los Castellets II y sus enterramientos tumulares con inhumaciones simples o colectivas, con influencias claras de la región pirenaica y del Languedoc (Royo: 1992-93, 95). Los enterramientos y sus ajuares son bastante pobres, al menos durante el Bronce final y los momentos iniciales del Hierro I, con presencia de la urna funeraria, en algún caso con un vasito de ofrendas y muy poco material metálico, casi todo él en bronce (Royo, op. cit.: 1992-93, 96). En los momentos avanzados de la Edad del Hierro y sobre todo a partir de los siglos VII-VI a. C. los ajuares se harán más ricos, como se constata en la necrópolis de La Pedrera, donde abundan las fíbulas de doble resorte, los broches de cinturón de un garfio y escotaduras laterales 
del tipo Fleury, junto a torques de tampones, y otros elementos definidores como la estela antropomorfa (Maya: 1990, 361 y 365).

En cuanto a las necrópolis localizadas en el Bajo Aragón, entre los ríos Guadalope, Matarraña y Algas (fig. 49), definido como grupo 3B dentro de nuestra clasificación para el valle medio del Ebro (Royo, op . cit.; 2000, 43, fig. 1), a partir de los trabajos previos de principios del siglo XX realizados por el Institut de Estudis Catalans (Rafel: 2003) y de trabajos posteriores, recientemente se han definido sus características principales (Graells y Fatás, op . cit.: 2010, 45-74, fig. 1. 2), identificadas gracias al estudio de las necrópolis de Coll del Moro de Gandesa (Rafel, op. cit.: 1989 y 1991), La Loma de los Brunos en Caspe (Eiroa, op. cit.: 1982), o El Cascarujo, La Reala o San Martín de Alcañiz (Benavente et alii: 2012, 41-46, figs. 2-10). La característica más sobresaliente de este grupo de necrópolis es su arquitectura funeraria, compuesta por pequeños cementerios con estructuras tumulares de planta circular y grandes cistas excéntricas, casi megalíticas en algunos casos, junto a un ritual generalizado de incineración y un ajuar funerario en general pobre, similar a la cultura material de las necrópolis del Hierro I de la margen derecha del Ebro Medio. Aunque los orígenes de esta tradición tumular con grandes cistas no están del todo claras (Graells y Fatás, op . cit.: 2010, 46-48), lo cierto es que junto a este grupo existen evidencias de una larga tradición tumular que arranca desde el Neolítico, perdura durante la Edad del Bronce y llega hasta el Hierro I, como hemos demostrado en las pervivencias megalíticas de la desembocadura del Segre en el Ebro, en la necrópolis neolítica del Barranco de la Mina Vallfera, la tumba megalítica del Bronce Medio de Riols I y los túmulos megalíticos del Bronce Final de Los Castellets II, todas ellas en la localidad de Mequinenza (Royo, op. cit.: 1994-96, 106). En este sentido, parece extenderse la influencia de estas necrópolis tumulares bajoaragonesas a algunas necrópolis del Alto Maestrazgo, como se ha constatado en la de Sant Joaquim de la Menarella -Forcall, Castellón-, donde podemos ver una arquitectura tumular y una cultura material muy similar, tanto en lo cultural como en lo cronológico (Vizcaíno, op . cit.: 2010, 159-162).

Otras necrópolis tumulares de incineración del Bajo Ebro, recientemente excavadas, como las de Sebes (Belarte et alii, op . cit.: 2013) o Santa Madrona (Belarte y Noguera: 2007) manifiestan unas características tanto en la arquitectura funeraria, como en el ritual y la cultura material, muy similares al Grupo del Bajo Aragón, con el que mantienen muchas relaciones, aunque con unos túmulos de menor tamaño (fig. 49). Recientemente, se ha planteado una síntesis sobre esta zona, comparando las necrópolis del Matarraña, caracterizadas por su arquitectura tumular, frente a las del
Priorato -Obagues, Tosseta, Molar- en las que se documenta la presencia de fosas simples (Rafel et alii: 2012, 31). Del mismo modo, se plantea una nueva evolución de los depósitos funerarios a partir de los más antiguos, señalados en Coll del Moro entre los siglos IX-VIII a. C., siguiendo a continuación los fechados en El Calvari entre los siglos VIII y $1^{\mathrm{a}} \operatorname{mitad}$ del VII, con algunos ejemplos en Coll del Moro que pueden llegar hasta el 575 a. C. y concluyendo con el depósito localizado en Les Ferreres y que se ha fechado entre el 575-550 a. C. (Rafel et alii: 2012, fig. 8).

Una cuestión específica es la planteada con las necrópolis de Los Pirineos, tanto en su vertiente española como francesa, muchos de cuyos yacimientos más representativos fueron excavados o documentados a finales del siglo XIX o comienzos del siglo XX (López y Pons, op . cit.: 1995). Hasta la fecha se han identificado una serie de grupos con ciertas características constructivas y rituales en las que alternan las necrópolis con estructuras tumulares y de círculos de piedras, como sería el caso de las conocidas en el Ampurdán, Els Vilars, Pla de Gibrella, La Foradada o Puig Alt, esta última con evidentes paralelos con algunas de las necrópolis de las Cinco villas aragonesas (López y Pons, op. cit.: 1995, 109-112, figs. 3-4). En cuanto a las necrópolis tumulares de los pirineos centrales, existen varios yacimientos que se han vinculado a los pasos relacionados con la trashumancia y que presentan una cierta variedad constructiva y ritual, aunque siempre relacionada con el ritual incinerador, como puede constatarse en los casos de Ayer, Le Labet, Baren y especialmente en la necrópolis de Arihouat (Alto Garona), una gran necrópolis de incineración con estructuras funerarias de grandes círculos de piedras, como en el caso de las necrópolis zaragozanas del entorno del embalse de Yesa, Arroyo Vizcarra y Barranco de la Paúl (López y Pons, op . cit.: 1995, 113115). Con relación a las necrópolis del grupo occidental, especialmente las localizadas entre el País Vasco y el área de los pirineos occidentales, se alternan distintas denominaciones para definir la estructura funeraria, entre los círculos de piedras de la escuela francesa o los crómlech utilizados sobre todo en el Pais Vasco y Navarra (López y Pons, op. cit.: 1995, 116-117). Recientes trabajos sobre el mundo de los "cromlech" pirenaicos intentan definir este tipo de estructuras, en muchos casos vinculadas a una funcionalidad funeraria y con una larga tradición, aunque con una cronología centrada en el primer milenio a. C. (Peñalver, op . cit.: 2005, 308-309), como se ha documentado recientemente en el valle de Benasque, en el círculo 106 del Plan de la Sarra (Calastrenc et alii: 2005), o en los círculos excavados con restos incinerados documentados en el yacimiento de Yermos del Cementerio, en la localidad de La Fueva en el Pirineo central y cuya fechación radiocarbónica también apunta al primer tercio 
del primer milenio a. C. (Rey: 2014, 89-91, fig. 6) (fig. 49). En nuestra opinión, la coexistencia de estructuras netamente tumulares con otras formadas por círculos de piedras en las necrópolis de Arroyo Vizcarra, Bco. de la Paúl o incluso en Corral de Mola, debe relacionarse con determinadas zonas de contacto entre las poblaciones agrícolas de los valles y los pasos ganaderos relacionados con la trashumancia y la cultura pastoril, muy asentada en todas las Altas Cinco Villas y en los Pirineos occidentales (López y Pons, op, cit.: 1995, 123).

Por lo que respecta a las necrópolis del sur de Francia, especialmente las de Aquitania y Languedoc, el panorama se presenta mucho más variado. Aunque ya desde el Bronce Medio parecen detectarse estrechas relaciones de algunas zonas del valle del Ebro con determinadas regiones del Sudeste francés y del centro y norte de Italia (Ruiz Zapatero: 2013, 642), la mayoría de autores han relacionado las necrópolis languedocienses con el mundo funerario de los Campos de Urnas del Noreste peninsular, especialmente el nordeste de Cataluña que se ha considerado como el corredor mediterráneo entre las dos vertientes pirenaicas (Pons, 2012, 59, fig. 1). Sin embargo, en los últimos años se están estudiando las relaciones entre las zonas pirenaicas y Aquitania, con el valle medio del Ebro, poniendo en valor unas relaciones mucho más estrechas de lo que hasta la fecha se habían considerado (Royo Guillén: 2005, 139-140, fig. 63). A esto ha contribuido el estudio o revisión de dichas necrópolis, de sus estructuras constructivas, su ritual funerario y su cronología (Adroit, op . cit.: 2014), pero sobre todo, de su cultura material, tanto cerámica como metalúrgica (Constantin, op . cit.: 2014; Torres-Martínez: 2013).

La tradición de la arquitectura tumular, no sólo se documenta en el valle del Ebro con la llegada de la cultura de los Campos de Urnas. Como ya hemos comprobado en la confluencia del Segre con el Ebro, dicha tradición tumular ya se constata a orillas del Ebro al menos desde el Neolítico Final, enlazando dicha tradición tumular con las primeras aportaciones de los C. U. en la necrópolis de Los Castellets, todavía asociada al ritual de la inhumación, pero muy pronto sustituida por la incineración generalizada al menos desde los inicios del siglo IX a. C (Ruiz Zapatero, op. cit.: 2013, 644-645).

Este mismo fenómeno se ha constatado en otras zonas del valle medio del Ebro, tanto de la zona riojana, como de la navarra y la aragonesa, al menos desde el Neolítico Final y Calcolítico y durante toda la Edad del Bronce con ejemplos que imitan o complementan lo documentado en la confluencia del Segre con el Ebro, tal y como sería el caso de los sepulcros colectivos bajo cubierta tumular de La Atalayuela de Agoncillo -Logroño- (Andrés y Barandiarán: 2004) y Tres Montes de Tudela -Navarra- (Andrés et alii:
2007), vinculados a la cultura campaniforme, o La Saga de Caseda -Navarra- (Sesma et alii: 2007), ya dentro de la Edad del Bronce, así como el sepulcro colectivo de la Senda de Robres en Leciñena -Zaragoza- (Ferreruela: 1991), por lo que podemos considerar el fenómeno tumular, al menos en lo que se refiere a la arquitectura funeraria, como un elemento plenamente indígena y generalizado en el valle del Ebro al menos desde el Neolítico Final (Andrés y Barandiarán, op . cit.: 2004, 85), con evidentes perduraciones durante la Edad del Bronce y total implantación durante la $\mathrm{I}^{\mathrm{a}}$ Edad del Hierro. Sobre esta tradición arquitectónica y ritual inhumador prehistórico se impondrá el nuevo ritual incinerador y la presencia de nuevos ajuares cerámicos y metálicos, representativos del profundo cambio que a partir del Bronce Final se producirá en la cuenca del río Ebro.

\section{3. Las estelas funerarias y sus paralelos}

El hallazgo de varias estelas pétreas en la necrópolis del Corral de Mola, nos acerca a un fenómeno generalizado desde el Bronce final hasta la Edad del Hierro que afecta a todo el valle del Ebro y áreas limítrofes. Identificadas por vez primera en la necrópolis de Coll del Moro de Gandesa (Rafel: 1989, 64, fig. 15), posteriormente se documentaron en Los Castellets II de Mequinenza, donde aparecen tanto estelas de señalización como cipos cilíndricos o antropomorfos (Royo: 1994, 121-122), reconociéndose también en La Colomina en Gerp, en Roques de San Formatge y en Pedrós (Serós), así como en La Pedrera de Vallfogona de Balaguer (fig. 50), además de otros paralelos en necrópolis del Alto Ebro como La Hoya, La Redonda o Arce Mirapérez (Royo, op. cit.: 1994, 124-125). También se han reconocido estelas o elementos de señalización en otras necrópolis de la Edad del Hierro, sobre todo celtibéricas, de las que hay un buen número de ejemplos reconocidos (Royo, op. cit.: 1994, 125126; Lorrio, op . cit.: 2005, 114-118, fig. 42). Se trata de un fenómeno que abarca todo el ámbito mediterráneo, desde la Grecia clásica hasta el mundo etrusco y fenicio, pasando por las necrópolis del sur de Francia, donde aparecen vinculadas al culto heroico de los difuntos, aunque en la mayoría de los casos las estelas se convierten en el elemento identificador de una sepultura tumular, contribuyendo así de forma rotunda a la conformación de un paisaje funerario, paisaje que para el área de Cataluña se ha fechado a partir del siglo VIII a. C., aunque existen evidencias de su uso desde épocas anteriores, como en La Colomina o en Los Castellets (Graells: 2008 a, 220-232) (fig. 51).

Junto al Corral de Mola, podemos plantear la existencia de posibles hitos de señalización en la vecina necrópolis de Busal I (Burillo, op. cit.: 1977, 64), aunque los ejemplares más importantes aparecen en la necrópolis de Arroyo Vizcarra, donde las estelas pue- 


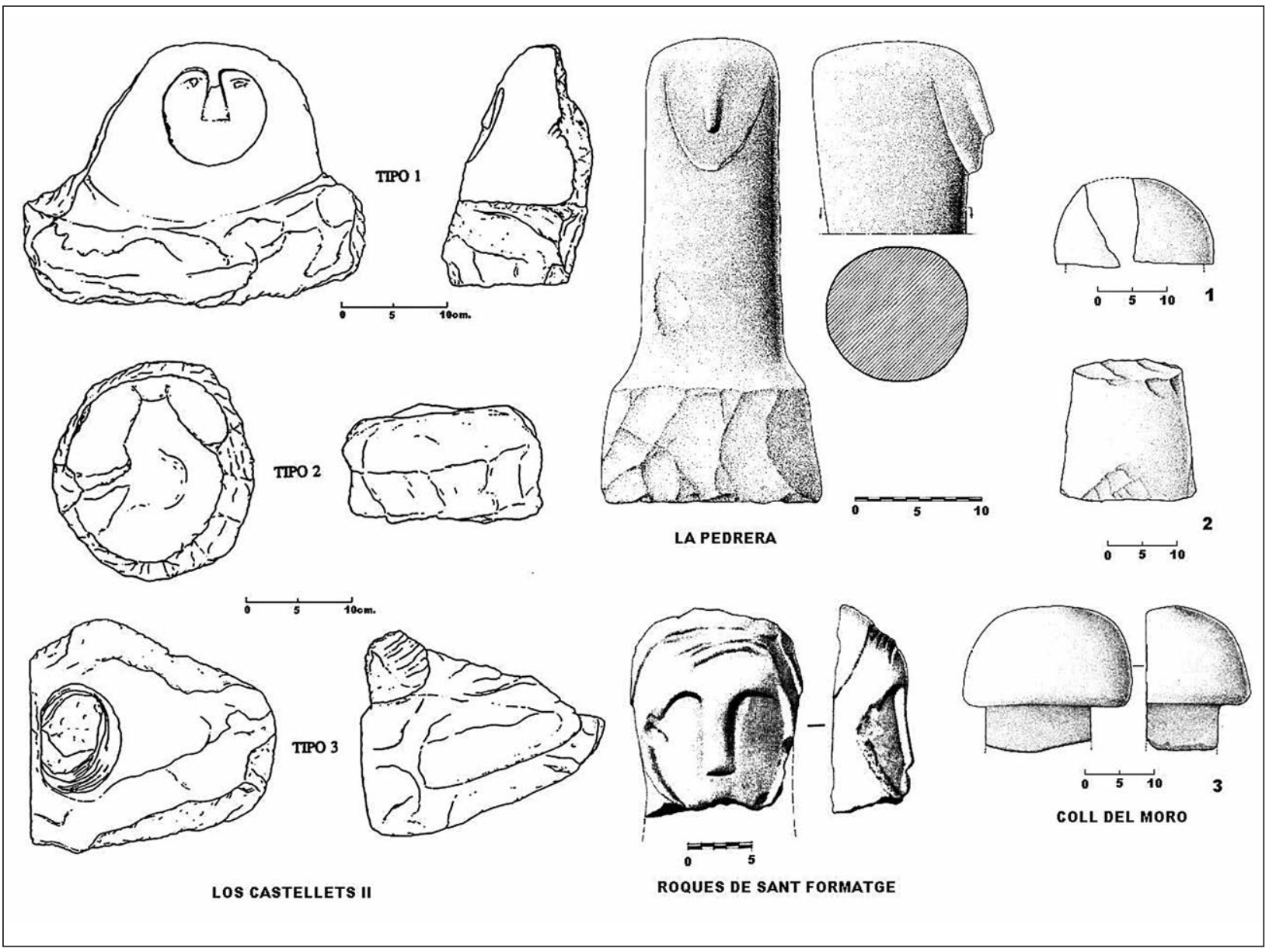

Fig. 50. Estelas antropomorfas y cipos funerarios procedentes de las necrópolis de Los Castellets II (Mequinenza), La Pedrera (Vallfogona de Balaguer), Roques de San Formatge (Serós) y Coll del Moro (Gandesa)

(A partir de Royo 1994-96 y Graells 2008a, modificado por Royo 2016).

den delimitar los círculos funerarios, señalizar los túmulos o incluso aparecer con determinadas orientaciones astrales (Royo, op. cit.: 1997 a, 53-54, figs. 6-7; Royo y Fatás, op. cit.: 2017, 51-52). Aunque ninguna de las estelas documentadas aparece decorada, la excavación completa de este cementerio protohistórico ha permitido documentar un número significativo de estelas que no sólo permiten organizar el espacio y paisaje funerario de la necrópolis, sino también delimitar las propias estructuras tumulares (Royo y Fatás, op. cit., 2017, 51-52) (fig. 52). Algo similar sucede en la necrópolis del Bco. de la Paúl en Los Pintanos, donde también aparecen delimitando los círculos funerarios, orientadas al Este o al Oeste y en algún caso con decoraciones geométricas (Royo, op. cit.: 1997 b, 266, fig. 7) (fig. 53). El caso de la estela de La Tiñica en Luna (Fatás: 1975) resulta un unicum en la zona por el momento y tanto su tipología como su descontextualización, no permiten señalar su función funeraria o como marcador territorial (Galán: 1993, 77-79, fig. 22. 4). Solamente encontramos en todo el valle medio del Ebro una organización espacial de la necrópolis y la utilización de estelas como delimitadoras de la estruc- tura tumular en la necrópolis oeste de La Codera en Alcolea de Cinca (Montón: 2001, 22) (fig. 54) y en el ejemplo ya citado de Arroyo Vizcarra.

Debido a las deficiencias del contexto de su hallazgo, no podemos concretar la existencia o no de estelas de señalización en la necrópolis de La Atalaya, aunque parece ser que la tumba 1 de La Torraza de Valtierra sí pudo contar con una, a juzgar por las descripciones de sus excavadores (Maluquer, op. cit.: 1957, 247). En el caso de la extensa necrópolis del Castejón de Arguedas, sólo se ha constatado la presencia de una estela de señalización en el enterramiento 59, un túmulo conformado por un anillo exterior de piedras de yeso y otro interior de adobes con un diámetro de 1,90 metros (Castiella y Bienés, op. cit.: 2002, 104 y 131). Más numerosos son los ejemplares de la necrópolis del Castillo de Castejón, donde se han documentado varias estelas en arenisca y caliza de formas prismáticas y tendencia rectangular, ubicadas en el anillo exterior por regla general, aunque también pueden aparecer en el anillo interior como en el túmulo 45 y en un caso, en el del túmulo 167, ocupando el centro de la estructura (Faro et alii, op. cit.: 2002-03, 61). 


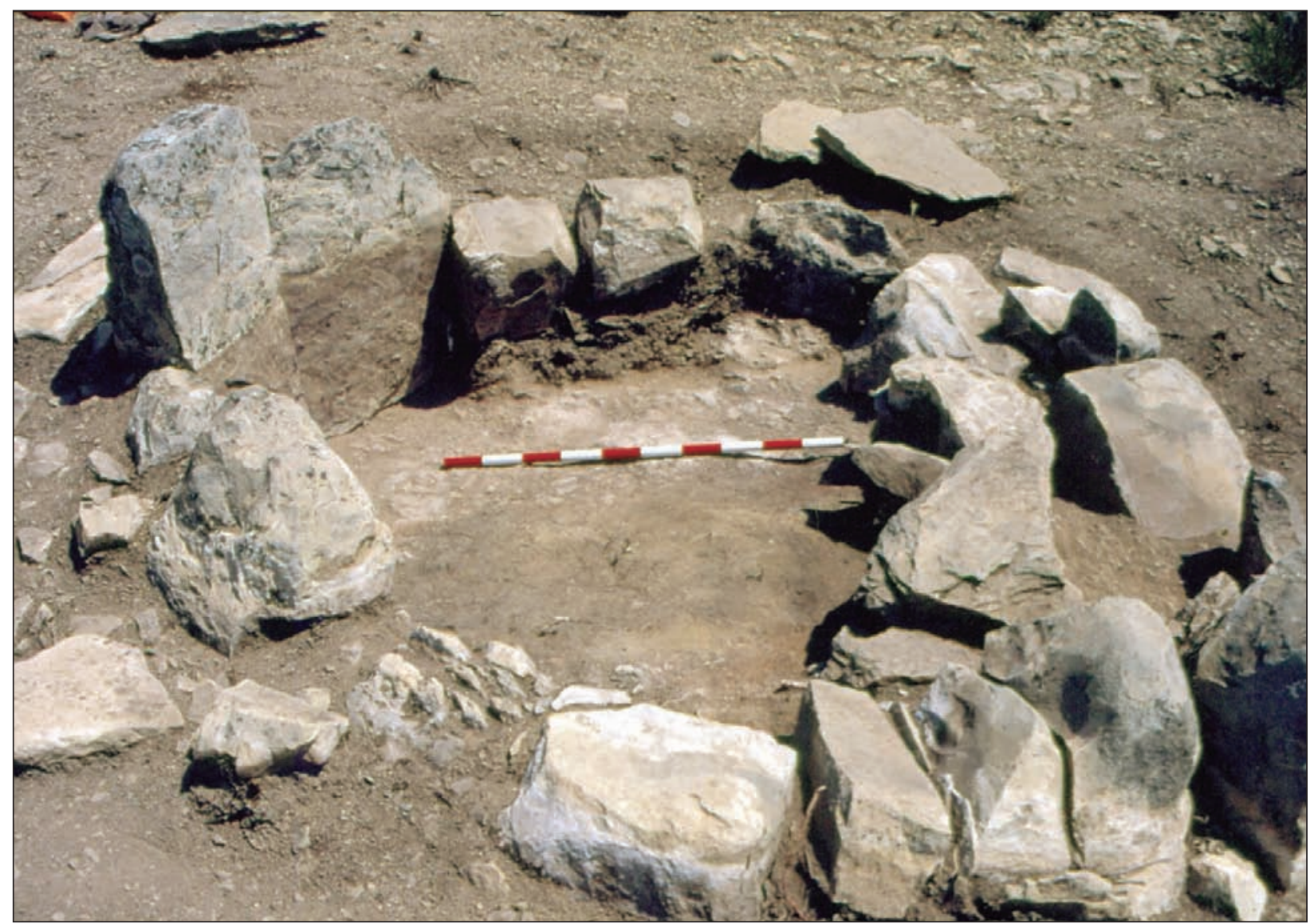

Fig. 51. Los Castellets II (Mequinenza, Zaragoza). Túmulo 18 una vez excavado con la estela de señalización insertada en el anillo tumular1 (Foto: Royo 1990).

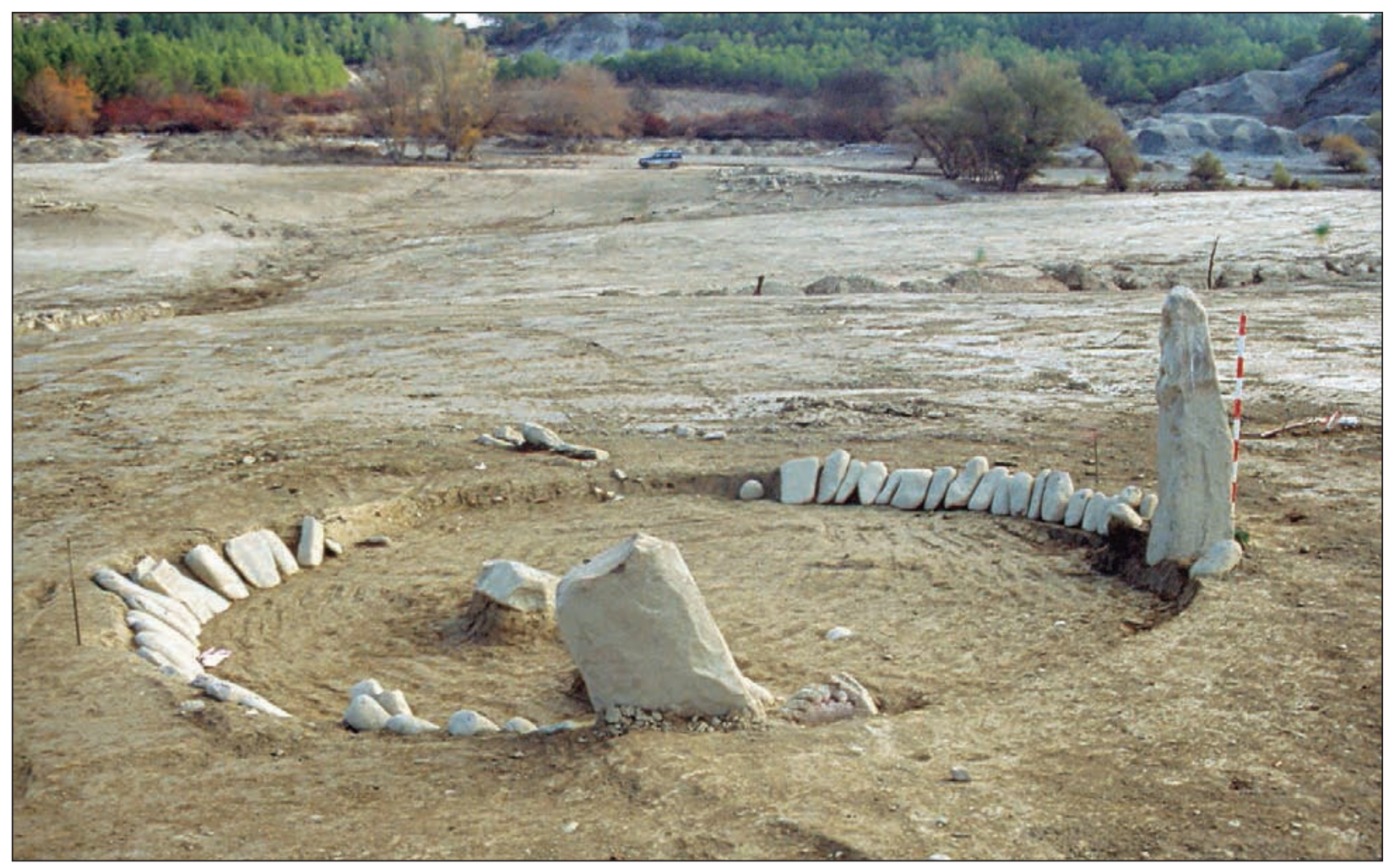

Fig. 52. Vista del túmulo 47 de la necrópolis de Arroyo Vizcarra, con dos estelas localizadas en el anillo tumular y con posible orientación astral (Foto: Royo 2005). 


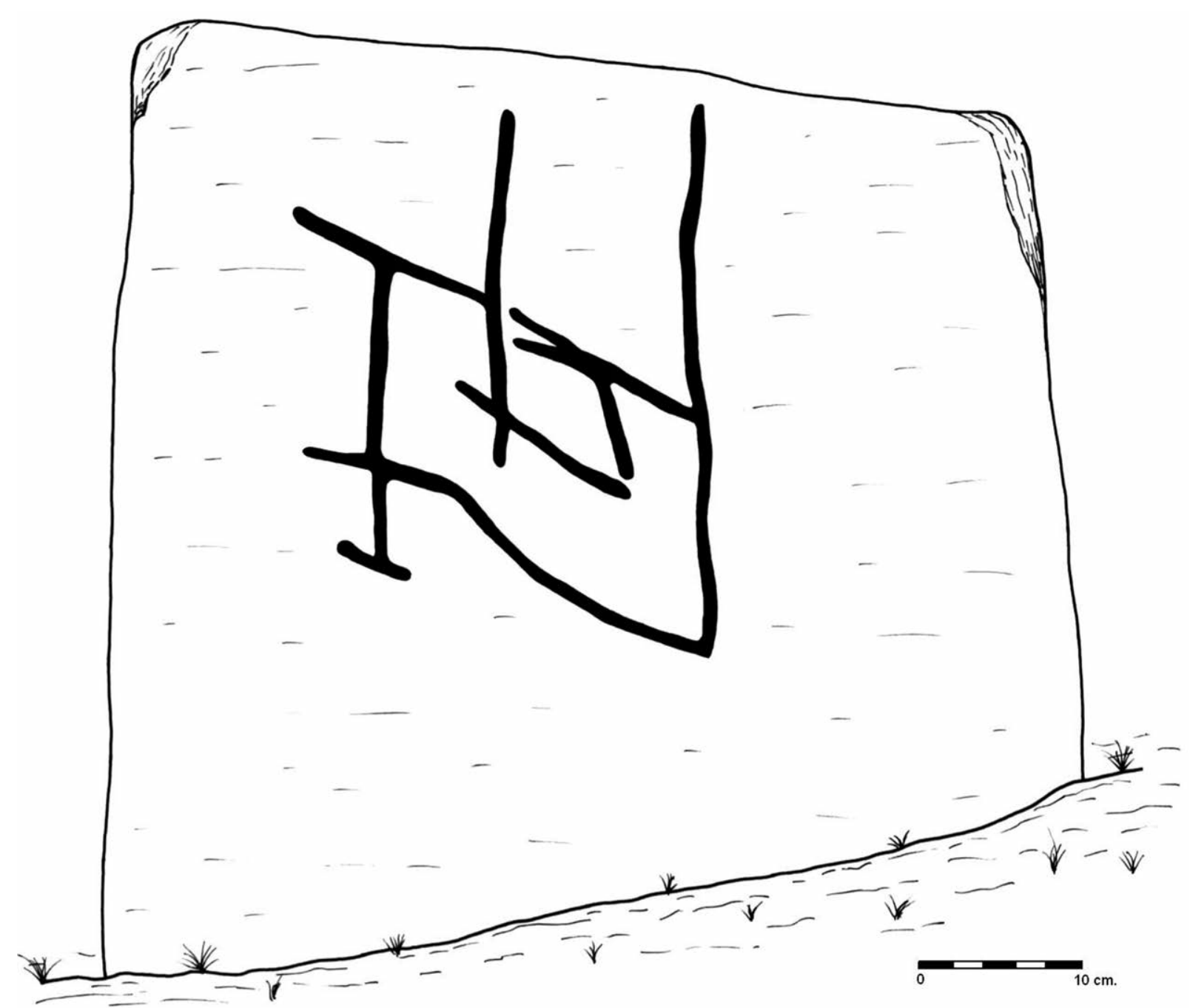

Fig. 53. Dibujo y calco de una de las estelas decoradas con grabados esquemáticos existentes en la necrópolis tumular de incineración del Barranco de la Paúl, en Los Pintanos (Zaragoza) (Dibujo: Royo 1987).

En definitiva, la constatación de la presencia de elementos señalizadores en las necrópolis de nuestro Grupo I, viene a confirmar un fenómeno generalizado en todo el valle del Ebro y que cuenta con una larga tradición, desde la prehistoria reciente, hasta bien entrada la segunda Edad del Hierro (Royo et alii: 2006, 99-101; López y Royo: 2009).

\section{4. Los ajuares funerarios de la necrópolis del Corral de Mola}

La identidad cultural entre el Corral de Mola y las necrópolis del Ebro Medio es claramente manifiesta, especialmente en los ajuares funerarios. Si comparamos dichos ajuares con los conjuntos bien conocidos de las principales necrópolis excavadas en el sector oriental del valle del Ebro en Navarra -La Atalaya, El Castejón de Arguedas, El Castillo de Castejón o La Torraza de Valtierra-, o bien con las necrópolis de los ríos Huecha -Mallén, Burrén y Burrena, Cabezo de las
Viñas, El Quez o Carraveruela- o Bajo Jalón -Bco. de la Peña de Urrea, San Sebastián y Cabezo Ballesteros de Epila-, vemos que la identidad es más que significativa, tanto en la cerámica manufacturada, cuya tipología se ha emparentado con la documentada en las necrópolis aquitanas (Royo, op. cit.: 2000, 53, figs. 8 y $9,1)$, como en el ajuar metálico, sobre todo con las necrópolis navarras y las del Bajo Jalón (Royo, op . cit.: 2000, 55, fig. 9), como veremos a continuación.

\section{4. 1. El broche de cinturón}

Las similitudes entre algunas piezas metálicas del Corral de Mola y los ejemplares de otras necrópolis, como El Castejón de Arguedas o La Atalaya, así como algún poblado, como es el caso del Alto de la Cruz en sus fases PIIb y PIa, son tan evidentes que podríamos pensar en algún tipo de taller o centro de producción local de algunos de los elementos documentados. Tal sería el caso del broche de cinturón del túmulo 1 de 


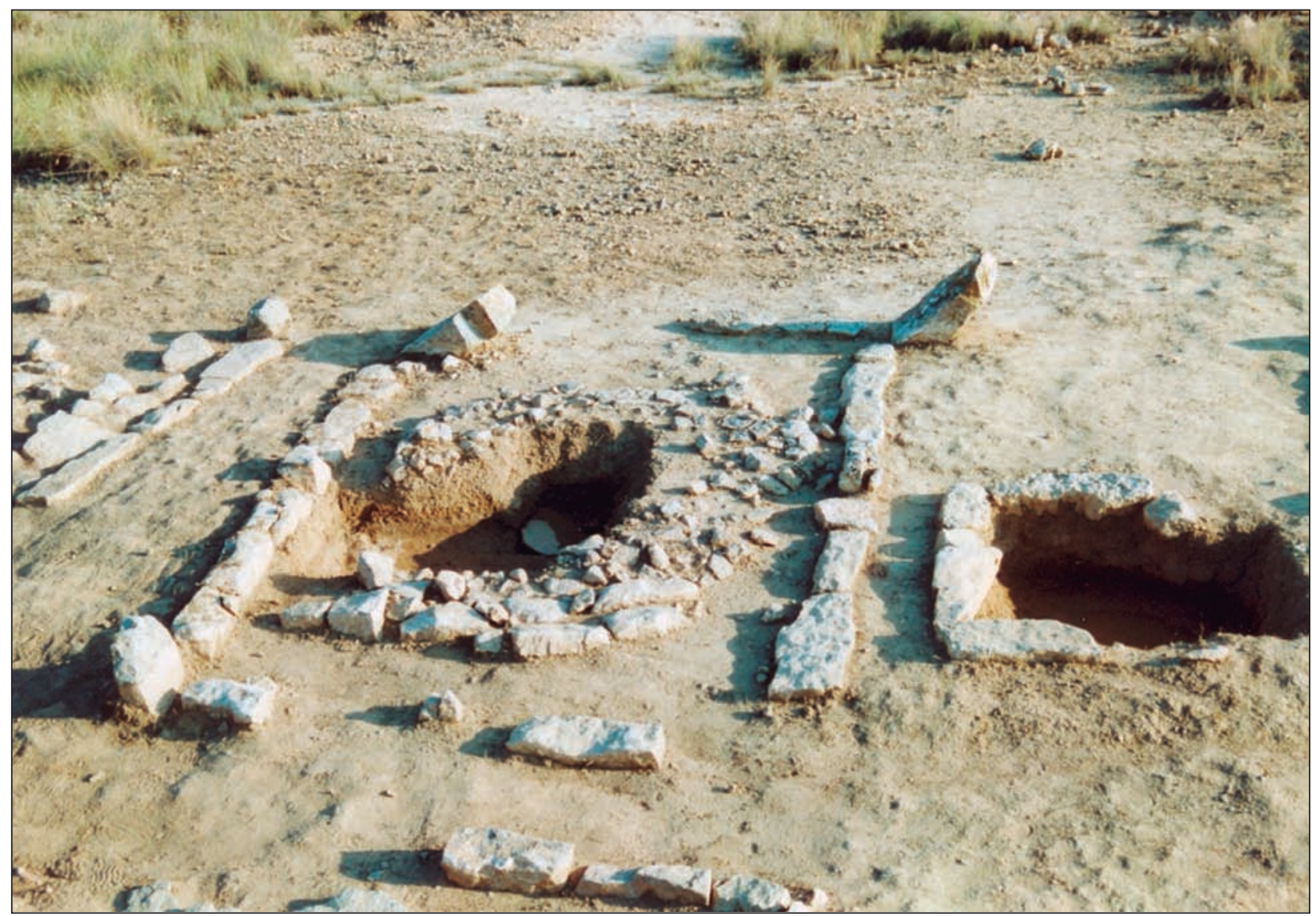

Fig. 54. Vista del túmulo 5 de la necrópolis de La Codera, con presencia de diversas estelas que delimitan la estructura funeraria (Foto: Montón 2004).

placa triangular (fig. 11), cuya área de distribución está bien definida dentro del sector occidental del valle medio del Ebro. En esta zona contamos con ejemplares muy similares procedentes de la necrópolis del Castejón de Arguedas y de La Atalaya, pero también del poblado del Alto de la Cruz de Cortes de Navarra (fig. 55). Los que guardan más parecido con el ejemplar del Corral de Mola están caracterizados todos ellos por ser de placa triangular, con nervadura longitudinal en el anverso y un solo garfio, con dos pestañas laterales en el reverso para sujeción del cinturón y decoración de triángulos que pueden ser incisos o a molde (Castiella y Bienés, op. cit.: 2002, 153 y 158-59, figs. 192 y 200). También debe destacarse la presencia de varios broches de placa cuadrangular en la necrópolis del Castejón, como los ejemplares de los enterramientos $\mathrm{n}^{\circ} 3,23,38$ y 68 , en este caso sin nervadura ni pestañas (Castiella y Bienés, op. cit.: 2002, 151-152, figs. 188-191) que se asemejan a otros ejemplares del mismo tipo aparecidos en los poblados del PII a del Alto de la Cruz y La Custodia (Castiella y Bienés, op. cit.: 2002, 158, fig. 199). Aunque no aparecen en la necrópolis de La Torraza, si son muy abundantes en la necrópolis del Castillo de Castejón, pero aquí con escotaduras abiertas o cerradas y con ejemplares de uno a tres garfios y decoración incisa o troquelada
(Faro et alii, op. cit.: 2002-03, 73). También aparecen en La Atalaya, donde presentan una gran variedad formal, con ejemplares de placa cuadrangular y un garfio, o con escotaduras abiertas o cerradas y entre uno y tres garfios (Maluquer y Vázquez, op. cit.: 1956, 25-28, figs. 10-11).

Desde la primera clasificación de estas piezas en la Península Ibérica (Cuadrado: 1961), se planteó su posible origen centroeuropeo, posiblemente a partir de modelos del círculo hallstáttico, señalando a los broches de la necrópolis languedociense de Fleury como los posibles precedentes de los ejemplares peninsulares (Cuadrado, op. cit: 1961, 215, figs. 2.8 y 3). Trabajos posteriores han profundizado en su clasificación crono-tipológica y en sus orígenes (Cerdeño: 1978), colocando a los broches de placa triangular y un solo garfio a continuación de los prototipos de la Ría de Huelva en su tipo B I-II, emparentándolos con las influencias tempranas del mundo centroeuropeo, aunque negando que los modelos franceses sean más antiguos y por tanto los precedentes inmediatos de los modelos hispanos (Cerdeño, op. cit.: 1978, 282 y 294, fig. 5). El estudio de la celtiberia y de las necrópolis meseteñas ha permitido documentar un número considerable de broches de cinturón, cuya ordenación tipocronológica ha confirmado que los ejemplares de placa 

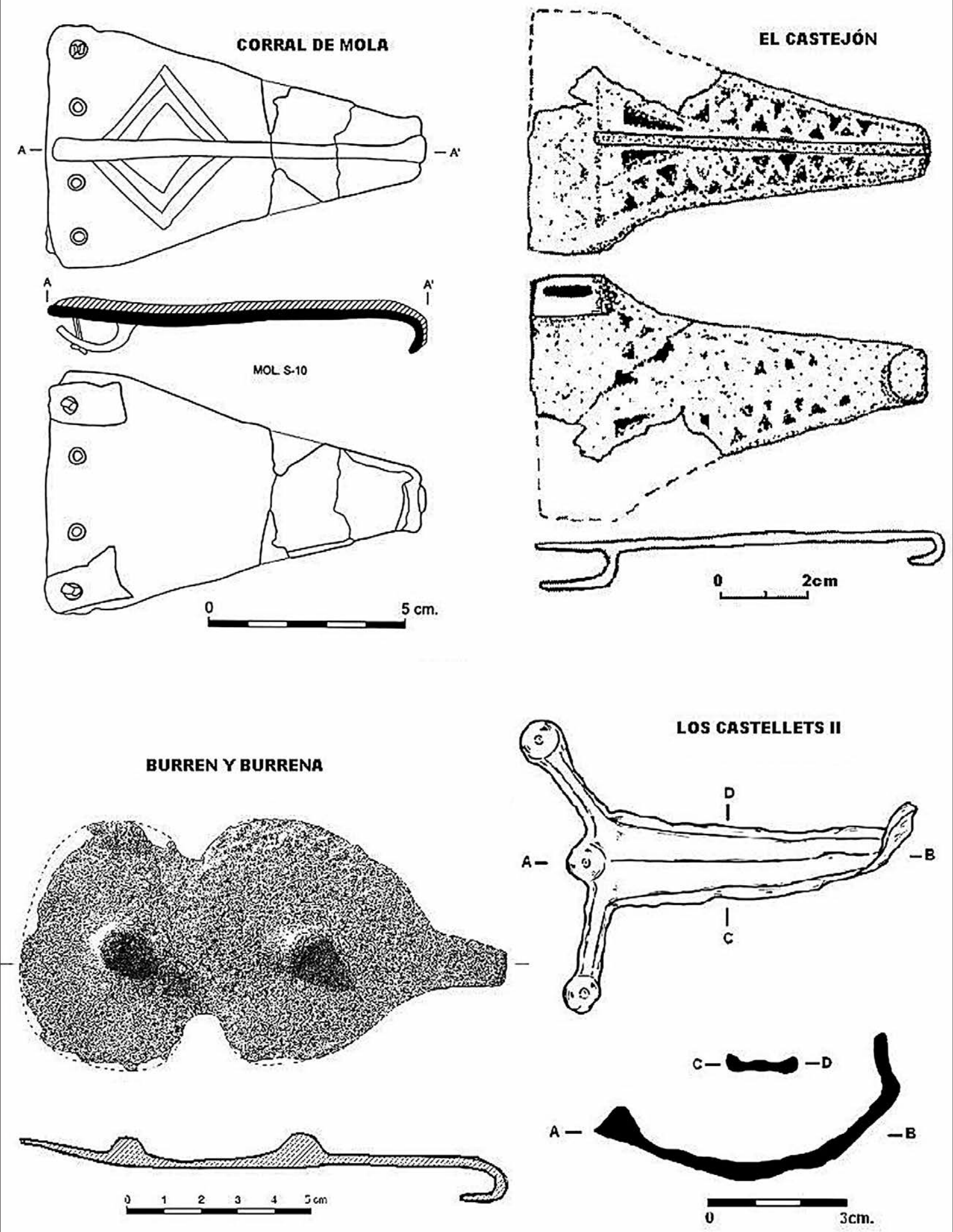


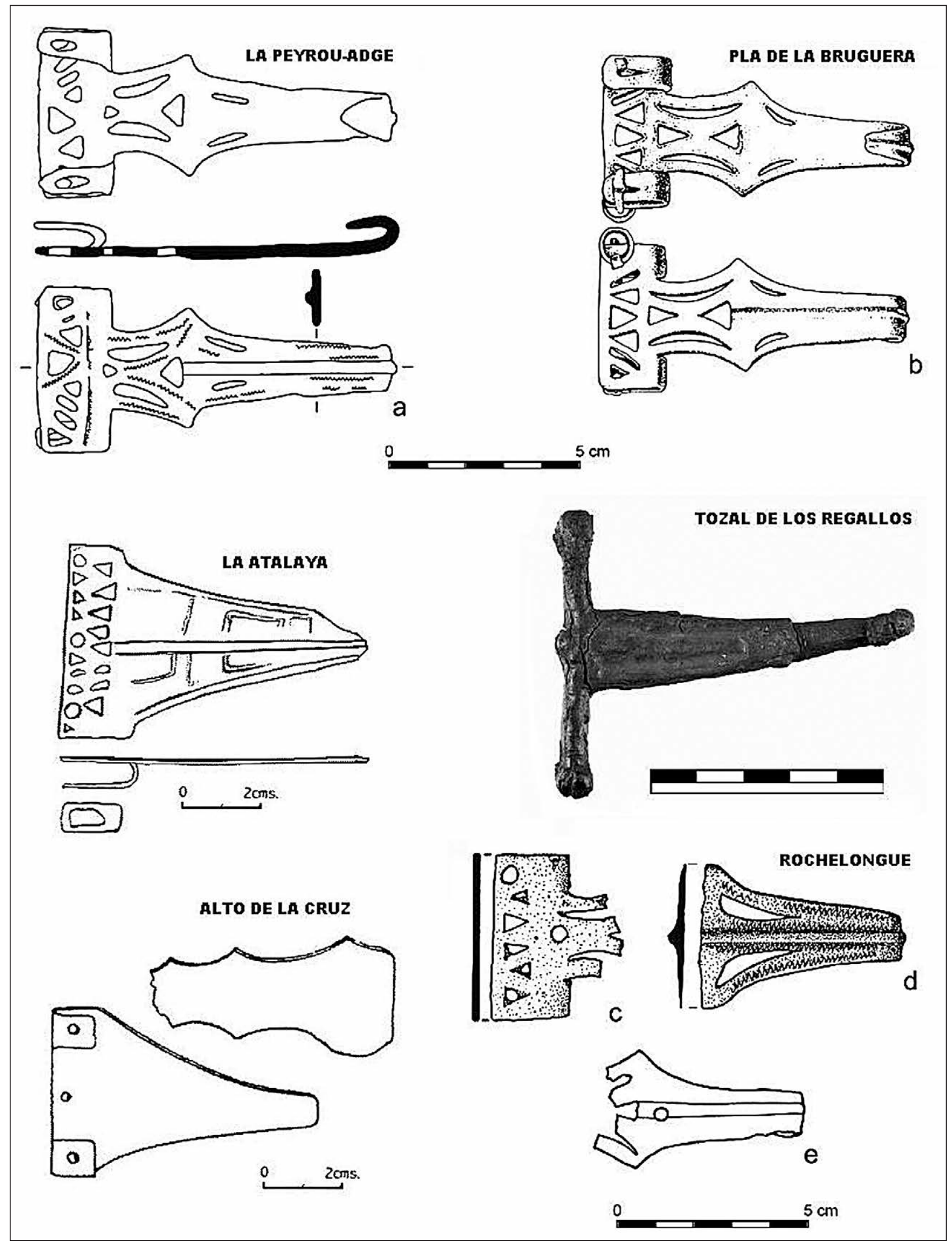

Fig. 55. El broche de cinturón del Corral de Mola y sus paralelos de las necrópolis de La Atalaya y El Castejón, así como del poblado del Alto de la Cruz. También se presentan otros ejemplares localizados en el valle medio del Ebro que pueden considerarse como prototipos: Burrén y Burrena, Tozal de los Regallos y Castellets II, junto a diversos ejemplares del tipo Fleury, localizados en diferentes necrópolis del Golfo de León (A partir de Royo 1992, Castiella y Bienés 2002, García Arilla 2016 y Graells 2014.

La imagen del broche procedente del Tossal de los Regallos ha sido cedida por el Museo Arqueológico Nacional para su estudio y publicación. Foto: Arantxa Boyero Lirón. N. I. G. 1975/71/2). 
triangular y un garfio corresponden a modelos tipologicamente antiguos pero de mucha perduración, distribuidos entre el valle del Ebro y el Alto Tajo y Alto Jalón (Lorrio, op. cit.: 2005, 221, figs. 89-90).

Existen en la actualidad dos corrientes principales en cuanto al origen y fabricación de los broches de cinturón denominados como célticos. Por un lado, la que plantea unos precedentes mediterráneos para este tipo de broches y más concretamente griegos que llegarían al sur de la Península Ibérica con las masivas importaciones jonias y focenses y que se manifestarían en los broches más antiguos producidos en Andalucía, los localizados en la necrópolis de La Joya, o en los yacimientos de Acebuchal o Peña Negra, para desde allí y a través del comercio colonial establecer nuevos centros de producción en el noreste, entre Cataluña y el Languedoc, en el Golfo de León, desde donde se extendería su uso por el valle del Ebro y la Meseta Norte (Jiménez Ávila: 2003, 44-45, fig. 3). Por otro lado, sin excluir la importancia del foco griego y la influencia mediterránea en las primeras producciones de broches hispanos, sobre todo las relativas al área catalana y el Golfo de León, en los últimos años se vuelve a plantear la importancia de las relaciones comerciales entre Italia y el nordeste peninsular, sobre todo a partir de la presencia de broches tipo Fleury y cuentas de ámbar en algunas de las necrópolis de esta área y en fechas ciertamente tempranas, por encima del siglo VII a. C. (Graells: 2014, 265, fig. 34) (fig. 55). Con todo, tanto las cronologías de los broches de tipo Fleury, como su propia morfología, no pueden compararse exactamente con los broches de placa triangular o cuadrada, con pestañas y nervadura y un solo garfio del sector occidental del valle medio del Ebro que representan una tipología cuyo origen podría estar a caballo entre el noreste peninsular y el sureste francés como plantean Graells y Lorrio, los cuales fechan los broches del tipo Corral de Mola entre el 625 y el 575 a. C. (Graells y Lorrio: 2017 , 97-98).

No obstante, vemos un enorme desfase entre los ejemplares documentados en el área catalana y Golfo de León, respecto al sector occidental de su valle medio, donde el número se reduce drásticamente salvo en algunas necrópolis como Cabezo de Ballesteros, La Atalaya, El Castejón de Arguedas o el Castillo de Castejón. La ausencia de contextos fiables de algunos yacimientos, como La Atalaya o la falta de estudio de otros, como Cabezo Ballesteros, han reducido los conjuntos con interés al Castillo de Castejón, al Castejón de Arguedas y cómo no, al Corral de Mola. Si embargo, la reciente publica- ción de un broche de cinturón en el poblado de Burrén y Burrena en el río Huecha, cuya morfología parece inspirarse en el tipo Unterhaching (García-Arilla: 2016,34-37, fig. 2), junto a la presencia de un ejemplar de la necrópolis de La Atalaya del cual hasta el momento no se ha dado cuenta (Maluquer y Vázquez, op. cit.: 1956, fig. 10), con paralelos en el tipo Larnaud, con ejemplares documentados en el depósito de Llavorsí, nos pone en contacto con una serie de broches de procedencia centroeuropea, entre los valles del Rhin y del Main (García-Arilla, op . cit.: 2016, 36-37, fig. 4) (fig. 55). A estas piezas tendríamos que añadir el hallazgo de otros broches de cinturón de tipo arcaico en el sector oriental del valle medio del Ebro, en el Tozal de los Regallos de Candasnos y en la necrópolis de Los Castellets II de Mequinenza, procedente del ajuar de su túmulo 24 (fig. 55), con claros paralelos en piezas de tipo hallstáttico y con cronologías por encima del siglo VIII a. C. (Royo, op. cit.: 1994-96, 104; Minguell: 1991, fig. 4), todo lo cual nos permite volver a valorar las relaciones de esta área geográfica con el mundo centroeuropeo desde épocas muy tempranas (García-Arilla, op . cit.: 2016, 38), volviendo a poner de relieve la importancia del eje del Ebro como elemento de entrada de elementos foráneos de los C. U, pero también como excelente vía de comunicación entre el cuadrante nororiental de la Península Ibérica y el mediterráneo o el sur de Francia.

Concluiremos este apartado con la referencia a un pequeño grupo de grapitas (fig. 56) que apareció en el túmulo 1 junto al broche de cinturón y que hemos vinculado a los elementos de sujeción de un cinturón realizado en materia orgánica, posiblemente cuero. Este tipo de elementos, no señalado hasta el momento en las

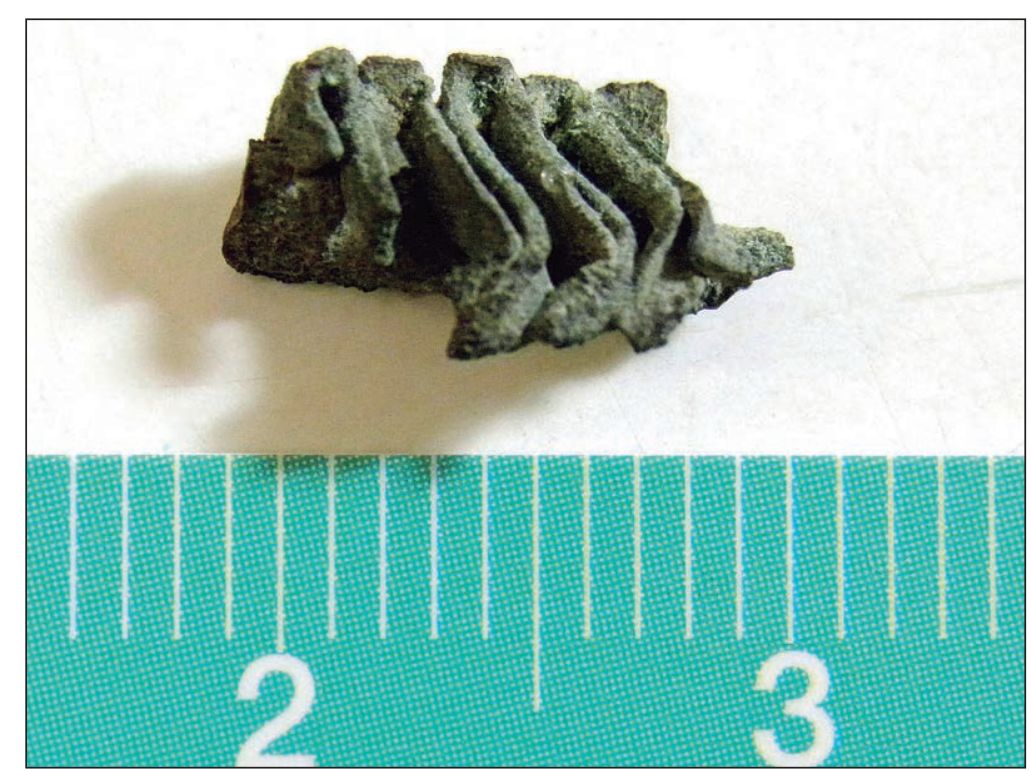

Fig. 56. Detalle de las grapitas aparecidas en el túmulo 1 del Corral de Mola, asociadas a la sujeción o decoración de un cinturón (Foto: Royo 2016). 
necrópolis del valle medio del Ebro, está presente en varios ejemplos repartidos por la Península Ibérica, pudiendo adoptar diversas morfologías pero siempre utilizadas para el adorno o sujeción de los rebordes del cinturón, como puede verse en varios ejemplares procedentes de la necrópolis de La Joya, de Acebuchal o de Peña Negra, todos ellos relacionados con broches de un solo garfio y decoración a molde (JiménezÁvila, op . cit.: 2003, 35, fig. 3). También se ha constatado su presencia en contextos más cercanos al valle del Ebro, ya en la zona costera catalana, como en la tumba de guerrero de Llinars del Vallés, también asociada a un broche de cinturón de un garfio, en este caso con pestañas en el dorso de la placa (Sanmartí: 1993, 28-29, figs. 14 y 15. 17). Otro ejemplo que podríamos citar, se localizó en el Alto Ebro, en la cueva de Ojo Guareña y se corresponde con un broche de placa cuadrangular y un garfio, unido a un cinturón de cuero con placas broncíneas unidas al mismo con grapas laterales que se ha vinculado tanto al mundo hallstáttico, como al del sur de la Península Ibérica (Rúiz Vélez: 2009, 266, fig. 4). Por último citaremos ya dentro de los yacimientos del valle medio del Ebro, la aparición de un tipo muy similar de grapitas vinculadas a la guarnición de un cinturón y que se documentaron en una calle de la fase III-IV del poblado del Alto de la Cruz de La Muela, fechada a mediados del siglo VI a. C. (Picazo y Rodanés, op. cit.: 2009, 412).

\section{4. 2. Las fíbulas de doble resorte y el ejemplar de pie vuelto y resorte bilateral}

Por lo que se refiere a las fíbulas aparecidas en Corral de Mola, tanto las de doble resorte (figs. 10. MOL-S-2 y 34. MOL. T5-19AQ'), como las de pie vuelto (fig. 39. R.C. $\mathrm{n}^{\circ}$ 211), también aparecen bien representadas en las necrópolis navarras y aragonesas del Ebro Medio, aunque en el caso de las de doble resorte, ligeramente más evolucionadas en La Atalaya (Castiella, op . cit.: 2005, 183-185, fig. 100) y con una presencia menor en El Castillo de Castejón, donde no son del tipo filiforme (Castiella y Bienés, op . cit.: 2002, 164-170). El mejor contexto estratigráfico para la temprana aparición de este tipo de fíbulas en el extremo occidental del Ebro medio, coincide con el yacimiento del Alto de la Cruz de Cortes de Navarra, donde se ha constatado su presencia en los poblados PIIa y PIIb, en el primero con sección filiforme y en el segundo ligeramente más evolucionadas, aportando una secuencia cronológica, entre los siglos VIII y mediados del VI a. C. (Maluquer, op. cit.: 1954, 135137, fig. 45; op. cit.: 1958, fig. 31) que coincide con las dataciones radiocarbónicas calibradas realizadas para dichos niveles (Munilla et alii, op. cit.: 1994-1996, 170). También aparece en el poblado de El Morredón con sección del puente acintada, asociada a botones semiesféricos con travesaño (Royo, op . cit.: 2005, 83, fig. 36) y en el importante conjunto del Cabezo de la
Cruz de La Muela, aunque en un contexto estratigráfico superficial, también con puente acintado y asociada a botones hemisféricos, lo que permitió a sus descubridores proponer una cronología para este conjunto del siglo VI a. C., muy similar a la del Morredón (Burillo y Fanlo: 1979, 52-54, fig. 4). Muy cerca de este poblado, también se conoce otra pieza incompleta sin contexto estratigráfico, aparecida en la partida de La Cueva de Mozota, en este caso con puente de sección trapezoidal (Burillo: 1981, 77-78, fig. 12).

Entre las necrópolis de nuestro Grupo I y en el área del sector occidental de Ebro Medio, también se ha constatado su presencia en la necrópolis de Arroyo Vizcarra, en el embalse de Yesa, en este caso con puente filiforme y asociada a brazaletes abiertos de sección acintada y botones semiesféricos, a caballo entre el siglo VI y el V a. C. (Royo, op. cit.: 1997 a, 56-58; Royo y Fatás, op . cit.: 2017, 50, fig. 4). En otras necrópolis de la margen derecha del Ebro, en la ribera del Jalón, también manifiestan su presencia como en el Cabezo Ballesteros de Épila (Pérez Casas, op . cit.: 1990, 117), o en la ribera del Jiloca, afluente de éste, asociada su presencia a las fases más antiguas de la necrópolis celtibérica de La Umbría de Daroca (Aranda, op. cit.: 1990, 107, fig. 5, 1). Fuera ya de nuestro Grupo I, en la rivera del río Alcanadre, también se ha localizado un ejemplar de fíbula de doble resorte en el poblado de La Codera, en un nivel que puede paralelizarse a los conjuntos ya fechados entre los siglos VII-VI a. C. del valle medio del Ebro (Montón: 2016, 109) (fig. 57).

No vamos a insistir demasiado en la polémica que en los últimos decenios ha girado en torno al origen y cronología de las fíbulas de doble resorte y que diversos autores han sistematizado en mayor o menor medida (Navarro: 1970, 27-40, figs. 4-7; Ruiz Zapatero, op. cit.: 1985, 952-955, fig. 270; Argente, op . cit.: 1994, 104, cuadro 3; Castro, op. cit.: 1994, 141-143, gráfico IV.4). No obstante, en los últimos años se han realizado varias propuestas cronológicas basadas en criterios tipológicos, estratigráficos y de asociación con otros elementos metálicos propios de los ajuares de la $\mathrm{I}^{\mathrm{a}}$ Edad del Hierro. En este sentido debemos señalar que a partir de los trabajos de los autores ya citados, se han establecido otros criterios sobre el origen de este tipo de fíbulas, su aparición en España y su distribución espacial y cronológica. Aunque hasta hace poco tiempo se venía pensando en un origen oriental para las fíbulas de doble resorte, como un producción derivada del mundo fenicio, con presencia de ejemplares de puente cilíndrico o filiforme desde inicios del siglo VIII en el área andaluza y en alguna necrópolis catalana como Agullana, dichas cronologías y su origen se han puesto recientemente en discusión (Graells, op. cit.: 2014, 248, cita 275). Lo cierto es que se trata de una fíbula cuya distribución geográfica concentra su 


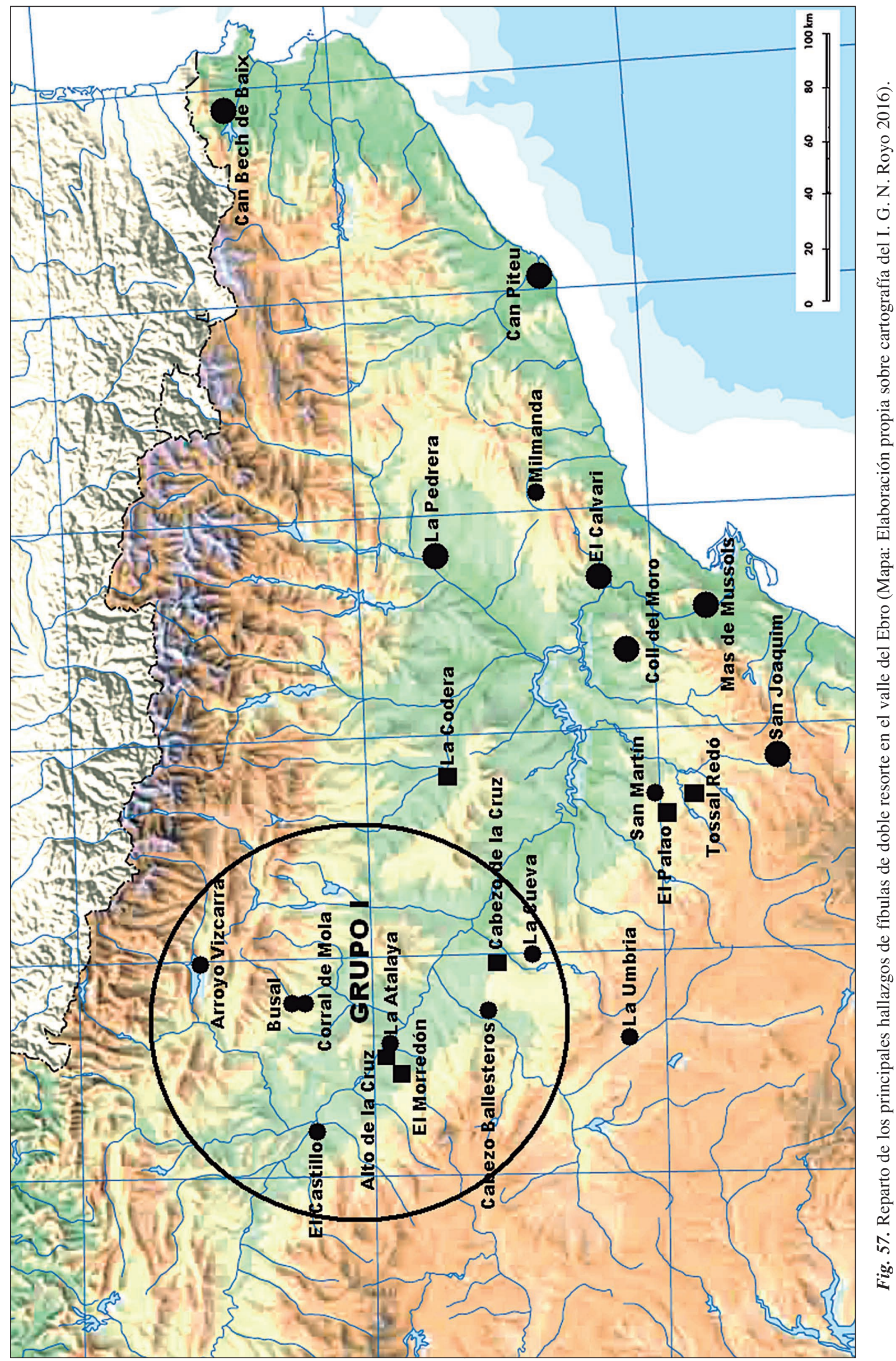


mayor número de ejemplares en el área del Golfo de León y más concretamente en el sureste francés, Cataluña, Bajo Ebro y Valencia, fechándose en esta área entre mediados del siglo VII y mediados del siglo VI a. C. (Graells, op . cit.: 2014, 247, tabla 1, fig. 25) (fig. 57), aunque también se han documentado diversos ejemplares de estas fíbulas en el sureste peninsular y en las costas andaluzas, al igual que en toda la meseta oriental, si bien aquí asociada a los ajuares de las necrópolis celtibéricas y con una cronología que como ya apuntó Argente en su día y posteriormente ha confirmado Lorrio, puede situarse desde el siglo VI a. C. hasta bien entrado el siglo IV a. C. en los modelos más evolucionados (Lorrio, op. cit.: 2005, 206-208, fig. 83, tipo 3).

A las zonas ya descritas habría que añadir la presencia de un número cada vez más significativo de fíbulas de doble resorte en necrópolis y poblados de la $\mathrm{I}^{\mathrm{a}}$ Edad del Hierro en el valle medio del Ebro, especialmente en su sector occidental, presencia que viene constatándose en etapas muy tempranas, aunque también se ha planteado que la concentración de hallazgos en torno al cuadrante nororiental de la Península Ibérica pueda deberse a un origen autóctono de este tipo de fíbula, posiblemente del levante peninsular y asumido como propio por el comercio mediterráneo a partir del siglo VII a. C. (Graells, op . cit.: 2014, 249). Los paralelos de este tipo de fíbula en Aquitania y Altos Pirineos se concentran por el momento en unos escasos ejemplares recuperados en una fosa de la necrópolis de Truc de Bordiou -Gironde-, en la tumba 275 de la necrópolis de Causse -Tarn-, o en la tumba 2 del túmulo $\mathrm{J}$ de la necrópolis de Ibos -Hautes Pyrenées-, fechadas entre el 750-650 a. C. (Constantin y Bilbao: 2013, 311, fig, 1, type 1212; Constantin, op. cit.: 2014, 137, fig. 5, type 1212). A tenor de lo ya comentado, las fíbulas de doble resorte del Corral de Mola, por su contexto y tipología, deberían situarse junto a los ejemplares de puente filiforme peninsulares, en un momento indeterminado de la segunda mitad del siglo VII a. C., posiblemente en su momento inicial, por su asociación al resto del ajuar funerario del túmulo 1 de esta necrópolis, especialmente el broche de cinturón, los brazaletes abiertos y el torques con terminaciones en bolas o engrosamientos, elementos que en otras necrópolis de la costa mediterránea catalana como en El Calvari, se han asociado a tumbas masculinas con ajuares especialmente ricos (Castro, op, cit.; 1994, 112-113).

En cuanto al ejemplar de fíbula de pie vuelto rematado en disco terminal y resorte bilateral del Corral de Mola, corresponde a un hallazgo de la necrópolis pero sin ningún tipo de contexto estratigráfico. No obstante, aporta información sobre un modelo ampliamente representado en el valle medio y Alto del Ebro y tam- bién en sus zonas limítrofes, especialmente en el área celtibérica de la meseta nororiental, pudiendo estar fabricada tanto en bronce como en hierro y denominada como tipo navarro-aquitano (Argente, op . cit.: 1994, 78, fig. 8). Ciñéndonos al valle medio del Ebro y a su sector occidental, está presente en la mayoría de las necrópolis navarras de forma muy numerosa, destacando los ejemplares recuperados en el yacimiento de La Atalaya con pie rematado en disco y alternando el bronce y el hierro, pero carentes de un estudio de conjunto (Maluquer y Vázquez, op . cit.: 1956, 21, fig. 8, 3; Castiella, op. cit.: 2005, 183-185, fig. 100, sep. 2). También aparecen en la necrópolis del Castejón de Arguedas, con un fuerte desarrollo del resorte bilateral y combinando la composición de bronce y hierro (Castiella y Bienes, op. cit.: 2002, 169-171, figs. 213214). Por último son muy numerosas en la necrópolis del Castillo de Castejón, donde también aparecen pies vueltos rematados en disco, alguno de ellos decorado con círculos concéntricos (Faro et alii, op . cit.: 20022003, 72; Faro, op. cit.: 2002, 210, no catálogo E. F. 46). Estas necrópolis representan, junto a la de Busal en Uncastillo, un momento más avanzado de la Edad del Hierro, por lo que dichas fíbulas se vienen fechando a partir del siglo VI y hasta mediados del V a. C. (Castiella y Bienés, op. cit.: 2002, 171). Por lo que se refiere a otros yacimientos del valle medio del Ebro, encontramos fíbulas de este tipo en algunas necrópolis tumulares tanto del Hierro I, Azaila o Cabezo de Ballesteros, como de tipo celtibérico, La Umbría de Daroca o Griegos (Cerdeño y Chordá: 2004, 164, fig. 1).

Un aspecto a destacar de nuestro ejemplar es su acabado dorado o sobredorado en gran parte de la pieza, característica poco señalada hasta la fecha (Camacho et alii: 2016), pero que se ha documentado en otros conjuntos, tanto del área celtibérica -Quintanas de Gormaz o la Osera- como del sudeste peninsular, asociadas a modelos de inspiración lateniense y con unas cronologías propuestas entre finales del siglo IV e inicios del III a. C. (Camacho et alii, op. cit.: 2016, 82, fig. 1). También del área y de cronología tardía serían otros ejemplares con dorado o sobredorado, como los documentados en La Umbría, donde aparecen fíbulas de tipo lateniense con sobredorado en el resorte (Aranda, op . cit.: 1990, 108, fig. 5), alguna de las cuales presenta una fabricación mixta en bronce y hierro y el puente decorado con círculos troquelados y sobredorados (Ceres, Colecciones en Red. Museo de Daroca $\mathrm{n}^{\circ}$ inventario 00277).

Tanto en el extremo occidental del valle medio del Ebro como en Navarra, las relaciones con las regiones francesas de Aquitania y Languedoc fueron muy intensas, posiblemente desde los inicios de la Edad del Hierro, pero con total seguridad en sus momentos más avanzados, a partir del siglo VI a. C. (Torres-Martínez: 


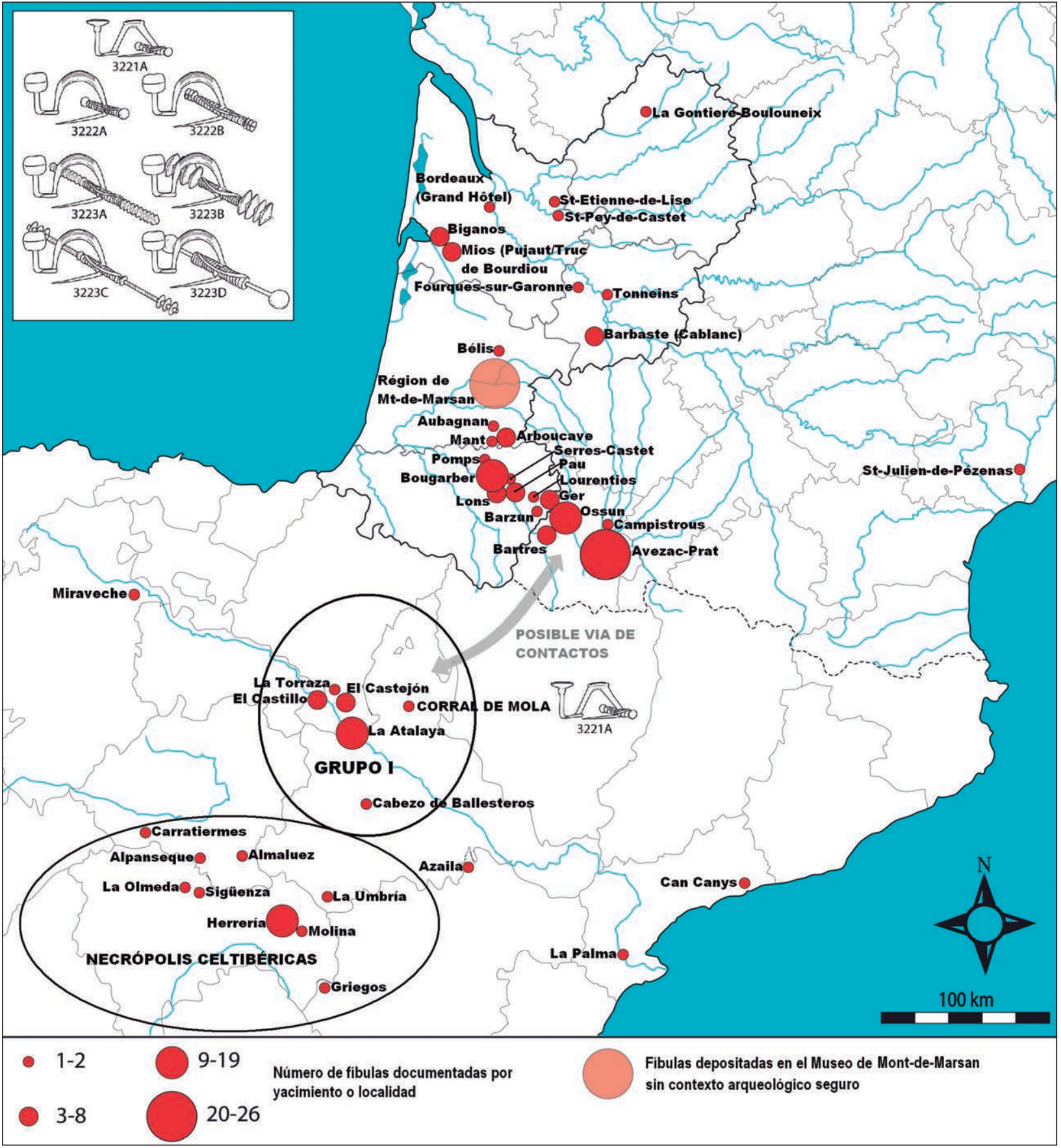

Fig. 58. Yacimientos en los que se ha documentado la presencia de fíbulas de tipo navarro aquitano en el valle del Ebro y en el sur de Francia (Cartografía elaborada por Constantin y Bilbao: 2014, modificado por Royo 2016).

2013, 265) (fig. 58). Esta relación es especialmente significativa en las fíbulas de pie vuelto y resorte bilateral, también denominadas como navarro-aquitanas, que aparecen con profusión a partir del siglo VI en las necrópolis tumulares francesas de Aquitania y Altos Pirineos, extendiéndose después hasta la cuenca del Garona con los tipos 3221, 3222 y 3223, ya definidos por Mohén y recientemente revisadas en trabajos específicos sobre las fíbulas de esta región (Constantin y Chorda: 2014, 223, fig. 2). Si vemos las características del tipo 3221A de fíbula aquitana que se caracteriza por su resorte bila- teral terminado en bolas, su puente trapezoidal y su pie rematado en disco, fechado en dicha zona a mediados del siglo VI a. C. (Constantin y Bilbao: 2013, 312, figs. 1-2), veremos que sus parecidos formales son más que evidentes con nuestro ejemplar del Corral de Mola, pudiendo corresponder a un tipo más antiguo que las fíbulas propiamente definidas como de discos o navarro-aquitanas, cuestión esta que en nuestro caso queda pendiente a la espera de la necesaria revisión y sistematización de los ejemplares de las necrópolis navarras y del valle medio del Ebro (fig. 58). 

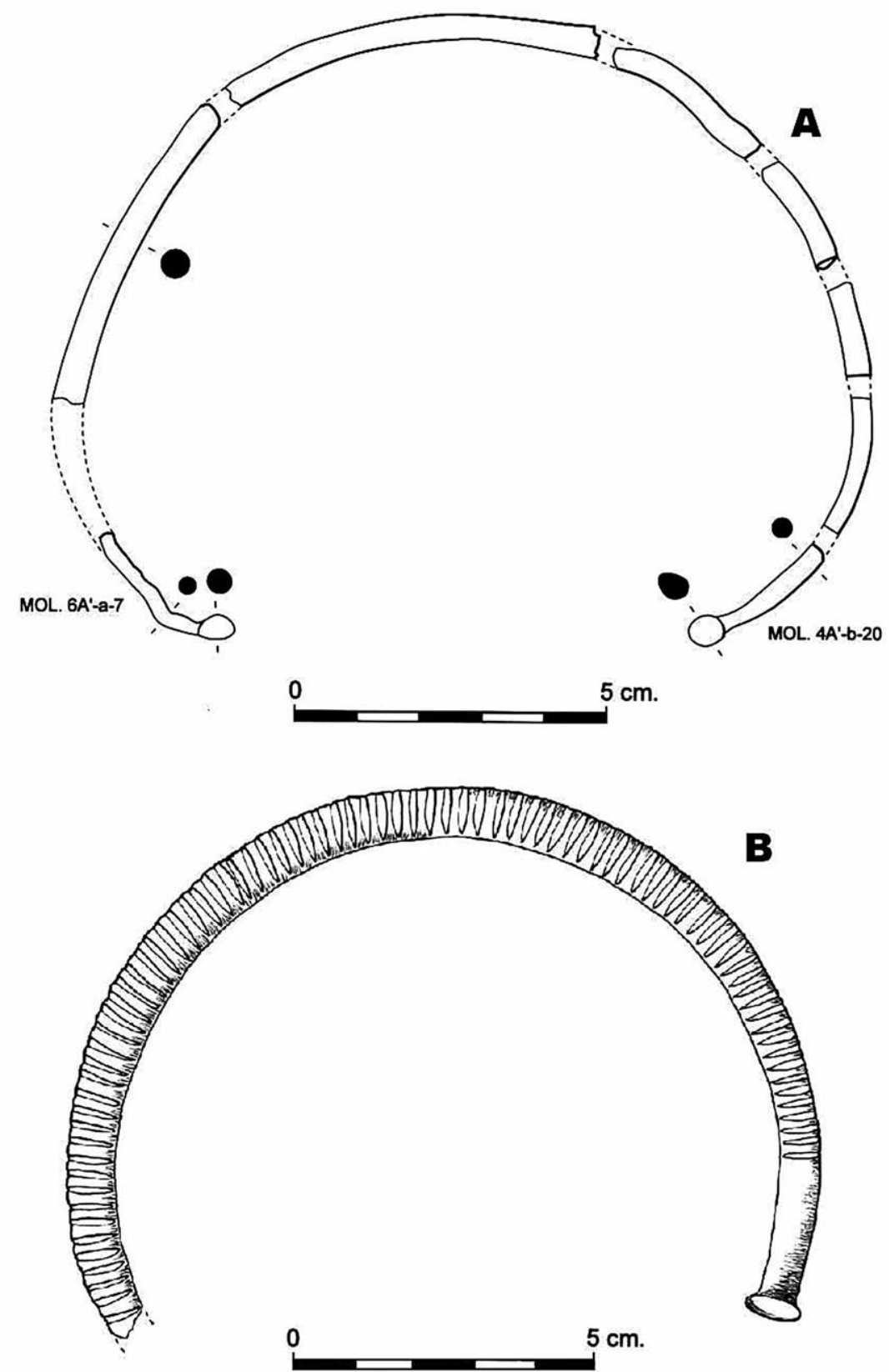

Fig. 59. Los dos torques aparecidos en la necrópolis de Corral de Mola: A, Torques de vástago liso, sección cilíndrica y terminaciones engrosadas del túmulo 1. B, Torques de vástago decorado con estrías transversales y tampones sin contexto estratigráfico (Dibujos: A. Blanco 2000 y Royo 2016).

\section{4. 3. Los torques}

De los dos ejemplares localizados en Corral de Mola, el más sencillo de vástago filiforme y engrosamientos terminales, se recuperó con el ajuar funerario del túmulo 1(fig. 59, A). El otro ejemplar, de decoración estriada trasversal en el vástago y tampones terminales, fue recuperado sin contexto en labores agrícolas en los terrenos de la necrópolis (fig. 59, B). Aunque este tipo de piezas cuenta con muchos estudios en Europa y en la península ibérica, lo cierto es que los trabajos se han centrado en los ejemplares realizados en metales preciosos, destacando los ejemplares peninsulares en oro del noroeste y los realizados en plata, tanto del área ibérica como del ámbito meseteño (Barril y Romero: 2002), dejando de lado un estudio de conjunto sobre los torques de bronce y hierro.

Las piezas del Corral de Mola tienen paralelos en las principales necrópolis navarras de incineración, apareciendo en La Atalaya de Cortes, La Torraza de Valtierra, El Castejón de Arguedas o El Castillo de Castejón, junto a otros hallazgos posiblemente relacionados con necrópolis como en La Ra en Arroniz, o con 
piezas aisladas como Murillo el Fruto o zaragozanos como Ejea de los Caballeros (Castiella: 2007-2008, fig. 1). De los cuatro tipos definidos por Castiella, clasificados a partir del vástago como lisos, de torsión o sogueados, de estrías longitudinales o transversales, todos ellos terminados en bolas o engrosamientos o en tampones (Castiella, op . cit.: 2007-2008, 903, fig. 10), dos aparecen representados en Corral de Mola. El primero correspondiente al tipo de vástago liso y engrosamientos terminales, apareció fracturado intencionadamente de forma previa a su deposición, práctica que se ha documentado con bastante asiduidad en otros ejemplares navarros y que debe vincularse a determinados rituales (Castiella, op. cit.: 2007-2008, 905), mientras que el segundo ejemplar, de estrías transversales y tampones aparece casi completo y sin ninguna deformación.

Aunque de características similares, las necrópolis navarras aportan torques con notables diferencias tipológicas. Así en La Atalaya destacan los cinco o seis ejemplares de vástago liso, realizados en bronce y con engrosamientos terminales variados, desde tampones, a bolas más o menos desarrolladas, pero siempre con secciones del vástago muy finas, sin decoración (Castiella, op . cit.: 2007-2008, 897-898, figs. 2-3). En el Castejón de Arguedas encontramos hasta diez ejemplares exclusivamente realizados en bronce con una tipología más variada, desde vástagos lisos a sogueados o estriados, destacando por su gran similitud con los de Corral de Mola los recuperados en la sepultura 35 , estriado, o en las sepulturas 2 y 10 , en estos casos de vástago liso y sección muy adelgazada (Castiella y Bienés, op. cit.: 2002, 179-180, figs. 224, 226-227). Salvo el torques estriado, el resto de piezas presenta un mayor o menor grado de fragmentación, en muchos casos intencionado y posiblemente relacionado con un ritual de amortización similar al de las espadas inutilizadas (Castiella, op . cit.: 2002, 186). También debemos señalar la presencia de torques en la necrópolis del Castillo de Castejón, de donde desconocemos el número de piezas recuperadas, pero de la que se han publicado varios ejemplares completos identificados con los tipos de vástago liso, decorado con incisiones o con estrías transversales, todos ellos con tampones terminales (Faro et alii, op . cit.: 2002-2003, 73-74; Faro, op . cit.: 2003, 214, n ${ }^{\circ}$ catálogo E. F. 46, 74 y 103). En cuanto a la necrópolis de La Torraza, la revisión de los materiales de la excavación de Maluquer en los años 60 del siglo XX, ha proporcionado dos piezas muy fragmentadas y deterioradas por la incineración que parecen corresponder a ejemplares de vástagos lisos y posibles terminaciones engrosadas (Castiella, op . cit.: 2007-2008, 902, fig. 9).

En diferentes trabajos, Castiella ha señalado la extraordinaria concentración de torques en el área Navarra y extremo oeste de la provincia de Zaragoza, su casi exclusiva utilización en sepulturas femeninas y sus paralelismos con los hallazgos de torques de las zonas francesas de Aquitania y Languedoc fechadas entre el 725 y el 450 a. C. y la escasez de este tipo de torques de bronce en el resto de la Península Ibérica durante la $\mathrm{I}^{\mathrm{a}}$ Edad del Hierro (Castiella y Bienés, op. cit.: 2002, 185; Castiella, op. cit.: 2007-2008, 905906). No obstante, deben realizarse algunas matizaciones a dichos supuestos, ya que se han obviado de dichas apreciaciones los hallazgos de significativos ejemplares de torques broncíneos del Hierro I en otras áreas de la cuenca del Ebro y costas mediterráneas que citaremos a continuación. En la necrópolis de El Cabo de Andorra, aparecen varios fragmentos de torques de bronce de vástago cilíndrico y sin decoración que se han puesto en relación con otros ejemplares del área oriental del valle del Ebro, aparecidos en las necrópolis de Pedrós, Coll del Moro o La Tosseta, todos ellos con vástagos lisos, extremos vueltos sobre si y situados cronológicamente entre los siglos VII-VI a. C. (Benavente et alii., op . cit.: 2015, 98). Especialmente interesante es el hallazgo de un torques broncíneo en la necrópolis de Milmanda, el cual presenta un vástago de sección circular, sin decoración -salvo dos hoyuelos ovalados- y con extremos engrosados, pieza que parece contar con ejemplos similares procedentes de la necrópolis de La Pedrera de Vallfogona de Balaguer, todo ello en un contexto cronológico de la primera mitad del siglo VI a. C. (Graells, op . cit.: 2008, 76 y 121-122, fig. 48, NM76).

También hay que señalar los torques aparecidos en la necrópolis tarraconense de El Calvari -El Molar, Priorato-, con dos tipos, el de vástago liso y el de torsión, en ambos casos con los extremos vueltos sobre si; representan un porcentaje mínimo en los ajuares de esta necrópolis, estando presentes en las sepulturas 24, 61 y 65 , pero significativamente se corresponden con los enterramientos más ricos, tanto cualitativa como cuantitativamente, con asociación de torques, fíbula de doble resorte y brazaletes abiertos de sección acintada (Castro, op. cit.: 1994, 106, 108 y 112, lams. VI-4, VI7 y VI-8), asociación de piezas y riqueza que se ha vinculado a una "polarización social basada en la adscripción social en el seno del grupo con mayor acceso a los ajuares metálicos de bronce" que en este caso sería de hombres adultos dominantes (Castro, op . cit.: 1994, 113). La cronología de esta necrópolis se sitúa entre el 800 y el 600 a. C., constatándose la dualidad de ajuares y espacios, destacando las asociaciones de fíbulas-torques pertenecientes al género masculino, frente a la asociación de cadenas-colgantes, pertenecientes al género femenino (Castro, op. cit.: 1994, 154155. En la necrópolis de Mas de Mussols, en el Bajo Ebro, también aparecen varios torques de vástago liso, uno de ellos decorado con incisiones geométricas o de torsión, en todos casos terminados en engrosamiento o bolas (Maluquer, op . cit.: 1987, 81-83, figs. 20-21). En 


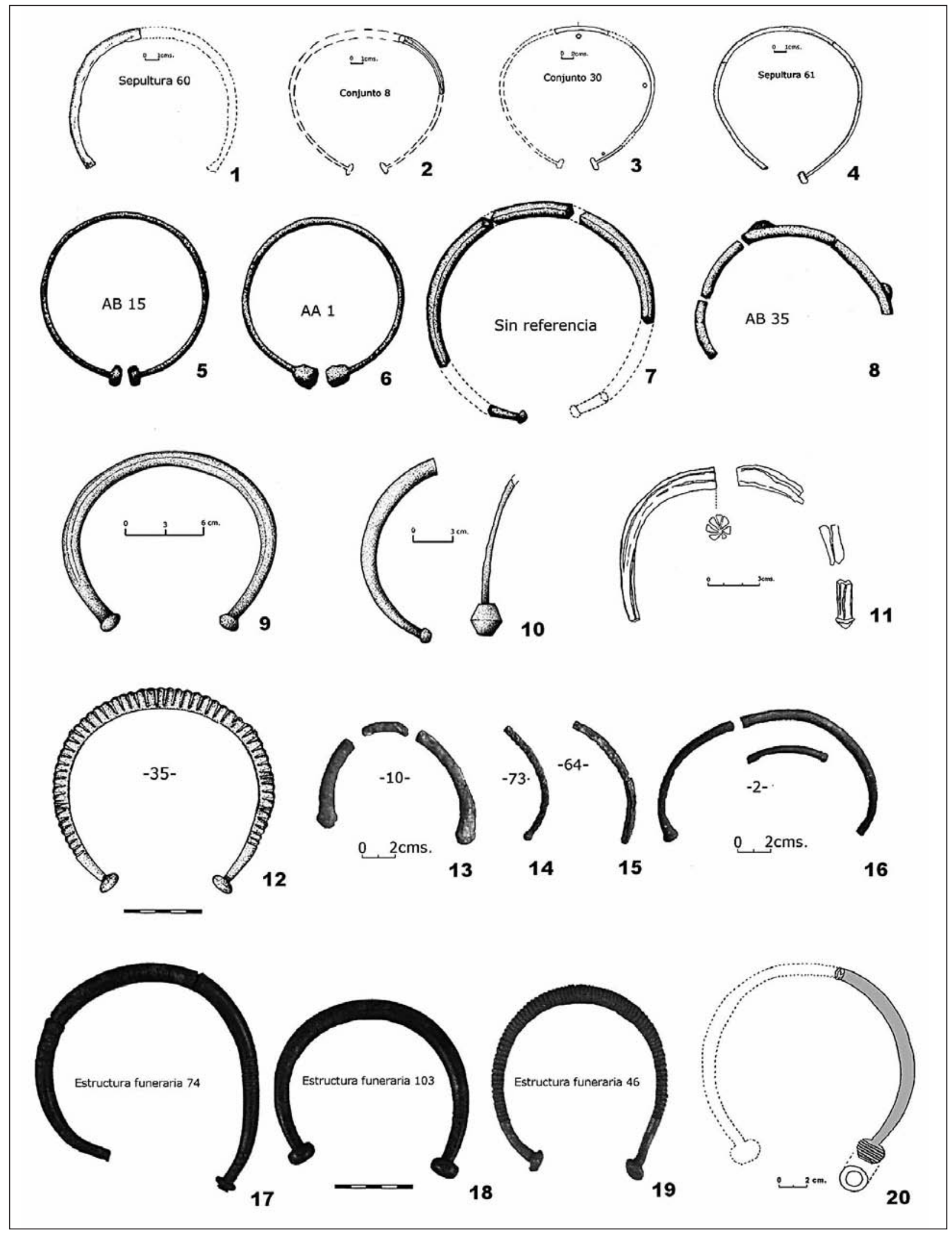

Fig. 60. Los diferentes tipos de torques aparecidos en Navarra y Aragón fechados en la I ${ }^{\mathrm{a}}$ edad del Hierro. 1-8, necrópolis de La Atalaya (Dibujos de Maluquer y Vázquez: 1956, 1-4 y Castiella: 2008, 5-8). 9, hallazgo de Murillo el Fruto (Dibujo: Castilla 2008). 10, dos fragmentos de torques de la necrópolis de La Rá en Arróniz

(Dibujo: Castilla 2008). 11, torques de la necrópolis de La Torraza de Valtierra (Dibujo: Castiella 2008). 12-16, diversos tipos de torques documentados en la necrópolis del Castejón de Arguedas (Dibujos: 12, Royo 2016, 13-16, Castiella 2008). 17-19, torques procedentes de la necrópolis de El Castillo de Castejón (Según Castiella 2008). 20, Torques procedente de El Escorón en Ejea de los Caballeros (Según Royo 2016). 
el caso del ejemplar decorado con incisiones, aparecido en la sepultura 50, está asociado a una fíbula de resorte con placa, broche de cinturón de placa con un garfio y escotaduras laterales y brazaletes abiertos ovalados (Maluquer, op. cit.: 1987, 54, fig. 5). El conjunto de esta necrópolis paleoibérica se ha situado entre el 580 y el 530 a. C. (Maluquer, op. cit.: 1987, 104). Del área costera catalana citaremos también la necrópolis de Can Bech de Baix de Agullana, en cuyo enterramiento $\mathrm{n}^{\circ} 9$ aparecieron dos fragmentos de torques de vástago liso y extremo en bola que fue vinculado en su momento con el conjunto de Mailhac II (Palol, op . cit.: 1958, 28 y 215, fig. 10). Muchos de los ejemplos de torques catalanes de vástagos de torsión y extremos vueltos sobre si, podrían emparentarse con producciones de origen ligur, como parece demostrar su dispersión por el Golfo de León y la presencia de siete torques picenos depositados en el Museo de Vic de un falso hallazgo tarraconense, producto del comercio de antigüedades de comienzos del siglo XX (Graells: 2011, 253-254, lams. 9-12).

En cuanto a las necrópolis navarras en la región francesa de Aquitania, contamos con ejemplos de torques de vástago estriado y tampones terminales en la necrópolis de Avezac-Prat, en el túmulo G de Mios en Pujaut y en la región de Mont-de-Marsan en las Landas (Castiella y Bienés, op . cit.: 2002, 185). Recientemente se ha realizado una nueva síntesis sobre el conjunto de adornos de las necrópolis aquitanas (Constantin, op . cit.: 2014) en el que se ha planteado que los ejemplares de la necrópolis de Pujaut -Gironda- y en el túmulo de Pau -Pirineos Atlánticos-, a partir de su asociación con fíbulas de resorte bilateral y discos, pueden fecharse entre 520 y 450 a. C. (Constantin, op. cit.: 2014, 141, fig. 5 y 16, 2-4). En lo referido a los torques de vástago liso y extremos engrosados o con tampones, se destaca la imprecisión cronológica a partir de la falta de contextos arqueológicos precisos, si bien atendiendo a algunas asociaciones, como en el caso del torques de Truc de Bourdiou, se plantea una cronología de 640-600 a. C. por lo que estaríamos ante uno de los torques más antiguos localizados en Francia durante la Edad del Hierro. Por el contrario, algunos ejemplares del museo de Mont-de-Marsan y de otras áreas cercanas, parecen evidenciar un cambio de material al final del Hierro I, sustituyéndose en los ajuares funerarios la presencia de torques férreos por los de bronce, por lo que este tipo de piezas se datarían en el sur de Francia a mediados del siglo VI a. C. (Constantin, op. cit.: 2014, 140-141, fig. 5 y 15). A partir de los paralelos de ajuares funerarios entre Aquitania y el área noroeste del valle del Ebro, se plantea una clara oposición, a partir de mediados del siglo VI a. C., entre el área navarro-aquitana y la fachada este de los pirineos, entre Languedoc y Cataluña, oposición que se manifiesta en algunas piezas metálicas del ajuar funerario específicamente propias de cada una de estas regiones
(Constantin, op . cit.: 2014, 157), como ya hemos visto con las fíbulas, con los broches de cinturón o incluso con los brazaletes.

\section{4. 4. Los brazaletes.}

Los brazaletes abiertos de forma arriñonada u ovalada que aparecen en Corral de Mola presentan dos tipos bien definidos: los de sección rectangular o acintada y los de sección cuadrangular, en los dos casos con decoración incisa de líneas paralelas o convergentes en los lados exteriores, pudiendo aparecer de forma aislada, formando conjuntos numerosos o incluso soldados entre sí, como hemos constatado en la excavación del túmulo 1 de este yacimiento (figs. 12-17). Ambos tipos, de extrema sencillez tipológica, son muy comunes en todas las necrópolis de la Primera Edad del Hierro de la cuenca del Ebro desde su cuenca alta hasta la costa catalana, así como en la Celtiberia y sur de Francia, desde Aquitania hasta el Languedoc y ya aparecen en el valle del Ebro desde los inicios del Bronce Final, como hemos atestiguado en el túmulo 14 de inhumación de la necrópolis de Los Castellets II, donde se documentó un conjunto de diez brazaletes abiertos como ajuar de un individuo inhumado, junto a los restos de tres anillos y dos vasos acanalados, aunque estos brazaletes cuentan con mayor peso y dimensiones que nuestros ejemplares (Royo: 1992, 84-87, fig. 4; Royo, op. cit.: 1994-96, 104, fig. 7). Este rico ajuar se fecha por C14 entre fines del siglo XIV y principios del siglo XIII Cal. B. C. (Castro, op. cit.: 1994, 134).

Este tipo de brazaletes, pueden rastrearse en diversos depósitos u ocultaciones de bronces, como el depósito de brazaletes de Sant Aleix (Lleida), localizado muy cerca de los pasos con el Garona y por tanto con acceso directo hacia Aquitania y donde aparecen varios brazaletes casi idénticos a los del Corral de Mola -tipo 4-, algunos de ellos decorados con motivos geométricos en el canto y que se han fechado entre el 900 y el 800 a. C., a caballo entre el Bronce Final y la Edad del Hierro (Rovira y Casanovas: 1993, 77, fig. 7). Del Bronce Final III serían los brazaletes del depósito de bronces de Llavorsí (Pallars Sobirá) (Gallart: 1991), donde encontramos algunos ejemplares de forma arriñonada, abiertos y con decoraciones incisas y pesos muy similares a los brazaletes del Corral de Mola, aunque con la sección más abultada (Gallart, op. cit.: 1991, lam. XLII). Para este gran depósito se propone un origen en la Francia Oriental, en las regiones del Jura, Savoia y Altos Alpes, pasando a Cataluña a través de la región languedociense y los Pirineos (Gallart, op. cit.: 1991, 177-178, fig. 22).

Todavía podemos ver un ejemplar de brazalete abierto y de sección aplastada, como único ajuar del túmulo $\mathrm{n}^{\circ} 35$ de Los Castellets II fechado en el Bronce Final (800/750 cal BC) por su urna funeraria de perfil 


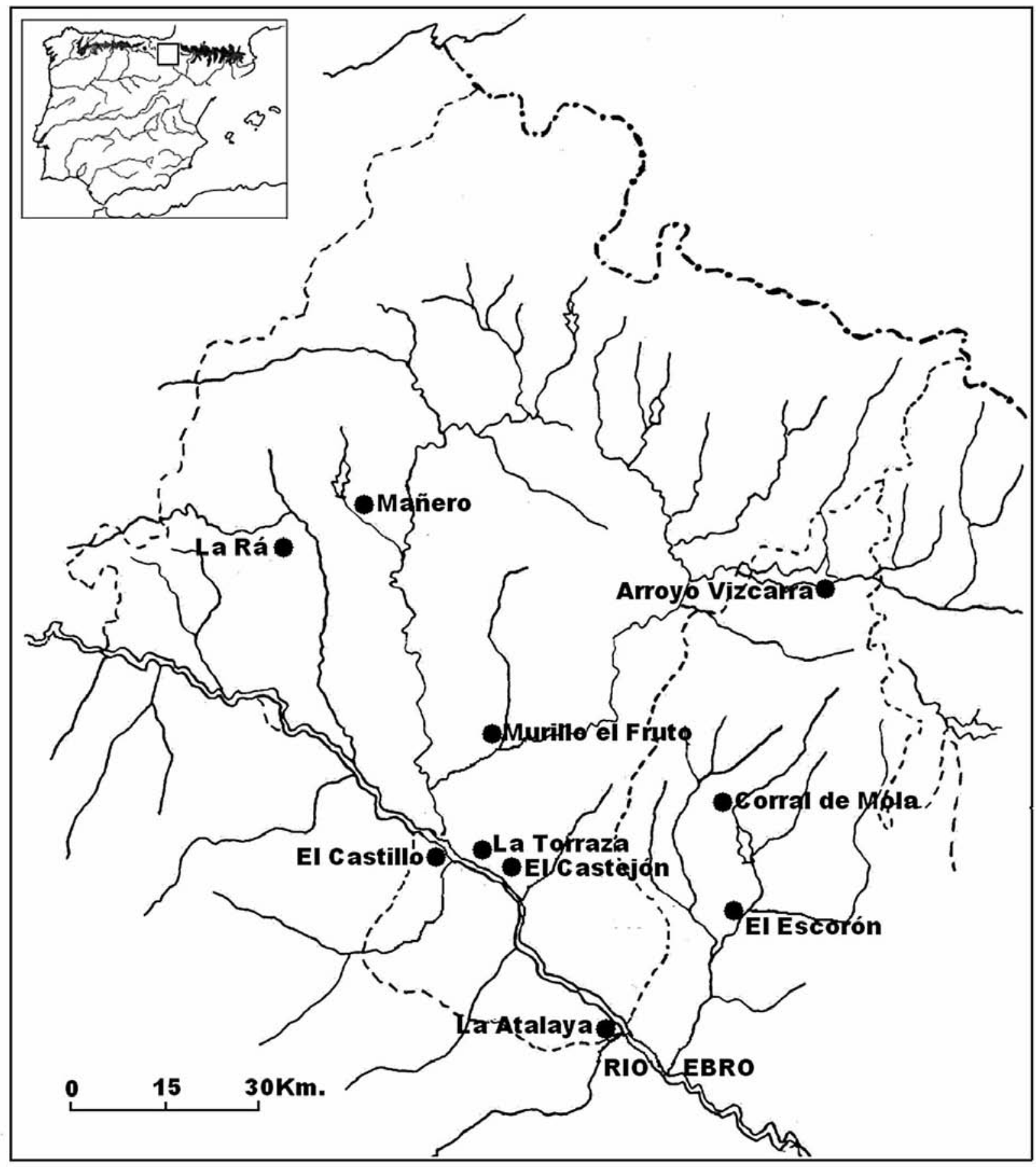

Fig. 61. Localización geográfica de los torques aparecidos en Navarra y Cinco Villas de Zaragoza (Cartografía a partir de Castiella 2008, modificada por Royo 2016).

bitroncocónico, con borde exvasado y decoración acanalada en cuyo interior se depositó dicho brazalete bajo los restos de la cremación (Royo: 1991, 123, fig. 2) y que podría marcar el momento inicial del uso generalizado de este tipo de brazaletes en el valle medio del Ebro. Teniendo en cuenta los citados precedentes y la simplificación de los tipos, que se reducen a secciones rectangulares aplastadas o acintadas y cuadrangulares, pero siempre con dimensiones muy pequeñas, lo que a buen seguro redundó en un ahorro de materia prima, a partir del siglo VII y durante el siglo VI a. C. es un modelo que se generaliza en todas las necrópolis de incineración del valle del Ebro, perdurando hasta los momentos finales del Hierro I e inicios del II en los ámbitos celtibéricos de la meseta oriental y protoibérico, como veremos a continuación.

Aparecen restos de brazaletes abiertos y algún ejemplar completo en la necrópolis de Arroyo Vizcarra, asociados a incineraciones "in situ" dentro de los círculos de piedra (Royo, op. cit.: 1997a, 56), aun- 
que el saqueo generalizado de sus ajuares funerarios (Royo, op . cit.: 1997a, 47) nos impide hacer una valoración sobre la importancia de este tipo de piezas en este conjunto. Con mucha mejor representación, encontramos brazaletes de los dos tipos del Corral de Mola en las necrópolis navarras como en La Atalaya, en la que pueden aparecer sueltos o soldados (Maluquer y Vázquez, op . cit.: 1956, 29), con sección cuadrangular o rectangular, como puede verse en la sepultura 44 o en el conjunto 22 donde aparecen completos (Castiella, op. cit.: 2005, 185-186, fig. 101). En La Torraza de Valtierra también aparecen muy destruidos por las cremaciones, aunque destacamos el enterramiento $\mathrm{n}^{\circ} 12$, donde se documentaron varias agrupaciones de brazaletes abiertos en grupos de entre 10 y 20 ejemplares (Maluquer, op . cit.: 1957, 255, fig. 7), por lo que suponemos un depósito bastante importante de este tipo de pulseras, hecho similar al documentado en Corral de Mola. En la necrópolis de Castejón de Arguedas también aparecen pero muy deteriorados por la cremación, estando presentes los dos tipos de Corral de Mola y también las agrupaciones o los ejemplares soldados, suponiendo que el número de estos fue importante en algunas sepulturas a pesar de su fragmentación (Castiella y Bienés, op . cit.: 2002, 190-193, figs. 241-245). También en El Castillo de Castejón aparecen este tipo de brazaletes con bastante profusión, destacando la presencia de agrupaciones de más de veinte ejemplares soldados, aunque pueden aparecer en grupos menores o aislados, como en el caso del enterramiento 121 (Faro, op. cit.: 2002, 220). Por su parte, en las necrópolis del Alto Ebro no aparecen estos tipos de brazaletes, aunque sí lo hacen con otras tipologías más evolucionadas, al menos en La Hoya y en Miraveche (Llanos, op. cit.: 1990, fig. 5).

Siguiendo el eje del Ebro, encontramos este tipo de brazaletes en las necrópolis del Jalón, especialmente en el Barranco de la Peña de Urrea de Jalón y en el Cabezo Ballesteros de Épila, donde estas pulseras abiertas de sección rectangular son bastante abundantes (Pérez Casas, op. cit.: 1990, 115 y 117). En el curso bajo del río Huerva, en la fase III del poblado del Cabezo de la Cruz de La Muela, apareció en la excavación de la casa 6 un ejemplar completo de brazalete abierto y sección aplastada (Picazo y Rodanés, op . cit.: 2009, 410-411, fig. 6).

En el Bajo Jiloca, afluente del río Jalón, aparecen en La Umbría de Daroca en contextos asociados a fíbulas de doble resorte evolucionadas y broches de cinturón de uno y tres garfios junto a una variada selección de fíbulas de pie vuelto y de La Tene (Aranda, op . cit.: 1990, 107-108, fig. 5). Por su parte, la revisión de las excavaciones del Marques de Cerralbo y el estudio exhaustivo de los materiales de la necrópolis de Arcóbriga, ha permitido constatar su ausencia en este yacimiento (Lorrio y Sánchez: 2009, 410-411, fig. 179,
1-2), aunque sí ha confirmado su presencia significativa en la necrópolis de Clarés o Valdenovillos, excavada por Cabré y en la que aparecen con profusión este tipo de pulseras o brazaletes simples o múltiples en un contexto cronológico claramente anterior al de Arcóbriga (Lorrio y Sánchez, op . cit.: 2009, 532-536, figs. II-9 y II-10). En la necrópolis de Carratiermes aparecen en gran número los brazaletes abiertos de sección rectangular, sencillos o múltiples, constatándose su presencia en 118 sepulturas con ajuares que remiten a la fase más antigua de esta necrópolis, de fines del siglo VI o inicios del V a. C. relacionadas con las necrópolis más antiguas de la Edad del Hierro del valle del Ebro (Argente et alii: 2000, 120-123, fig. 51, 1-3). También debemos destacar la presencia significativa de brazaletes como los del Corral de Mola en la necrópolis de Herrería III (Guadalajara-Alto Tajo), donde aparece en tumbas femeninas y masculinas, incluso asociados a la presencia de armamento, pudiendo destacarse como ejemplo el de la tumba 135, donde aparece un gran número de ejemplares fundidos por la cremación (Cerdeño y Sagardoy, op . cit.: 2007, 93-94 y 130, fig. 215). La datación radiocarbónica de Herrería III, entre los siglos VIII-VII a. C. (Cerdeño y Sagardoy, op . cit.: 2007, 185), a nuestro juicio excesivamente alta, no parece concordar con la cultura material documentada en esta necrópolis, por lo que en el futuro deberá revisarse. Por último citaremos la necrópolis del Cuarto de Griegos, en la serranía de Albarracín y en el entorno del Alto Tajo, donde también se documentó la presencia de brazaletes abiertos, como en la sepultura $n^{\circ} 5$ en la que aparecen simples y soldados entre sí en número superior a la veintena (Almagro Basch, op. cit.: 1942, 107, fig. 3). Las excavaciones realizadas en los años 90 del siglo pasado, han permitido ampliar el conocimiento de esta necrópolis y documentar la presencia de estos brazaletes en la mayoría de las sepulturas (Chordá et alii: 2013-14, 233, figs. 8-9), con una datación radiocarbónica que elevaría el conjunto al siglo VIII Cal BC, pero que por el contexto material y la problemática específica provocada por la "meseta de Hallstatt" obliga a sus investigadores a proponer unas fechas entre los siglos VII y VI a. C. (Chordá et alii, op. cit.: 2013-14, 233-234), mucho más acordes con los ajuares documentados.

Otra necrópolis del valle medio del Ebro, donde se han documentado este tipo de brazaletes es la de Azaila, como es el caso del túmulo 96 de la Edad del Hierro, donde hay ejemplares soldados en grupos de tres a cinco, aunque muy deteriorados por la incineración (Beltrán Lloris, op . cit.: 1976 b, 50, fig. 17, 3513). El sector oriental del valle medio del Ebro, en las necrópolis del Segre-Cinca o el Bajo Aragón, también aparecen estos brazaletes, de los que solamente citaremos su hallazgo en La Pedrera, Roques de Sant Formatge, Coll del Moro o Fila de la Muela (Ruiz 

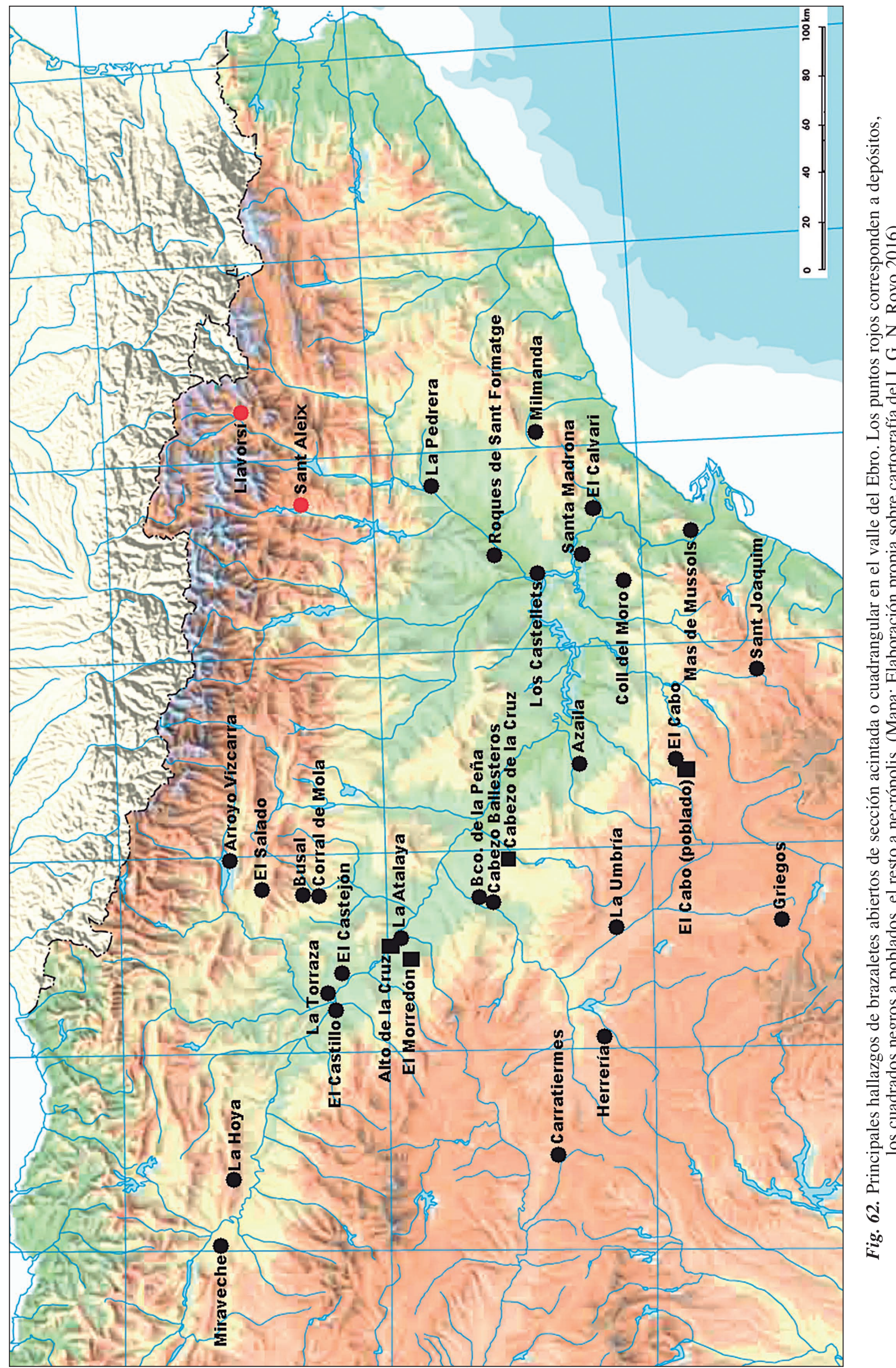
Zapatero, op . cit.: 1985, 965-967), destacando el caso de la necrópolis de El Cabo (Andorra, Teruel), donde se combinan dos tipos, el abierto con sección cuadrangular aplastada y el cilíndrico, cuyo estudio detallado ha permitido fechar el conjunto entre fines del siglo VII y el primer cuarto del siglo VI a. C. gracias a su asociación con otros materiales bien contextualizados, como las fíbulas de doble resorte y los torques de tampones o botones (Benavente et alii, op . cit.: 2015, 8895), asociación que repite lo ya documentado por nosotros en Corral de Mola. Ya de la primera mitad del siglo V a. C. serían los ejemplares de brazaletes abiertos aparecidos en el poblado de El Cabo, a caballo entre el Ibérico Antiguo y Medio del Bajo Aragón (Benavente y Galve: 2000, 35 y 39).

La aparición de este tipo de brazaletes abiertos está atestiguada en las necrópolis catalanas de incineración del Bajo Ebro, destacando las de Milmanda -Conca de Barberá, Tarragona- donde aparecen en contextos donde también aparecen fíbulas de doble resorte, broches de cinturón de un garfio con escotaduras o torques terminados en bolas (Graells: 2008b, 73-89), o la de Santa Madrona -Ribera d'Ebre, Tarragona- en este caso con mayor pobreza de ajuares metálicos, aunque siguen presentes los referidos brazaletes, lisos o con decoración en los laterales (Belarte y Noguera: 2007, 50-52, figs. 69-73). No obstante, los paralelos más notables los encontramos en la necrópolis paleoibérica de Mas de Mussols -Tortosa, Tarragona-, donde aparece un notable grupo de brazaletes abiertos de muy variada tipología, desde los de sección cilíndrica a los de sección rectangular aplastada, o los terminados en bolas o botones, entre los que también están presentes ejemplares plenamente coincidentes con los del Corral Mola (Maluquer: 1987, 84-85, fig. 22) que aparecen junto a broches de cinturón de un garfio del tipo Fleury, fíbulas de doble resorte de puente aplastado o torques terminados en bolas (Maluquer, op . cit.: 1987 , 69-70, figs. 13, 17 y 20) que llevan a su investigador a una datación centrada a lo largo del siglo VI a. C. (Maluquer, op . cit.: 1987, 104). No obstante es en la necrópolis de El Calvari (El Molar, Priorat, Tarragona), donde la presencia de los brazaletes abiertos y sección aplastada, ya sean simples o soldados alcanza su máxima expresión, ya que es en las tumbas más ricas donde se concentra su aparición, con más de treinta ejemplares por sepultura, además de estar siempre asociados a ajuares con presencia de fíbulas de doble resorte de puente filiforme, muchas espiras y mortaja corta, así como torques, la misma asociación que se produce en el Corral de Mola y que en El Calvari se ha definido como un símbolo de acumulación de riqueza en las sepulturas masculinas, como puede verse en las sepulturas 61 o 65 (Castro, op . cit.: 1994, 112-113, lams. VI-7 y VI-8). Al igual que en el caso de El Calvari, la asociación de este tipo de braza- letes con las fíbulas de doble resorte de tipología más antigua, nos permitiría situar los brazaletes del Corral de Mola entre las producciones más antiguas de la Edad del Hierro del valle medio del Ebro, con una antigüedad como mínimo similar a la necrópolis catalana (Castro, op. cit.: 1994, 141-143).

La difusión de este tipo de brazaletes hacia la costa mediterránea y hacia el Alto Maestrazgo, queda plenamente constatada con su presencia en la necrópolis tumular de Sant Joaquim de la Menarella (Forcall, Castellón), en la que parece constatarse una clara influencia de las necrópolis del Bajo Aragón y Bajo Ebro que se fecha entre finales del siglo VII y la segunda mitad del VI a. C. (Vizcaíno, op . cit.: 2010, 159166, fig. 6.1). En este yacimiento también aparecen restos de brazaletes abiertos de sección rectangular y alguna fíbula de doble resorte, aunque de puente aplastado y decorado, por lo tanto de datación más moderna que las de puente filiforme (Vizcaíno, op. cit.: 2010, 138-141, figs. 4.13 y 4.16). Estas influencias de los C. U. en toda la costa mediterránea, también se documentan en el sureste de la Península Ibérica (Lorrio, op. cit.: 2008), donde encontramos varias necrópolis con enterramientos de inhumación y ajuares en los que predominan los brazaletes abiertos, decorados o no con incisiones laterales y con secciones que van de las rectangulares, a las cuadrangulares o circulares (Lorrio, op . cit.: 2008, 255-258, figs. 151-153). Estos brazaletes se asocian en varios casos a fíbulas de doble resorte de tipo filiforme, fechándose dichos hallazgos entre los siglos VIII y VI a. C. (Lorrio, op . cit.: 2008, 247248, fig. 147).

En cuanto a las necrópolis situadas al norte de los Pirineos, tanto en el sureste como en el suroeste francés contamos con hallazgos de brazaletes abiertos muy similares a los del Corral de Mola en las necrópolis aquitanas y del Languedoc. Se encuentran en gran número en las colecciones antiguas del museo de Mont-de-Marsan, en el túmulo de Camí Salie de Pau, $\mathrm{o}$ en la sepultura 1 de Fourques-sur-Garonne (Constantin, op . cit.: 2014, 139, fig. 13, 9-10). Muy similares a estos se encuentran brazaletes en otras necrópolis de los Altos Pirineos o en el área de Castres, pudiendo citar como ejemplo los ejemplares recuperados en la sepultura 4 de Lesparre a Barbaste -Lot-etGaronne- (Constantin, op . cit.: 2014, 139, fig. 14, 1-6). La cronología asignada a este tipo de piezas es muy problemática, ya que sus principales tipos son herederos de la Edad del Bronce y perduran a lo largo de toda la Edad del Hierro en el sur de Francia, desde mediados del siglo VIII hasta el siglo V a. C., sin que la mayoría de los contextos documentados permitan mayores precisiones (Constantin, op . cit.: 2014, 138139). No obstante, algún hallazgo puede contribuir a contextualizar el origen de las primeras producciones de estos brazaletes en el sudeste francés. En la necró- 
polis de Negabous recientemente excavada, con más de 300 sepulturas en fosa sin señalización y fechada entre el Bronce Final IIIB y la Primera Edad del Hierro (Toledo: 2012, 246), en las sepulturas 105 y 183, datadas en el Bronce Final IIIB, aparecen varios brazaletes abiertos de varias secciones muy similares a los del Corral de Mola junto a botones semiesféricos (Toledo, op. cit.: 2012, 246, fig. 3). Otro ejemplo bien contextualizado lo podemos encontrar en el depósito fluvial de La Motte en Adge, fechado entre finales del siglo VIII a. C. y mediados del siglo VII a. C., con algunos elementos del Hallstatt $\mathrm{C}$ centroeuropeo (Verger et alii: 2007). Dicho depósito se ha identificado con un ajuar femenino de gran importancia por tratarse de un descubrimiento en su contexto original y por lo tanto de un conjunto cerrado compuesto por más de 300 objetos (Verger et alii, op. cit.: 2007, 162-163) en el que se han recuperado una serie de brazaletes ovalados y abiertos con decoración incisa en el costado lateral, cuyas similitudes con los ejemplares de Corral de Mola resultan más que evidentes (Verger et alii., op. cit.: 2007, 108-109, fig. 18, 1-4, 19).

\section{4. 5. Los botones.}

Los botones hemisféricos, con tres ejemplares recuperados en Corral de Mola (fig. 10. MOL.4A' -a11, MOL.S-25 y MOL.S-12), también son muy comunes en los yacimientos del valle medio del Ebro, especialmente en su sector occidental y están bien representados en las necrópolis de la zona, especialmente en Arroyo Vizcarra, a orillas del embalse de Yesa, donde aparecen en cantidades más que significativas, destacando su número en el enterramiento $\mathrm{n}^{\circ} 1$, con 30 ejemplares y en el $n^{\circ} 2$ con más de 40 piezas, además de la presencia de otros tipos de botones como los cónicos, que aumentan el número de este tipo de piezas hasta cerca del centenar (Royo, op . cit.: 1997 a, 56; Royo y Fatás, op . cit.: 2017, 50, fig. 4). Son muy abundantes en algunas de las necrópolis navarras (Castiella y Bienés, op. cit.: 2002, 190-196), especialmente en La Torraza de Valtierra donde se recuperaron varios centenares, tanto de perfil cónico como semiesférico con travesaño, lo que unido a su aparición en contextos no bien identificados, les resta valor cronológico (Maluquer, op . cit.: 1957, 265). En la necrópolis de La Atalaya, los botones son extrañamente escasos, reducidos a dos ejemplares, uno semiesférico y el otro cónico (Castiella, op . cit.: 2005, 192-193, fig. 107), escasez posiblemente vinculada al tipo de recuperación de restos durante la intervención arqueológica (Maluquer y Vázquez, op . cit.: 1956, 5-6). En la necrópolis del Castejón de Arguedas, sólo aparecen los correspondientes al tipo semiesférico en número muy variable en cinco de los ochenta y siete enterramientos tumulares, con trece ejemplares en el túmulo 22 , cuatro y seis en los túmulos 38 y 52, uno en el enterramiento 3 del nivel D y cerca de dos centenares en el túmulo 19 (Castiella y Bienés, op. cit.: 2002, 69, fig. 107 y 195). También destaca la ausencia de botones hemisféricos en la necrópolis de El Castillo de Castejón, bien por su no aparición, o por que no se ha constatado.

Como pieza de carácter funcional, aparece en los principales poblados del valle medio del Ebro, como en el Alto de la Cruz de Cortes, donde aparece en gran parte de su estratigrafía, ya desde el primitivo poblado PIIIa (Maluquer, op. cit.: 1958, fig. 5), o bien en el poblado de El Morredón de Fréscano, con seis ejemplares semiesféricos con travesaño en un contexto arqueológico paralelizable al PIIb del Alto de la Cruz (Royo Guillén, op. cit.: 2005, 83, fig. 36). Otro ejemplar cónico con travesaño se documentó en el poblado de Burrén y Burrena, también en Fréscano (Aguilera y Royo: 1978, 28, lám. XI, 29), también asociado a una cultura material del Hierro I en su fase plena. Uno de los conjuntos mejor contextualizados es el localizado en la casa I del segundo poblado del Hierro I del Cabezo de la Cruz de La Muela, donde se documentaron hasta diez ejemplares de los que ocho corresponden a botones semiesféricos y dos a cónicos, señalando sus autores que estos tipos aparecen muy extendidos por todo el valle del Ebro, desde los poblados del País Vasco hasta las necrópolis catalanas, siendo fechados entre los siglos VII-VI, aunque pueden llegar hasta bien entrado el siglo V a. C. (Picazo y Rodanés, op. cit.: 2009, 409-410, fig. 3).

Dada la indefinición de estas piezas no realizaremos un estudio exhaustivo de sus paralelos pero citaremos algunas necrópolis de nuestro Grupo I en las que también aparecen, como en las del Jalón, especialmente en el Cabezo de Ballesteros (Pérez Casas: 1988, 8586). También citaremos su aparición en la necrópolis de Los Castellets II, donde se descubren desde los inicios de la Edad del Hierro, a partir del 800 a. C., coexistiendo los dos principales tipos, cónicos y semiesféricos, ambos con travesaño, como se ha constatado en el ajuar metálico de los túmulos 24 y 24 bis de dicha necrópolis (Royo Guillén, op. cit.: 1994-1996, 104). Algunos autores han rastreado el origen y posterior evolución de estos pequeños objetos, señalando que el origen en la Península Ibérica de los más antiguos, los cónicos, debe situarse entre el 800-750 a. C., pudiendo perdurar a lo largo de toda la $\mathrm{I}^{\mathrm{a}}$ Edad del Hierro, evolucionando hasta generalizarse el modelo semiesférico que puede llegar hasta bien entrado el siglo $\mathrm{V}$ a. C. (Ruiz Zapatero, op . cit.: 1985, 974-975, fig. 281). Al igual que en el caso de los brazaletes, el depósito fluvial de La Motte en Adge, en la frontera entre el Languedoc occidental y oriental, fechado en la primera mitad del siglo VII a. C. también cuenta con una nutrida presencia de botones semiesféricos y especialmente cónicos, en este caso posiblemente utilizados como elementos de decoración de un cinturón (Verger et alii., op. cit.: 2007, 117-119, fig. 26, 1-7). 


\section{4. 6. Una pieza singular: El cuchillo/navaja de afeitar}

Por lo que se refiere al cuchillo o navaja de afeitar (fig. 10. MOL.6A'-s-2 y MOL.4A'-b-30), estamos ante una pieza incompleta, pero que permite su reconstrucción parcial. Se trata de uno de los elementos que peor hemos podido contextualizar en el valle del Ebro, en el que no hemos encontrado ningún paralelo que pueda relacionarse con esta pieza. Tanto su morfología, como su decoración y el hecho de que tanto la espiga como la anilla aparezcan perfectamente acabadas y pulidas y por lo tanto se hayan fabricado con intención de permanecer a la vista, nos indica que aún cuando pudiera pensarse en una posible utilidad como cuchillo de uso ritual, la realidad es que debe clasificarse como una navaja de afeitar, de una tipología no constatada en el área en estudio, salvo si consideramos como posible precedente o modelo la navaja de afeitar que apareció en el enterramiento 207 de la necrópolis de Agullana (Gerona) (Palol, op . cit.: 1958, fig. 189,11$)$ y que aparece asociada a un ajuar cerámico de vasos bitroncocónicos de carena acusada y decoración incisa asociados al grupo Mailhac I, junto a los que se recuperaron dos fíbulas de doble resorte de sección filiforme (Palol, op . cit.: 1958, 176-179). Este tipo de navajas de afeitar, así como otras aparecidas en esta necrópolis, fueron emparentadas en su momento a modelos centroitálicos, fechándose en la fase inicial de esta necrópolis, Agullana I, a caballo entre el Bronce Final y los inicios de la Edad del Hierro (Palol, op . cit.: 1958, 212). Sin descartar totalmente la posibilidad de que esta pieza pudiera considerarse o utilizarse como cuchillo, también podríamos encontrar paralelos en ajuares de algunas necrópolis de C. U. del grupo Rhin-SuizaFrancia Oriental, como sería el caso de Vicreuses -Nièvre-, donde aparece un cuchillo del Bronce Final IIa con anilla, espiga con perforaciones y hoja con corte lateral y tres incisiones longitudinales del tipo Baierdorf (Bouthier et alii:1988, 421-422, INH 23) cuyos paralelos y precedentes se localizan en el valle del Rhin (Rihovsky: 1972, tafel 11, 125 y tafel 12, 126). Cuchillos similares fechados entre los siglos VIII y VII a. C., todos ellos con espiga y anilla y hoja decorada con incisiones, también aparecen en el norte de Italia en necrópolis de los inicios de la Edad del Hierro (Bianco: 1976, 28, tafel 10). El único ejemplo conocido en todo el noreste peninsular de este tipo de cuchillos del Bronce Final centroeuropeo es el localizado sin contexto en Tarragona del tipo Dasice (Ruiz Zapatero, op, cit.: 1985, 899, fig. 251) que se ha vinculado al ajuar de determinadas élites guerreras como un elemento de exhibición de poder (Ruiz Zapatero, op . cit.: 2004, 305). Con todo, la revisión exhaustiva del material publicado de La Atalaya, nos ha permiti- do reconsiderar una serie de laminitas de bronce de tamaño y decoración similar y que hasta el momento han pasado desapercibidas para los investigadores. Maluquer y Vázquez propusieron, sin ningún tipo de paralelos conocidos, clasificarlas como fragmentos de diademas, como en el caso de la sepultura 22 (Maluquer y Vázquez, op . cit.: 1956, 30-31, figs. 9 y 22), comparando dichas piezas con la auténtica diadema aparecida en la necrópolis de La Torraza de Valtierra, decorada con círculos troquelados (Maluquer, op . cit.: 1957, 254, fig. 5) que en las excavaciones realizadas en la necrópolis de El Castillo de Castejón se han documentado con una variadísima decoración (Faro, op . cit.: 2002, 214). La ausencia de una documentación adecuada de este tipo de piezas en La Atalaya hace muy difícil considerarlas en un sentido u otro, al no contar con secciones de las referidas placas que nos permitan saber si contaban con algún tipo de filo cortante o no.

Podríamos plantear como hipótesis, la posibilidad de una producción local que estuviera imitando o recreando algunos "prototipos" o producciones, tanto de origen centroeuropeo, como noritálico, aunque no podemos asegurarlo, ante la falta de analíticas metalográficas o de otros paralelos más significativos para esta pieza del Corral de Mola. En todo caso podría relacionarse con los contactos que se detectan entre la zona del Golfo de León y el área Ligur desde fechas muy tempranas y que pudieron dar lugar a fenómenos de imitación-asimilación de determinadas producciones metálicas, como ya se ha puesto de manifiesto para algunos tipos de fíbulas de la Edad del Hierro (Graells, op. cit.: 2014, 281-283, figs. 45-46), o para algunos modelos de broches de cinturón aparecidos en valle medio del Ebro y cuyos orígenes centroeuropeos parecen haberse demostrado (García-Arilla, op . cit.: 2016, 37-39, fig. 2).

\section{4. 7. Otras piezas del ajuar metálico}

Otros elementos metálicos recuperados en el Corral de Mola -anillo, chapita-, etc. (fig. 10. MOL-S-13), son muy comunes en las necrópolis del hierro I del valle medio del Ebro y aparecen en diversos contextos cronológicos, por lo que no aportan cronologías seguras, dada su larga pervivencia. Es muy frecuente encontrar anillos o pequeñas anillas sueltas o formando parte de distintos adornos en las necrópolis navarras, donde pueden ser muy abundantes y formar parte de collares, como en La Atalaya (Castiella, op. cit.: 2005, 188, fig. 103), en La Torraza o en El Castejón, donde aparecen en 34 enterramientos en forma de collares (Castiella y Bienés, op. cit.: 2002, 197-198, fig. 251). También aparecen en la necrópolis de Busal, donde también aparecen chapitas del mismo tipo 
(Burillo, op. cit.: fig. 47, 9-10 y 25), o en el poblado del Morredón, con arandelas y anillos tanto abiertos como cerrados (Royo, op . cit.: 2005, 83, fig. 36), al igual que en el poblado del Hierro I del Cabezo de la Cruz (Picazo y Rodanés, op. cit.: 2009, 411, fig. 8). No obstante, queremos destacar la presencia de alguna pieza concreta, como el fragmento de hilo de bronce en espiral recuperado sin contexto (fig. 39, R.C. $n^{\circ} 216$ ), con abundantes paralelos concentrados en necrópolis del área celtibérica, como Carratiermes, donde aparecen aisladas o formando parte de elementos de adorno de cierto prestigio denominados "pectorales". Suelen aparecer en la fase protoceltibérica de esta necrópolis durante el siglo VI a. C. y su origen se ha centrado en el Mediterráneo y más concretamente en la península itálica, donde se documentan fíbulas en espirales desde el siglo IX y VIII a. C. (Argente et alii: 1992, 304-305, figs 8-9). Otros necrópolis donde las encontramos serían Numancia, La Olmeda o Clares entre otras (Lorrio: 2007, 299, fig. 6) formando parte de pectorales, o a otros tipos de adornos, agujas o fíbulas (Lorrio, op. cit.: 2005, 206-211, figs. 84, A2, 85 y 86). También pueden aparecer en los poblados del Hierro I vinculados a nuestro Grupo I, como en Morredón, donde también se ha documentado una pequeña espiral de cobre o bronce (Royo, op . cit.: 2005, 83, fig. 36, MOR.S .28). Estos adornos en espiral tuvieron una gran difusión en el sur de Francia, apareciendo en algunas necrópolis aquitanas, como en Pujaut o Truc de Bourdiou (Mohen y Coffyn, op. cit.: 1970, planche XX, 5 y 12).

\section{4. 8. La cerámica}

La alteración de los restos tumulares, nos ha impedido contar con un elemento básico en las necrópolis de incineración: la cerámica. No obstante, los fragmentos recuperados en el propio yacimiento y los estudiados en el Instituto de Ejea de los Caballeros procedentes del Corral de Mola, nos permiten acercarnos a su contexto, tanto tipológico, como cronológico y funcional (fig. 63). Centrándonos en el sector occidental del valle medio del Ebro, vemos que estas cerámicas se encuadran en las tipologías de los principales yacimientos del Hierro I de esta zona, tanto en poblados como necrópolis. En este sentido, las cerámicas del Corral de Mola manifiestan una clara identidad con al ajuar doméstico del poblado PIIB del Alto de la Cruz (Maluquer, op. cit. 1958, 89-98) y el de los poblados I y II del Hierro del Cabezo de la Cruz de La Muela (Picazo y Rodanés, op. cit.: 2009, 345-365) que documentan el inicio y desarrollo de la Edad del Hierro en el valle medio del Ebro, gracias a sus dataciones radiocarbónicas situadas entre mediados del siglo VIII y mediados del siglo VI cal BC (Picazo y Rodanés, op . cit.: 2009, 76-79). Esta tipología también aparece en los principales poblados del Hierro del río Huecha, como en El Morredón (Royo, op. cit.: 2005, figs. 13-24) o Burrén y Burrena (Aguilera y Royo, op. cit.: 1978, 29, lams. VIII-IX), o en los niveles del Hierro I de Bursau-La Corona Esquilar (Royo y Aguilera: 1981, 50-55, figs. 10-13).

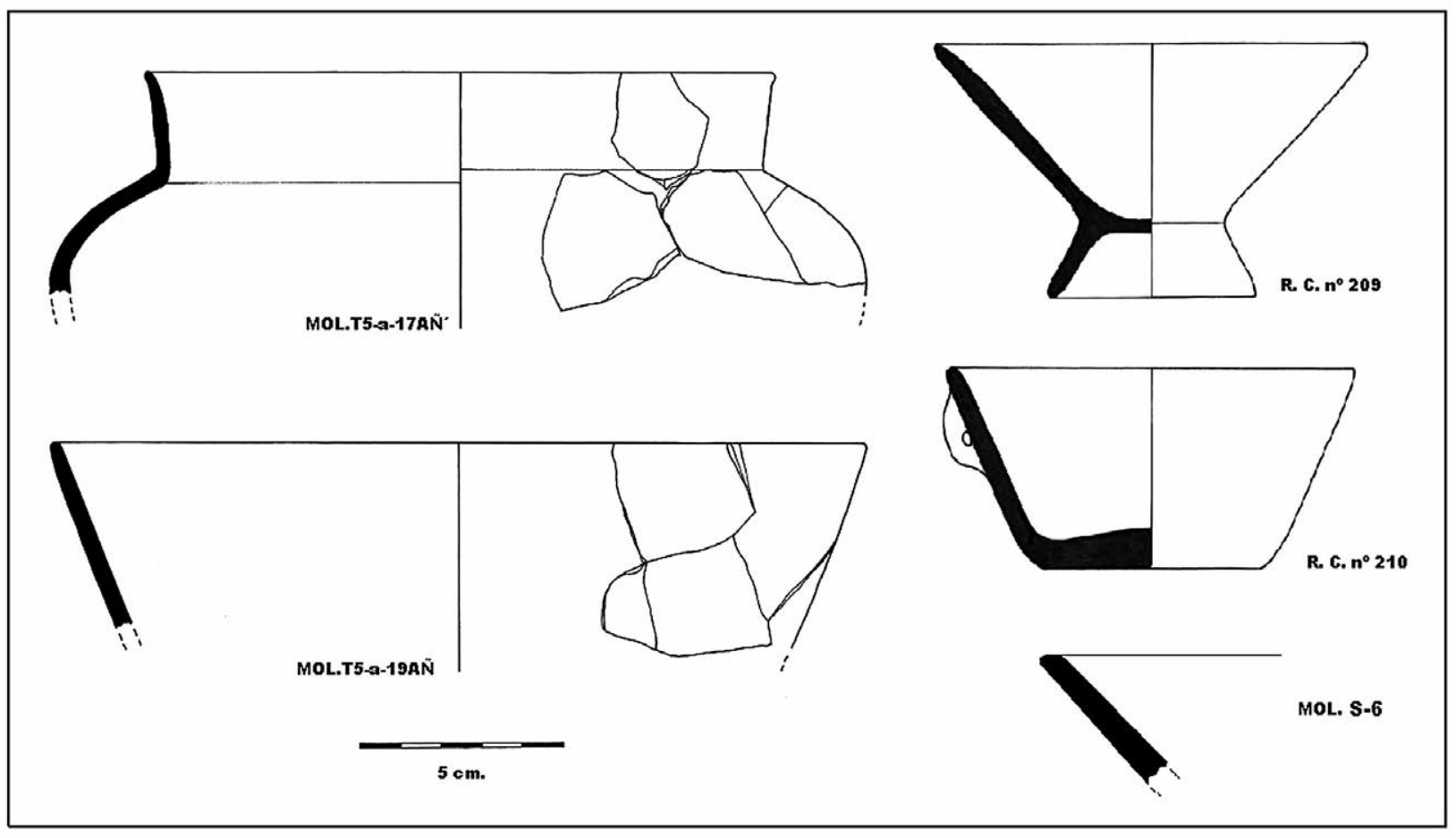

Fig. 63. Restos del ajuar cerámico recuperado en la necrópolis del Corral de Mola (Dibujo: Royo 2016). 
Ninguno de los ejemplares recuperados nos demuestra su uso como urna funeraria, tanto por su tamaño, como por la descontextualización del hallazgo de los fragmentos recuperados. Es más, las piezas documentadas en el túmulo 5 fueron recuperadas entre el encachado pétreo y totalmente reducidas a fragmentos, por lo que los consideramos como vasos de ofrendas o piezas ya amortizadas o destruidas durante el ritual funerario y arrojadas al túmulo. Tampoco los dos vasos documentados en el instituto de Ejea pueden incluirse en la categoría de urnas cinerarias, identificados como vasitos de ofrendas, con morfología muy similar a los perfiles de las necrópolis del valle medio del Ebro y áreas cercanas a éste. A partir de la tipología establecida por A. Castiella para la Edad del Hierro en Navarra (Castiella, op . cit.: 1977, fig. 178), revisada en nuestro trabajo sobre el poblado del Morredón (Royo, op . cit.: 2005, fig. 55, I-III), el repertorio formal de las cerámicas del Corral de Mola queda limitado a unos pocos perfiles que se definen por sus acabados bien alisados o espatulados, con formas no decoradas que se identifican con cazuelitas de cuello cilíndrico y cuerpo globular -forma 5 de Castiella y Royo-, platos o escudillas de paredes rectas -forma 9 de Castiella y Royo-, copas de paredes rectas y pie desarrollado o vasos troncocónicos de fondo plano -forma 9 de Castiella y 9 variantes $c$ - $d$-e de Royo-.

Se trata de vasos muy comunes en las necrópolis del sector occidental del valle medio del Ebro, especialmente en las necrópolis navarras, como en La Atalaya (Maluquer y Vázquez, op. cit.: 1956, figs. 3 a 7), La Torraza (Maluquer, op. cit.: 1957, fig. 10), el Castejón de Arguedas (Castiella y Bienés, op. cit.: 2002, fig. 186) y el Castillo de Castejón (Faro et alii, op . cit.: 2002-2003, 66-67), pero también muy presentes en el resto de necrópolis del Ebro Medio, como en el Cabezo de Ballesteros de Epila (Pérez Casas, op. cit.: 1990, 117, fig. 7), Azaila (Beltrán Lloris, op . cit.: 1976 b, figs. 21-25) e incluso en la fase final de la necrópolis de Los Castellets II de Mequinenza (Royo, op . cit.: 2000, fig 6). En el resto del valle del Ebro, aparecen en las fases más antiguas de algunas necrópolis celtibéricas como la Umbría de Daroca (Aranda, op . cit.: 1990, 105, fig. 2) (fig. 64), en otras necrópolis del Hierro I como El Cabo de Andorra (Benavente et alii, op. cit.: 2015, 64, fig. 5. 1) o Sant Joaquim de la Menarella, donde su tipo I coincide plenamente con nuestros vasos de cuello cilíndrico (Vizcaíno, op . cit.: 2010, 129-131). Entre los ajuares de las necrópolis del sur de Francia, esta tipología cerámica aparece bien representada en las regiones de Aquitania (Mohén y Coffyn, op . cit. 1970, planche XX) y Pirineos (Toledo, op. cit.: 2012, 246-249, figs. 2, 4 y 6), donde los paralelos son más evidentes. En definitiva, las formas identificadas en el Corral de Mola permiten confirmar su identidad absoluta con las tipologías cerámicas de nuestro Grupo I de necrópolis del Hierro I y su paralelismo evidente con otros grupos del valle del Ebro y también con el suroeste de Francia, tal y como se ha visto también para los ajuares funerarios metálicos.

\section{5. Datación y contexto cronológico del Corral de Mola a partir de su ajuar funerario}

Teniendo en cuenta lo dicho hasta este punto, debemos puntualizar algunas consideraciones que tienen especial relevancia a la hora de determinar la cronología del Corral de Mola. A pesar del tiempo transcurrido desde su excavación y de las novedades respecto a las necrópolis de la $\mathrm{I}^{\mathrm{a}}$ Edad del Hierro en el valle medio del Ebro, tanto la arquitectura funeraria de esta necrópolis, como sus materiales, siguen representando un yacimiento excepcional dentro del Grupo I de los conjuntos funerarios del valle medio del Ebro. La presencia de un conjunto cerrado como el túmulo 1 y la acumulación de materiales metálicos de su depósito, le confiere ese grado de excepcionalidad dentro de los conjuntos funerarios que podemos considerar como singulares en esta área geográfica y que podríamos concretar en algunos ejemplos, como el enterramiento y ajuar del túmulo 152 de la necrópolis del Castillo de Castejón (Faro, op . cit.: 2015, 62), la tumba de Les Ferreres de Calaceite (Graells y Armada, op . cit.: 2011) o la tumba de guerrero de Llinars del Vallès (Sanmartí, op. cit.: 1993). En todos estos casos se constata la presencia de elementos excepcionales dentro del ajuar funerario, así como una acumulación de piezas que contrasta con la norma habitual en enterramientos del Hierro I en su fase plena o tardía. No obstante, el túmulo 1 del Corral de Mola representaría una fase más antigua que los ejemplos citados, emparentándose mejor con otro tipo de enterramientos singulares, como las sepulturas $\mathrm{n}^{\circ} 61$ y 65 de la necrópolis del Calvari en El Molar (Castro, op . cit.: 1994, 108-112, láms. VI-7 y 8) que representan las tumbas más ricas de dicha necrópolis y que se han clasificado como las que definen un grupo social de élite dentro de este conjunto funerario (Castro, op . cit.: 1994, 113).

Esta singularidad del depósito del túmulo 1 del Corral de Mola, también debe interpretarse como la manifestación funeraria de un estatus social elevado o de élite dentro del grupo, aunque no se haya podido analizar sistemáticamente la población representada en esta necrópolis debido a su destrucción. En este sentido, juega a favor de dicha clasificación la asociación de los diferentes tipos metálicos y la representación casi completa de la panoplia de elementos suntuarios o de adorno que acompañan a los personajes incinerados en dicho túmulo: fíbula de doble resorte, broche de cinturón, torques, brazaletes, cuchillo/navaja de afeitar y botones. Hasta la fecha, lo corriente en este tipo de enterramientos de las fases antigua y media del Hierro $\mathrm{I}$, es que dichas asociaciones se compongan de dos o 
tres elementos, como sería el caso de la asociación de fíbula-torques-brazaletes de la necrópolis del Calvari, pasando a combinaciones más variadas en necrópolis de fases más avanzadas y geográficamente más cercanas, como en el Castejón de Arguedas, con fíbula-broche-brazalete-botones del enterramiento 19, fíbulabroche-colgantes del enterramiento 24 , torques-brazaletes-fíbula del enterramiento 54, o broche-torquesfíbula del enterramiento 64 (Castiella y Bienés, op. cit.: 2002, figs. 107, 114, 141 y 151).

En ninguno de los conjuntos analizados, hemos visto una asociación tan completa como en el ajuar del túmulo 1 del Corral de Mola. A esto podemos sumar como elemento significativo de la riqueza de este ajuar el peso del mismo. Sin haber recuperado la totalidad de las piezas que acompañaron a la incineración de este túmulo, contamos con la mayor parte del mismo, con lo que el peso total del ajuar supone 2.052, 84 gramos, es decir que supera los dos kilos de diferentes piezas fabricadas en aleaciones de cobre.

Aunque no hemos podido realizar las analíticas pertinentes de este ajuar, todo parece indicar que se trata de piezas realizadas en bronce, dada la resistencia y elasticidad de las piezas conservadas, especialmente de las fíbulas. Las escasas analíticas metalográficas realizadas hasta el momento en contextos de similar cronología y cultura material, así parecen confirmarlo a través del análisis de un número significativo de materiales broncíneos procedentes del poblado del Alto de la Cruz, y de las necrópolis de La Atalaya y de
La Torraza (Maluquer et alii: 1990, 151-172). Los resultados de dichos análisis metalográficos arrojan los resultados esperados para estas cronologías y tipo de material, es decir porcentajes de cobre de entre el 65 y el $75 \%$ y de estaño entre el 15 y el $30 \%$, lo que se acercaría a un tipo de aleación bastante común. La presencia de mínimos porcentajes de plomo o hierro pueden corresponder a las impurezas del mineral usado, tal y como parece documentarse en la metalurgia protohistórica del Bajo Aragón (Maluquer et alii, op . cit.: 1990, 157-165). Se ha documentado una gran actividad metalúrgica en el poblado del Alto de la Cruz así como una reutilización clara del bronce amortizado, como puede comprobarse por la presencia de tortas de fundición, hornos y abundantes moldes de fundición. No sería descabellado pensar en que algunos de los materiales metálicos presentes en el Corral de Mola pudieron ser fabricados en el Alto de la Cruz, aunque este extremo sólo podrá confirmarse con la necesaria comprobación analítica.

Por otra parte, si vemos el volumen y peso de otros ajuares estudiados en necrópolis de cronología similar al Corral de Mola, como El Cabo de Andorra, comprobamos que la sepultura 5, la más rica del conjunto y con presencia de torques, brazaletes, fíbulas, anillas y otros elementos fundidos, contiene un peso de 307,8 gramos, mientras que el enterramiento 1 , el segundo más rico, con brazaletes, anillas y otros elementos fundidos, tiene un peso de 274,45 gramos (Benavente et alii, op. cit.: 2015, 116-117). Algo similar se ha cons-

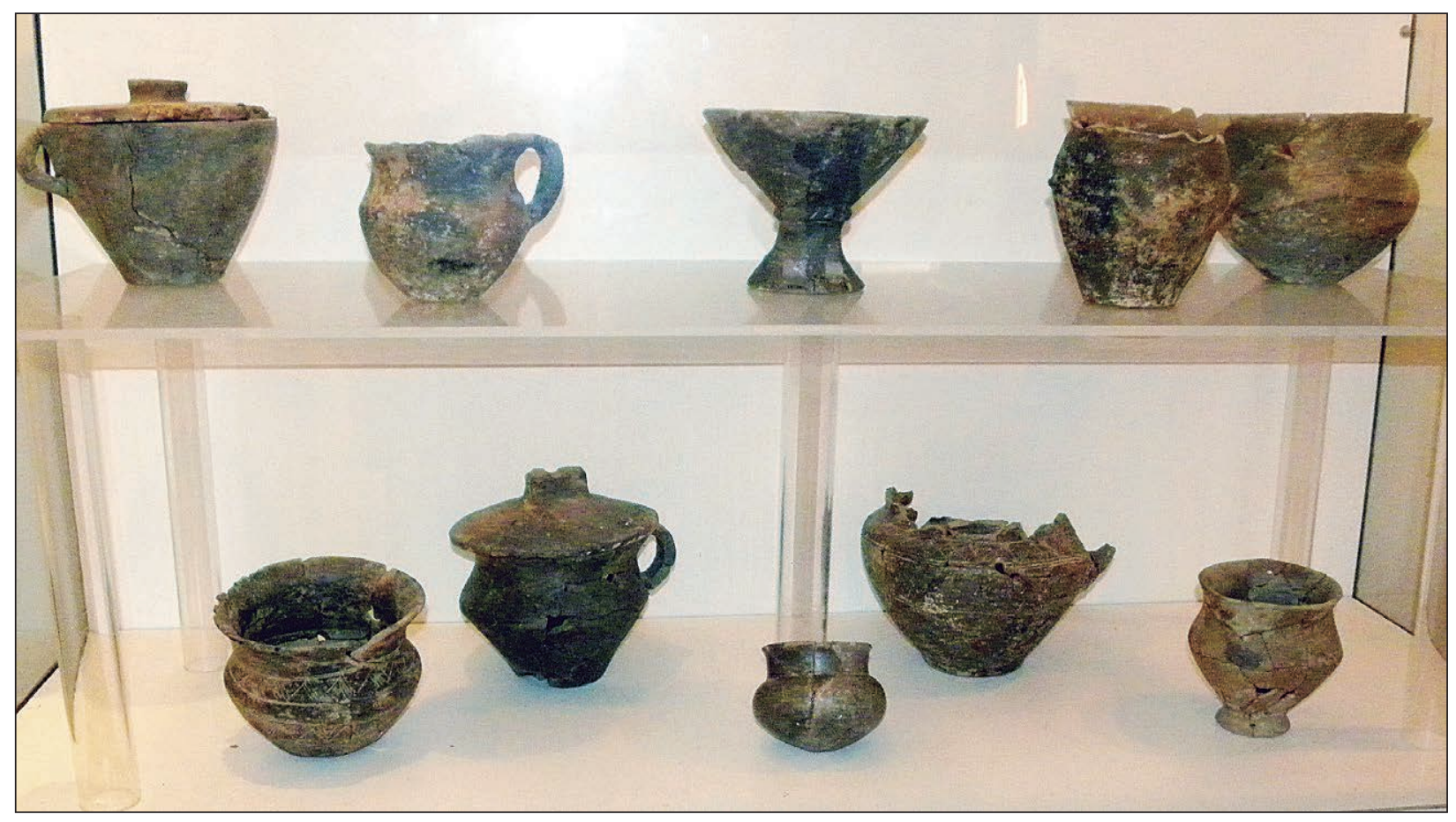

Fig. 64. Cerámica a mano de tipología del Hierro I aparecida en los niveles más antiguos de la necrópolis de La Umbría de Daroca (Museo de Daroca. Foto: Royo 2014). 
tatado en la necrópolis del Calvari, donde las sepulturas más ricas en metal, las $\mathrm{n}^{\circ} 61$ y 65 , contenían 258 y 367 gramos de piezas de bronce respectivamente (Castro, op . cit.: 1994, 103, cita 9), pesos muy parecidos a las tumbas más ricas de El Cabo, pero en ambos casos más de seis veces inferiores al peso documentado del ajuar del túmulo 1 del Corral de Mola. Aunque no se han publicado datos del peso de los ajuares metálicos de las necrópolis navarras, a juzgar por el volumen del material extraído en alguna de ellas, en especial en El Castejón o en El Castillo, es posible que estas cantidades puedan superarse sobradamente, dada la presencia de piezas metálicas muy pesadas -torques, armas, o elementos de banquete o ritual-, pero en todo caso se corresponden con enterramientos datados en fases cronológicas posteriores al Corral de Mola.

Otro aspecto a tener en cuenta es la identificación del sexo de los cadáveres a partir del ajuar funerario de una necrópolis de incineración. La propia dificultad que supone la identificación antropológica de los restos humanos cremados ha supuesto hasta hace muy poco tiempo un serio hándicap para la correcta clasificación de los enterramientos en relación a la atribución a un sexo o a otro. Este hecho ha supuesto una clasificación de la población de las necrópolis de incineración, basada en los propios ajuares y en la presencia o no de determinados elementos metálicos, como los torques, los colgantes, los adornos o las armas. Tal sería el caso de las determinaciones de género realizadas en la necrópolis del Calvari, donde la dualidad de ajuares y de espacios funerarios permite constatar dos asociaciones vinculadas al género: las tumbas con asociación de cadenas-colgantes pertenecerían a enterramientos de mujeres, mientras que los enterramientos con asociaciones de fíbulas-torques, pertenecerían a hombres adultos. En estos casos se dan las sepulturas con ajuares más ricos, pertenecientes al grupo social dominante con mayor acceso a los productos metálicos (Castro, op. cit.: 1994, 155). En las necrópolis navarras del Hierro I, que tampoco cuentan con estudios antropológicos (Zapatero, op . cit.: 2008, 104-105), se han aplicado diversos criterios para asociar los ajuares funerarios a un género determinado. Así, algunos autores han asignado determinadas piezas de prestigio, como los torques de bronce aparecidos en Navarra a las mujeres, siguiendo la corriente de investigadores europeos que asignan las piezas de dicho metal a las féminas (Castiella, op . cit.: 2007-2008, 897). De este modo, los ajuares metálicos de la necrópolis del Castejón de Arguedas, por la preponderancia de elementos de adorno, representarían en su mayoría enterramientos de mujeres, pudiendo tratarse de un sector de la necrópolis dedicado a este género (Castiella y Bienés, op . cit.: 2002, 208).

En las necrópolis donde sí se han realizado análisis antropológicos de las cremaciones, como en El Cabo de Andorra o Sant Joaquim de la Menarella, encontra- mos resultados dispares. En El Cabo, el estudio antropológico apunta a un conjunto de enterramientos individuales integrado solamente por mujeres jóvenes, por lo que elementos como los torques estarían integrados en su ajuar funerario (Benavente et alii, op . cit.: 2015, 151). Por el contrario, en la necrópolis de Sant Joaquim, los datos antropológicos apuntan a una población mixta, con presencia de todos los grupos de edad y sin ningún patrón concreto en la distribución del espacio o de los ajuares funerarios (Vizcaíno, op. cit.: 2010, 163-165, fig. 6.3-6.5). Frente a los escasos datos constatados, en la necrópolis del Corral de Mola, el análisis antropológico de los restos cremados del túmulo 1 han dado como resultado la presencia de dos posibles individuos masculinos, uno maduro y otro joven, sin que podamos establecer relaciones de parentesco entre ellos (Lorenzo y Royo, op. cit.: en este volumen). El ajuar funerario que les acompaña representa un atesoramiento metálico extraordinario que indica sin lugar a dudas una posición de preeminencia social en los individuos incinerados, pero no con elementos propios de una tumba de guerrero, sino con materiales de adorno, representación y vestido que en otros contextos se han asociado a tumbas femeninas. Por este motivo hay que ser muy cautos en las adscripciones de ajuares funerarios a un determinado género, ya que la realidad indica que suele haber notables diferencias entre las teorías al uso y las evidencias arqueológicas. Así, el ajuar funerario del túmulo 1 del Corral de Mola, representaría el acceso a bienes suntuarios metálicos por parte de determinados grupos sociales, en este caso dos hombres que pese a no tener como acompañamiento entre los materiales enterrados ningún objeto de carácter heroico en forma de armas defensivas u ofensivas, cuentan con otros elementos de prestigio social y económico, como el torques, el broche de cinturón o el cuchillo/navaja, además de una gran cantidad de brazaletes. La presencia exclusiva de bronce y los tipos metálicos representados, señalan tradiciones que seguramente habrá que rastrear en el Bronce Final, pero que ya representan ajuares del Hierro I, aunque en un momento temprano de implantación, al menos en el extremo occidental del valle medio del Ebro.

En este sentido, las dataciones más antiguas de algunos ajuares del sur de Francia situadas entre fines del siglo VIII y mediados del siglo VII a. C. (Verger et alii, op . cit.: 2007, 162; Constantin, op. cit.: 2014, 143) parecen corroborar para el ajuar del túmulo 1 del Corral de Mola, unas fechas más acordes a la realidad económica, social y tecnológica que supondría el inicio de la Edad del Hierro en las Cinco Villas aragonesas y el extremo occidental del Ebro Medio.

En este punto debemos reiterar determinados aspectos del ritual funerario documentado en este yacimiento. Por un lado, la cremación del difunto in situ en 
el caso del túmulo 1 y muy posiblemente también en el túmulo 5, cremación muy intensa como se desprende del estudio antropológico y que ha planteado la presencia en el primer enterramiento de dos individuos varones, uno adulto y otro joven (Lorenzo y Royo, op. cit.: en este volumen). Los restos óseos, además de sufrir una calcinación muy intensa, fueron fragmentados mecánicamente, sin que se introdujeran en una urna, con la única protección de una suave fosa u hondonada sobre la que se construye el túmulo pétreo. Este tipo de ritual crematorio se repite en otras necrópolis del entorno geográfico del Corral de Mola, como en Arroyo Vizcarra, tanto en estructuras del tipo crómlech (Royo, op. cit.: 1997 a, 56), como en auténticos túmulos (Royo y Fatás, op . cit.: 2017, 40-50, fig. 3). La presencia de algún resto óseo de fauna en la cremación y de cerámica en el túmulo ofrendes aspectos novedosos en el proceso de enterramiento. La recuperación de restos de vasos cerámicos amortizados y mezclados en la estructura tumular podría explicarse dentro del proceso constructivo del túmulo, como parte de la ofrenda, o como amortización del ajuar cerámico utilizado en el ritual funerario. La identificación de algunos restos óseos de fauna acompañado a los restos de los difuntos, entre ellos algunos de pájaro, nos plantea posibles rituales relacionados con el banquete funerario o con ofrendas funerarias. En este sentido, las recientes excavaciones en la necrópolis bajoaragonesa del Cascarujo, han demostrado la presencia de este tipo de restos junto al difunto incinerado, en este caso identificados con ovicáprido (Balsera et alii: 2014, 453). El estado de los restos óseos y su tratamiento idéntico al del difunto, al igual que sucede en Corral de Mola, lleva a interpretar este hecho como la incorporación de la fauna al ritual funerario, sea como ofrenda alimenticia o como animal de tipo psicopompo, en clara relación con otros yacimientos donde se ha estudiado este fenómeno, como en la necrópolis de Can Piteu-Can Roqueta de Sabadell (Balsera et alii, op . cit.: 2014, 454). La presencia en Corral de Mola de restos de pájaro, además de relacionarse con un posible banquete funerario o con una ofrenda alimentaria para el más allá, podría vincularse con la imaginería protohistórica y la representación de pájaros en la cerámica y en otros soportes y que muy bien pueden asimilarse al mundo espiritual de este momento, con influencias tanto prehistóricas autóctonas, como por contactos europeos y mediterráneos (Royo, op. cit.: 2005, 71-75, fig. 26; Neumaier, op. cit.: 2006, 162, fig. 6, 5).

Por lo que se refiere al encuadre cronológico de este conjunto, debemos conjugar dos elementos clave: sus materiales y su datación radiocarbónica calibrada. Hay un hecho que debemos resaltar que puede ayudarnos a dar una datación para los túmulos de esta necrópolis. En primer lugar debemos señalar que todo el ajuar metálico recuperado de este cementerio está realizado en bronce. Sólo se ha localizado una fíbula de bronce de pie terminado en disco cuyo soporte para el resorte bilateral está realizado en hierro que apareció sin contexto arqueológico definido. Del mismo modo, entre el material cerámico no se ha recuperado ni un fragmento de cerámica a torno. Estos dos hechos son muy importantes, si tenemos en cuenta que en las necrópolis de Busal y de Arroyo Vizcarra aparece hierro y también cerámica a torno, al igual que ocurre en las necrópolis navarras del Ebro, en especial La Atalaya o El Castillo de Castejón. Esta ausencia de cerámica a torno y de hierro, junto a la falta de armamento, nos permite situar el Corral de Mola en una fase anterior al momento de crisis y evolución del poblamiento protohistórico del valle medio del Ebro fechado a mediados del siglo VI a. C., fenómeno que propicia que en muchas de estas necrópolis navarras citadas aparezca armamento, sobre todo espadas, lanzas y cuchillos que deben situarse a partir de este momento (Royo, op. cit.: 2005, 139-140).

Corral de Mola se encuadraría en un momento situado entre la segunda mitad del siglo VII y la primera mitad del VI a. C., cronología que encajaría perfectamente con el ajuar metálico documentado en el túmulo 1 , donde el broche de cinturón, la fíbula de doble resorte o el torques, responden a los denominados "prototipos" o hablando con más propiedad, a los tipos más sencillos y antiguos de esa morfología, al igual que ocurre con el escaso ajuar metálico recuperado en el túmulo 5. Esta cronología puede aplicarse al resto del ajuar metálico recuperado fuera de contexto, en especial la fíbula de pie vuelto o el torques con estrías transversales que podrían fecharse a partir de mediados del siglo VI a. C., pudiendo llegar hasta finales del siglo VI a. C. Así parecen confirmarlo los contextos de conjuntos bien estudiados en Navarra, Aquitania, golfo de León y Cataluña. Conjuntos como los localizados en El Calvari, en La Pedrera, en las necrópolis del Hierro I de Gandesa, o en el Cabo de Andorra, atestiguan asociaciones de piezas muy similares a lo documentado en Corral de Mola, pero especialmente deben citarse los conjuntos documentados en el sector occidental del valle medio del Ebro, en necrópolis como Cabezo Ballesteros, Herrería III o La Umbría, o las necrópolis de Arroyo Vizcarra, Busal I, La Atalaya, El Castillo o El Castejón. Todas ellas cubren el periodo comprendido entre la mitad del siglo VI y todo el V a. C., pero también en contados casos, como en Cabezo Ballesteros, aparecen elementos que permiten suponer un inicio anterior, casi con toda seguridad desde mediados del siglo VII a. C.

A esta aparente falta de concreción cronológica en la protohistoria del valle del Ebro, contribuye la escasa información que aportan las dataciones radiocarbónicas entre el siglo VIII y el IV a. C., debido a las alteraciones que produce la "Meseta de Hallstatt" (Ruiz Zapatero, op. cit.: 2014, 643). En efecto, la 
mayor parte de las fechas calibradas cuentan con unas desviaciones estándar superiores entre doscientos y trescientos años, por lo que se vuelven inútiles en la mayoría de los casos. Solamente dos yacimientos ayudan a datar la necrópolis del Corral de Mola. El primero es una necrópolis, la del Cabezo de Ballesteros, con una banda de dataciones que calibradas abarcan desde mediados del siglo VIII a. C. hasta mediados del siglo IV a. C. (fig. 42), periodo que parece englobar la variedad de material de sus ajuares funerarios (Pérez Casas, op. cit.: 1990, 117-118, figs. 7-8). El segundo corresponde al poblado del Alto de la Cruz de Cortes, cuyas dataciones radiocarbónicas se centran entre mediados del siglo IX y mediados del siglo VIII a. C. (814/760 y 865/800 cal BC) para el poblado PIIIb, finales del siglo IX a mediados del siglo VIII a. C. (818/760 cal BC) para el poblado PIIa, y mediados del siglo VII a mediados del siglo VI a. C. (648/543 y 606/516 cal BC) para el poblado $\mathrm{PIIb}$, fase claramente relacionada con la utilización del Corral de Mola (Munilla et alii, op . cit.: 1994-96, 170). Estas dataciones coinciden a grandes rasgos con las fechas de $\mathrm{C} 14$ calibradas del poblado del Cabezo de la Cruz de La Muela, cuyo primer poblado se fecha entre el 780/630 cal BC, el segundo entre el $650 / 550$ cal BC y el tercero, entre el 650/545 cal BC (Picazo y Rodanés, op. cit.: 2009, 75-80).

La coincidencia de las dataciones del PIIb de Cortes de Navarra con el segundo poblado del Cabezo de la Cruz de La Muela, aportan un marco cronológico de referencia que viene a coincidir con las dataciones aportadas por otros conjuntos similares fechados en la fase media del Hierro I. En este sentido, los materiales del Corral de Mola encuentran su exacta coincidencia con la cultura material de dicho periodo, ya sea en poblados o necrópolis. Pero el ajuar metálico recuperado en nuestras excavaciones permite realizar algunas precisiones, tanto para el material metálico y cerámico procedente de los túmulos 1 y 5 , como para el resto del material descontextualizado.

Los materiales metálicos de dichos túmulos representan modelos muy arcaicos dentro de la Edad del Hierro, especialmente las fíbulas de doble resorte, el broche de cinturón, el torques de extremos engrosados o el cuchillo/navaja de afeitar, objetos con clara contextualización crono-tipológica, como ya hemos analizado en las páginas anteriores. Este arcaísmo se constata en los tipos señalados, en la tecnología de su fabricación que plantea la existencia de talleres locales y en el hecho de que en la Edad del Hierro se siga utilizando y atesorando objetos procedentes de la metalurgia del bronce, en un vano intento de perpetuar tradiciones anteriores. Teniendo en cuenta todos los datos analizados, las fechas que se vienen proponiendo para este tipo de materiales entre el último tercio del siglo VII y el primer tercio del siglo VI a. C., deberían ajustarse algo más, pero elevando algo más la datación para los conjuntos de los túmulos 1 y 5 del Corral de Mola, que se centrarían en un periodo entre el 650/625 y el $600 / 575$ a. C. Respecto al resto del material recuperado fuera de contexto arqueológico, y en especial el material metálico, sobre todo la fíbula de pie vuelto y disco terminal, el fragmento de colgante de espiral o el torques de estrías transversales, cuentan con contextos bien definidos y de cronología algo posterior. Su aparición en las necrópolis del Castejón, El Castillo o en las necrópolis aquitanas, permitirían una datación centrada a mediados del siglo VI a. C., pudiendo perdurar durante la segunda mitad de dicho siglo, por lo que una cronología del 550/500 a. C. sería lo más acorde con sus paralelos contextualizados. Estas dataciones situarían el periodo de utilización del Corral de Mola en un periodo de unos cien años, entre mediados del siglo VII y mediados del VI a. C. (650/550 cal BC), pudiendo perdurar hasta finales del siglo VI a. C.

\section{Conclusiones}

A pesar de la problemática de este yacimiento, no podemos infravalorar los resultados de su estudio. En primer lugar aporta un importante ajuar funerario prácticamente desconocido en la bibliografía de la protohistoria del noreste peninsular, y en segundo, las estructuras y materiales estudiados nos permiten revisar la secuencia cronocultural y material de las necrópolis del sector occidental del valle medio del Ebro durante la Edad del Hierro, poco valoradas hasta la publicación de los cementerios del Castejón de Arguedas y del Castillo de Castejón, ambas en el área oriental de la rivera oriental de Navarra.

Por otra parte, la presencia de un ajuar funerario singular en el Corral de Mola, realizado exclusivamente en bronce, con diversos elementos como el torques, el broche de cinturón o la navaja de afeitar, junto a las fíbulas de doble resorte, considerados todos ellos como productos "prototipo" o de tipología muy arcaica dentro de la Edad del Hierro, conceden a esta necrópolis la cronología más antigua del Grupo I de necrópolis del Ebro medio. Tanto las fíbulas de doble resorte como los broches de cinturón de placa triangular y un solo garfio, incluso los torques citados, vienen fechándose entre los inicios de la Edad del Hierro y su fase plena. Estas cronologías se han situado recientemente en las necrópolis catalanas y poblados excavados en dicha zona, entre el último cuarto del siglo VII a. C. y la primera mitad del siglo VI a. C. $-625 / 550$ a. C.- (Graells, op. cit.: 2014, 265; Graells y Lorrio, op . cit.: 2017,97).

No obstante, el ajuar metálico recuperado en el túmulo 1 del Corral de Mola, presenta en los modelos documentados un gran arcaísmo, poco reconocido en otros ejemplares peninsulares hasta ahora publicados, especialmente en el broche de cinturón que presenta 
las dos pestañas laterales para la sujeción del broche al cinturón, además de la nervadura central y la decoración incisa, todo ello tipologicamente casi exclusivo de los broches tipo Fleury ya constatados en el Golfo de León entre Languedoc y Cataluña, aunque los parecidos formales de nuestro ejemplar con dichos broches son muy remotos (Graells y Lorrio, op. cit.: 2017, 6570). Si a esto unimos la presencia del cuchillo o navaja de afeitar con decoración incisa en la hoja y enmangue de espiga con anilla, cuyos paralelos remiten a algunos modelos del Bronce Final/Hierro I de Cataluña, como el ejemplar de tipo Dasice de Tarragona (Ruiz Zapatero, op. cit.: 1985, 899, fig. 251), otro posible de la necrópolis de Agullana (Palol, op. cit.: 1958, lam. XX, 207) o a precedentes de cuchillos de uso ritual de los C. U. centroeuropeos o noritálicos que pueden fecharse a partir del siglo VIII a. C. (Bianco, op . cit.: 1976, 28, tafel 9-10), nos encontraríamos ante un ajuar que representaría los momentos iniciales de la Edad del Hierro en las necrópolis de las Cinco Villas zaragozanas.

A tenor de lo aquí expuesto, consideramos que debería elevarse la datación de la necrópolis de Corral de Mola, no sólo por la tipología del ajuar descrito, sino por el contexto cronológico-cultural que representa y por las dataciones radiocarbónicas conocidas para contextos habitacionales del Ebro Medio (Munilla et alii, op . cit.: 1994-96, 170; Picazo y Rodanés, op. cit.: 2009, 76-79), datos por los que proponemos llevar esta necrópolis a una banda alta del Hierro I Medio, situada entre el 650-625 y el 600-575 a. C., mas acorde con la exclusiva presencia de bronce en la necrópolis y de elementos de adorno, vestido o aseo personal de singular riqueza y status social. Es muy posible que en los momentos más avanzados de esta primera fase, en el primer cuarto del siglo VI a. C., pudieran aparecer los primeros elementos de ajuar realizados en hierro, de forma única o combinando con el bronce, como podría ser el caso de la fíbula de resorte bilateral y pie vuelto terminado en disco recuperada en el Corral de Mola y que encajaría perfectamente a finales de este periodo, a tenor de los paralelos estudiados y de su presencia en Aquitania desde comienzos del siglo VI a. C. (Constantin, op . cit.: 2014, 146). Por otro lado, los paralelos de las piezas estudiadas, también nos permiten prolongar la posible utilización de este yacimiento hasta la mitad del siglo VI a. C., momento del máximo apogeo del la I ${ }^{\mathrm{a}}$ Edad del Hierro en este sector del Ebro medio, pudiendo llegar hasta el final de dicho siglo.

En la fase siguiente de estas necrópolis del Grupo I, coincidente con el denominado como Hierro I Tardío, se generaliza la utilización del hierro y sobre todo su presencia en los ajuares funerarios, con la introducción de nuevos elementos, como la panoplia armamentística, compuesta básicamente por espadas, cuchillos y lanzas, o la presencia importante de ele- mentos de adorno en este metal, sobre todo en brazaletes, fíbulas o torques. Este momento responde al cambio generado por la crisis generalizada en todo el mediterráneo que provocó en el valle del Ebro la "crisis del Ibérico Antiguo" (Burillo, op. cit.: 1989-90), siendo especialmente significativo el hecho de abandonos o destrucciones generalizadas en algunas comunidades protohistóricas del valle medio del Ebro, como la del río Huecha (Royo, op. cit.: 2005, 158-161). Si consideramos los materiales estudiados y las cronologías absolutas disponibles, esta fase comenzaría a mediados del siglo VI a. C. (550 cal BC) y podría continuar hasta mediados del siglo V a.C. (450 cal BC). A esta segunda fase podría adscribirse la necrópolis de Busal, donde se comprueba el uso generalizado del hierro, la introducción de armamento y las primeras producciones cerámicas a torno, todo ello relacionado con los estímulos mediterráneos y también continentales, en especial los relacionados con el suroeste francés, los pirineos y muy especialmente Aquitania. También debe incluirse en esta fase, aunque en sus primeros momentos, la necrópolis del Castejón de Arguedas, La Torraza de Valtierra, La Atalaya de Cortes y también las sepulturas más antiguas del Castillo de Castejón, donde además de todos los elementos citados, nos encontramos de forma generalizada determinadas piezas del ajuar relacionadas con los rituales del sacrificio y del banquete funerario relacionado con el nacimiento y ascenso social de las nuevas elites ecuestres (Faro, op. cit.: 2015, 109-110).

La tercera fase de las necrópolis del Hierro I del sector occidental del valle medio del Ebro representa el momento de la completa asimilación de los estímulos transpirenaicos y mediterráneos y marca el contacto entre el mundo final de la Primera y el inicio de la Segunda Edad del Hierro (Royo, op . cit.: 2008-09, 118, lám. XXI), donde los pueblos ibéricos y especialmente los celtibéricos a partir del 425-400 a. C., desarrollarán la protohistoria de los pueblos indígenas del valle medio del Ebro hasta la llegada de Roma a finales del siglo III a. C. (Royo, op. cit.: 2005, 160).

No obstante, estas cronologías, basadas principalmente en la clasificación del material funerario de las citadas necrópolis, deberán confirmarse en un futuro próximo mediante el estudio de los diferentes contextos estratigráficos y evolutivos de cada una de las necrópolis excavadas en la zona de estudio y en la fechación radiocarbónica sistemática de dichos contextos y materiales, utilizando siempre que sea posible elementos de "vida corta" para conseguir dataciones nuevas con el mínimo de desviación estándar (Jover et alii, op. cit.: 2016, 86-87, fig. 2).

Quedan otras cuestiones que debemos señalar con respecto a las aportaciones de Corral de Mola al mundo funerario del Hierro I en el valle del Ebro. Quizás la más significativa sea la presencia de un ente- 
rramiento de una especial singularidad entre las sepulturas documentadas en la zona en estudio. El túmulo 1 del Corral de Mola representa, a través de su ritual y su ajuar funerario, la presencia en los inicios de la $\mathrm{I}^{\mathrm{a}} \mathrm{Edad}$ del Hierro en el sector occidental del valle medio del Ebro, de claros indicios de diferenciación social y de la presencia de determinadas élites con clara preeminencia social y económica, lo que les permite acumular y atesorar diferentes objetos relacionados con el adorno, vestido y representación de la riqueza del momento, pero en todo caso no representativos de una aristocracia guerrera, como así parece constatarse en otras sepulturas singulares de este momento en el área oriental del valle del Ebro y en el sur de Francia. Estos indicios de riqueza y de emergencia social en tumbas del Hierro I Antiguo, no asociadas a armamento, ya se han señalado en otras necrópolis de este momento, como en El Calvari, algunos de cuyos ajuares también se ha identificado con dichas élites sociales (Castro, op . cit.: 1994, 112-113).

A partir del Corral de Mola y de las necrópolis de las Cinco Villas aragonesas y de la zona oriental de Navarra, podemos deducir que en un momento entre el Bronce Final y los inicios del Hierro I Antiguo -entre el 800/750 cal BC- se produce la asimilación y generalización del ritual de la incineración, constituyéndose la arquitectura tumular en un fenómeno exclusivo para todas las necrópolis de incineración del sector occidental del valle medio del Ebro. Este profundo cambio en el ritual funerario no se tradujo en la presencia de grandes necrópolis tumulares, al menos en las fases antiguas de la Edad del Hierro. De hecho la arquitectura tumular no supone una novedad en el valle medio del Ebro, donde las tumbas al aire libre se suelen cubrir con estructuras tumulares al menos desde el Neolítico Final -como ocurre en Mequinenza- o con total seguridad desde el Calcolítico y Bronce Antiguo en esta zona, como ya se ha comentado más arriba. Pero la generalización de la arquitectura tumular en la cuenca central del Ebro, aún a pesar de cierta similitud técnica y tipológica, no supone ni muchos menos la uniformidad de los cementerios, ya que existen marcadas diferencias comarcales, debido sobretodo a la disponibilidad de materia prima para la construcción de los túmulos. Como ya hemos señalado, en las áreas con abundancia de rocas -sobre todo en los somontanos ibéricos o pirenaicos- los túmulos se construyen con piedras del terreno, pero en las zonas con escasez de piedra, como las más cercanas a los ríos o junto al Ebro, se utiliza el material más abundante: los cantos rodados, el barro y pequeñas rocas de yeso, apareciendo las necrópolis con túmulos y cistas de adobes que a nuestro juicio, debieron estar mucho más extendidas de lo conocido hasta el momento. Esta diferenciación en los distintos tipos tumulares, es especialmente significativa en nuestro Grupo I localizado en el sector occidental del Ebro medio.
El estudio comparativo realizado en este trabajo, nos permite comprobar cómo en el área analizada también está inmersa en los influjos mediterráneos ya constatados en las necrópolis del Ebro oriental y de la costa mediterránea, pero también se constatan diversas aportaciones centroeuropeas, llegadas no sólo a través de los pasos pirenaicos orientales del Languedoc hacia Cataluña y remontando el valle del Ebro. Hoy resulta evidente que también se produjeron desde épocas muy tempranas una serie de contactos entre el valle medio del Ebro y las regiones francesas de Aquitania y Pirineos, sobre todo a través del río Garona, auténtico paso por el que debieron circular en ambos sentidos gentes, materiales e ideas, pudiendo vincular estas comunicaciones con las actividades relacionadas con la trashumancia y la cultura pastoril bien documentada en las Altas Cinco Villas y en el pirineo español, como ya hemos expuesto. Necrópolis como Arroyo Vizcarra o Barranco de la Paúl son plenamente representativas de una arquitectura tumular donde coexistieron de forma armónica tanto los túmulos como los cromlech, siempre asociados al ritual incinerador.

No podemos olvidar la fuerte identidad cultural y material de las necrópolis cincovillesas y navarras del Ebro, lo cual plantea la posible existencia de un grupo homogéneo en su cultura material, en el modo de ocupación y explotación del territorio y en su ritual funerario. Dicho grupo, claramente diferenciado del resto de los C. U. del noreste peninsular, sería plenamente coincidente con nuestro Grupo I B de necrópolis del Hierro I, presentando unas claras relaciones tipológicas, cronológicas y culturales con el grupo de cementerios de la Edad del Hierro de Aquitania y pirineos, con el que a buen seguro mantuvo unas relaciones fluidas y constantes, sin olvidar ni mucho menos, los influjos mediterráneos y europeos que llegaron a través del Ebro, como gran vía de comunicación entre la costa mediterránea y las tierras del interior peninsular.

Los elementos que definirían este grupo, en lo que se refiere a los ajuares funerarios serían las fíbulas de doble resorte en su fase antigua y posteriormente las fíbulas de pie vuelto y navarro-aquitanas, los torques de tampones o de terminaciones engrosadas lisos o decorados con estrías, los broches de cinturón triangulares de placa triangular con un garfio y decoración incisa o a molde, los brazaletes acintados abiertos decorados en los cantos y los botones semiesféricos. A estos elementos del ajuar funerario habría que añadir la cerámica, así como otros elementos propios del enterramiento, el túmulo como estructura funeraria y el propio ritual incinerador. La riqueza mostrada por el ajuar del túmulo 1 del Corral de Mola, nos ha permitido analizar de forma exhaustiva un conjunto material de evidente singularidad y su encaje cronotipológico dentro de las tipologías al uso, tanto del sur de Francia, como del valle del Ebro y Golfo de 
León, aportando alguna pieza de evidente interés, como el cuchillo/navaja de afeitar, hasta el momento inédita en la zona.

El estudio de algunas necrópolis excavadas, como Arroyo Vizcarra, o Barranco de la Paúl, en la que recientemente se han iniciado excavaciones, así como el análisis detallado de conjuntos funerarios como el Castillo de Castejón, permitirán en un futuro concretar tanto las facies más antiguas de las necrópolis del Hierro I del sector occidental del Ebro medio, como las más recientes, a caballo entre la Primera y Segunda Edad del Hierro, además de identificar los sucesivos cambios en el ritual relacionado con la muerte y el proceso de diferenciación social y de género dentro de las sociedades protohistóricas a través del estudio de los ajuares funerarios, lo que llevó al nacimiento y desarrollo de las élites ecuestres y guerreras y a los cambios que desembocaron en el nacimiento de los populi prerromanos en el valle medio del Ebro.

\section{Agradecimientos}

A continuación citaremos a una serie de personas e instituciones sin las que no hubiera sido posible concluir este trabajo. En primer lugar reconocer la figura de Luis Pueyo Campos, descubridor de la necrópolis del Corral de Mola y benefactor de las excavaciones realizadas. También expresar mi reconocimiento a Miguel Beltrán Llorís y Juan Ángel Paz Peralta, compañeros del trabajo de campo y de las primeras fases del estudio en el Museo de Zaragoza. A éstos hay que sumar los participantes en las sucesivas campañas de excavación: Antonio Ferreruela, Amado López, Jesús Mayayo, María Luisa de Sus y Javier Bona. El dibujo de los materiales y la confección de planos del yacimiento, realizados por Alfredo Blanco, se realizó a partir de la ayuda de la Dirección General de Cultura y Patrimonio del Gobierno de Aragón.

Agradecer también la colaboración del equipo directivo del I. E. S. "Reyes Católicos" de Ejea de los Caballeros, por permitir el estudio de los materiales allí depositados, labor en la que colaboró de forma excepcional Fabiola Gómez. La revisión del material de la excavación se realizó en el Museo de Zaragoza, agradeciendo a su actual director, Isidro Aguilera, las facilidades prestadas. El estudio antropológico ha sido realizado por José I. Lorenzo, labor que ha hecho posible concluir un apartado muy importante de este yacimiento. Manuel Rojo-Guerra, Iñigo García Martínez y Cristina Tejedor han aportado su experiencia en algunos aspectos de la cronología radiocarbónica. También expresar un especial reconocimiento a Alberto Lorrio y Raimón Graells, por sus acertadas apreciaciones respecto a todo el planteamiento del estudio y sus consejos sobre los aspectos tipo-cronológicos de los materiales publicados. Por último citar a los evaluadores de este trabajo, cuyas consideraciones han permitido mejorar notablemente el texto definitivo. Muchas de las aportaciones novedosas de este trabajo deben su origen a estos colegas y amigos. Los errores, falta de concreción en algunos temas, o especulaciones, son absoluta responsabilidad del que suscribe.

\section{Bibliografia}

Adroit, S. (2014) "Dynamiques funeraires et faciés Culturels. L'exemple du Sud-ouest de la France et du Nord de l'Espagne de la Première moitié du 1er millénaire avant notre Ère". Archimede $\mathrm{n}^{\circ} 1$. Archéologie et Histoire Ancienne: 203-216.

Aguilera, I.; Paz, J.; Pérez, J. A.; Royo, J. I. (1984). "Dos fechas radiocarbónicas para la protohistoria en la ciudad de Zaragoza. Gavín/Sepulcro". Museo de Zaragoza, Boletín no 3. Zaragoza: 101-112.

Aguilera, I; Royo, J. I. (1978). "Poblados hallstátticos del valle de La Huecha. Contribución al estudio de la $\mathrm{I}^{\mathrm{a}}$ Edad del Hierro en la cuenca del Ebro". Cuadernos de Estudios Borjanos, II. Centro de Estudios Borjanos. Borja: 9-44.

Almagro Basch, M. (1942). "La necrópolis céltica de Griegos". Archivo Español de Arqueología XV. Madrid: 101-117.

Almagro Basch, M. (1952). La España de las Invasiones Célticas. Historia de España Menéndez Pidal, Tomo I., Vol. II. Madrid.

Almagro Gorbea, M. (1973). Los campos de túmulos de Pajaroncillo (Cuenca). Aportación al estudio de los túmulos de la Península Ibérica. Excavaciones Arqueológicas en España 83. Madrid.

Almagro Gorbea, M. (1977). "El Pic dels Corbs, de Sagunto, y los campos de urnas del N. E. de la Península Ibérica”. Saguntum 12. Valencia: 89141.

Almagro Gorbea, M. (1992). "Los intercambios culturales entre Aragón y el litoral mediterráneo durante el Bronce Final". Aragón/Litoral Mediterráneo. Intercambios Culturales durante la Prehistoria. Zaragoza: 633-658.

Alvarez Gracia, A. (1993). "El Bronce Final-Hierro I en el Bajo Aragón y sus relaciones con el valle medio del Ebro". Bajo Aragón Prehistoria, IX-X. Caspe-Zaragoza: 51-62.

Andrés, M ${ }^{\mathrm{a}}$ T.; Barandiarán, I. (2004). "La tumba calcolítica de La Atalayuela, treinta y cinco años después". Salduie $\mathrm{n}^{\mathrm{0}}$ 4. Universidad de Zaragoza. Zaragoza: 85-124.

Andrés, M T.; García, Mª L.; Sesma, J. (2007). “Tres Montes: Un sepulcro singular del III milenio en las Bardenas Reales”. En Hurtado, M. A.; Cañada, F.; Sesma, J.; García, J. (Coords.): La tierra te sea leve. 
Arqueología de la muerte en Navarra. Catálogo de la exposición en el Museo de Navarra (27 noviembre 2007 al 30 abril 2008). Pamplona: 84-88.

Aranda, A. (1990). "Necrópolis celtibéricas en el Bajo Jiloca". Necrópolis Celtibéricas. II Simposio sobre los Celtíberos. Zaragoza: 101-109.

Argente, J. L. (1994). Las fíbulas de la Edad del Hierro en La Meseta Oriental. Valoración tipológica, cronológica y cultural. Excavaciones Arqueológicas en España 168. Madrid.

Argente, J. L.; Díaz, A.; Bescós, A.; Alonso, A. (1992). "Los conjuntos protoceltibericos de la meseta oriental: ejemplos de la necrópolis de Carratiermes (Montejo de Tiermes, Soria)". Trabajos de Prehistoria, 49. C. S. I. C. Madrid: 295-325. https://doi.org/10.3989/tp.1992.v49.i0.547

Argente, J. L.; Díaz, A.; Bescós, A. (2000). Tiermes V. Carratiermes. Necrópolis celtibérica. Arqueología en Castilla y León, Memorias 9. Junta de Castilla y León/Iberdrola. Valladolid.

Armendariz, J. (2008). De aldeas a ciudades. El poblamiento durante el primer milenio a. $C$. en Navarra. Trabajos de Arqueología Navarra. Monografías Arqueológicas, 2. Gobierno de Navarra. Pamplona.

Balsera, R.; Bermejo, J.; Fatás, L.; Jornet, R.; Ardá, S. (2014). "Ritual funerario de la Primera Edad del Hierro en el túmulo 1 del cabezo del Cascarujo (Alcañiz, Bajo Aragón)". En A: Mercadal i Fernández, Oriol (coord.). La Transició Bronze Final - 1a Edat del Ferro en els Pirineus i territoris veïs: $X V$ Col-loqui Internacional d'Arqueologia de Puigcerdà. Congrés Nacional d'Arqueologia de Catalunya. Puigcerdà 17, 18 i 19 de novembre de 2011. Puigcerdà: Institut d'Estudis Ceretans: 447-461.

Baquedano, I. (2001). "La necrópolis de La Osera". En Almagro-Gorbea, M.; Mariné, M.; Álvarez Sanchís, J. R. (editores): Celtas y Vettones. Catálogo de la Exposición celebrada en Ávila -Septiembre/Diciembre 2001. Ávila: 305-314.

Barril, M.; Romero, A. (Comisarias) (2002). Torques, belleza y poder. Catálogo de la exposición. Museo Arqueológico Nacional. Ministerio de Cultura. Madrid.

Belarte, M. C.; Noguera, J. (2007). La necrópolis protohistòrica de Santa Madrona. Hic et Nunc, 2. Institut Catalá d'Arqueologia Classica. Tarragona.

Belarte, M. C.; Malgosa, A.; Noguera, J.; Olmos, P.; Piga, J. (2013). "Las necrópolis protohistóricas tumulares de Cataluña meridional: El ejemplo de Sebes (Flix, Tarragona)". Trabajos de Prehistoria 70, no 2. Madrid: 295-314. https://doi.org/10.3989/ tp.2013.12114

Beltrán Lloris, M. (1976 a). Museo de Zaragoza: Secciones de Arqueología y Bellas Artes. Ministerio de Cultura. Madrid.
Beltrán Lloris, M. (1976 b). Arqueología e historia de las ciudades antiguas del Cabezo de Alcalá de Azaila (Teruel). Monografías Arqueológicas, 19. Universidad de Zaragoza. Zaragoza.

Beltrán Lloris, M. (1978). "Teoría del Museo II. El Museo de Zaragoza (1974-1978)". Caesaraugusta 45-46. Institución Fernando el Católico. Diputación de Zaragoza. Zaragoza: 233-263.

Beltrán Lloris, M. (1986). "La arqueología de las Cinco Villas (Sintesis)". Actas de las I Jornadas de Estudio sobre las Cinco Villas. Ejea de los Caballeros, diciembre 1985. Centro de estudios de las Cinco Villas. Ejea de los Caballeros: 19-51.

Beltrán Lloris, M. (2013). Azaila. Estado de la cuestión en el año 2013. Caesaraugusta, 83. Institución Fernando el Católico. Diputación de Zaragoza, Zaragoza.

Beltrán Lloris, M.; Paz Peralta, J. A. (2003). Guía Museo de Zaragoza. Gobierno de Aragón. Zaragoza.

Benavente, J. A.; Galve, F. J. (2000). "Informe preliminar de la excavación arqueológica del poblado ibero de El Cabo, Andorra (Teruel)." Revista de Andorra, 2. Centro de Estudios Locales de Andorra. Andorra-Teruel: 17-52.

Benavente, J. A.; Fatás, L.; Graells, R.; Melguizo, S. (2012). "Novedades sobre el mundo funerario en el Bajo Aragón (2001-2011”. En M M C. Belarte; J. A. Benavente; L. Fatás; J. Dilodi; P. Moret y J. Noguera (editores): Iberos del Ebro. Actas del II Congreso Internacional. Alcañiz-Tivissa, 16-19 de noviembre de 2011. Documenta, 25. Institut Catalá d'Arqueologia Clàssica. Tarragona: 17-36.

Benavente, J. A.; Graells, R.; Melguizo, S. (2015). La necrópolis de El Cabo de Andorra (Teruel). Relación entre género y cultura material durante la Primera Edad del Hierro. Al-Qannis, 12. Taller de Arqueología de Alcañiz/Instituto de Estudios Turolenses. Alcañiz (Teruel).

Bianco, V. (1976). Die Messer in Italien. I Coltelli nell'Italia continentale. Praehistorische Bronzefunde, Abteilung VII, 2, Band. C. H. Beck'sche Verlagsbuchhhandlung. Munchen.

Bienes, J. J. (1994). "La necrópolis celta de Arguedas. Primeros datos sobre las campañas de excavación de 1989-90". Merindad de Tudela, $\mathrm{n}^{\circ}$ 6. Tudela: 19-28.

Bouthier, A.; Daugas, J. P.; Vital, J. (1988). "La nécropole Bronze Final des Vicreuses a Pougues-LesEaux (Nièvre). Bilan et perspectives". Le Groupe Rhin-Suisse-France Orientale et la Notion de Civilisation des Champs de Urnes. Actes du Colloque de Nemour, 1986. Memoires du Musée de Préhistoire d'Ile-de-France $\mathrm{n}^{\circ} 1$. Nemours: 417-424. 
Burillo, F. (1977). "Materiales de la Primera Edad del Hierro aparecidos en el 'Busal' (Uncastillo, Zaragoza). Estudios III. Zaragoza: 51-67.

Burillo, F. (1981). "Hallazgos de la Primera Edad del Hierro en el curso final de La Huerva (Zaragoza)". Bajo Aragón Prehistoria, III. Zaragoza, Caspe: 63-82.

Burillo, F. (1989-90). “La crisis del Ibérico Antiguo y su incidencia sobre los Campos de Urnas Finales del Bajo Aragón”. Kalathos, 9-10. Teruel: 95-124.

Burillo, F.; Fanlo, J. (1979). "El yacimiento del Cabezo de la Cruz de La Muela (Zaragoza)". Caesaraugusta, 47-48. Institución Fernando el Católico. Diputación de Zaragoza. Zaragoza: 39-95.

Burillo, F.; Royo, J. I. (1994-1996). “El yacimiento del Castillo de Cuarte (Zaragoza) y su contribución al conocimiento del inicio del Ibérico Pleno en el valle medio del Ebro". En: Models d'Ocupació, Tranformació y Explotació del Territori entre el 1600 y el 500 a.n.e. a la Catalunya Meridional y zones limítrofes de la Depressió de l'Ebre (J. Rovira, ed.). Gala, 3-5. Barcelona: 387-397.

Cabello, J. (2007). ArquEJEAlogía. Ejea de los Caballeros y las Cinco Villas, de la Prehistoria a la Antigüedad Tardía. Catalogo exposición. Diputación de Zaragoza y Ayuntamiento de Ejea de los Caballeros. Ejea de los Caballeros.

Cabré, J. (1942). "El Thymaterion céltico de Calaceite". Archivo Español de Arqueología, XV. Madrid: 181-198.

Calastrenc, C; Pastor, M ${ }^{\mathrm{a}}$ V.; Ruiz, J. J. (2011). "Informe-memoria de la excavación arqueológica del círculo de piedras 106 del Plan de la Sarra de Benasque". Informe depositado en la Fundación Hospital de Benasque. Consultado el 2 de agosto de 2016 en http://www.fundacion-hospital-benasque.org/arqueologia/excavacionesyreabilitaciones/circulosdepiedrasedaddelbronce.

Camacho, P.; Graells, R.; Lorrio, A. J., "Fíbulas de bronce dorado con puente decorado con triángulos sobre el puente y resorte cubierto". Zephyrus LXXVIII, julio-diciembre 2016. Universidad de Salamanca. Salamanca: 67-85.

Castiella, A. (1977). La Edad del Hierro en Navarra y Rioja. Excavaciones en Navarra VIII. Pamplona.

Castiella, A. (2005). "Sobre los ajuares de la necrópolis de La Atalaya. Cortes. Navarra". Cuadernos de Arqueología de la Universidad de Navarra, $\mathrm{n}^{\circ} 13$. Universidad de Navarra. Servicio de Publicaciones. Pamplona: 115-210.

Castiella, A. (2007-2008). "Torques femeninos en la protohistoria navarra". Veleia 24-15: 895-907.

Castiella, A.; Bienés, J. (2002). La Vida y la Muerte durante la Protohistoria en el Castejón de Arguedas
(Navarra). Cuadernos de Arqueología de la Universidad de Navarra, $\mathrm{n}^{\circ} 10$. Universidad de Navarra. Servicio de Publicaciones. Pamplona.

Castillea, A.; Sesma, J. (1988-89). "Piezas metálicas de la Protohistoria navarra: armas". Zephyrus, XLIXLII. Universidad de Salamanca. Salamanca: 383404.

Castiella, A.; Tajadura, J. (2001). "Campos de Urnas en Navarra". Cuadernos de Arqueología de la Universidad de Navarra, 9. Universidad de Navarra. Pamplona: 197-222.

Castro, P. V. (1994): La sociedad de los Campos de Urnas en el Nordeste de la Península Ibérica. La necrópolis de El Calvari (El Molar, Priorat, Tarragona). BAR Internacional. Series 592. Oxford, England.

Castro, P. V.; Lull, V.; Mico, R. (1996): Cronología de la Prehistoria Reciente de la Península Ibérica y Baleares (2800-900 cal ane.).Tempus Reparatum. BAR Internacional. Series 662. Oxford.

Castro, P. V.; Mico, R. (1995). "El C14 y la resolución de problemas arqueológicos. La conveniencia de una reflexión". Revista d'Arqueología de Ponent, 5. Universidad de Lleida. Lleida: 252-260.

Cerdeño, Ma , L. (1978). "Los broches de cinturón peninsulares de tipo céltico". Trabajos de Prehistoria, 35. Consejo Superior de Investigaciones Científicas -C. S. I. C.- Madrid: 279-306.

Cerdeño, M ${ }^{\mathrm{a}}$ L.; García Huerta, R. (1990). "Las necrópolis de incineración del Alto Jalón y el Alto Tajo". Necrópolis Celtibéricas. II Simposio sobre los Celtíberos. Zaragoza: 75-92.

Cerdeño, M ${ }^{\mathrm{a}}$ L.; Chorda, M. (2004). "Fíbulas de tipo navarro-aquitano en el área celtibérica". Cuadernos de Arqueología de la Universidad de Navarra, $\mathrm{n}^{\circ} 12^{\circ}$. Servicio de Publicaciones. Universidad de Navarra. Pamplona: 161-175.

Cerdeño, Mª L.; Sagardoy, T. (2007). La necrópolis celtibérica de Herrería III y IV (Guadalajara). Fundación Segeda-Centro de Estudios Celtibéricos-Junta de Comunidades de Castilla-La Mancha. Zaragoza.

Chorda, M.; Collado, O.; Nieto, E. (2013-2014). "Las tumbas inéditas de la necrópolis celtibérica de "El Cuarto" (Griegos, Teruel)". Kalathos 26-27. Revista del S. A. E. T. Teruel: 211-237.

Constantin, T. (2014). "Les parures métalliques du premier âge du Fer en Aquitaine: synthèse typo-chronologique régionale des fibules, bracalets et torques". Aquitania, Tome 30. Bordeaux:131-159.

Constantin, T.; Bilbao, M. V. (2013). "Les fibules du Premier âge du Fer en Aquitaine”. En Colín, A. Et 
Verdin, Fl. (Dirs.): L'âge du Fer en Aquitaine et sur ses marges. Mobilité des hommes, diffusión des idées, circulation des biens dans l'espace européen à l'âge du Fer. 35 Colloque International de l'A.F.E.A.F., Bordeaux, 2-5 juin 2011. Aquitania supplement, 30. Bordeaux: 309-318.

Constantin, T.; Chorda, M. (2014). "Las fíbulas navarro-aquitanas y su contextualización a ambos lados de los Pirineos". VII Simposio sobre los celtíberos. Nuevos Hallazgos, Nuevas Interpretaciones. Teruel: 223-230.

Cuadrado, E. (1961). "Broches de cinturón de placa romboidal en la Edad del Hierro Peninsular". Zephyrus, XII. Universidad de Salamanca. Salamanca: 208-220.

Dedet, B.; Janin, T.; Marchand, G.; Schwaller, M. (2012). "La nécropole de Saint Julien à Pézanas en Languedoc du VIIIe au Ive siècles avant J.-C. “. En Rovira, Ma C.; López Cachero, F. J.; Mazière, F. (Directores): Les necròpolis d'incineració entre l'Ebre $i$ el Tíber (segles IX-VI aC): metodologia, pràctiques funeràries i societat. Monografíes 14. Museu d'Arqueologia de Catalunya. Barcelona: 281-289.

Dedet, B.; Marchand, G. (2015). "Héros, caciques et paysans armés en Languedoc et en Provence du VIIIe au IIe siècles avant J.-C.” En M. C. Belarte, D. Garcia y J. Sanmartí (Eds. científics): Arqueo Mediterrània, 14. Les Estructures Socials Protohitoriques a la Gàl.lia i a Ibèria. Homenatge a Aurora Martin i Enriqueta Pons. Universitat de Barcelona-Institut Catalá d’Arqueologia Clàssica. Barcelona: 67-85.

Día-Andreu, M.; Mora, G. (1995). “Arqueología y política: el desarrollo de la arqueología española en su contexto histórico (1)". Trabajos de Prehistoria, $52, \mathrm{n}^{\circ} 1$. Consejo Superior de Investigaciones Científicas. Madrid: 25-38.

Escudé-Quillet, J. M. (2000). “Éléments d'études sur les pratiques funéraires du Bronze Final et du début de l'Âge du Fer en Aquitaine mérionale". Monographies d'Archéologie Méditerranéenne, 5. Archéologie de la Mort, Archéologie de la Tombe au Premier Âge du Fer. Actes du XXI Colloque International de l'Association Française pour l'Étude de l'Àge du Fer. Conques-Montrozier. Lattes (France): 131-140.

Eiroa, J. J.; Bachiller, J. A. (1985). "Informe sobre la IV campaña de excavaciones arqueológicas en el poblado y necrópolis de La Loma de los Brunos de Caspe (Zaragoza)". Bajo Aragón, Prehistoria VI. Grupo Cultural Caspolino. Institución Fernando el Católico. Caspe: 147-192.

Farnié, C.; Quesada, F. (2009). Espadas de hierro, grebas de bronce. Símbolos de poder e instrumentos de guerra a comienzos de la Edad del Hierro en la Península Ibérica. Monografías del Museo de Arte Ibérico de El Cigarralejo, 2. Región de Murcia. Murcia.

Faro, J. A. (2002). "Catálogo. Protohistoria”. En A. García Paredes (Coord.): Castejón: Cuatro Milenios de Historia. Catálogo de la Exposición (20 octubre 2002 a 6 enero 2003). Casa de Cultura. Ayuntamiento de Castejón. Navarra: 200-229.

Faro, J. A. (2015). "La necrópolis de El Castillo (Castejón, Navarra). Vajilla e Instrumental metálico de sacrificio y banquete en el valle medio del Ebro (S. VI-III a. C.)". Lucentum XXXIV. Universidad De Alicante. Alicante: 31-118.

Faro, J. A.; Canada, F.; Unzu, M. (2002-03). "Necrópolis de El Castillo (Castejón, Navarra). Primeras valoraciones, Campañas 2000, 2001, 2002". Trabajos de Arqueología Navarra, n ${ }^{\circ} 16$. Institución Príncipe de Viana-Gobierno de Navarra. Pamplona: 45-77.

Faro, J. A.; Unzu, M. (2006). “La necrópolis de la Edad del Hierro de El Castillo (Castejón, Navarra). Primeras valoraciones: campañas 2000-2002". Complutum, vol. 17. Alcalá de Henares: 145-166.

Fatas, G. (1972). "Excavaciones en Castillo de Miranda (Juslibol, Zaragoza)". Noticiario Arqueológico Hispánico I. Madrid: 227-263.

Fatas, G. (1975). "Una estela de guerrero con escudo escotado en $<<\mathrm{V}>>$ aparecida en las Cinco Villas de Aragón”. Pyrenae, 11: 165-169.

Fatás, L.; Graells, R. (2010). Historia gráfica de los túmulos protohistóricos del Bajo Aragón. Consorcio Patrimonio Ibérico de Aragón. Serie de Divulgación Número 3. Zaragoza.

Ferreruela, A. (1991). "Informe sobre la excavación de urgencia en Senda de Robres-Los Estancos (Leciena, Zaragoza)". Arqueología Aragonesa, 19861987. Gobierno de Aragón. Zaragoza: 91-92.

Galán, E. (1993). Estelas, paisaje y territorio en el Bronce Final del Suroeste de la Península Ibérica. Complutum, extra 3. Universidad Complutense. Madrid.

Gallart, J. (1991). El dipòsit de bronzes de Llavorsí. Pallars Sobirà. Excavacions Arqueològiques a Catalunya, 10. Generalitat de Catalunya. Barcelona.

García-Arilla, A. (2016). “A propósito de un broche o aplique de cinturón hallado en el yacimiento de Burrén y Burrena (Fréscano, Zaragoza)". Cuadernos de Estudios Borjanos LIX. Centro de Estudios Borjanos. Borja: 29-45.

García-Martínez De Lagrán, I.; Tejedor, C.; Royo Guillén, J. I. (prensa). “Cronometría, crono-tipología, estratigrafía y estadística bayesiana: herra- 
mientas analíticas complementarias para la determinación cronológica de la I $\mathrm{I}^{\mathrm{a}}$ Edad del Hierro en el valle medio del Ebro". Congreso: el Carbono 14 y sus problemas. Barcelona, noviembre 2016.

Giraud, J. P.; Pons, F. (2000). "Les nécropoles protohistoriques à incinération de la région de Castres (Tarn)". Monographies d'Archéologie Méditerranéenne, 5. Archéologie de la Mort, Archéologie de la Tombe au Premier Âge du Fer. Actes du XXI Colloque International de l'Association Française pour l'Étude de l'Àge du Fer. Conques-Montrozier. Lattes (France): 95-112.

Graells, R. (2008a). Análisis de las manifestaciones funerarias en Catalunya durante los ss. VII y VI a. C. Sociedad y cultura material: La asimilación de estímulos mediterráneos. Tesis Doctoral leída en la Universidad de Lérida. Universitat de Lleida.

Graells, R. (2008b). La necrópolis protohistòrica de Milmanda (Vimbodi, conca de Barberà, Tarragona). Un exemple del mòn funerari català durant el transit entre les segles VII $i$ VI $a$. C. Hic et Nunc, 2. Institut Catalá d'Arqueologia Classica. Tarragona.

Graells, R. (2011). "El conjunto de bronces picenos del depósito de $<<$ Tarragona $>$ en el Museu Episcopal de Vic (Barcelona/e)". Jahrbuch des Römisch-germanischen Zentralmuseums Mainz, 58. Mainz: 727-736.

Graells, R. (2013). "De Italia al Bajo Aragón: la dinámica de intercambios indígena entre el s. VII y VI a.C.". En A. Colin, F. Verdin (Dirs.) L'âge du Fer en Aquitaine et sur ses marges. Mobilité des hommes, diffusion des idées, circulation des biens dans l'espace européen à l'âge du Fer. Actes du 35 e Colloque international de l'AFEAF (Bordeaux, 2-5 juin 2011). Aquitania, Supplément 30. Bordeaux: 257-273.

Graells, R. (2014). "Problemas de cultura material. Las fíbulas itálicas de la Primera edad del Hierro en el Golfo de León occidental". Madrider Mitteilungen, 55. Deutsches Archäologisches Institut. Madrid: 212-315.

Graells, R.; Armada, X. L. (2011). "La Tumba de Les Ferreres de Calaceite a partir de los materiales del Musée des Antiquités Nationales de Saint-Germanen-Laye”. Studi Etruschi LXXIV. Firenze: 17-37.

Graells, R.; Sardá, S. (2011). "Residencias, élites y ritual en el bajo valle del Ebro (siglos VII-V a.C.)". En F. Quantin (Editor): Archéologie des Religions Antiques. Archaia I. Université de Pau et des pays de l'Adour. France: 151-188.

Graells, R.; Lorrio, A. J. (2017). Problemas de Cultura Material: los Broches de Garfios con decoración a molde de la Península Ibérica (s VII-VI a. C.). Universidad de Alicante. Alicante.
Iriarte, $M^{\mathrm{a}}$ J. (2009). "Los inicios del Holoceno reciente en el valle del río Huerva: la secuencia palinológica protohistórica del Cabezo de la Cruz". En Picazo, J. y Rodanés, J. Mª : Cabezo de la Cruz. La Muela, Zaragoza. Los poblados del Bronce Final y Primera Edad del Hierro. Gobierno de Aragón. Zaragoza: 108-131.

Jiménez Ávila, J. (2003). "Las sandalias de Apolo. Sobre el origen griego de los cinturones $<<$ célticos>>". Archivo Español de Arqueología, 76. Madrid, 31-46.

Jover, Fco. J.; Lorrio, A.; Díaz, Ma A. (2016). “El Bronce Final en el Levante de la Península Ibérica: bases arqueológicas y periodización”. Complutum, vol. 27(1). Alcalá de Henares -Madrid-: 81-108.

Juste, N. (1992). "Estudio de los materiales de la Avenida Martínez de Velasco". Arqueología Aragonesa, 1990. Gobierno de Aragón. Zaragoza: 265-269.

Juste, N. (1993). "Hacia los orígenes de Bolskan. Documentada en Huesca una necrópolis tumular protohistórica". Revista de Arqueología, no 141. Zugarto Ediciones. Madrid: 30-37.

Juste, N. (1994). "Estudio de los materiales de la Avda. Martínez de Velasco y Coso Alto n 56 de Huesca". Arqueología Aragonesa, 1991. Gobierno de Aragón. Zaragoza: 129-133.

Lanzarote, M. P.; Ramón, N.; Rey, J. (1991): La Prehistoria Reciente en las Cinco Villas: Del Neolítico a la Edad del Bronce. Diputación de Zaragoza-Centro de Estudios de las Cinco Villas. Ejea de los Caballeros.

Llanos, A. (1990). "Necrópolis del Alto Ebro". Necrópolis Celtibéricas. II Simposio sobre los Celtíberos. Zaragoza: 137-147.

López Cachero, F. J. (2005). La necrópolis de Can Piteu Can Roqueta (Sabadell) en el contexto del Bronce Final y la Primera Edad del Hierro en el Vallès: Estudio de los materiales cerámicos. Tesis Doctoral leída en la Universidad de Barcelona.

López Cachero, F. J. (2007) "Sociedad y economía durante el Bronce Final y la Primera Edad del Hierro en el Noreste peninsular: Una aproximación a partir de las evidencias arqueológicas". Trabajos de Prehistoria, 64, n 1. Enero-Junio. Madrid: 99120.

López Cachero, F. J. (2008). "Necrópolis de incineración y arquitectura funeraria en el Noreste de la Península Ibérica durante el Bronce Final y la Primera Edad del Hierro". Complutum 19 (1). Madrid: 139-171.

Lopez, J. B.; Pons, E. (1995). "Les necròpolis d'incineració tumulària de la zona pirinenca". Muntanyes i Població. El Passat dels Pirineus des d'una 
Perspectiva Multidisciplinària. Govern d'Andorra. Andorra la Vella: 107-123.

Lopez, J. B.; Royo Guillén, J. I. (2009). "Stèles et cippes funéraires dans le bassin de l'Ebre (Espagne) pendant le Bronze Final et le Premier Age du Fer". En Gruat, Ph.; Agogué, O.; Garcia, D. (Coords.): Stèles et Statues des Celtes du Mide de la France (VIIIe-IVes. av.J.-C.): 26-27.

Lorenzo Lizalde, J. I. (2015). "Estudio antropológico de las incineraciones". En Benavente, J. A.; Graells, R. y Melguizo, S. (Coords.). La necrópolis de El Cabo de Andorra (Teruel). Relación entre género y cultura material durante la Primera Edad del Hierro. Al-Qannis, 12. Taller de Arqueología de Alca-iz/Instituto de Estudios Turolenses. Alcañiz (Teruel): 133-143.

Lorenzo Lizalde, J. I.; Royo Guillén, J. I. (2017). "Estudio antropológico de las incineraciones de la necrópolis tumular del Corral de Mola (Uncastillo, Zaragoza)" CUPAUAM 43. En este mismo volumen.

Lorenzo Magallón, I. (1991). "Excavaciones en el poblado de San Jorge (Plou, Teruel). $7^{\mathrm{a}}$ campaña". Arqueología Aragonesa, 1986-1987. Gobierno de Aragón. Zaragoza: 157-159.

Lorrio, A. J. (2005). Los Celtíberos. (2 ${ }^{\mathrm{a}}$ Edición Ampliada y Actualizada). Bibliotheca Archaeologica Hispana, 25/Complutum Extra, 7. Real Academia de la Historia-Universidad Complutense. Madrid.

Lorrio, A. J. (2007). “Arte y artesanado celtibérico". En L. Abad y J. A. Soler (Eds.): Actas del Congreso Arte Ibérico en la España Mediterránea. Alicante, 24-27 octubre 2005. Diputación de Alicante. Alicante: 289-315.

Lorrio, A. J. (2008). Qurénima. El Bronce Final del Sureste de la Península Ibérica. Bibliotheca Archaeologica Hispana, 27-Anejo a la revista Lucentum, 17. Real Academia de la HistoriaUniversidad de Alicante. Madrid.

Lorrio, A. J. (2009-2010). "El Bronce Final en el Sureste de la Península Ibérica: Una (re)visión desde la arquitectura funeraria". Anales de la Universidad de Murcia, 25-26. Murcia: 119-176.

Lorrio, A.; Sánchez De Prado, Mª D. (2009). La necrópolis celtibérica de Arcóbriga. Monreal de Ariza, Zaragoza. Caesaraugusta, 80. Institución Fernando el Católico. Diputación de Zaragoza. Zaragoza.

Maestro, E. (2005). “Acerca de una figurita cerámica procedente del yacimiento de Los Castellazos de Mediana de Aragón (Zaragoza)". Salduie, no 5. Departamento de Ciencias de la Antigüedad. Facultad de Filosofía y Letras. Universidad de Zaragoza. Zaragoza: 143-157.
Maluquer, J. (1945-46). "Las culturas hallstátticas en Cataluña”. Ampurias VII-VIII. C. S. I. C. Barcelona: 115-184.

Maluquer, J. (1957). "La necrópolis de la Edad del Hierro de 'La Torraza' en Valtierra (Navarra)". Excavaciones en Navarra, V. Pamplona: 15-41.

Maluquer, J (1987). Catalunya, Baix Ebre. Programa de Investigaciones Protohistóricas, VIII. Departamento de Prehistoria y Arqueología. Universidad de Barcelona. Barcelona.

Maluquer, J.; Vazquez, L. (1956). “Avance al estudio de la necrópolis de La Atalaya, Cortes de Navarra". Príncipe de Viana, LXV. Pamplona: 389-454.

Maluquer, J.; Gracia, F.; Munilla, G. (1990). Alto de la Cruz. Cortes de Navarra. Campañas, 1986-1988. Trabajos de Arqueología Navarra, 9. Gobierno de Navarra. Pamplona.

Maya, J. L. (1990). "Primera Edad del Hierro". En A. Domínguez Ortíz, ed.: Historia de España. Tomo 1: Desde la Prehistoria hasta la Conquista Romana (siglo III a. c.). Editorial Planeta. Barcelona: 295-377.

Maya, J. L. (1993). "El Bronce Final-Hierro Inicial en la zona norte del valle del Ebro”. Bajo Aragón Prehistoria, IX-X. Segundos Encuentros de Prehistoria Aragonesa. Caspe-Zaragoza: 7-50.

Mederos, A. (1997). "Nueva cronología del Bronce Final en el Occidente de Europa". Complutum, 8. Alcalá de Henares, Madrid: 73-96.

Minguell, J. A. (1991). "Limpieza y restauración de material arqueológico procedente de $<<$ Los Castellets $>>$ de Mequinenza (Zaragoza)". Arqueología Aragonesa 1988-1989. Gobierno de Aragón. Zaragoza: 589-592.

Mohen, J. P. (1976a). "Les civilisations de l'Age du Fer dans les Pyrénées". En J. Guilaine (Direction): La Préhistoire Française. Tome II. Les Civilisations Neolithiques et Protohistoriques de la France. IX Congress de la U. I. S. P. P. Nice. Editions du Centre National de la Recherche Scientifique. Paris: 753-760.

Mohen, J. P. (1976b). "Les civilisations de l'Age du Fer en Aquitaine". En J. Guilaine (Direction): La Préhistoire Française. Tome II. Les Civilisations Neolithiques et Protohistoriques de la France. IX Congress de la U. I. S. P. P. Nice. Editions du Centre National de la Recherche Scientifique. Paris: 762-769.

Mohen J. P.; Coffyn, A. (1970). Les necropoles hallstattiennes de la region d'Arcachon. Bibliotheca Praehistorica Hispana, vol. XI. Madrid.

Montón, F. (2001). "La Codera. I Edad del Hierro en el valle del Cinca (Huesca)". Revista de Arqueologia, año XXII, no 248 (Diciembre). Zugarto Ediciones. Madrid: 16-23. 
Montón, F. (2002). "Ritual funerario en la I Edad del Hierro. La necrópolis de La Codera". XXVII Congreso Nacional de Arqueología. Bolskan 19, Instituto de Estudios Altoaragoneses. Diputación de Huesca. Huesca: 115-120.

Monton, F. (2016). "Edad del Hierro en el valle del Cinca: La Codera". En J. I. Lorenzo y J. M ${ }^{\mathrm{a}}$ Rodanés (Editores): Actas del I Congreso de Arqueología y Patrimonio Aragonés, CAPA. Zaragoza, 24 y 25 de noviembre de 2015. Colegio Oficial de Doctores y Licenciados de Aragón y Universidad de Zaragoza. Zaragoza: 103-110.

Munilla, G.; Gracia, F.; García, E. (1994-96). "La secuencia cronoestratigráfica del Alto de la Cruz (Cortes de Navarra) como base para el estudio de la transición Bronce Final-Hierro en el valle medio del Ebro". En J. Rovira (editor): Models de Ocupació, Transformació i Explotació del territori entre el 1600 i el 500 A. N. E. a la Catalunya Meridional $i$ zones limítrofes de la depressió de L'Ebre. Actes. Gala, 3-5. Sant Feliú de Codines: 153-170.

Navarro, R. (1970). Las fíbulas en Cataluña. Publicaciones Eventuales $\mathrm{n}^{\circ} 16$. Instituto de Arqueología y Prehistoria. Universidad de Barcelona. Barcelona.

Neumaier, J. (2006). "Mito, artesanía e identidad cultural: Los campos de urnas peninsulares y languedocienses a la luz de elementos <italianizantes $>$. A propósito del paradigma de los Urnenfelder norte y sur entorno del 1300-700 arq. ane". Cuaderns de Prehistoria y Arqueología Castellonenses, 25. Diputación de Castellón. Castellón de la Plana: 147-166.

Nuñez, Fco. J. (2015). "Reflexiones sobre la cronología de los inicios de la Edad del Hierro en el Mediterráneo occidental y sus problemas". CUPAUAM 41. Universidad Autónoma de Madrid. Madrid: 23-37. https://doi.org/10.15366/ cupauam2015.41.002

Palol, P. (1958). La necrópolis hallstáttica de Agullana (Gerona). Bibliotheca Praehistorica Hispana, Vol. I. Consejo Superior de Investigaciones Científicas C.S.I.C. Madrid.

Pellejero, C. (1984). “Las Cinco Villas de Aragón: Una aproximación a su realidad Histórica. I". Suessetania, $\mathrm{n}^{\circ}$ 6. Diciembre. Boletín del Centro de Estudios de las Cinco Villas. Ejea de los Caballeros: 33-37.

Pellicer, M. (1982). "La influencia orientalizante en el Bronce Final-Hierro del Nordeste Hispano". Habis 13. Sevilla: 211-237.

Pellicer, M. (1987). "Orígenes del urbanismo y las necrópolis tumulares en el valle medio del Ebro".
Archivo de Prehistoria Levantina, 17. 1. Museo de Prehistoria de Valencia. Valencia: 157-175.

Pellicer, M. (2008). "Los inicios del rito funerario de la incineración en la Península Ibérica”. Revista Tabona, 16. Enero: 13-35.

Peñalver, X. (2005). Los Crómlech Pirenaicos. Bolskan, 22. Instituto de Estudios Altoaragoneses. Diputación de Huesca. Huesca.

Pérez Casas, J. A. (1987). "Las sepulturas de adobe en la necrópolis de incineración del Cabezo de Ballesteros de Épila, Zaragoza. III campaña de excavación (1985)". Arqueología Aragonesa, 1985. Gobierno de Aragón. Zaragoza: 81-84.

Pérez Casas, J. A. (1988). "La necrópolis del Cabezo de Ballesteros". En Burillo, F.; Pérez Casas, J. A.; De Sus, M ${ }^{\mathrm{a}}$ L.: Celtíberos. Catálogo de la Exposición celebrada en el Palacio de Sástago. Diputación Provincial de Zaragoza. Zaragoza: 81-86.

Pérez Casas, J. A. (1990). "Las necrópolis de incineración en el Bajo Jalón”. Necrópolis Celtibéricas. II Simposio sobre los Celtíberos. Zaragoza: 111-121.

Picazo, J. V. (2005). "El poblamiento en el valle medio del Ebro durante la Prehistoria Reciente: Zonas y procesos". Revista d'Arqueologia de Ponent, $\mathrm{n}^{\circ} 15$. Universidad de Lleida. Lleida: 97-117.

Picazo, J. V.; Rodanés, J. Mª (2009). Cabezo de la Cruz. La Muela, Zaragoza. Los poblados del Bronce Final y Primera Edad del Hierro. Gobierno de Aragón. Zaragoza.

Pons, E. (2012). "Les necrópolis d’incineració en el nord-est catalá (1100-550 ANE): Una nova síntesi”. En Rovira, $\mathrm{M}^{\mathrm{a}}$ C.; López Cachero, F. J.; Maziere, F. (Directores): Les necròpolis d'incineració entre l'Ebre i el Tíber (segles IX-VI $a C$ ): metodologia, pràctiques funeràries $i$ societat. Monografíes 14. Museu d'Arqueologia de Catalunya. Barcelona: 57-74.

Pueyo, A. L. (1979). "Yacimientos y necrópolis de la Edad del Hierro en el Barranco de Busal (estado de la cuestión)". Estado Actual de los Estudios Sobre Aragón. Volumen I. Actas de las Primeras Jornadas. Zaragoza: 220-223.

Quesada, F. (1997). El armamento ibérico. Estudio tipológico, geográfico, funcional, social y simbólico de las armas en la Cultura Ibérica (siglos VI-I a. C.). Monographies Instrumentum, 3. Volumen I y II. Editions Monique Mergoil. Montagnac.

Rafel, N. (1989). La necrópolis del Coll del Moro de Gandesa: Les estructures funeràries. Publicacions de l'Ajuntament de Tarragona. Col.lecció Monografies, 1. Tarragona. 
Rafel, N. (1991). La necròpolis del Coll del Moro de Gandesa. Els Materials. Publicacions de la Diputació de Tarragona. Tarragona.

Rafel, N. (2003) Les necrópolis tumulàries de tipus baix aragonès: Les campanyes de L'Institut d'Estudis Catalans al Matarranya. Monografies de la secció Històrico-Arqueològica. VIII. Institut d'Estudis Catalans. Barcelona.

Rafel, N.; Hernández, G. (1992). "Practiques funeraries a la necrópolis del Coll del Moro (Gandesa, La Terra Alta)". Revista d' Arqueologia de Ponent, 2. Universidad de Lleida. Lleida: 37-57.

Rafel, N.; Belarte, C.; Graells, R.; Noguera, J. (2012). "Les necròpolis d'incineració a la Catalunya meridional i el Matarranya (segles IX-VI ANE). Novetats de la recerca”. En Rovira, $\mathrm{M}^{\mathrm{a}} \mathrm{C}$.; López Cachero, F. J.; Maziere, F. (eds.): Les necròpolis d'incineració entre l'Ebre i el Tíber (segles IX-VI $a C)$ : metodologia, pràctiques funeràries i societat. Monografíes 14. Museu d'Arqueologia de Catalunya. Barcelona: 25-36.

Reimer, P. J.; Bard, E.; Bayliss, A.; Beck, J. W.; Blackwell, P. G., Bronk Ramsey, C., Buck, C. E.; Cheng, H.; Edwards, R. L.; Friedrich, M.; Grootes, P. M.; Guilderson, T. P.; Haflidason, H.; Hajdas, I.; Hatté, C.; Heaton, T. J.; Hoffmann, D. I.; Hogg, A. G.; Hughen, K. A.; Kaiser, K. F.; Kromer, B.; Manning, S. W.; Niu, M.; Reimer, R. W.; Richards, D. A.; Scott, E. M.; Southon, J. R.; Staff, R. A.; Turney, C. S. M. y Van Der Plicht, J. (2013): "IntCal13 and Marine13 Radiocarbon Age Calibration Curves 0-50,000 Years cal BP". Radiocarbon, 55 (4): 1869-1887. https://doi.org/ 10.2458/azu_js_rc.55.16947

Rey, J. (2014). "El final de la prehistoria en Sobrarbe". En I. Clemente; E. Gassiot y J. Rey (eds.): Sobrarbe antes de Sobrarbe. Pinceladas de Historia de los Pirineos. Centro de Estudios de Sobrarbe-Comarca de Sobrarbe. Huesca: 71-93.

Rihovsky, J. (1972). Die Messer in Mähren und dem Ostalpengebiet. Praehistorische Bronzefunde, Abteilung VII, I, Band. C. H. Beck'sche Verlagsbuchhhandlung. Munchen.

Rojo Guerra, M.; Arcusa, H.; Peña, 1.; Royo Guillén, J. I.; Tejedor, C.; García, I.; Garrido, R.; Moreno, M.; Pimienta, C.; Mazzuco, N.; Gibaja, J. Fco.; Pérez, G.; Jimenez, I.; Iriarte E.; Alt, K. (2014). "Los primeros pastores trashumantes de la Alta Ribagorza". En I. Clemente; E. Gassiot y J. Rey (eds.): Sobrarbe antes de Sobrarbe. Pinceladas de Historia de los Pirineos. Centro de Estudios de Sobrarbe-Comarca de Sobrarbe. Huesca: 127-151.

Rovira, J.; Cura, M. (1989). "El món tumular català des del Bronze Antic fins època ibèrica. Continuitat versus substitución". Espacio, Tiempo y Forma.
Serie I. 2. Prehistoria y Arqueología. Madrid: 153-171.

Rovira, J.; Casanovas, A. (1993). "El depósito de brazaletes de Sant Aleix (Lleida) y los depósitos de objetos metálicos del Bronce Final en Cataluña". Complutum 4. Alcalá de Henares: 69-80.

Rovira, Ma C.; López Cachero, F. J.; Mazière, F., eds. (2012). Les necròpolis d'incineració entre l'Ebre $i$ el Tíber (segles IX-VI aC): metodologia, pràctiques funeràries i societat. Monografíes 14. Museu d'Arqueologia de Catalunya. Barcelona.

Royo Guillén, J. I. (1979). "Una pervivencia indoeuropea en la endocultura pastoril: La leyenda del Corral de Mola (Uncastillo, Zaragoza). I Congreso de Aragón de Etnología y Antropología. Diputación de Zaragoza. Institución Fernando el Católico. Zaragoza: 217-221.

Royo Guillén, J. I. (1980). "Hallazgos metalúrgicos de la I ${ }^{a}$ Edad del Hierro en Aragón”. Turiaso I. Centro de Estudios Turiasonenses. Tarazona: 241-324.

Royo Guillén, J. I. (1986). "Estudio de un ajuar funerario de la I ${ }^{a}$ Edad del Hierro descubierto en las cercanías de Mallén (Zaragoza)". Cuadernos de Estudios Borjanos, XVII-XVIII. Borja: 35-59.

Royo Guillén, J. I. (1990). "Las necrópolis de los Campos de Urnas del valle medio del Ebro como precedente del mundo funerario celtibérico". Necrópolis Celtibéricas. II Simposio sobre los Celtíberos. Zaragoza: 123-136.

Royo Guillén, J. I. (1991). "La necrópolis tumular de Los Castellets II (Mequinenza, Zaragoza). Quinta campaña”. Arqueología Aragonesa 1988-1989. Gobierno de Aragón. Zaragoza: 121-125.

Royo Guillén, J. I. (1992). "Estudio de materiales de los Castellets de Mequinenza. Campa-a de 1990”. Arqueología Aragonesa 1990. Gobierno de Aragón. Zaragoza: 81-87.

Royo Guillén, J. I. (1992-93). "El mundo funerario de los Campos de Urnas del valle medio del Ebro. Aproximación a su problemática". Segundos Encuentros de Prehistoria Aragonesa. Bajo Aragón Prehistoria, IX-X. Caspe-Zaragoza: 89-99.

Royo Guillén, J. I. (1994).’'Estelas y cipos funerarios en la necrópolis tumular de Los Castellets de Mequinenza (Zaragoza, España)". $V^{o}$ Congreso Internacional de Estelas Funerarias. Soria: 117134.

Royo Guillén, J. I. (1994-1996). "Ritual funerario y cultura material en las necrópolis tumulares de Los Castellets de Mequinenza (Zaragoza): Una aportación al estudio del Bronce Final/Hierro I en el N. E. peninsular". Taules Rodones d'Arqueologia. Actes. Gala 3-5. Sant Feliu de Codines (Barcelona): 93-108. 
Royo Guillén, J. I. (1997 a). "La necrópolis de incineración del Arroyo Vizcarra en Ruesta (Urriés, Zaragoza). Actuación de urgencia”. Arqueología Aragonesa, 1993. Gobierno de Aragón. Zaragoza: 47-58.

Royo Guillén, J. I. (1997 b). "Prospecciones y nuevos hallazgos arqueológicos en las Altas Cinco Villas: términos de Sos del Rey Católico, Urriés y Los Pintanos (Zaragoza)". Arqueología Aragonesa, 1993. Gobierno de Aragón. Zaragoza: 261-270.

Royo Guillén, J. I. (2000). “Tipología funeraria, ritos y ofrendas en las necrópolis del valle del Ebro durante la Primera Edad del Hierro (s. VIII- s. V a. C.)". Monographies d'Archéologie Méditerranéenne, 5. Archéologie de la Mort, Archéologie de la Tombe au Premier Âge du Fer. Actes du XXI Colloque International de l'Association Française pour l'Étude de l'Àge du Fer. Conques-Montrozier. Lattes (France): 41-58.

Royo Guillén, J. I. (2005). "Los poblados de El Morredón y El Solano (Fréscano, Zaragoza) y la cultura de los Campos de Urnas en el valle del río Huecha”. Cuadernos de Estudios Borjanos, XLVIII. Centro de Estudios Borjanos. Zaragoza: 17-178.

Royo Guillén, J. I. (2008-2009). “El Molino de Trasmoz (Zaragoza) y la transición del poblamiento de la Edad del Hierro al mundo celtibérico a la sombra del Moncayo". TURIASO XIX. Centro de Estudios Turiasonenses. Tarazona: 63-122.

Royo Guillén, J. I.; Aguilera, I. (1981).” Avance de la II campaña de excavaciones arqueológicas en Bursau. 1979. (Borja, Zaragoza)". Cuadernos de Estudios Borjanos VII-VIII. Centro de Estudios Borjanos. Institución Fernando el Católico. Borja: 27-73.

Royo Guillén, J. I.; Burillo, F. (1997). “Excavaciones en el Castillo de Cuarte (Zaragoza): El solar de la Calle Mayor, ${ }^{\circ} 3$ y sus niveles ibéricos (19931994)". Arqueología Aragonesa, 1994. Zaragoza: 121-134.

Royo Guillén, J. I.; Gómez, F. (2004). "Prehistoria, Protohistoria y arte rupestre en la confluencia del Bajo Cinca con el Ebro". En Montón, F. (Coordinador): Comarca del Bajo Cinca. Colección Territorio, 14. Gobierno de Aragón. Zaragoza: 87-76.

Royo Guillén, J. I.; Gómez, F.; Benavente, J. A. (2006). "La estela grabada de la Edad del Hierro de Torre Cremada" En P. Moret; J. A. Benavente y A. Gorges (Dirs.): Iberos del Matarraña. Investigaciones arqueológicas en Valdeltormo, Calaceite, Cretas y La Fresneda (Teruel). AlQannis, 11. Taller de Arqueología de Alcañiz y Casa de Velazquez. Alcañiz: 88-105.
Royo Guillén, J. I.; Perez Casas, J. A. (1987). “Un ejemplo de actuación de urgencia en defensa del patrimonio arqueológico: Burrén y Burrena (Fréscano, Zaragoza)". Arqueología Aragonesa, 1985. Gobierno de Aragón. Zaragoza: 207-213.

Royo Guillén, J. I.; Fatás, L. (2017). “Arquitectura funeraria y gestión del espacio durante la I ${ }^{\mathrm{a}}$ Edad del Hierro en la necrópolis de Arroyo Vizcarra (Urriés, Zaragoza)". En S. Adroit y R. Graells (Coords.): Arquitecturas Funerarias y Memoria: La Gestión de las Necrópolis en Europa Occidental (Siglos X-III a-C.). Archeologia Nuova Serie, 4. Actas de la reunión celebrada los días 13-14 de marzo de 2014 en la Casa de Velázquez (Madrid). Osanna Edizioni. Roma: 47-57.

Ruiz Vélez, I. (2009). "La cueva de Ojo Guareña (Burgos): el "príncipe" que se perdió y murió en ella". Sautuola XV. Instituto de Prehistoria y Arqueología "Sautuola”. Santander: 261-274.

Ruiz Zapatero, G. (1985). Los Campos de Urnas del N. E. de la Península Ibérica. 2 tomos. Tesis Doctoral. Universidad Complutense. Madrid.

Ruiz Zapatero, G. (2004). "Casas y tumbas. Explorando la desigualdad social en el Bronce Final y Primera Edad del Hierro del NE de la Península Ibérica". Mainake XXVI. Diputación Provincial de Málaga. Málaga: 293-330.

Ruiz Zapatero, G. (2008). "Morir, enterrar y recordar. Las tierras navarras durante la Edad del Hierro". En Hurtado, M. A.; Ca-ada, F.; Sesma, J.; García, J. (Coords.): La tierra te sea leve. Arqueología de la muerte en Navarra. Catálogo de la exposición en el Museo de Navarra (27 noviembre 2007 al 30 abril 2008). Pamplona: 97-113.

Ruiz Zapatero, G. (2014). "Bronce Final-Hierro: la naturaleza de los Campos de Urnas". En A: Mercadal i Fernández, Oriol (coord.). La Transició Bronze Final - 1a Edat del Ferro en els Pirineus $i$ territoris veïns: $X V$ Col-loqui Internacional d'Arqueologia de Puigcerdà. Congrés Nacional d'Arqueologia de Catalunya. Puigcerdà 17, 18 i 19 de novembre de 2011. Puigcerdà: Institut d'Estudis Ceretans: 635-658.

Ruiz Zapatero, G.; Lorrio, A. J. (1995). "La muerte en el norte peninsular durante el primer milenio a. C.”. En Fábregas, R,; Pérez, F. y Fernández, C.: Arqueoloxía da Morte na Península Ibérica desde a Orixes ata o Medievo. Excmo. Concello (Biblioteca Arqueohistórica Limiá. Serie Cursos e Congresos, 3). Xinzo de Limiav 223-248.

Sanmartí, E. (1993). "Una tomb de guerrer de la primera edat del ferro trobada a Llinars del Vallès (Vallès Oriental, Barcelona)". Treballs del Museu de Granollers, 1. Museu de Granollers. 
Sesma, J.; García, J.; Tabar, Mª I. (2007). "La Saga (Cáseda). Una sepultura colectiva de la Edad del Bronce". En Hurtado, M. A.; Ca-ada, F.; Sesma, J.; García, J. (Coords.): La tierra te sea leve. Arqueología de la muerte en Navarra. Catálogo de la exposición en el Museo de Navarra (27 noviembre 2007 al 30 abril 2008). Pamplona: 89-92.

Toledo i Mur, A. (2012a). "La necrópolis de Can Bech de Baix, Agullana (Alt Ampurdà, Girona)". En Rovira, $\mathrm{M}^{\mathrm{a}} \mathrm{C}$.; López Cachero, F. J.; Maziere, F. (eds.): Les necròpolis d'incineració entre l'Ebre $i$ el Tíber (segles IX-VI aC): metodologia, pràctiques funeràries $i$ societat. Monografíes 14 . Museu d'Arqueologia de Catalunya. Barcelona: 161-170.

Toledo i Mur, A. (2012b). "La necrópole à incineration protohistorique de Nagabous (Perpignan, Pyrénées-orientales". En Rovira, $\mathrm{M}^{\mathrm{a}} \mathrm{C}$.; López Cachero, F. J.; Maziere, F. (eds.) : Les necròpolis d'incineració entre l'Ebre i el Tíber (segles IX-VI $a C$ ): metodologia, pràctiques funeràries $i$ societat.
Monografíes 14. Museu d'Arqueologia de Catalunya. Barcelona: 245-253.

Torres-Martínez, J. F. (2013). "De l'autre côté des Pyrénées. La Navarre a l'âge du Fer'. En A. Colin, F. Verdin (Dirs.) L'âge du Fer en Aquitaine et sur ses marges. Mobilité des hommes, diffusion des idées, circulation des biens dans l'espace européen à l'âge du Fer. Actes du 35e Colloque international de l'AFEAF (Bordeaux, 2-5 juin 2011). Aquitania, Supplément 30. Bordeaux: 257-273.

Verger, S.; Dumont, A.; Moyat, PH.; Mille, B. (2007). "Le dépôt de bronzes du site fluvial de La Motte à Agde (Hérault)". Jahrbuch des Römisch-Germanischen Zentralmuseums 54. Mainz: 85-171.

Vizcaino, D. -Coordinador- (2010). La necrópolis de Sant Joaquim de la Menarella (Forcall, Castellón). La práctica de la incineración en la comarca de Els Ports. Parque Eólico de Refoyas. Zona II del Plan Eólico Valenciano. Generalitat Valenciana, RENOMAR, S. A. y EIN Mediterráneo, S. L. Valencia 